\title{
Alpha-glucosidase inhibitors for type 2 diabetes mellitus (Review)
}

Van de Laar FA, Lucassen PLBJ, Akkermans RP, Van de Lisdonk EH, Rutten GEHM, Van Weel C

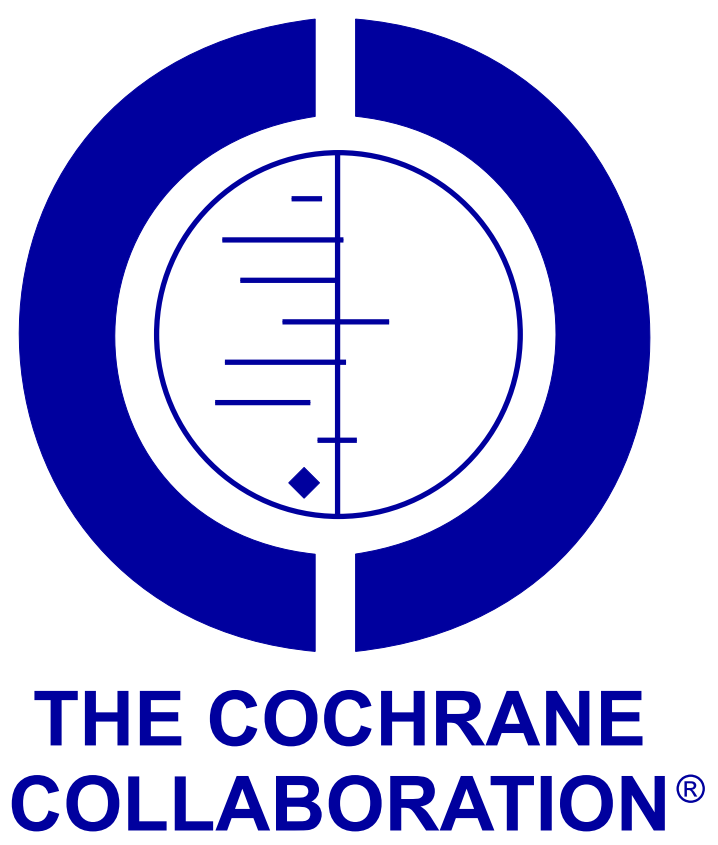

This is a reprint of a Cochrane review, prepared and maintained by The Cochrane Collaboration and published in The Cochrane Library 2005, Issue 4

http://www.thecochranelibrary.com

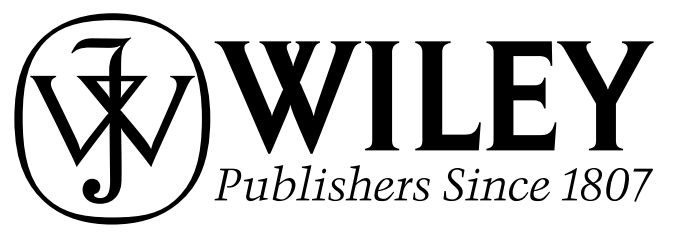

Alpha-glucosidase inhibitors for type $\mathbf{2}$ diabetes mellitus (Review)

Copyright $@ 2005$ The Cochrane Collaboration. Published by John Wiley \& Sons, Ltd 
TABLE OF CONTENTS

ABSTRACT . . . . . . . . . . . . . . . . . . . . . . . . . . . . . . . . . . . . . . . . . 1

SYNOPSIS . . . . . . . . . . . . . . . . . . . . . . . . . . . . . . . . . . . . . . 2

BACKGROUND . . . . . . . . . . . . . . . . . . . . . . . . . . . . . . . . . . . . 2

OBJECTIVES . . . . . . . . . . . . . . . . . . . . . . . . . . . . . . . . . . . . . . 3

CRITERIA FOR CONSIDERING STUDIES FOR THIS REVIEW . . . . . . . . . . . . . . . . . . . . . . 3

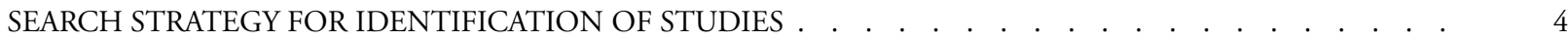

METHODS OF THE REVIEW . . . . . . . . . . . . . . . . . . . . . . . . . . . . . . . . . . . . . . . 4

DESCRIPTION OF STUDIES . . . . . . . . . . . . . . . . . . . . . . . . . . . . . . . . . . . . . . . . . . . . .

METHODOLOGICAL QUALITY . . . . . . . . . . . . . . . . . . . . . . . . . . . . . . . . . . . . 8

RESULTS . . . . . . . . . . . . . . . . . . . . . . . . . . . . . . . . . . . . . 8

DISCUSSION . . . . . . . . . . . . . . . . . . . . . . . . . . . . . . . . . . . . . . . . . . .

AUTHORS' CONCLUSIONS . . . . . . . . . . . . . . . . . . . . . . . . . . . . . . . . . . . . . 14

POTENTIAL CONFLICT OF INTEREST . . . . . . . . . . . . . . . . . . . . . . . . . . . . . . . . . 14

ACKNOWLEDGEMENTS . . . . . . . . . . . . . . . . . . . . . . . . . . . . . . . . . . . . . . . . . . . 14

SOURCES OF SUPPORT . . . . . . . . . . . . . . . . . . . . . . . . . . . . . . . . . . . . . . . 14

REFERENCES . . . . . . . . . . . . . . . . . . . . . . . . . . . . . . . . . . . . . 15

TABLES . . . . . . . . . . . . . . . . . . . . . . . . . . . . . . . . . . . . . . . . 20

Characteristics of included studies

Characteristics of excluded studies . . . . . . . . . . . . . . . . . . . . . . . . . . . . . . . . . . . 45

Characteristics of ongoing studies . . . . . . . . . . . . . . . . . . . . . . . . . . . . . . . . . . . . . .

ADDITIONAL TABLES . . . . . . . . . . . . . . . . . . . . . . . . . . . . . . . . . . . . . . . . . . . . . 447

Table 01. Methods post-load glucose / insulin measurement . . . . . . . . . . . . . . . . . . . . . . . . 47

GRAPHS . . . . . . . . . . . . . . . . . . . . . . . . . . . . . 51

Comparison 01. Acarbose versus placebo . . . . . . . . . . . . . . . . . . . . . . . . . . . . . . . . . . . $\quad .51$

Comparison 02. Acarbose versus sulphonylurea $(\mathrm{SU})$. . . . . . . . . . . . . . . . . . . . . . . . . $\quad . \quad 52$

Comparison 03. Acarbose versus Metformin . . . . . . . . . . . . . . . . . . . . . . . . . . . . . 52

Comparison 04. Acarbose versus nateglinide / repaglinide . . . . . . . . . . . . . . . . . . . . . . . . . . . 53

Comparison 05. Miglitol versus placebo . . . . . . . . . . . . . . . . . . . . . . . . . . . . . . . 53

Comparison 06. Miglitol versus sulphonylurea $(\mathrm{SU})$. . . . . . . . . . . . . . . . . . . . . . . . . . . . . . 54

Comparison 07. Miglitol versus metformin . . . . . . . . . . . . . . . . . . . . . . . . . . . . . . . $\quad 54$

Comparison 08. Voglibose versus placebo . . . . . . . . . . . . . . . . . . . . . . . . . . . . . . . . $\quad . \quad 55$

Comparison 09. Voglibose versus diet therapy . . . . . . . . . . . . . . . . . . . . . . . . . . . . . 55

Comparison 10. Voglibose versus sulphonylurea $(\mathrm{SU})$. . . . . . . . . . . . . . . . . . . . . . . . . . . $\quad 55$

Comparison 11. Miglitol versus voglibose . . . . . . . . . . . . . . . . . . . . . . . . . . . . . 56

INDEX TERMS . . . . . . . . . . . . . . . . . . . . . . . . . . . . . . . . . . . . . 56

COVER SHEET . . . . . . . . . . . . . . . . . . . . . . . . . . . . . . . . . . . . . . . . . . . . . . 56

GRAPHS AND OTHER TABLES . . . . . . . . . . . . . . . . . . . . . . . . . . . . . . . . . . 58

Fig. $1 . \quad$. . . . . . . . . . . . . . . . . . . . . . . . . . . . . . . . . . . . . . 58

Fig. 2. . . . . . . . . . . . . . . . . . . . . . . . . . . . . . . . . . . . . . . . . . . . . 5

Fig. 3. Comparison 01. Acarbose versus placebo. . . . . . . . . . . . . . . . . . . . . . . . . . . . . . . . 60

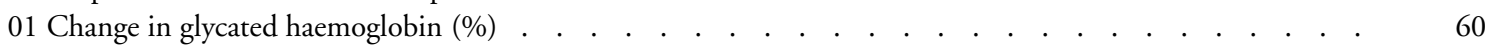

Fig. 4. Comparison 01. Acarbose versus placebo. . . . . . . . . . . . . . . . . . . . . . . . . . . . . . . . . . 6

02 Change in fasting blood glucose $(\mathrm{mmol} / \mathrm{l})$.

Fig. 5. Comparison 01. Acarbose versus placebo. . . . . . . . . . . . . . . . . . . . . . . . . . . . . 64

03 Change in post-load blood glucose $(\mathrm{mmol} / \mathrm{l})$. . . . . . . . . . . . . . . . . . . . . . . . . . . $\quad .64$

Fig. 6. Comparison 01. Acarbose versus placebo. . . . . . . . . . . . . . . . . . . . . . . . . . . . . . . . . $\quad 66$

04 Change in total cholesterol $(\mathrm{mmol} / \mathrm{l})$. . . . . . . . . . . . . . . . . . . . . . . . . . . . . . 66

Fig. 7. Comparison 01. Acarbose versus placebo. . . . . . . . . . . . . . . . . . . . . . . . . . . . . . . . . . . $\quad .68$

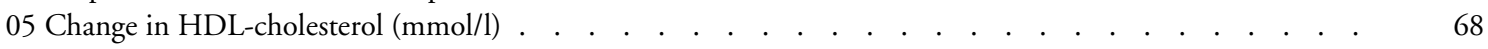

Fig. 8. Comparison 01. Acarbose versus placebo. . . . . . . . . . . . . . . . . . . . . . . . . . . . . . . . . . . . 69

06 Change in LDL-cholesterol $(\mathrm{mmol} / \mathrm{l}) \quad$.

Alpha-glucosidase inhibitors for type 2 diabetes mellitus (Review)

Copyright @2005 The Cochrane Collaboration. Published by John Wiley \& Sons, Ltd 
Fig. 9. Comparison 01. Acarbose versus placebo. . . . . . . . . . . . . . . . . . . . . . . . . . . . . 70

07 Change in triglycerides $(\mathrm{mmol} / \mathrm{l}) \quad$. . . . . . . . . . . . . . . . . . . . . . . . . . $\quad$. 70

Fig. 10. Comparison 01. Acarbose versus placebo. $\quad . \quad$. . . . . . . . . . . . . . . . . . . . . . . . . . . . .

08 Change in fasting insulin levels $(\mathrm{pmol} / \mathrm{l})$. . . . . . . . . . . . . . . . . . . . . . . . . . . $\quad$. 72

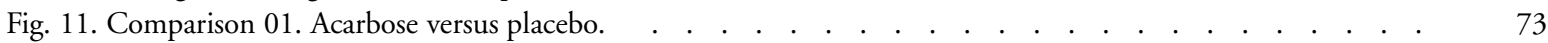

09 Change in post-load insulin levels $(\mathrm{pmol} / \mathrm{l})$. . . . . . . . . . . . . . . . . . . . . . . . . . 73

Fig. 12. Comparison 01. Acarbose versus placebo. $\quad . \quad$. . . . . . . . . . . . . . . . . . . . . . . . . . . . . . . . . 74

10 Change in fasting C-peptide levels $(\mathrm{nmol} / \mathrm{l})$. . . . . . . . . . . . . . . . . . . . . . . . . . . . 74

Fig. 13. Comparison 01. Acarbose versus placebo. . . . . . . . . . . . . . . . . . . . . . . . . . . . . . . $\quad$. 75

11 Change in post-load C-peptide levels $(\mathrm{nmol} / \mathrm{l})$. . . . . . . . . . . . . . . . . . . . . . . . . . . $\quad 75$

Fig. 14. Comparison 01. Acarbose versus placebo. . . . . . . . . . . . . . . . . . . . . . . . . . . . . . . . . 75

12 Change in body weight $(\mathrm{Kg})$. $\quad . \quad$. . . . . . . . . . . . . . . . . . . . . . . . . . . . . . . . $\quad . \quad 75$

Fig. 15. Comparison 01. Acarbose versus placebo. $\quad . \quad$. . . . . . . . . . . . . . . . . . . . . . . . . . . . . . $\quad$. 77

13 Change in body mass index $(\mathrm{Kg} / \mathrm{m} 2)$. . . . . . . . . . . . . . . . . . . . . . . . . . . . . $\quad . \quad 77$

Fig. 16. Comparison 01. Acarbose versus placebo. . . . . . . . . . . . . . . . . . . . . . . . . . . . . . . $\quad 78$

15 Total deaths . . . . . . . . . . . . . . . . . . . . . . . . . . . . . . . . . . . . . . 78

Fig. 17. Comparison 01. Acarbose versus placebo. $\quad . \quad$. . . . . . . . . . . . . . . . . . . . . . . . . . . . 79

16 Disease related deaths . . . . . . . . . . . . . . . . . . . . . . . . . . . . . . . . . . . . $\quad .79$

Fig. 18. Comparison 01. Acarbose versus placebo. $\quad . \quad$. . . . . . . . . . . . . . . . . . . . . . . . . . . . . . 79

20 Occurence of morbidity (total) . . . . . . . . . . . . . . . . . . . . . . . . . . . . . . . $\quad$. 79

Fig. 19. Comparison 01. Acarbose versus placebo. $\quad . \quad$. . . . . . . . . . . . . . . . . . . . . . . . . . . . . $\quad . \quad 80$

21 Occurence of morbidity (disease specific) . . . . . . . . . . . . . . . . . . . . . . . . . . . . . . . . . $\quad$. $\quad 80$

Fig. 20. Comparison 01. Acarbose versus placebo. $\quad . \quad$. . . . . . . . . . . . . . . . . . . . . . . . . . . . . . $\quad$. 8

30 Occurence of adverse effects . . . . . . . . . . . . . . . . . . . . . . . . . . . . . . . . . . . . . $\quad . \quad 80$

Fig. 21. Comparison 01. Acarbose versus placebo. . . . . . . . . . . . . . . . . . . . . . . . . . . . . . . 82

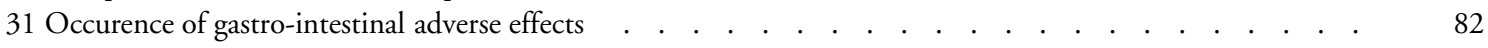

Fig. 22. Comparison 01. Acarbose versus placebo. $\quad . \quad$. . . . . . . . . . . . . . . . . . . . . . . . . . . . . . $\quad$. 83

50 Quality of life . . . . . . . . . . . . . . . . . . . . . . . . . . . . . . . . . . $\quad . \quad 83$

Fig. 23. Comparison 01. Acarbose versus placebo. . . . . . . . . . . . . . . . . . . . . . . . . . . . . . . $\quad$. 83

90 Change in post-load blood glucose $(\mathrm{mmol} / \mathrm{l})(2$-hours $)$. . . . . . . . . . . . . . . . . . . . . . . . . $\quad . \quad 83$

Fig. 24. Comparison 01. Acarbose versus placebo. . . . . . . . . . . . . . . . . . . . . . . . . . . . . . . . . $\quad 85$

91 Change in post-load insulin levels (pmol/l) $(2$-hours) $\quad . \quad$. . . . . . . . . . . . . . . . . . . . . . . . $\quad . \quad 85$

Fig. 25. Comparison 02. Acarbose versus sulphonylurea (SU). . . . . . . . . . . . . . . . . . . . . . . . . ..

01 Change in glycated haemoglobin $(\%)$. . . . . . . . . . . . . . . . . . . . . . . . . . . . . . . . $\quad . \quad$. 86

Fig. 26. Comparison 02. Acarbose versus sulphonylurea $(\mathrm{SU}) . \quad$. . . . . . . . . . . . . . . . . . . . . . . . . $\quad$. $\quad$. 8

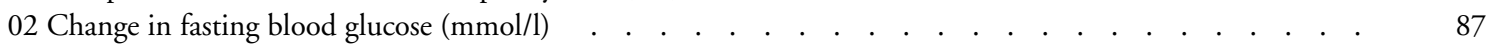

Fig. 27. Comparison 02. Acarbose versus sulphonylurea $(\mathrm{SU}) . \quad$. . . . . . . . . . . . . . . . . . . . . . . . . . $\quad$.

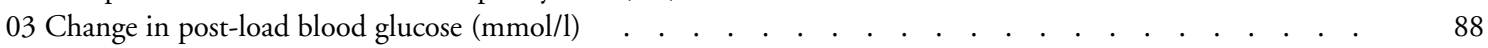

Fig. 28. Comparison 02. Acarbose versus sulphonylurea $(\mathrm{SU})$. . . . . . . . . . . . . . . . . . . . . . . . . . $\quad$. $\quad$. 89

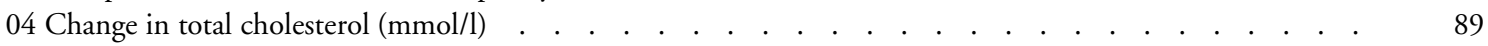

Fig. 29. Comparison 02. Acarbose versus sulphonylurea $(\mathrm{SU})$. . . . . . . . . . . . . . . . . . . . . . . . . . . $\quad$. 90

05 Change in HDL-cholesterol $(\mathrm{mmol} / \mathrm{l})$. $\quad . \quad$. . . . . . . . . . . . . . . . . . . . . . . . . . . . . . . . . $\quad . \quad 90$

Fig. 30. Comparison 02. Acarbose versus sulphonylurea $(\mathrm{SU}) . \quad$. . . . . . . . . . . . . . . . . . . . . . . . . . . . $\quad 91$

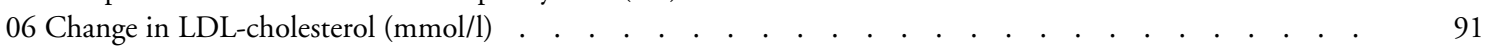

Fig. 31. Comparison 02. Acarbose versus sulphonylurea $(\mathrm{SU}) . \quad$. . . . . . . . . . . . . . . . . . . . . . . . . . . .9

07 Change in triglycerides $(\mathrm{mmol} / \mathrm{l}) \quad$. . . . . . . . . . . . . . . . . . . . . . . . . . . . . . . . . . . $\quad .92$

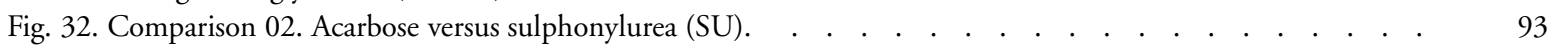

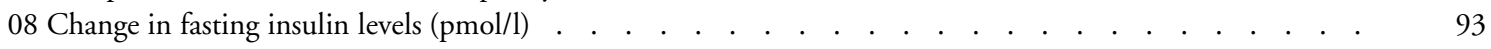

Fig. 33. Comparison 02. Acarbose versus sulphonylurea (SU). . . . . . . . . . . . . . . . . . . . . . . . . . . . 94

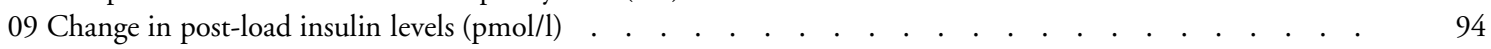

Fig. 34. Comparison 02. Acarbose versus sulphonylurea (SU). . . . . . . . . . . . . . . . . . . . . . . . . . . . 95

10 Change in fasting C-peptide levels $(\mathrm{nmol} / \mathrm{l})$. $\quad . \quad$. . . . . . . . . . . . . . . . . . . . . . . . . . . . . $\quad$. 95

Fig. 35. Comparison 02. Acarbose versus sulphonylurea $(\mathrm{SU}) . \quad$.

Alpha-glucosidase inhibitors for type 2 diabetes mellitus (Review)

Copyright @2005 The Cochrane Collaboration. Published by John Wiley \& Sons, Ltd 


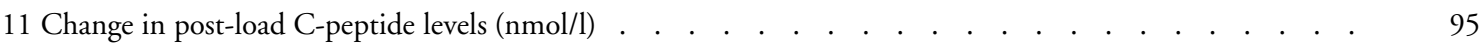

Fig. 36. Comparison 02. Acarbose versus sulphonylurea $(\mathrm{SU}) . \quad$. . . . . . . . . . . . . . . . . . . . . . . . . .96

12 Change in body weight $(\mathrm{Kg})$. . . . . . . . . . . . . . . . . . . . . . . . . . . . . . . . . . . 96

Fig. 37. Comparison 02. Acarbose versus sulphonylurea $(\mathrm{SU}) . \quad$. . . . . . . . . . . . . . . . . . . . . . . . . . $\quad$. $\quad 97$

13 Change in body mass index $(\mathrm{Kg} / \mathrm{m} 2)$. . . . . . . . . . . . . . . . . . . . . . . . . . . . . . . 997

Fig. 38. Comparison 02. Acarbose versus sulphonylurea $(\mathrm{SU}) . \quad$. . . . . . . . . . . . . . . . . . . . . . . . . . . 98

15 Total deaths . . . . . . . . . . . . . . . . . . . . . . . . . . . . . . . . . . 98

Fig. 39. Comparison 02. Acarbose versus sulphonylurea $(\mathrm{SU}) . \quad$. . . . . . . . . . . . . . . . . . . . . . . . . . $\quad . \quad 98$

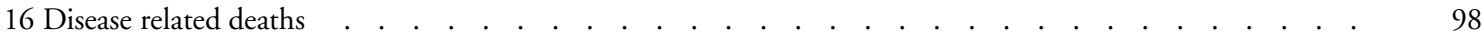

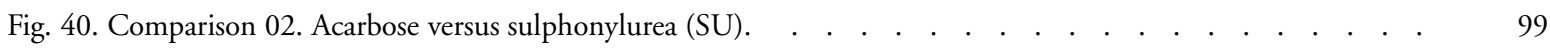

30 Occurence of adverse effects . . . . . . . . . . . . . . . . . . . . . . . . . . . . . . . . . . . . . . . 9

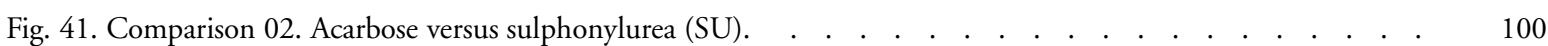

31 Occurence of gastro-intestinal adverse effects c . . . . . . . . . . . . . . . . . . . . . . . . . . . . $\quad . \quad 100$

Fig. 42. Comparison 02. Acarbose versus sulphonylurea $(\mathrm{SU}) . \quad$. . . . . . . . . . . . . . . . . . . . . . . . $\quad . \quad$. 100

90 Change in post-load blood glucose $(\mathrm{mmol} / \mathrm{l})(2$ hours $)$. . . . . . . . . . . . . . . . . . . . . . . . . 100

Fig. 43. Comparison 02. Acarbose versus sulphonylurea (SU). . . . . . . . . . . . . . . . . . . . . . . . . . . . 102

91 Change in post-load insulin levels (pmol/l) $(2$ hours) . . . . . . . . . . . . . . . . . . . . . 102

Fig. 44. Comparison 03. Acarbose versus Metformin. . . . . . . . . . . . . . . . . . . . . . . . . . . . . 103

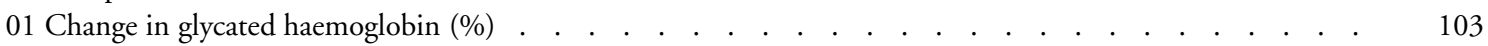

Fig. 45. Comparison 03. Acarbose versus Metformin. $\quad . \quad$. . . . . . . . . . . . . . . . . . . . . . . . . . . $\quad . \quad 103$



Fig. 46. Comparison 03. Acarbose versus Metformin. . . . . . . . . . . . . . . . . . . . . . . . . . . . . . . 104

03 Change in post-load blood glucose $(\mathrm{mmol} / \mathrm{l}) \quad$. . . . . . . . . . . . . . . . . . . . . . . . . . . $\quad 104$

Fig. 47. Comparison 03. Acarbose versus Metformin. . . . . . . . . . . . . . . . . . . . . . . . . . . . . . 104

04 Change in total cholesterol $(\mathrm{mmol} / \mathrm{l})$. . . . . . . . . . . . . . . . . . . . . . . . . . . . . . $\quad . \quad 104$

Fig. 48. Comparison 03. Acarbose versus Metformin. . . . . . . . . . . . . . . . . . . . . . . . . . . . 105

05 Change in HDL-cholesterol $(\mathrm{mmol} / \mathrm{l})$. . . . . . . . . . . . . . . . . . . . . . . . . . . . . . 105

Fig. 49. Comparison 03. Acarbose versus Metformin. . . . . . . . . . . . . . . . . . . . . . . . . . . . . . . 105

06 Change in LDL-cholesterol $(\mathrm{mmol} / \mathrm{l})$. . . . . . . . . . . . . . . . . . . . . . . . . . . . . . . $\quad$.

Fig. 50. Comparison 03. Acarbose versus Metformin. . . . . . . . . . . . . . . . . . . . . . . . . . . 106

07 Change in triglycerides $(\mathrm{mmol} / \mathrm{l}) \quad$. . . . . . . . . . . . . . . . . . . . . . . . . . . 106

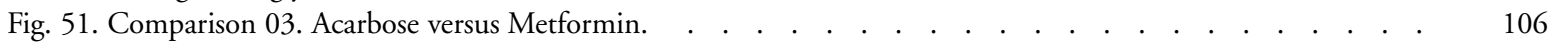

08 Change in fasting insulin levels $(\mathrm{pmol} / \mathrm{l})$. . . . . . . . . . . . . . . . . . . . . . . . . . . . . 106

Fig. 52. Comparison 03. Acarbose versus Metformin. . . . . . . . . . . . . . . . . . . . . . . . . 107

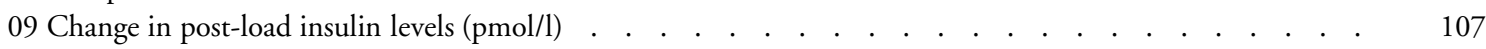

Fig. 53. Comparison 03. Acarbose versus Metformin. . . . . . . . . . . . . . . . . . . . . . . . . . . . . 107

12 Change in body weight $(\mathrm{Kg})$. . . . . . . . . . . . . . . . . . . . . . . . . . . $\quad . \quad 107$

Fig. 54. Comparison 03. Acarbose versus Metformin. . . . . . . . . . . . . . . . . . . . . . . . . . . . 108

30 Occurence of adverse effects . . . . . . . . . . . . . . . . . . . . . . . . . . . . . . . . 108

Fig. 55. Comparison 04. Acarbose versus nateglinide / repaglinide. . . . . . . . . . . . . . . . . . . . . . . . 108

01 Change in glycated haemoglobin $(\%)$. . . . . . . . . . . . . . . . . . . . . . . . . . . . . . . . . $\quad$. 108

Fig. 56. Comparison 04. Acarbose versus nateglinide / repaglinide. . . . . . . . . . . . . . . . . . . . . . . . . 109

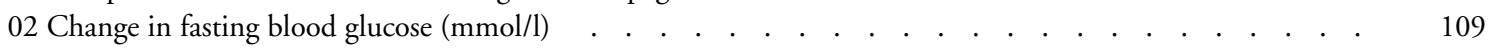

Fig. 57. Comparison 04. Acarbose versus nateglinide / repaglinide. . . . . . . . . . . . . . . . . . . . . . . . . . 109

12 Change in body weight $(\mathrm{Kg})$. . . . . . . . . . . . . . . . . . . . . . . . . . . . . . . . . . . . $\quad . \quad 109$

Fig. 58. Comparison 04. Acarbose versus nateglinide / repaglinide. . . . . . . . . . . . . . . . . . . . . . . . 110

30 Occurence of adverse effects . . . . . . . . . . . . . . . . . . . . . . . . . . . . . . . . . . . . . . . $\quad$.

Fig. 59. Comparison 04. Acarbose versus nateglinide / repaglinide. . . . . . . . . . . . . . . . . . . . . . 110

31 Occurence of gastro-intestinal adverse effects c c c . . . . . . . . . . . . . . . . . . . . . . . . . . . $\quad$. 110

Fig. 60. Comparison 05. Miglitol versus placebo. . . . . . . . . . . . . . . . . . . . . . . . . . . . . . . . . 111

01 Change in glycated haemoglobin $(\%)$. . . . . . . . . . . . . . . . . . . . . . . . . . . . . . . . $\quad . \quad 111$

Fig. 61. Comparison 05. Miglitol versus placebo. . . . . . . . . . . . . . . . . . . . . . . . . . . . . . . 112

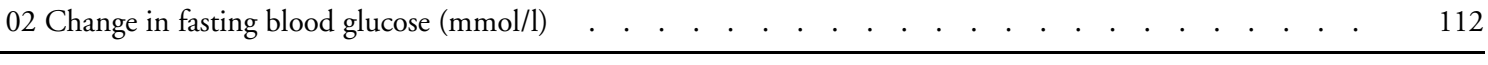

Alpha-glucosidase inhibitors for type 2 diabetes mellitus (Review)

Copyright @2005 The Cochrane Collaboration. Published by John Wiley \& Sons, Ltd 
Fig. 62. Comparison 05. Miglitol versus placebo. . . . . . . . . . . . . . . . . . . . . . . . . . . . . . . . . 113

03 Change in post-load blood glucose $(\mathrm{mmol} / \mathrm{l})$. . . . . . . . . . . . . . . . . . . . . . . . . . $\quad$. 113

Fig. 63. Comparison 05. Miglitol versus placebo. . . . . . . . . . . . . . . . . . . . . . . . . . . . . . . . 114

08 Change in fasting insulin levels $(\mathrm{pmol} / \mathrm{l})$. . . . . . . . . . . . . . . . . . . . . . . . . . . . . . $\quad . \quad 114$

Fig. 64. Comparison 05. Miglitol versus placebo. . . . . . . . . . . . . . . . . . . . . . . . . . . . . . . . 114

09 Change in post-load insulin levels $(\mathrm{pmol} / \mathrm{l})$. . . . . . . . . . . . . . . . . . . . . . . . . . . . . 114

Fig. 65. Comparison 05. Miglitol versus placebo. . . . . . . . . . . . . . . . . . . . . . . . . . . . . 115

12 Change in body weight $(\mathrm{Kg})$. . . . . . . . . . . . . . . . . . . . . . . . . . . . . . . . . . . 115

Fig. 66. Comparison 05. Miglitol versus placebo. . . . . . . . . . . . . . . . . . . . . . . . . . . . 116

15 Total deaths . . . . . . . . . . . . . . . . . . . . . . . . . . . . . . . . . . . . . . . 116

Fig. 67. Comparison 05. Miglitol versus placebo. . . . . . . . . . . . . . . . . . . . . . . . . . . . . . 117

16 Disease related deaths . . . . . . . . . . . . . . . . . . . . . . . . . . . . . . 117

Fig. 68. Comparison 05. Miglitol versus placebo. . . . . . . . . . . . . . . . . . . . . . . . . . . . . . . . . 118

30 Occurence of adverse effects . . . . . . . . . . . . . . . . . . . . . . . . . . . . . . . . . . . . . . . .

Fig. 69. Comparison 05. Miglitol versus placebo. . . . . . . . . . . . . . . . . . . . . . . . . . . 119

31 Occurence of gastro-intestinal adverse effects c . . . . . . . . . . . . . . . . . . . . . . . . . . . . . . $\quad . \quad 119$

Fig. 70. Comparison 05. Miglitol versus placebo. . . . . . . . . . . . . . . . . . . . . . . . . . . . 120

90 Change in post-load blood glucose $(\mathrm{mmol} / \mathrm{l})(2$-hours $)$. . . . . . . . . . . . . . . . . . . . . . 120

Fig. 71. Comparison 05. Miglitol versus placebo. . . . . . . . . . . . . . . . . . . . . . . . . . . . . . . 121

91 Change in post-load insulin levels (pmol/l) (2-hours) $\quad$. . . . . . . . . . . . . . . . . . . . . . . . 121

Fig. 72. Comparison 06. Miglitol versus sulphonylurea (SU). . . . . . . . . . . . . . . . . . . . . . . . . . . 121

01 Change in glycated haemoglobin $(\%)$. . . . . . . . . . . . . . . . . . . . . . . . . . . . . . . . . $\quad$. 121

Fig. 73. Comparison 06. Miglitol versus sulphonylurea (SU). . . . . . . . . . . . . . . . . . . . . . . . . . . . . 122

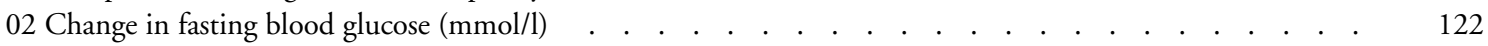

Fig. 74. Comparison 06. Miglitol versus sulphonylurea (SU). . . . . . . . . . . . . . . . . . . . . . . . . . 122

03 Change in post-load blood glucose $(\mathrm{mmol} / \mathrm{l}) \quad$. $\quad . \quad$. . . . . . . . . . . . . . . . . . . . . . . . . . . . . $\quad$. 122

Fig. 75. Comparison 06. Miglitol versus sulphonylurea (SU). . . . . . . . . . . . . . . . . . . . . . . . . . . . 123

04 Change in total cholesterol $(\mathrm{mmol} / \mathrm{l})$.

Fig. 76. Comparison 06. Miglitol versus sulphonylurea (SU). . . . . . . . . . . . . . . . . . . . . . . . . . . . . 123

05 Change in HDL-cholesterol $(\mathrm{mmol} / \mathrm{l})$. $\quad . \quad$. . . . . . . . . . . . . . . . . . . . . . . . . . . . . $\quad . \quad 123$

Fig. 77. Comparison 06. Miglitol versus sulphonylurea (SU). . . . . . . . . . . . . . . . . . . . . . . . . . . . 124

07 Change in triglycerides $(\mathrm{mmol} / \mathrm{l}) \quad$. . . . . . . . . . . . . . . . . . . . . . . . . . . . . . $\quad 124$

Fig. 78. Comparison 06. Miglitol versus sulphonylurea (SU). . . . . . . . . . . . . . . . . . . . . . . . . . . $\quad$. 124

08 Change in fasting insulin levels $(\mathrm{pmol} / \mathrm{l})$. . . . . . . . . . . . . . . . . . . . . . . . . . . . . . 124

Fig. 79. Comparison 06. Miglitol versus sulphonylurea (SU). . . . . . . . . . . . . . . . . . . . . . . . . . . . $\quad$. 125

12 Change in body weight $(\mathrm{Kg})$. . . . . . . . . . . . . . . . . . . . . . . . . . . . . . . . . . $\quad . \quad 125$

Fig. 80. Comparison 06. Miglitol versus sulphonylurea (SU). . . . . . . . . . . . . . . . . . . . . . . . . . . 125

15 Total deaths . . . . . . . . . . . . . . . . . . . . . . . . . . . . . . . . . . 125

Fig. 81. Comparison 06. Miglitol versus sulphonylurea (SU). . . . . . . . . . . . . . . . . . . . . . . . . . $\quad$. 126

16 Disease related deaths . . . . . . . . . . . . . . . . . . . . . . . . . . . . . . . . . . . . $\quad . \quad 126$

Fig. 82. Comparison 06. Miglitol versus sulphonylurea (SU). . . . . . . . . . . . . . . . . . . . . . . . . . . $\quad$. 127

30 Occurence of adverse effects . . . . . . . . . . . . . . . . . . . . . . . . . . . . . . . . . . . . . $\quad . \quad . \quad 127$

Fig. 83. Comparison 07. Miglitol versus metformin. . . . . . . . . . . . . . . . . . . . . . . . . . . . . . $\quad$. 127

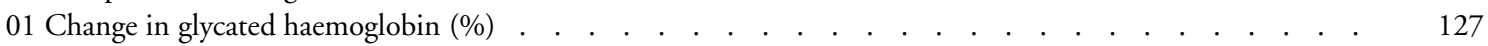

Fig. 84. Comparison 07. Miglitol versus metformin. . . . . . . . . . . . . . . . . . . . . . . . . . . . . . . . 128

02 Change in fasting blood glucose $(\mathrm{mmol} / \mathrm{l})$.

Fig. 85. Comparison 07. Miglitol versus metformin. . . . . . . . . . . . . . . . . . . . . . . . . . . . . . $\quad$. 128

03 Change in post-load blood glucose $(\mathrm{mmol} / \mathrm{l})$. . . . . . . . . . . . . . . . . . . . . . . . . . . . . 128

Fig. 86. Comparison 07. Miglitol versus metformin. . . . . . . . . . . . . . . . . . . . . . . . . . . . 129

08 Change in fasting insulin levels $(\mathrm{pmol} / \mathrm{l})$. . . . . . . . . . . . . . . . . . . . . . . . . . . . . . . $\quad . \quad 129$

Fig. 87. Comparison 07. Miglitol versus metformin. . . . . . . . . . . . . . . . . . . . . . . . . . . . . 129

09 Change in post-load insulin levels $(\mathrm{pmol} / \mathrm{l})$.

Fig. 88. Comparison 07. Miglitol versus metformin. .

Alpha-glucosidase inhibitors for type 2 diabetes mellitus (Review)

Copyright @2005 The Cochrane Collaboration. Published by John Wiley \& Sons, Ltd 
12 Change in body weight $(\mathrm{Kg})$. . . . . . . . . . . . . . . . . . . . . . . . . . . . . . . . $\quad$. 130

Fig. 89. Comparison 07. Miglitol versus metformin. . . . . . . . . . . . . . . . . . . . . . . . . . . . . 130

17 Occurence of gastro-intestinal side-effects . . . . . . . . . . . . . . . . . . . . . . . . . $\quad$. 130

Fig. 90. Comparison 07. Miglitol versus metformin. . . . . . . . . . . . . . . . . . . . . . . . . . . . . . . 131

30 Occurence of adverse effects . . . . . . . . . . . . . . . . . . . . . . . . . . . . . . . . . . . . .

Fig. 91. Comparison 07. Miglitol versus metformin. . . . . . . . . . . . . . . . . . . . . . . . . . . . . 131

90 Change in post-load blood glucose $(\mathrm{mmol} / \mathrm{l})(2$ hours $)$. . . . . . . . . . . . . . . . . . . . . . . 131

Fig. 92. Comparison 07. Miglitol versus metformin. . . . . . . . . . . . . . . . . . . . . . . . . . . 132

91 Change in post-load insulin levels (pmol/l) (2-hours) . . . . . . . . . . . . . . . . . . . . . . . . 132

Fig. 93. Comparison 08. Voglibose versus placebo. . . . . . . . . . . . . . . . . . . . . . . . . . . . . . . . 132

01 Change in glycated haemoglobin $(\%)$. . . . . . . . . . . . . . . . . . . . . . . . . . . . $\quad$. 132

Fig. 94. Comparison 08. Voglibose versus placebo. $\quad . \quad$. . . . . . . . . . . . . . . . . . . . . . . . . . . . . . . $\quad$. 133

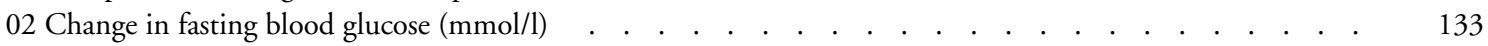

Fig. 95. Comparison 08. Voglibose versus placebo. $\quad . \quad$. . . . . . . . . . . . . . . . . . . . . . . . . . . . . . $\quad$. 133

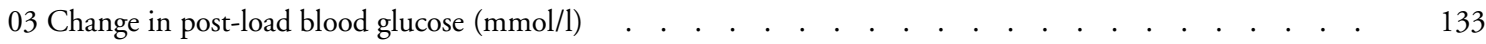

Fig. 96. Comparison 08. Voglibose versus placebo. . . . . . . . . . . . . . . . . . . . . . . . . . . . . . . . 134

08 Change in post-load insulin levels $(\mathrm{pmol} / \mathrm{l})$. . . . . . . . . . . . . . . . . . . . . . . . . . . . . 134

Fig. 97. Comparison 08. Voglibose versus placebo. . . . . . . . . . . . . . . . . . . . . . . . . . . . . . . . . . . 134

30 Occurence of adverse effects . . . . . . . . . . . . . . . . . . . . . . . . . . . . . . . . . . . .

Fig. 98. Comparison 08. Voglibose versus placebo. $\quad$. . . . . . . . . . . . . . . . . . . . . . . . . . . . . . . $\quad$. 135

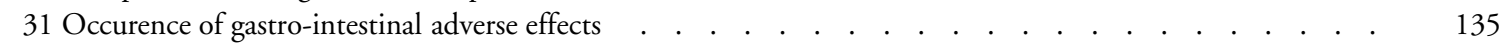

Fig. 99. Comparison 08. Voglibose versus placebo. . . . . . . . . . . . . . . . . . . . . . . . . . . . . . . . 135

90 Change in post-load blood glucose $(\mathrm{mmol} / \mathrm{l})(2$ hours $)$. . . . . . . . . . . . . . . . . . . . . . . . . $\quad$. 135

Fig. 100. Comparison 09. Voglibose versus diet therapy. . . . . . . . . . . . . . . . . . . . . . . . . . . . . . 136

01 Change in glycated haemoglobin $(\%)$. . . . . . . . . . . . . . . . . . . . . . . . . . . . . . 136

Fig. 101. Comparison 09. Voglibose versus diet therapy. $\quad . \quad$. . . . . . . . . . . . . . . . . . . . . . . . . . . 136

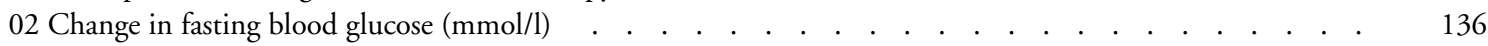

Fig. 102. Comparison 09. Voglibose versus diet therapy. $\quad$. . . . . . . . . . . . . . . . . . . . . . . . . . . $\quad$. 137

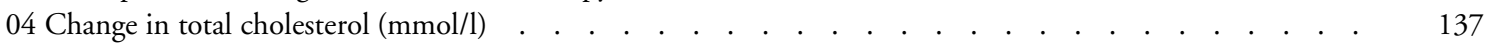

Fig. 103. Comparison 09. Voglibose versus diet therapy. . . . . . . . . . . . . . . . . . . . . . . . . . . . 137

05 Change in HDL-cholesterol $(\mathrm{mmol} / \mathrm{l})$. . . . . . . . . . . . . . . . . . . . . . . . . . . . . . . $\quad . \quad 137$

Fig. 104. Comparison 09. Voglibose versus diet therapy. . . . . . . . . . . . . . . . . . . . . . . . . . . . 138

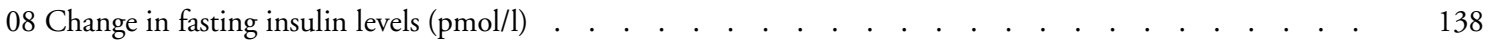

Fig. 105. Comparison 09. Voglibose versus diet therapy. . . . . . . . . . . . . . . . . . . . . . . . . . 138

12 Change in body weight $(\mathrm{Kg})$. . . . . . . . . . . . . . . . . . . . . . . . . . . . . . 138

Fig. 106. Comparison 09. Voglibose versus diet therapy. $\quad . \quad$. . . . . . . . . . . . . . . . . . . . . . . . . 139

13 Change in body mass index $(\mathrm{Kg} / \mathrm{m} 2)$. . . . . . . . . . . . . . . . . . . . . . . . . . . . . $\quad 139$

Fig. 107. Comparison 10. .Voglibose versus sulphonylurea $(\mathrm{SU}) . \quad$. . . . . . . . . . . . . . . . . . . . . . . . . 139

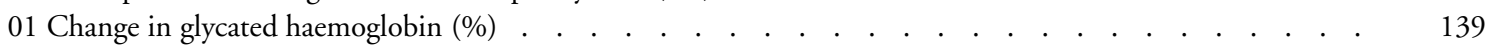

Fig. 108. Comparison 10. Voglibose versus sulphonylurea $(\mathrm{SU}) . \quad$. . . . . . . . . . . . . . . . . . . . . . . . 140

02 Change in fasting blood glucose $(\mathrm{mmol} / \mathrm{l}) \quad$. $\quad . \quad$. . . . . . . . . . . . . . . . . . . . . . . . . . . $\quad . \quad 140$

Fig. 109. Comparison 10. Voglibose versus sulphonylurea $(\mathrm{SU}) . \quad$. . . . . . . . . . . . . . . . . . . . . . . . 140

04 Change in total cholesterol $(\mathrm{mmol} / \mathrm{l}) \quad$. . . . . . . . . . . . . . . . . . . . . . . . . . . . . . . . $\quad$. 140

Fig. 110. Comparison 10. .Voglibose versus sulphonylurea (SU). . . . . . . . . . . . . . . . . . . . . . . . . . 141

05 Change in HDL-cholesterol $(\mathrm{mmol} / \mathrm{l})$. . . . . . . . . . . . . . . . . . . . . . . . . . . . . . . . . . . 141

Fig. 111. Comparison 10. .Voglibose versus sulphonylurea (SU). . . . . . . . . . . . . . . . . . . . . . . . . 141

08 Change in fasting insulin levels $(\mathrm{pmol} / \mathrm{l})$. . . . . . . . . . . . . . . . . . . . . . . . . . . . . . . . . . 141

Fig. 112. Comparison 10. Voglibose versus sulphonylurea $(\mathrm{SU}) . \quad$. . . . . . . . . . . . . . . . . . . . . . $\quad$. 142

12 Change in body weight $(\mathrm{Kg})$. . . . . . . . . . . . . . . . . . . . . . . . . . . . . . . . . . . . . . 142

Fig. 113. Comparison 10. .Voglibose versus sulphonylurea (SU). . . . . . . . . . . . . . . . . . . . . . . . . $\quad 142$

13 Change in body mass index $(\mathrm{Kg} / \mathrm{m} 2)$. . . . . . . . . . . . . . . . . . . . . . . . . . . . . . . $\quad . \quad 142$

Fig. 114. Comparison 11. Miglitol versus voglibose. . . . . . . . . . . . . . . . . . . . . . . . . . . . . $\quad 143$

01 Change in glycated haemoglobin $(\%)$.

Alpha-glucosidase inhibitors for type 2 diabetes mellitus (Review)

Copyright @2005 The Cochrane Collaboration. Published by John Wiley \& Sons, Ltd 
Fig. 115. Comparison 11. Miglitol versus voglibose. . . . . . . . . . . . . . . . . . . . . . . . . . . . . 143

02 Change in fasting blood glucose $(\mathrm{mmol} / \mathrm{l})$. . . . . . . . . . . . . . . . . . . . . . . . . $\quad . \quad 143$

Fig. 116. Comparison 11. Miglitol versus voglibose. . . . . . . . . . . . . . . . . . . . . . . . . . . . . . . 144

03 Change in post-load blood glucose $(\mathrm{mmol} / \mathrm{l})$. . . . . . . . . . . . . . . . . . . . . . . . . . 144

Fig. 117. Comparison 11. Miglitol versus voglibose. . . . . . . . . . . . . . . . . . . . . . . . . 144

09 Change in post-load insulin levels $(\mathrm{pmol} / \mathrm{l})$. . . . . . . . . . . . . . . . . . . . . . . . . . . . . 144

Fig. 118. Comparison 11. Miglitol versus voglibose. . . . . . . . . . . . . . . . . . . . . . . . . . . . 145

30 Occurence of adverse effects . . . . . . . . . . . . . . . . . . . . . . . . . . . . . . . . . $\quad . \quad 145$

Fig. 119. Comparison 11. Miglitol versus voglibose. . . . . . . . . . . . . . . . . . . . . . . . 145

31 Occurence of gastro-intestinal adverse effects . . . . . . . . . . . . . . . . . . . . . . . . . . . . $\quad . \quad 145$

Fig. 120. Comparison 11. Miglitol versus voglibose. . . . . . . . . . . . . . . . . . . . . . . . . . . . 146

90 Change in post-load blood glucose $(\mathrm{mmol} / \mathrm{l})(2$ hours $)$. . . . . . . . . . . . . . . . . . . . . . . . 146 


\title{
Alpha-glucosidase inhibitors for type 2 diabetes mellitus (Review)
}

\author{
Van de Laar FA, Lucassen PLBJ, Akkermans RP, Van de Lisdonk EH, Rutten GEHM, Van \\ Weel C
}

\begin{abstract}
This record should be cited as:
Van de Laar FA, Lucassen PLBJ, Akkermans RP, Van de Lisdonk EH, Rutten GEHM, Van Weel C. Alpha-glucosidase inhibitors for type 2 diabetes mellitus. The Cochrane Database of Systematic Reviews 2005, Issue 2. Art. No.: CD003639.pub2. DOI: 10.1002/14651858.CD003639.pub2.
\end{abstract}

This version first published online: 20 April 2005 in Issue 2, 2005.

Date of most recent substantive amendment: 23 February 2005

\section{A B S T R A C T}

\section{Background}

Alpha-glucosidase inhibitors such as acarbose or miglitol, have the potential to improve glycemic control in type 2 diabetes mellitus. The true value of these agents, especially in relation to diabetes related mortality and morbidity, has never been investigated in a systematic literature review and meta-analysis.

\section{Objectives}

To assess the effects of alpha-glucosidase inhibitors $s$ in patients with type 2 diabetes mellitus.

\section{Search strategy}

We searched The Cochrane Library, MEDLINE, EMBASE, Current Contents, LILACS, databases of ongoing trials, reference lists of reviews on the topic of alpha-glucosidase inhibitors and we contacted experts and manufacturers for additional trials. Date of most recent search: December 2003 (Current Contents) and April 2003 (other databases).

\section{Selection criteria}

Randomised controlled trials of at least 12 weeks duration comparing alpha-glucosidase inhibitor monotherapy in patients with type 2 diabetes with any other intervention and that included at least one of the following outcomes: mortality, morbidity, quality of life, glycemic control, lipids, insulin levels, body weight, adverse events.

\section{Data collection and analysis}

Two reviewers read all abstracts, assessed quality and extracted data independently. Discrepancies were resolved by consensus or by the judgement of a third reviewer. A statistician checked all extracted data entrance in the database. We attempted to contact all authors for data clarification.

\section{Main results}

We included 41 trials (8130 participants), 30 investigated acarbose, seven miglitol, one trial voglibose and three trials compared different alpha-glucosidase inhibitors. Study duration was 24 weeks in most cases and only two studies lasted amply longer than one year. We found only few data on mortality, morbidity and quality of life. Acarbose had a clear effect on glycemic control compared to placebo: glycated haemoglobin $-0.8 \%$ ( $95 \%$ confidence interval -0.9 to -0.7$)$, fasting blood glucose $-1.1 \mathrm{mmol} / \mathrm{L}$ ( $95 \%$ confidence interval -1.4 to - 0.9 ), post-load blood glucose $-2.3 \mathrm{mmol} / \mathrm{L}$ ( $95 \%$ confidence interval -2.7 to -1.9$)$. The effect on glycated haemoglobin by acarbose was not dose-dependent. We found a decreasing effect on post-load insulin and no clinically relevant effects on lipids or body weight. Adverse effects were mostly of gastro-intestinal origin and dose dependent. Compared to sulphonylurea, acarbose decreased fasting and post-load insulin levels by $-24.8 \mathrm{pmol} / \mathrm{L}$ (95\% confidence interval -43.3 to -6.3 ) and $-133.2 \mathrm{pmol} / \mathrm{L}$ (95\% confidence interval -184.5 to -81.8) respectively and acarbose caused more adverse effects. 


\section{Authors' conclusions}

It remains unclear whether alpha-glucosidase inhibitors influence mortality or morbidity in patients with type 2 diabetes. Conversely, they have a significant effect on glycemic control and insulin levels, but no statistically significant effect on lipids and body weight. These effects are less sure when alpha-glucosidase inhibitors are used for a longer duration. Acarbose dosages higher than $50 \mathrm{mg}$ TID offer no additional effect on glycated hemoglobin but more adverse effects instead. Compared to sulphonylurea, alpha-glucosidase inhibitors lower fasting and post-load insulin levels and have an inferior profile regarding glycemic control and adverse effects.

\section{S Y N O P S I S}

Alpha-glucosidase inhibitors lower blood sugars, have no effect on lipids and there is no evidence for an effect on morbidity and mortality.

Alpha-glucosidase inhibitors may be used for patients with type 2 diabetes. They delay the absorbance of carbohydrates ('complex form of sugar') in the gut. In this review we present data from meta-analyses that show (among other things) a decrease in glycated haemoglobin, fasting and post-load blood glucose and post-load insulin. But we found no evidence for an effect on mortality or morbidity. We found clues that with higher dosages the effect on glycated haemoglobin, in contrast to post-load blood glucose, remains the same. This might be because a lower compliance due to increasing side-effects.

\section{B A C K G R O U N D}

Diabetes mellitus is a metabolic disorder resulting from a defect in insulin secretion, insulin action, or both. As a result there is a disturbance of carbohydrate, fat and protein metabolism. Long-term complications of diabetes mellitus include retinopathy, nephropathy, neuropathy and increased risk of cardiovascular disease. For a detailed overview of diabetes mellitus, please see under'Additional information' of the Metabolic and Endocrine Disorders Group on The Cochrane Library (see 'About the Cochrane Collaboration', 'Collaborative Review Groups', 'Cochrane Metabolic and Endocrine Disorders Group'). For an explanation of methodological terms, see the main Glossary on The Cochrane Library.

\section{Alpha-glucosidase inhibitors}

One therapeutic option in the treatment of type 2 diabetes mellitus are alpha-glucosidase inhibitors, reversible inhibitors of alphaglucosidase, an enzyme present in the brush border of the small intestine. alpha-glucosidase inhibitors delay absorption of complex carbohydrates and thus inhibit postprandial glucose peaks thereby leading to decreased postprandial insulin levels.

Currently, four alpha-glucosidase inhibitors exist: acarbose, miglitol, voglibose and emiglitate. Of these, acarbose is by far the most prescribed drug. In most guidelines it is not a drug of first choice but used as an addition to other drugs for type 2 diabetes when treatment goals are not met, or in case of contra-indications for other medications (EDPG 1999; Rutten 2000). The price of acarbose and miglitol is approximately $\$ 72$ per month for $100 \mathrm{mg}$ tablets, three times daily.

Because of its lowering effect on the postprandial elevation of insulin levels, a beneficial effect on body weight is to be expected. Further, a positive effect on hypertriglyceridaemia has been re- ported (Reaven 1990). Abdominal discomfort like flatulence, diarrhoea and stomachache are the most frequently occurring adverse effects of alpha-glucosidase inhibitors. Because of their specific working mechanism hypoglycaemic adverse events do not occur. They do not increase insulin output potentially leading to hypoglycaemia.

Recently, alpha-glucosidase inhibitors have been put in a new light as a result of a study on the efficacy of acarbose in patients with impaired glucose tolerance (IGT) (Chiasson 2002; Chiasson 2003). This study showed that acarbose could prevent or delay the development of IGT into type 2 diabetes. Moreover, it showed a reduced risk of cardiovascular disease and hypertension in the acarbose treated group, but the conclusions of this study are heavily debated (Kaiser 2004).

\section{Existing evidence}

\section{Systematic reviews}

Some reviews have been published recently on the topic of acarbose (Breuer 2003; Laube 2002) and miglitol (Campbell 2000; Scott 2000), these reviews were not performed systematically with respect to one or more of the following items: literature search, inclusion criteria of studies and quality assessment. In none of these reviews a meta-analysis was performed.

A recent meta-analysis of seven trials with acarbose in the treatment of type 2 diabetes suggested a significant decrease in the occurrence of myocardial infarction (Hazard ratio $0.32,95 \%$ CI 0.14 to 0.80 ) (Hanefeld 2004). However, we do not support the conclusions of this meta-analysis because the study was subject to publication bias, heterogeneity, detection bias and confounding (Van de Laar 2004b).

RCTs 
Several randomised clinical trials evaluating the efficacy of alphaglucosidase inhibitors as monotherapy or as a combination with other agents have been published. Most of these evaluated the efficacy of acarbose. One major trial reported a decrease in glycated haemoglobin of $0.6 \%$ when acarbose was given as sole therapy and compared to placebo (Coniff 1995).

Another large $(\mathrm{n}=1946)$ randomised clinical trial, performed within the United Kingdom Prospective Diabetes Study (UKPDS), investigated acarbose versus placebo given in addition to diet, (combined) oral antidiabetic medication or insulin therapy (Holman 1999). At the three-years endpoint, 39\% of the patients in the acarbose group and $58 \%$ in the placebo group were still taking the study medication. The intention-to-treat analysis showed, that compared with placebo during three years, acarbose lowered glycated haemoglobin by $0.2 \%(\mathrm{p}=0.003)$. When only the proportion of patients that continued to take the study medication was considered, this difference was $0.5 \%$. The clinical relevance of this finding remains unclear, especially when considering that even in the per-protocol analysis for most patients using acarbose glycated haemoglobin remained higher than $8.0 \%$. Further, data on other important outcomes like morbidity and mortality are not available from this study. Adverse effects were mostly of gastrointestinal origin (flatulence, stomachache) and were reported to resolve after a short while.

The scope of the current review was to assess the value of monotherapy with alpha-glucosidase inhibitors in the treatment of type 2 diabetes mellitus with respect to patient-oriented outcomes such as morbidity, mortality and quality of life. Further we investigated the value of alpha-glucosidase inhibitors with respect to parameters related to glucose and lipid metabolism, body weight and adverse events. We sought studies that compared alpha-glucosidase inhibitors with placebo or any other intervention. In the future, the review will be regularly updated to include relevant new trials.

\section{O B JE C T IVES}

To assess the effects of alpha-glucosidase inhibitors primarily on mortality, morbidity and quality of life in patients with type $2 \mathrm{di}$ abetes mellitus, and secondly, the effects on parameters representing glucose and lipid metabolism (that is glycated haemoglobin, glucose, insulin and cholesterol).

\section{CRITERIA FOR CONSIDERING STUDIES FOR THIS REVIEW}

\section{Types of studies}

Only randomised controlled trials with a minimum duration of three months were eligible for inclusion in this review. Because the common adverse effects of alpha-glucosidase inhibitors make true blinding difficult, both blinded and non-blinded studies were included. We included studies published in any language and all identified trials, published or unpublished, were investigated.

\section{Types of participants}

Patients with existing or newly diagnosed type 2 diabetes mellitus. Changes in diagnostic criteria (ADA 1997; ADA 1999; NDDG 1979; WHO 1980; WHO 1985; WHO 1998) may have produced variability in the clinical characteristics of the patients included as well as in the results obtained. These differences will be considered and explored in a sensitivity analysis.

\section{Types of intervention}

Monotherapy with alpha-glucosidase inhibitors (acarbose, miglitol, voglibose, emiglitate) compared with any other intervention: 1. Placebo;

2. Sulphonylurea (for example, glibenclamide);

3. Thiazolidinedione (for example, pioglitazone);

4. Meglitinide (for example, nateglinide);

5. Biguanide (for example, metformin);

6. Insulin;

7. Any other pharmacological intervention;

8. A non-pharmacological intervention (for example, diet therapy).

\section{Types of outcome measures}

\section{Main outcome measures}

1. Mortality: diabetes-related mortality (death from myocardial infarction, stroke, renal disease, or sudden death, death from hyperosmolar nonketotic coma), total mortality;

2. Diabetes-related complications: vascular complications (angina pectoris, myocardial infarction, stroke, peripheral vascular disease, amputation), neuropathy, retinopathy, nephropathy, erectile dysfunction, hyperosmolar nonketotic dysregulation;

3. Quality of life, assessed with a validated instrument.

\section{Additional outcome measures}

4. Glycaemic control: glycated haemoglobin levels, fasting and post-load blood glucose levels;

5. Plasma lipids (triglycerides, total-, high-density lipoprotein (HDL)- and low-density lipoprotein (LDL)-cholesterol);

6. Fasting and post-load insulin and C-peptide levels;

7. Body weight (or body mass index);

8. Adverse effects (i.e. diarrhoea, stomachache, flatulence).

Specific patient co-variates thought to be effect modifiers

9. Compliance.

Timing of outcome measurement

We assessed a possible influence of treatment duration in a sensitivity analysis. 


\section{SEARCH STRATEGY FOR I DENTIFICATIONOF TUDIES}

See: Metabolic and Endocrine Disorders Group search strategy

\section{Electronic searches}

We used the following sources for the identification of trials:

- The Cochrane Central Register of Controlled Trials (CENTRAL) (2003, issue 3);

- MEDLINE (up to April 2003) using the search terms listed below and combined with the MEDLINE search strategy for randomised controlled trials from the Cochrane Metabolic and Endocrine Disorders Group (see review group search strategy), without language restriction;

- EMBASE (up to April 2003);

- LILACS (www.bireme.br/bvs/I/ibd.htm) from up to April 2003;

- Current Contents (up to December 2003).

- Handsearching: checking references of existing reviews, checking abstract books and poster displays on congresses or meetings attended by the first author. The internet was searches non-systematically by using different combinations of (brand)names for alpha-glucosidase inhibitors.

Databases of ongoing trials (latest access April 2003):

- Current Controlled Trials (http://www.controlled-trials.com with links to other databases of ongoing trials);

- UK National Research Register (http://www.update-software. com/National/nrr-frame.html);

- USA - CenterWatch Clinical Trials Listing Service (http:// www.CenterWatch.com/);

- USA - National Institutes of Health (http://clinicalstudies. info.nih.gov/).

All records from each database that seemed eligible after assessing the title and/or abstract were imported to a bibliographic database, Reference Manager (Version 10, ISI ResearchSoft), checked for duplicates and merged into one core database. The content of that database was exported to the Review Manager computer program (Revman 4.2.3, The Cochrane Collaboration).

The described search strategy has been used for MEDLINE. For use with EMBASE and Current Contents this strategy was slightly adapted because these databases were only available with different browsers. The necessary alterations in search string were done in such a way that the search became more sensitive (that is yielded a higher number of 'hits'). In CENTRAL, LILACS and the databases of ongoing trials we searched with the various text words for the alpha-glucosidase inhibitors and their brand names. For the detailed search strategy see under 'Additional tables' (Table 02).

\section{Handsearching}

We searched reference lists of relevant trials and alpha-glucosidase inhibitor reviews and selected possible references that were not already in our database.

\section{Other search strategies}

Authors of relevant identified studies and other experts were contacted by mail in order to obtain additional references, unpublished trials, and ongoing trials or to obtain missing data not reported in the original trials. Similarly, manufacturers and patent holders (Bayer AG, Sanofi-Synthelabo, Pfizer, Takeda) were contacted in order to retrieve information on alphaglucosidase inhibitors trials, published and unpublished.

\section{METHODS OF THE REVIEW}

\section{Trial selection}

Two reviewers (FVDL and PL) independently checked the titles, abstract sections and keywords of every record retrieved. Full articles were retrieved for further assessment when the information given suggested that the study: 1) included patients with diabetes mellitus, 2) compared alpha-glucosidase inhibitors with placebo or any other active intervention, 3) assessed one or more relevant predefined clinical outcome measure, 4) used random allocation to the comparison groups. In case of any doubt regarding these criteria from the information given in the title and abstract, the full article was retrieved for clarification. Interrater agreement for study selection was measured using the kappa statistic (Cohen 1960). Differences in opinion were resolved by a third party (EVDL) and when resolving the disagreement was not possible, the article was added to those 'awaiting assessment' and the authors were contacted for clarification. If the authors provided no clarification, the review group editorial base was consulted.

\section{Quality assessment of trials}

The two reviewers assessed each trial independently. Possible disagreement was resolved with consensus, or with consultation of a third reviewer (EVDL) in case of disagreement. In particular, the following quality criteria were assessed:

\section{Minimisation of selection bias:}

- Randomisation procedure: the randomisation procedures were scored adequate if the resulting sequences were unpredictable (that is computer generated schemes, tables of random numbers, coin tossing).

- Allocation concealment: allocation concealment was scored adequate if participating patients and investigators could not foresee the assignment (that is by central randomisation remote from trial site, sequentially numbered and sealed radio-opaque envelopes). 


\section{Minimisation of performance bias:}

- Method of blinding: blinding was considered adequate if the two (or more) interventions were similar in size, colour and shape or when a double-dummy method was applied. Because of the sometimes-obvious adverse effects of alpha-glucosidase inhibitors, true blinding was difficult. For trials that reported blinding of patients for medications, we also investigated whether blinding was checked; for example by asking patient and investigator afterwards about the medication they suspected to be supplied.

\section{Minimisation of attrition bias:}

- Handling of drop-outs: handling of drop-outs was considered adequate if studies gave a complete description of all patients failing to participate until the end of the trial and if the data were analysed on intention-to-treat (ITT) basis, that means with all randomised patients included.

- Quantity of dropouts: overall dropout rate less than $15 \%$ was considered adequate.

- Selective dropout: a difference in dropout rate the in main treatment groups less than $10 \%$ was considered adequate.

Minimisation of detection bias:

- Method of blinding outcome-assessment: this item was considered less relevant for studies with laboratory data or death as main outcomes or if the (blinded) investigator was also outcome assessor. If applicable, outcome assessment was considered adequate if the outcome assessors were completely blind for the intervention.

We explored the influence of individual quality criteria in a sensitivity analysis (see under 'sensitivity analyses').

Based on these criteria, studies were broadly subdivided into the following three categories adapted from the Cochrane Handbook criteria (see Cochrane Handbook):

A - All quality criteria met (1. adequate randomisation and allocation concealment, 2 . adequate blinding, 3. adequate ITT analysis and/or both drop-out rate less than $15 \%$ and selective drop-out less than 10\%): low risk of bias.

B - One or more quality criteria only partially met (1. adequate randomisation or adequate allocation concealment, 2 . mentioning of blinding but exact method unclear, 3. inadequate/unclear ITT analysis but drop-out less than $15 \%$ or selective drop-out less than 10\%): moderate risk of bias.

C - One or more quality criteria not met (1. inadequate randomisation and allocation concealment, 2 . inadequate or no blinding, 3. inadequate ITT and drop-out rate equal to or more than $15 \%$ and selective drop-out equal to or more than $10 \%$ ): high risk of bias.

This adapted classification was also used as the basis of a sensitivity analysis.

\section{Data extraction}

Two reviewers extracted data on intervention and outcomes independently, using a pre-tested data extraction form that was adapted from a standard form provided by the review group. The data extraction form included the following items:

- General information: author, type of publication (including the existence of duplicate or multiple publications), year of publication, language, country were the study was conducted, setting (general practice, hospital or outpatient / rural, city, developed / developing world / single or multi-centre), the stated aim of the study published, sponsor(s), ethics approval;

- Study characteristics: parallel or cross-over, type of control groups (placebo, other medication etc.), existence of runin and/or wash-out period, description of possible carry-over effect (for cross-over studies), method, type and quality of randomisation, method and quality of allocation concealment, method and quality of blinding, information about handling of drop-outs, withdrawals and losses to follow-up, numbers of and reasons for drop-out, existence of possible sub-groups, method of assessment of compliance;

- Participants: description of diagnostic criteria for type 2 diabetes mellitus, inclusion and exclusion criteria,

- Interventions: specification of a possible reinforcement of diet therapy, the nature, dose and regimen (including: fixed or titrated dose, step-up dosage scheme) of alpha-glucosidase inhibitor(s) and control interventions, duration of intervention and follow-up;

- Baseline characteristics and measurements: numbers of patients, sex, age, ethnicity, socio-economic status and duration of diabetes, existence of significant differences at baseline, baseline glycated haemoglobin, fasting and post-load blood glucose, plasma lipids (triglycerides, total-, HDL-and LDL-cholesterol), height, weight and body mass index (BMI), fasting and postload insulin and C-peptide (standard deviations if applicable), specifications (including reference ranges) of all laboratory measurements, type of post-load test, time between fasting and post-load measurements, centralisation of laboratory measurements;

- Outcomes: total and disease specific deaths and morbidity, quality of life (including method of assessment), mean changes (standard deviation, SD) of the following values: glycated haemoglobin, fasting and post-load blood glucose, lipids, fasting and post-load insulin / C-peptide, body weight, BMI, occurrence of adverse events (total and gastro-intestinal), compliance.

When more than onde publication was available from a study, all articles were abstracted and scores separately and the collected data was synthesized. In case of contradictorily findings, the author was contacted for clarification.

Alpha-glucosidase inhibitors for type 2 diabetes mellitus (Review) 
Differences in data extraction were resolved by consensus, referring back to the original article. If necessary, information was sought from the authors of the original studies.

If necessary, data were also extracted from graphical figures: two reviewers (FVDL and PL) calculated the data independently and if both outcomes were not similar, a third reviewer (EVDL) recalculated the data. A statistician checked all extracted data for errors, after transfer to the database.

\section{Data analysis}

Data were summarised statistically if available and of sufficient quality. The table of comparison was first divided in all possible comparisons (that is acarbose versus placebo / voglibose versus sulphonylurea), then sub-divided into all possible outcomes (that is death, glycated haemoglobin adverse events) and finally, within the outcomes sub-groups were made for the different dosages. Outcomes were calculated per sub-group and for all sub-groups together.

Dichotomous data were expressed as odds ratios (OR), but in some cases the relative risk (RR) was also calculated in addition to the OR since its interpretation is easier, especially if the outcome was a negative event, for example death. We calculated the risk difference $(\mathrm{RD})$ and we converted the RD into the number needed to treat (NNT) or the number needed to harm (NNH) taking into account the time of follow-up.

Continuous data were expressed as weighted mean differences (WMD) and an overall WMD was calculated. The actual measure of effect of all continuous variables were the differences from baseline to endpoint. The standard deviations of these differences were essential for the data to be included in the meta-analysis. When the standard deviation (SD) of the difference was not reported we first asked the authors to provide these data. If the SDs were not provided we estimated the SD of the difference with the following formula:

SDpaireddifference $=$ ?? $(\mathrm{SD} 1) 2+(\mathrm{SD} 2) 2-2 \mathrm{x}$ r x SD1 x SD2]

SDpaireddifference $=$ standard deviation of the difference $($ pre- $/$ post-treatment)

SD1 = Standard deviation of the pre-treatment value, SD2 = Standard deviation of the post-treatment value, $r=$ correlation coefficient. We used a conservative correlation coefficient of 0.4 .

Overall results were calculated based on the random effects model. Heterogeneity was statistically tested by using the $\mathrm{Z}$ score and the Chi square statistic with significance set at $\mathrm{p}<0.10$. Possible sources of heterogeneity were assessed by subgroup, sensitivity and meta-regression analyses as described below. Small study bias was tested for using the funnel plot or other corrective analytical methods depending on the number of clinical trials included in the systematic review (Begg 1994; Egger 1997; Hedges 1992). Quantification of the effect of heterogeneity will be assessed by means of I squared, ranging from $0-100 \%$ including its $95 \%$ confidence interval (Higgins 2002). I squared demonstrates the percentage of total variation across studies due to heterogeneity and will be used to judge the consistency of evidence.

The analyses were done with the computer program RevMan Analyses 1.0.2 in Review Manager 4.2.3 (2003, The Cochrane Collaboration).

\section{Subgroup analyses}

Significant main outcome measures were explored by subgroup analyses in order to explore differences in effect as follows:

1) Glycated haemoglobin level at baseline (subdividing into three groups: less than $7 \%, 7$ to $9 \%$, more than $9 \%$ );

2) Age (based on mean age of total randomised group);

3) Gender (subdivided in two groups, based on data: less than $45 \%$ female, equal or more than $45 \%$ female);

4) Body mass index (BMI) (Normal: male less than 27, female less than 25; overweight: male 27 to 30 , female 25 to 30 ; obese: more than 30);

5) Different kind of diets or exercise schedules used;

6) Duration of intervention (less than 24 weeks, 24 weeks, more than 24 weeks);

Sensitivity analyses

The sensitivity of the analysis for a number of factors was determined by comparing the results of the meta-analysis for studies with and without certain characteristics. Data from a minimum of five studies had to be available for both groups to be considered. The following factors were investigated:

1) Comparing published and unpublished studies;

2) Comparing studies with and without (or with unknown) quality characteristics: adequate randomisation, adequate allocation concealment, adequate method of blinding, adequate ITT analyses. Further, comparing studies with an overall drop-out rate equal to or more than $15 \%$ and less than $15 \%$, difference of dropout rates less than $10 \%$ and equal to or more than $10 \%$ between the main treatment groups. In addition, the overall score for quality based on the adapted Cochrane criteria was used so that studies with score $\mathrm{A}$ and $\mathrm{B}$ were compared with studies with $\mathrm{C}$;

3) Repeating the analysis excluding trials using the following filters: diagnostic criteria, language of publication, source of funding (industry versus other or no sponsoring) or country;

4) Repeating the analyses using different measures of effect size (relative risk, risk difference) and different statistical models (fixed and random effects models);

\section{Meta-regression analyses}

We used meta-regression analyses (in SAS proc MIXED, version 8.0) to explore the influence of characteristics of study population and study design on the outcomes. We studied the dependent variables glycated haemoglobin, fasting and post-load glucose, fasting and post-load insulin, total cholesterol, triglycerides and adverse effects. The independent variables were similar to the predefined sub-groups (baseline glycated haemoglobin, age, gender, baseline BMI, and duration of treatment). In addition we studied 
duration of diabetes at baseline, the use of a fixed dose and the use of a step-up dosage regimen. The weight of each trial was equal to the inverse sum of the within trial variance and the residual between trial variance, in order to perform a random effects analysis. To gain sufficient power, data from at least 10 studies had to be available to calculate results from the metaregression.

\section{DESCRIPTIONOF STUDIES}

Trials identified (See study flow diagram Figure 02)

* CENTRAL: 262 records were retrieved and assessed on the basis of title and/or abstract (Issue 3 2003), 59 records were initially included. Ten records were excluded after the full article had been read. So 49 records were finally included in the review.

* MEDLINE: 328 records found (April 2003), 43 records initially included, 34 records finally included in the review.

* Embase: 567 records found (April 2003), 50 records initially included, 40 records finally included in the review.

* Current Contents (December 2003): 260 records found, 27 records initially included, 23 records finally included in the review. * LILACS: 13 records found, one records initially but excluded after further scrutiny.

Experts: We obtained 14 references as a result of correspondence with experts: seven references after a general mailing to 27 experts with a request for additional references (six out of 27 forms were returned), and another seven references as a result of contacts which we established searching for missing or additional data. Two references were already in our possession (one study performed by our group but that was not published at that time (Van de Laar 2004a) and an article referring to two trials (Fölsch 1990, using data from Hoffmann 1990 and Spengler 1992).

We included nine (out of these 16) references in the final review.

Manufacturers: Bayer, the developer of acarbose and miglitol, sent us 23 references, 17 were initially included and 16 were finally included in the review. The developer and patent holder of voglibose (Takeda) and the patent holders of miglitol (Pfizer and SanofiSynthelabo) did not reply to our letters.

Handsearch: 22 possibly eligible references were found by handsearching (checking references of existing reviews, browsing on the internet, posters on congresses etc.). Seventeen references were initially included, of which 14 references were finally included in the review.

Databases of ongoing trials (see table Characteristics of ongoing trials): in addition three studies were identified as ongoing studies in trial registers. All attempts to retrieve reports or data from these studies, failed so far.

\section{Interrater agreement}

Interrater kappa for agreement on inclusion, calculated on basis of the first 852 titles and / or abstracts read by the two reviewers
(FVDL and PL) was good: 0.74 (95\% confidence interval 0.67 to 0.81 ). All differences in opinion were resolved by consensus.

\section{Missing data}

Because none of the articles contained all the study data we required for the quality assessment and meta-analyses, we attempted to contact all corresponding authors. For one study we could not retrieve contact information (Hillebrand 1987). For 22 out of 41 studies we received additional data about design, quality and/or outcomes. For 12 studies the authors delegated the reply to representatives of Bayer Germany, USA or Italy because the data-files were kept by this firm. Studies for which we received additional data are indicated in the table 'Characteristics of included studies' and the reference list (published and unpublished data).

\section{Excluded studies}

Fifteen studies were excluded after reading the full article (see Figure 02). The most common reason was that patients used antidiabetic medication in addition to the study medication. See table 'Charcteristics of excluded studies' for further details.

\section{Included studies}

Fourty-one studies with 8130 participants, described in 69 articles, abstracts, posters or unpublished documents were finally included in the review. Details are given in the Table of included studies.

Thirty-five studies were published as journal articles, three studies as abstract only (Campbell 1998; Hillebrand 1987; Rybka 1999) and two studies were found by their poster presentation (Holmes 2001; Kawamori 2003), one study done by our own group was accepted for publication during the review process (Van de Laar 2004a)

Four studies were performed in general practice, for one study the patients were recruited in general practice but all study related activities were done in so-called 'study-centres' (Drent 2002), patients from 34 studies were characterised as 'outpatients' and for two studies the setting was not reported.

Thirty-nine studies had a parallel design and two were crossover studies (Gentile 1999, Hillebrand 1987). Thirty-three studies were double-blinded, five studies were not blinded and three studies with three treatment groups were not blinded with respect to one treatment arm (metformin and glibenclamide).

Nineteen studies compared acarbose with placebo, four of which compared two or more doses with placebo. Eleven studies compared acarbose with other anti-diabetic medication and in most cases also with placebo. Miglitol was studied in comparison with placebo in three studies, one of which with four different dosages. In four studies miglitol was compared with other anti-diabetic medication (and placebo eventually). Two three-arm studies compared acarbose with miglitol and placebo (one study) or glibenclamide (one study). One study compared miglitol and voglibose (and placebo) and one trial studied voglibose versus diet and glyburide (a sulphonylurea). We found no studies with emiglitate. Study duration was 24 weeks (21 studies), 16 weeks (seven studies), one year (four studies), 12 weeks (four studies), three years (two 
studies), 30 weeks, 36 weeks or 56 weeks (all one study). Two studies reported data on mortality (Coniff 1995; Johnston 1998) and one crossover study reported that no patients had died (Gentile 1999). Two studies reported data on morbidity (Holman 1999; Johnston 1998) and one study reported quality of life as an outcome (Meneilly 2000), but none of these data were primary efficacy measures.

\section{Measurement of post-load blood glucose, insulin and c-peptide} There are several methods to determine the patients' response to a glucose load. The 'load' may consist of simple glucose (like in an oral Glucose Tolerance Test, oGTT), a standardised or ad libitum meal, or a standardised portion of carbohydrates. Studies may also differ in the time-interval used for the test and if the study drug was given prior to the test. We assessed all those differences and described them in a table (Table 01). Most studies used some form of test-meal with carbohydrates, except for two studies which used an OGTT (Hotta 1993; Van de Laar 2004a). In two studies the type of test was unclear (Hillebrand 1987; Rybka 1999).

For two studies, the only post-load measurement was at a 2-hours interval (Hotta 1993; Pagano 1995) and six studies reported both one and two hour values (Chiasson 2001; Coniff 1994; Coniff 1995; Coniff 1995b; Kawamori 2003; Santeusanio 1993), all other studies that measured post-load values for glucose, insulin and/or C-peptide used an 1-hour interval. Therefore, we chose to report the 1-hour values for post-load glucose, insulin and Cpeptide, and to use the 2-hour outcomes if 1-hour data were not available. As a sensitivity analysis, we repeated the analysis with the opposite method: using the 2 -hour values, and the 1 -hour values for studies that did not report 2-hour measurements.

\section{METHODOLOGICAL QUALITY}

See table quality of studies in Figure 01.

\section{Methodological quality}

With respect to selection bias 11 studies had both an adequate randomisation and allocation concealment. The risk of attrition bias was low in 14 studies: one study had adequate ITT; one study had both adequate ITT analysis and low total / selective drop-out (less than $15 \%$ total drop-out, less than $10 \%$ difference between groups); 12 studies had low total / selective drop-out. Blinding (performance bias) was adequate in 22 studies.

The overall quality was roughly assessed on a three point scale according to the Cochrane handbook: five studies scored A (low risk of bias) and five studies $\mathrm{B}$ (moderate risk of bias). The other 31 studies scored $\mathrm{C}$ (high risk of bias).

\section{Missing data}

In a number of cases it was reported that certain outcomes (that is fasting blood glucose, triglycerides) were investigated, but the results were not or insufficiently reported (that is standard deviations missing). This was especially striking for a study with acarbose, that was of long duration and with a large number of participants (Campbell 1998). Data from this trial could not be used because the main outcome measure was the time until patients with good control on diet alone needed additional medication. Data from a large study of long duration investigating miglitol could not be used as no measures of variance were reported for the main outcomes (that are standard deviations) (Johnston 1998). Our written request for these data, has not been answered so far.

One large study (603 participants) comparing miglitol and acarbose was published as an abstract only (Rybka 1999). Attempts to contact the author failed so far.

\section{R E S U L T S}

\section{Heterogeneity}

Statistical tests for heterogeneity yielded statistically significant results in many cases. Studies were homogenous with respect to the fact that all participants were described as having type 2 diabetes and that they used the test drug as mono therapy for at least three months. But studies could differ with respect to country (and thus dietary habits), age, severity and duration of diabetes. These possible sources for heterogeneity were investigated in the subgroup and meta-regression analyses.

\section{Effects of the intervention}

\section{Mortality, morbidity, quality of life}

Three studies reported the occurrence of death (Coniff 1995; Holman 1999; Johnston 1998). No statistically or clinically significant differences in outcomes were found.

One 3-year study reported data on morbidity as relative risks (Holman 1999). The relative risk for acarbose users compared with placebo for "any diabetes-related end point" was 1.0 (95\% confidence interval 0.8 to 1.2$)$ and for microvascular disease $0.9(95 \%$ confidence interval 0.6 to 1.4 ). The outcome for the subgroup actually receiving acarbose monotherapy was not reported. One 56-weeks study that compared $25 \mathrm{mg}$ and $50 \mathrm{mg}$ TID miglitol with glyburide and placebo, reported the number of cardiovascular events in the table of adverse effects (Johnston 1998). The percentage of occurrence of any cardiovascular event was 19\%, $17 \%, 22 \%$ and $29 \%$ for miglitol $25 \mathrm{mg}$ TID, miglitol $50 \mathrm{mg}$ TID, placebo and glyburide respectively. Statistical significance was reached for the comparison miglitol $50 \mathrm{mg}$ and glyburide.

Glycemic control

Glycated haemoglobin, alpha-glucosidase inhibitors versus placebo

alpha-glucosidase inhibitors had a clear beneficial effect on glycemic control compared to placebo. Glycated haemoglobin was considered the primary measurement in most studies. The results of the meta-analysis for overall effect of alpha-glucosidase inhibitor on glycated haemoglobin compared to placebo was $-0.8 \%(95 \%$ confidence interval -0.9 to $-0.6,28$ comparisons) for acarbose and 
$-0.7 \%$ ( $95 \%$ confidence interval -0.9 to -0.4 , seven comparisons) for miglitol. For voglibose, data from only one comparison were available: $-0.5 \%$ (95\% confidence interval -0.6 to -0.3 ). We did not see a clear dose dependency of the effect on glycated haemoglobin with respect to acarbose. Effect sizes for the subgroups for dosage $25 \mathrm{mg}$ ( $\mathrm{n}=1$ study), $50 \mathrm{mg}(\mathrm{n}=2), 100 \mathrm{mg}(\mathrm{n}=17), 200 \mathrm{mg}(\mathrm{n}$ $=4)$ and $300 \mathrm{mg}(\mathrm{n}=2)$ TID were $-0.5 \%,-0.9 \%,-0.8 \%,-0.8 \%$ and $-0.8 \%$ respectively.

For miglitol, there seemed to be a dose dependent effect on glycated haemoglobin, but data from only seven comparisons, of which four originating from the same multi-arm study (Drent 2002), were available.

Fasting and post-load blood glucose, alpha-glucosidase inhibitors versus placebo

We also found a beneficial effect on fasting blood glucose for acarbose compared to placebo in a meta-analysis with 28 comparisons: $-1.1 \mathrm{mmol} / \mathrm{L}$ (95\% confidence interval -1.4 to -0.8$)$. For miglitol and voglibose two and one comparisons were available in the meta-analysis with fasting blood glucose as outcome. These analyses resulted in a mean decrease in fasting blood glucose of -0.5 $\mathrm{mmol} / \mathrm{L}$ (miglitol, $95 \%$ confidence interval -0.9 to -0.2 ) and -0.6 $\mathrm{mmol} / \mathrm{L}$ (voglibose, $95 \%$ confidence interval -1.0 to -0.2 ).

The influence on (1-hour) post-load blood glucose was more profound. Overall effect on post-load blood glucose was $-2.3 \mathrm{mmol} / \mathrm{L}$ (95\% confidence interval -2.7 to $-1.9,22$ comparisons). The subgroups for dosage showed a dose dependent pattern. For miglitol and voglibose only very limited data were available: miglitol -2.7 $\mathrm{mmol} / \mathrm{L} 95 \%$ confidence interval -5.5 to 0.1 , two comparisons), voglibose $-2.4 \mathrm{mmol} / \mathrm{L}$ ( $95 \%-3.0$ to -1.8 , one comparison).

In contrast to the effect on glycated haemoglobin, the forest plots for the comparison acarbose versus placebo and the outcome fasting and post-load blood glucose suggested a dose dependency of the treatment effect.

Because not all studies used similar methods for the measurement of post-load blood glucose we repeated the analyses replacing 1hour post-load data by 2 -hour values (if available). We found no differences in that analysis compared with the meta-analysis in which we primarily used the 1-hour values.

Alpha-glucosidase inhibitors versus other medication

Studies that compared an alpha-glucosidase inhibitor with other interventions than placebo were scarce. Pooling of results was only possible for the comparison acarbose with sulphonylurea, as data from eight comparisons were available. For other comparisons, pooling was not possible because of lack of studies (metformin and nateglinide, both one study). The overall comparison acarbose versus sulphonylureas yielded a non-significant trend for sulphonylureas with respect to glycated haemoglobin $(0.4 \%, 95 \%$ confidence interval -0.0 to 0.8 ). The results in the subgroup 'Acarbose 100 mg TID versus Glibenclamide 3.5 mg TID' were not consistent with the other comparisons (overall test for heterogeneity $\mathrm{p}<$ 0.00001 ). Leaving the entire sub-group out of the analysis would give an overall effect of $0.6 \%$ (95\% confidence interval 0.3 to 1.0 ) in favour of sulphonylurea with a non-significant chi-square test for heterogeneity $(p=0.15)$. In the comparison acarbose versus sulphonylurea one study seemed to be an outlier (Kovacevic 1997), but the results of that study were again in line with the comparisons with other sulphonylurea. For most comparisons acarbose versus sulphonylurea, acarbose was given as a fixed dose and the sulphonylurea individually adjusted, mostly sub-maximal.

The result for fasting blood glucose showed a similar pattern: superiority for sulphonylurea except for the subgroup 'Acarbose $100 \mathrm{mg}$ TID vs. Glibenclamide $3.5 \mathrm{mg}$ TID'. Overall effect $0.7 \mathrm{mmol} / \mathrm{L}$ (95\% confidence interval 0.2 to 1.2 ) in favour of sulphonylurea. Without the deviating sub-group: $1.2 \mathrm{mmol} / \mathrm{L}$ (95\% confidence interval 0.6 to 1.8 ) in favour of sulphonylurea.

The outcome post-load blood glucose yielded no statistically significant differences between acarbose and sulphonylurea.

Results from studies not included in the meta-analyses:

In a four-arm study comparing miglitol $25 \mathrm{mg}$ TID, miglitol 50 mg TID, glyburide maximum $20 \mathrm{mg}$ QD or placebo, glycated haemoglobin decreased by $0.5 \%, 0.4 \%, 0.9 \%$ and $0.0 \%$ respectively (Johnston 1998). Similarly fasting blood glucose decreased by $0.7 \mathrm{mmol} / \mathrm{L}, 1.1 \mathrm{mmol} / \mathrm{L}, 1.7 \mathrm{mmol} / \mathrm{L}$ and $0.1 \mathrm{mmol} / \mathrm{L}$ and one hour post-load blood glucose decreased by $2.4 \mathrm{mmol} / \mathrm{L}, 3.2$ $\mathrm{mmol} / \mathrm{L}, 1.8 \mathrm{mmol} / \mathrm{L}$ and $0.0 \mathrm{mmol} / \mathrm{L}$ respectively.

One study with 603 participants and of 24 weeks duration (Rybka 1999) reported a placebo subtracted decrease of glycated haemoglobin of $0.4 \%, 0.5 \%$ and $0.4 \%$ respectively for miglitol $50 \mathrm{mg}$ TID, miglitol $100 \mathrm{mg}$ TID and acarbose $100 \mathrm{mg}$ TID.

\section{Plasma lipids}

We found no effects of acarbose compared to placebo on total, HDL- and LDL-cholesterol. There was no statistically significant effect on triglycerides: $-0.1 \mathrm{mmol} / \mathrm{L}$ (21 comparisons, $95 \%$ confidence interval -0.2 to 0.0 ). With respect to the comparison with sulphonylurea no statistically significant differences were found. Very few comparisons (arcabose versus metformin etc.) were available.

\section{Fasting and post-load insulin and c-peptide}

The 25 studies that assessed pancreatic function mostly used insulin levels for this purpose. We found that acarbose had no statistically significant effect on fasting insulin levels compared to placebo and a non-statistically significant decreasing effect on post-load insulin levels (fasting insulin: $-1 \mathrm{pmol} / \mathrm{L}$ (15 comparisons, 95\% confidence interval -8 to 7$)$, post-load insulin: $-41 \mathrm{pmol} / \mathrm{L}(13$ comparisons, $95 \%$ confidence interval -61 to -19$)$ ). For miglitol and voglibose only a limited number of comparisons were available and no statistically significant differences were found.

Compared to sulphonylurea, acarbose had a statistically significant decreasing effect on fasting insulin (seven comparisons, -25 $\mathrm{pmol} / \mathrm{L}, 95 \%$ confidence interval -43 to -6 ) and post-load insulin as well (seven comparisons, $-133 \mathrm{pmol} / \mathrm{L}, 95 \%$ confidence interval -185 to -82$)$. Only one study compared miglitol with a sulphonylurea and found an opposite result: fasting insulin $28 \mathrm{pmol} / \mathrm{L}$ 
increase compared to sulphonylurea (Pagano 1995). Post-load insulin was not measured in that study.

\section{Body weight and Body Mass Index}

Compared to placebo, alpha-glucosidase inhibitors had minimal effects on body weight. There were no statistically significant differences for body weight in the meta-analysis for acarbose versus placebo, but BMI decreased slightly in favour of acarbose: -0.2 $\mathrm{kg} / \mathrm{m} 2$ (13 comparisons, $95 \%$ confidence interval -0.3 to -0.1 ).

The reported advantage for alpha-glucosidase inhibitors on body weight compared to sulphonylurea could not be confirmed: no significant differences were found.

\section{Adverse events}

Most studies reported the total number of adverse events and although it became clear from most reports that by far the most adverse effects were of gastro-intestinal origin, the number of patients with gastro-intestinal adverse effects were rarely reported exactly.

Compared to placebo, patients treated with acarbose reported significantly more adverse effects: OR 3.4 (or relative risk 1.4) (23 comparisons, $95 \%$ confidence interval 3.4 to 4.4 ). There was a dose dependent increase in adverse effects in the range $25 \mathrm{mg}$ TID to $200 \mathrm{mg}$ TID. When the sub-group for studies that applied a fixed dosage scheme (in contrast to studies with an individually titrated dose) was considered, the dose dependency was more clear: ORs for adverse events were 1.6, 2.9, 4.1, 7.0 and 8.3 for the dosages 25, 50,100, 200 and $300 \mathrm{mg}$ TID respectively. Most studies reported that the adverse events mainly consisted of gastro-intestinal symptoms. The meta-analysis on gastro-intestinal adverse events yielded a similar result: OR 3.30 (or relative risk 1.8) (four comparisons, 95\% confidence interval 2.2 to 4.7 ). The comparison miglitol versus placebo resulted in similar figures: all adverse events OR 4.0 (seven comparisons, 95\% confidence interval 1.7 to 9.5 ).

Compared to sulphonylurea, patients treated with acarbose had more adverse effects: OR 4.0 (seven comparisons, 95\% confidence interval 2.0 to 7.8). Only two studies provided data for the comparison miglitol versus sulphonylurea: OR 1.3 (95\% confidence interval 0.7 to 2.4$)$.

\section{Sensitivity analyses}

We compared outcomes of meta-analyses between studies with and without certain characteristics. The results were considered of possible interest when the $95 \%$ confidence intervals of the two groups in the analysis (for example results from studies with adequate randomisation versus inadequate randomisation) did not overlap, or when one group yielded a statistically significant result whereas the other did not. At least five studies had to be in each groups to be considered, this was only the case for the comparison acarbose versus placebo.

1. Unpublished versus published studies

By the time the analyses were done, one study that was initially included as unpublished study was published (Van de Laar 2004a).
All other studies were published in some form. Some studies were published otherwise than as a journal article: letter-to-the-editor (Calle-Pascual 1996) or congress abstract (Campbell 1998, Hillebrand 1987, Holmes 2001, Kawamori 2003, Rybka 1999). Because data from three of these studies could not be included in the meta-analysis, sensitivity analysis was not possible.

\section{Quality criteria}

Randomisation: studies with inadequate or unclear randomisation showed a beneficial effect of acarbose on total cholesterol: -0.3 ( $95 \%$ CI -0.5 to -0.0 ) versus 0.0 (95\% CI -0.1 to 0.1 ) for studies with adequate randomisation. No other differences between studies with adequate and inadequate/unclear randomisation were found.

Allocation concealment: the studies with adequate allocation concealment showed a slightly more profound effect on glycaemic control although not statistically significant: glycated haemoglobin $-0.8 \%$ (adequate allocation concealment) versus - 0.7 (not adequate or unclear).

Blinding: we found no differences between studies with no or inadequate blinding and studies with adequate blinding.

ITT adequate: only two studies were considered to have done adequate ITT analyses, therefore sensitivity analyses were not possible.

Total dropout rate: studies with a total dropout rate less than $15 \%$ showed a beneficial effect on post-load insulin levels compared to studies with a total dropout rate equal to or more than 15\%: -52 (95\% confidence interval -77 to -29$)$ versus -18 (95\% confidence interval -55 to 19$)$. No other differences between studies with high or low drop-out rates were found.

Selective drop-out (difference in drop-out between treatment groups): we found no differences between studies with selective dropout rate less than $10 \%$ or equal to or more than $10 \%$.

Overall quality: studies with a overall quality A or B (high) showed a beneficial effect on post-load insulin levels compared to studies with an overall quality score of C (low): -46 (95\% confidence interval -64 to -29$)$ versus -8 ( $95 \%$ confidence interval -68 to 52$)$. No other differences were found.

3. Other

Diagnostic criteria

Eight studies referred to the WHO criteria from 1985 (WHO 1985), three studies to the criteria from the National Diabetes Data group 1979 (NDDG 1979), two studies referred to WHO criteria of unknown data, one study referred to both ADA guidelines from 1997 (ADA 1997) and WHO guidelines from 1987 (unknown origin, no reference given), one study used the so-called UKPDS protocol (Holman 1999) and one study referred to diagnostic criteria of the Japan Diabetes Society. Twenty-five studies did not refer to specific diagnostic criteria of type 2 diabetes. Although most studies referred diagnostic criteria (that is fasting blood glucose more than $7.8 \mathrm{mmol} / \mathrm{L}$ ), it was often not clear whether these criteria were used for the trial selection or for the original diagnosis. Sensitivity analysis was not possible with these data. 
Language of publication

For most included studies the primary publication was in English, with exception of one study in Russian (Dedov 1995) and one in the Italian language (Gentile 1999). Thus, sensitivity analysis was not performed.

Source of funding

For one study the authors made clear that it was not sponsored (Calle-Pascual 1996), two study were sponsored by fundings other than a pharmaceutical company (Gentile 1999, Haffner 1997), for five studies possible sponsoring was not specified and all other studies were sponsored by a pharmaceutical company. Accordingly, sensitivity analysis was not performed.

\section{Country}

Twenty-five studies were conducted in Europe (including one Russian study), nine studies in the USA or Canada, six studies in Asia (including one Turkish study) and one study was performed in New Zealand and Australia.

European studies versus non-European studies: studies that were conducted in Europe showed a tendency towards a greater effect on glycated haemoglobin $(-0.9 \%, 95 \%$ confidence interval -1.0 to $-0.7)$ compared to non-European studies $(-0.7 \%, 95 \%$ confidence interval -0.8 to -0.5$)$. On the other hand, the effect on post-load blood glucose was significantly less than for the non-European studies: $-1.9 \mathrm{mmol} / \mathrm{L}$ (95\% confidence interval -2.2 to -1.5 ) for the European studies versus $-3.3 \mathrm{mmol} / \mathrm{L}$ (95\% CI -4.2 to -2.3 ) for the non-European studies. These differences could not be fully explained when the Asian studies were excluded from the analyses. We also compared the Asian studies with non-Asian studies separately because of the high carbohydrate food habits in Asia. The analyses with Asian studies only yielded a lower effect on glycated haemoglobin compared with the analyses with non-Asian studies $(-0.5 \%$ versus $-0.8 \%)$ but in the Asian group only three comparisons were available.

\section{Different statistical models}

We repeated the analyses for all outcomes using a fixed effects model. This yielded similar results with only two exceptions: 1) the effect on fasting insulin levels in the comparison acarbose versus placebo was statistically significant with a fixed effects model (5 $\mathrm{pmol} / \mathrm{L}$ in favour of placebo, 95\% confidence interval 1 to 10 ) 2) the effect on body weight in the comparison acarbose versus sulphonylurea was statistically significant with a fixed effects model (-1.4 in favour of acarbose, $95 \%$ confidence interval -1.9 to -0.9$)$.

\section{Sub-group analyses (Tables available on request)}

- Subgroups baseline glycated haemoglobin: Subgroup 1a (acarbose - placebo), Subgroup $1 \mathrm{~b}$ (tables available on request) (acarbose - sulphonylurea). The effects on glycated haemoglobin and post-load insulin tended to be more profound with higher baseline glycated haemoglobin.
- Subgroups gender: Subgroup 2a, Subgroup 2b (tables available on request). No significant differences between studies with less and more or equal than $45 \%$ female participants were observed.

- Subgroups baseline BMI: Subgroup 3a, Subgroup 3b (tables available on request). No significant differences between studies in patients with different mean baseline BMI values were observed.

- Subgroups study duration: Subgroup 4a, Subgroup 4b (tables available on request). We found a tendency towards a lower effect in studies that lasted longer than 24 weeks. The effect on glycated haemoglobin was $-0.8 \%,-0.8 \%$ and $-0.5 \%$ for studies less than 24, 24 and more than 24 weeks respectively. However only three studies were included in the latter (more than 24 weeks) categorie.

In addition to the pre-defined sub-groups, we also investigated the following subgroups: different duration of diabetes (mean duration of diabetes less or equal/more than 55 months), groups with a step-up dose regimen versus studies that administered the full dose at once and studies that used a fixed dosage scheme versus studies with an individually titrated scheme.

- Subgroups mean duration of diabetes: Subgroup 5a, Subgroup $5 \mathrm{~b}$ (tables available on request). No significant differences between studies in patients with a mean duration of diabetes less or equal/more 55 months were observed.

- Subgroups step-up dosage versus no step-up dosages: Studies investigating acarbose versus placebo that used a step-up dosing schedule, tended to result in less effect on glycated haemoglobin, fasting and post-load blood glucose than studies that gave the full dose at once. On the other hand, the latter studies reported more adverse effects. The $95 \%$ confidence intervals for fasting blood glucose and adverse effects in both groups did not overlap indicating statistical significance (Subgroup 6a).

This effect was also found in the comparison acarbose versus sulphonylurea. (Subgroup 6b) (tables available on request)

- Subgroups fixed dose versus individually titrated: Subgroup $7 \mathrm{a}$, Subgroup $7 \mathrm{~b}$ (tables available on request). Studies that used a fixed dose showed more profound effect on glycated haemoglobin $(-0.8 \%$ versus $-0.5 \%)$ with no different effect on fasting blood glucose.

Meta-regression analyses (Tables available on request)

For the comparison acarbose versus placebo, sufficient data were available to perform meta-regression analyses.

Glycated haemoglobin: regression coefficient for mean baseline glycated $\mathrm{Hb}$ was -0.12 , indicating a decrease in outcome value of $0.12 \%$ per $1 \%$ increase of baseline glycated $\mathrm{Hb}$. The use of a fixed dosage yielded a regression coefficient of -0.32 (95\% CI -0.69 to 0.04$)$ and a step-up dosage scheme regression coefficient of 0.36 (95\% CI 0.06 to 0.66 ), thus having an increasing influence 
on glycated haemoglobin (Metaregression 1, table available on request).

Fasting blood glucose: use of a step-up dosages scheme had a deteriorating effect on the outcome: correlation coefficient $0.62(95 \%$ CI 0.05 to 1.19) (Metaregression 2, table available on request).

Post-load blood glucose: no statistically significant effects were found (Metaregression 3, table available on request).

Total cholesterol: no statistically significant effects were found (Metaregression 4, table available on request).

Triglycerides: no statistically significant effects were found (Metaregression 5, table available on request).

Fasting insulin: no statistically significant effects were found (Metaregression 6, table available on request).

Post-load insulin: no statistically significant effects were found (Metaregression 7, table available on request)

Body weight: no statistically significant effects were found (Metaregression 8, table available on request).

Total adverse effects: The use of a step-up dosing scheme had a statistically significant decreasing effect on the occurrence of adverse effects (regression coefficient $0.50,95 \%$ CI 0.29 to 0.88 ) (Metaregression 9, table available on request).

\section{I S C USSION}

\section{Summary}

In this systematic review, we found no statistically significant effect for an effect of alpha-glucosidase inhibitors on mortality, morbidity and quality of life in patients with type 2 diabetes mellitus. Compared to placebo, alpha-glucosidase inhibitors reduce glycated hemoglobin ( $0.8 \%$ acarbose, $0.7 \%$ miglitol), fasting and postprandial blood glucose (acarbose: fasting glucose $1.1 \mathrm{mmol} / \mathrm{L}$, post-load blood glucose $2.3 \mathrm{mmol} / \mathrm{L}$ ) and post-load insulin. We found no clinically relevant effects on plasma lipids and body weight. We found no dose dependency for the effect on glycated haemoglobin for acarbose. alpha-glucosidase inhibitors caused significant more adverse effects, especially of gastro-intestinal origin. It should be noted that the data of the largest and longest studies could not be used for meta-analyses. Compared to sulphonylurea alpha-glucosidase inhibitors were inferior with respect to glycemic control and adverse effects, the extent of this effect differed with the sulphonylurea used. On the contrary, alpha-glucosidase inhibitors had a decreasing effect on fasting and post-load insulin levels compared to sulphonylurea. Of the three alpha-glucosidase inhibitors investigated, acarbose, miglitol and voglibose, most data and best outcomes were obtained for acarbose.

\section{Comparison with existing literature}

Although this is the first systematic review concerning alpha-glucosidase inhibitor monotherapy, some reviews have been published recently about acarbose (Breuer 2003; Laube 2002) or miglitol (Campbell 2000; Scott 2000). The quality of those reviews is limited: selection criteria for the studies were insufficiently specified and there was no mention of the criteria used to assess the validity of individual trials. Further, these reviews did not present explicit methods on data extraction, assessment of heterogeneity or subgroup analyses. Both reviews on acarbose referred also to a 'metaanalysis' of older date (Lebovitz 1998), which calculated the mean outcomes on glycemic control for 13 studies, using outcomes for single treatment arms (baseline minus endpoint) as well as placebo extracted outcomes in a non-transparent way.

Our results are roughly in line with the previous reviews with respect to the overall effect on glycemic control compared to placebo, but there are relevant differences and additional findings. First, we found no dose-dependency of acarbose on glycated haemoglobin in the meta-analysis. Remarkably, the effect on fasting and postload blood glucose appeared to be dose dependent. This discrepancy might be explained by a better compliance of patients that were using the lower dosages, because higher dosages induce more adverse effects. Prior to their visit to the study centre, it is more likely that patients took their study medication and thus achieving good fasting and post-load glucose values. Only for glycated haemoglobin, the effect of low compliance will show up. Secondly, we could not find relevant effects on lipid levels, especially triglycerides. Thirdly, we also could not confirm the optimistic view on adverse effects reported in the previous reviews. Twenty out of 41 included studies were subject to a skewed drop-out pattern (? 10\% difference per treatment group) and 25 studies had a total dropout rate that was ? $15 \%$, in most cases this was caused by adverse effects. Finally, the previous reviews are optimistic about the glucose lowering capacities of alpha-glucosidase inhibitors compared to other agents such as sulphonylurea. We confirm a clear beneficial effect with respect to fasting and post-load insulin levels. But overall, the effects on glycemic control are inferior to sulphonylurea. For glycated haemoglobin this is not statistically significant, but most studies that compare acarbose with sulphonylurea use inappropriate comparators (that is too low dose for sulphonylurea or using an individually titrated dosage versus a fixed dosage). Therefore, we feel that a conclusion that sulphonylurea have superior glucose lowering properties, is justified. In addition, alphaglucosidase inhibitors cause more adverse effects.

The three-years trial performed within the UKPDS (Holman 1999) was one of the main studies included in the review. The effects regarding glycated hemoglobin obtained in this trial alone (a decrease of $0.2 \%$ ) are considerably less profound than those from the meta-analysis. This discrepancy with the results from the meta-analysis, point in the direction of a possible overestimation of the effect in the long ( 3 years) term.

\section{Strengths of the review}

This is the first high-quality systematic review and meta-analysis on the topic of alpha-glucosidase inhibitors. It offers an up-to-date and most complete overview of all randomised trials concerning alpha-glucosidase inhibitor monotherapy, because it is the result of an extensive search, including grey literature and unpublished studies. In addition, maximum efforts have been done to minimise 
missing or incomplete data by attempting to contact all authors. This has been successful in 22 out of 41 cases.

Although we included a high number of studies, the data are remarkably consistent and heterogeneity is limited. Statistical tests for heterogeneity are less reliable when a high number of studies are involved and further scrutiny by sub-group analysis and metaregression analysis yielded few possible sources for heterogeneity. The use of a fixed dose (instead of an individually titrated dosage) may cause a more profound effect with respect to glycemic control but causes also more adverse effects. The same applies to giving the full dose at once, instead of using a step-up scheme.

Although this review presents a possibly confusing amount of data and figures, we feel that completeness is one of the strengths of a Cochrane systematic review. The way we presented these data, subdivided in types of alpha-glucosidase inhibitor, controls and outcome measures, makes it possible for the reader to find whatever specific piece of information on alpha-glucosidase inhibitor monotherapy he or she needs.

This review will be regularly updated, leaving the possibility open to add information or to correct possible errors. In fact, this is a plea for anyone who is aware of such additional data or errors in the data presented here, to report this to the authors.

\section{Limitations of the review}

Our main research question was not answered with the trials we included in this review so far. Only few studies reported data on morbidity and mortality on a reliable and consistent way. It is not likely that in the (near) future a randomised trial of long enough duration will be conducted with acarbose monotherapy to investigate mortality and morbidity. This raises the question whether our review, with its strict inclusion criteria and high demands for outcome data, overshoots the mark. Maybe with broader inclusion criteria, that is inclusion of (high quality) observational studies, we would have gained data to study a possible influence on mortality and morbidity. The use of observational data does not necessarily lead to biased outcomes (Concato 2000). Still, we feel that for the evaluation of medical interventions, well designed randomised trials are the first choice. To improve systematic reviews in the future, we strongly plea for the integration of outcome measures such as death or morbidity into all trials that evaluate medical interventions for patients with chronic diseases. Even if the trial is underpowered for that outcome, the data might always be of value for a meta-analysis. The question of including observational studies in a future update of this review is still open to us.

Despite an exhaustive and thorough search, including requests to experts and manufacturers, we still cannot rule out publication bias. For the three trials that we found in a database for ongoing trials, we were not able to reveal outcome data or additional information about the design despite the fact that one trial ended six years ago (Whitby 1998) and the others in 2003 (Holman 2003; Sa-adu 2003). Another clue for possible publication bias was that we, despite maximum efforts to retrieve unpublished data, discovered three previously unpublished studies coincidentally (Bayer
2003; Bayer 2003a; Campbell 1998) that were used for a study on a congress poster (Hanefeld 2003). Altogether, we still think that the overall risk for publication bias is limited because the funnel plots do not point at small study bias and because of the exhaustive search. Still, we welcome unpublished data for future updates.

Not all papers reported outcomes in a way that could contribute to meta-analyses. This problem was partially solved by asking authors for additional data, imputing the standard deviation of the mean difference (see under methods, data analysis) or using data from graphical figures. As an example, data from only four of the 32 studies investigating glycated haemoglobin in relation to the use of acarbose, suited for use in the meta-analysis directly; for twelve studies additional data had to be obtained from the authors to complete all blanks; for twelve studies we had to calculate the SD of the mean difference from the baseline and endpoint SDs and for four studies the data could not be used at all. Unfortunately, one of those four studies was of long duration (3 years) and had a high number of participants (Campbell 1998). In summary, we used the most precise data in about half of the cases (16 out of 32) and we had to use less precise figures in 12 out of 32 cases. Because we used a conservative correlation coefficient of 0.4 , this will most probably have made the confidence interval larger. The influence of the missing data from the largest studies was discussed under 'existing literature'.

Only nine out of the 41 studies lasted longer than 24 weeks, and only two studies were amply longer than one year (Holman 1999; Campbell 1998). For one of those two studies data could not be included in the meta-analyses (Campbell 1998). The importance of long-term studies is evident, especially for a chronic disease such as type 2 diabetes. In the subgroup analysed for study duration, we found clues that the effect of alpha-glucosidase inhibitors decrease with time, This was mostly due to the UKPDS study un which a decrease of only $0.2 \%$ was found after three years of treatment (Holman 1999). Therefore, we feel that the results from our study should be interpreted with caution when applied to the long-term treatment with alpha-glucosidase inhibitors of patients with type 2 diabetes.

Research funded by pharmaceutical companies is more likely to produce results favouring the tested drug; this is often due to inappropriate comparators or small study bias (Lexchin 2003). In this review at least 33 studies were sponsored by a pharmaceutical company, including one study in which the sponsor was the producer of the comparison drug (Holmes 2001). We suppose that this will cause a slight overestimation of the results, especially concerning the studies that compare alpha-glucosidase inhibitors with other medication. In fact, this is probable in the comparison acarbose versus sulphonylurea (glycated haemoglobin) where acarbose is dosed in a fixed way and the comparison drugs are individually adjusted (Coniff 1995; Hoffmann 1990; Hoffmann 1994; Kovacevic 1997; Rosenthal 2002; Salman 2001) or very low dosed (Haffner 1997). In one study both treatment arms used an individually adjusted dosage scheme (Van de Laar 2004a). For the comparison with placebo the influence of this 'bias by sponsor- 
ing' is less sure as it would be similar to publication bias like we discussed before.

\section{Applicability}

The results from this review are relevant for physicians dealing with patients with type 2 diabetes and for the developers of treatment guidelines. Data of beneficial effects on mortality or complications from diabetes mellitus are not available at the moment. Alphaglucosidase-inhibitors inhibit post-pranidal glucose peaks thereby leading to decreased post-load insulin levels. Further, alpha-glucosidase inhibitors lower post-load insulin levels, especially when compared to sulphonylurea. There are no additional advantages with respect to the lipid profile or body weight. Most evidence is available for acarbose, which has also the best results for most outcomes. The importance of these findings and the exact place of alpha-glucosidase inhibitors in the treatment of type 2 diabetes mellitus, has to be judged in view of other evidence regarding the clinical importance of (post-load) hyperglycaemia and hyperinsulinaemia.

This review investigated alpha-glucosidase inhibitors as monotherapy. Although, from a theoretical point of view, it seems logical that alpha-glucosidase inhibitors offer similar potentials in addition to other antidiabetic therapies, this cannot be concluded from this review. Evidence for the possible efficacy for alpha-glucosidase inhibitors as add-on therapy might be derived from a systematic review that is currently going on (Navarro 2003).

\section{A U THORS' CONCLUSIONS}

\section{Implications for practice}

In patients with type 2 diabetes, alpha-glucosidase inhibitor monotherapy inhibit post-prandial glucose peaks thereby leading to decreased post-load insulin levels. There are no advantages with respect to lipid metabolism or body weight. Compared to sulphonylurea, alpha-glucosidase inhibitors have less favourable effects with respect to glycemic control and adverse effects but they lower fasting and post-load insulin levels compared to sulphonylurea. For all outcomes, the largest evidence base exists for acarbose.

\section{Implications for research}

New studies that investigate alpha-glucosidase inhibitors on proxy indicators such as glycaemic control, lipids, insulin, body weight would be redundant. Large randomised controlled trials of long duration that investigate mortality, morbidity and quality of life as primary endpoints are necessary. In addition studies comparing alpha-glucosidase inhibitors with other glucose lowering agents (especially metformin and thiazilodines) are of use. When these trials are not available, inclusion of well-designed observational studies in this review may be considered.

\section{POTENTIALCONFLICTOF I N T ER ES T}

FvdL, PL, EvdL, GR and CvW conducted and published a trial that was sponsored by Bayer (Van de Laar 2004a).

\section{ACKNOWLEDGEMENTS}

We would like to thank the following people:

All authors, investigators and manufacturers who were willing to answer our many questions and who provided us with additional data.

Henk van den Hoogen (University Medical Centre Nijmegen, Department of General Practice) for his help and advice with the analyses and interpretation of the data.

Shuan Wang (West China Hospital, Sichuan University, Geriatrics department. Chengdu, Sichuan, China) for her help with the protocol development.

The following people for their help with translation of articles: Leon Bax (Japanese), Ka Wai Wu (Chinese), Caroline Roos (Spanish), Emile van den Hoogen and Natasja Odelevskaia (Russian).

Anja van Guluck (Library of the Elkerliek Hospital, Helmond, The Netherlands) for library assistance.

The members from the Brazilian Cochrane Centre for their help with retrieval of abstracts from LILACS.

The members of the Editorial Base of the Cochrane Metabolic and Endocrine Disorders Group and the Dutch Cochrane Centre for their help and advice.

\section{SOURCESOF S P P ORT}

\section{External sources of support}

- No sources of support supplied

Internal sources of support

- Radboud University Nijmegen Medical Centre NETHERLANDS

- Julius Centre for for Health Sciences and Primary Care NETHERLANDS 


\section{R E F E R E N C E S}

\section{References to studies included in this review}

Braun 1996 \{published data only\}

* Braun D, Schonherr U, Mitzkat H-J. Efficacy of acarbose monotherapy in patients with type 2 diabetes: A double-blind study conducted in general practice. Endocrinology \& Metabolism 1996;3 (4):275-280. 355 .

Buchanan 1988 \{published data only\}

* Buchanan DR, Collier A, Rodrigues E, Millar AM, Gray RS, Clarke BF. Effectiveness of acarbose, an alpha-glucosidase inhibitor, in uncontrolled non-obese non-insulin dependent diabetes. European Journal of Clinical Pharmacology 1988;34(1):51-53. 121.

Calle-Pascual 1996 \{published and unpublished data\}

* Calle-Pascual A, Garcia-Honduvilla J, Martin-Alvarez PJ, Calle JR, Maranes JP. Influence of 16-week monotherapy with acarbose on cardiovascular risk factors in obese subjects with non-insulindependent diabetes mellitus: a controlled, double-blind comparison study with placebo [letter]. Diabetes \& Metabolism 1996;22(3):201202. 94 .

Campbell 1998 \{published and unpublished data\}

* Campbell I, Robertson-Mackay F, Streets E, Gibbons F, Holman RR. Maintenance of glycaemic control with acarbose in diet treated Type 2 diabetic patients. Diabetic Medicine 1998;15(Suppl 2):S29_ 30. 506 .

Holman RR, Robertson-Mackay F, Gibbons F, Montegriffo E, Campbell I. Acarbose maintains glycaemic control in diet treated type 2 diabetes. Clinical Science 1999;96:7p. 505.

Chan 1998 \{published data only\}

* Chan JC, Chan KW, Ho LL, Fuh MM, Horn LC, Sheaves R, et al. An Asian multicenter clinical trial to assess the efficacy and tolerability of acarbose compared with placebo in type 2 diabetic patients previously treated with diet. Asian Acarbose Study Group. Diabetes Care 1998;21(7):1058-1061. 11.

Chiasson 1994 \{published data only\}

* Chiasson JL, Josse RG, Hunt JA, Palmason C, Rodger NW, Ross $\mathrm{SA}$, et al. The efficacy of acarbose in the treatment of patients with non-insulin-dependent diabetes mellitus. A multicenter controlled clinical trial [see comments]. Annals of Internal Medicine 1994;121 (12):928-935. 19.

Josse RG. Acarbose for the treatment of type II diabetes: the results of a Canadian multi-centre trial [published erratum appears in Diabetes Res Clin Pract 1995 Sep;29(3):215]. Diabetes Research and Clinical Practice 1995;28 Suppl:S167-S172. 15.

Rodger NW, Chiasson JL, Josse RG, Hunt JA, Palmason C, Ross SA, et al. Clinical experience with acarbose: results of a Canadian multicentre study. Clinical and investigative medicine. Medecine clinique et experimentale 1995;18(4):318-324. 148.

Ross S, Hunt J, Josse R, Mukherjee J, Palmason C, Rodger W, et al. Acarbose significantly improves glucose control in non-insulindependent diabetes mellitus subjects (NIDDM): results of the multcentre Canadian trial. Diabetes 1992;41(Suppl. 1):193A. 512.

Wolever TM, Chiasson JL, Josse RG, Hunt JA, Palmason C, Rodger NW, et al. No relationship between carbohydrate intake and effect of acarbose on HbA1c or gastrointestinal symptoms in type 2 diabetic subjects consuming 30-60\% of energy from carbohydrate. Diabetes Care 1998;21(10):1612-1618. 151.

Wolever TM, Chiasson JL, Josse RG, Hunt JA, Palmason C, Rodger NW, et al. Small weight loss on long-term acarbose therapy with no change in dietary pattern or nutrient intake of individuals with non-insulin-dependent diabetes. International Journal of Obesity and Related Metabolic Disorders 1997;21(9):756-763. 152.

Chiasson 2001 \{published data only\}

* Chiasson JL, Naditch L. The synergistic effect of miglitol plus metformin combination therapy in the treatment of type 2 diabetes. Diabetes Care 2001;24(6):989-94. 469.

Wolever TMS, Assiff L, Basu T, Chiasson J-L, Boctor M, Gerstein $\mathrm{HC}$, et al. Miglitol, an alpha-glucosidase inhibitor, prevents the metformin-induced fall in serum folate and vitamin B12 in subjects with type 2 diabetes. Nutrition Research 2000;20(10):1447-1456. 93.

Coniff 1994 \{published and unpublished data\}

* Coniff RF, Shapiro JA, Seaton TB. Long-term efficacy and safety of acarbose in the treatment of obese subjects with non-insulin-dependent diabetes mellitus. Archives of Internal Medicine 1994;154(21): 2442-2448. 123

Innerfield RJ, Coniff RF. A multi-center, double-blind, placebo-controlled study of the long-term efficacy and safety of acarbose (Bay $g$ $5421)$ in the Rx of obese patients with NIDDM Rxed by diet alone. Diabetes 1990;39(Suppl. 1):211A. 511.

Coniff 1995 \{published and unpublished data\}

* Coniff RF, Shapiro JA, Seaton TB, Bray GA. Multicenter, placebocontrolled trial comparing acarbose (BAY g 5421) with placebo, tolbutamide, and tolbutamide-plus-acarbose in non-insulin-dependent diabetes mellitus. The American Journal of Medicine 1995;98 (5):443-51. 18.

Coniff 1995b \{published and unpublished data\}

* Coniff RF, Shapiro JA, Robbins D, Kleinfield R, Seaton TB, Beisswenger $\mathrm{P}$, et al. Reduction of glycosylated hemoglobin and postprandial hyperglycemia by acarbose in patients with NIDDM. A placebocontrolled dose-comparison study. Diabetes Care 1995;18(6):817824. 17.

Dedov 1995 \{published data only\}

* Dedov II, Balabolkin MI, Mkrtumyan AM, Ametov AS, Kakhnovsky IM, Chazova TE, et al. Glucobai therapy of diabetes mellitus. [Russian]. Problemy Endokrinologii 1995;41(3):11-13. 424.

Delgado 2002 \{published data only\}

* Delgado H, Lehmann T, Bobbioni-Harsch E, Ybarra J, Golay A. Acarbose improves indirectly both insulin resistance and secretion in obese type 2 diabetic patients. Diabetes \& Metabolism 2002;28(3): 195-200. 484.

Drent 2002 \{published and unpublished data\}

Drent ML, The Dutch Miglitol Investigators Group. Miglitol as single oral hypoglycemic agent in type 2 diabetes. Diabetologia 1994;37 (Suppl. 1):A211. 494.

* Drent ML, Tollefsen AT, van Heusden FH, Hoenderdos EB, Jonker JJ, van der Veen EA. Dose-dependent efficacy of miglitol, an alpha- 
glucosidase inhibitor, in type 2 diabetic patients on diet alone: results of a 24-week double-blind placebo-controlled study. Diabetes, Nutrition \& Metabolism 2002;15(3):152-159. 489.

Fischer 1998 \{published and unpublished data\}

* Fischer S, Hanefeld M, Spengler M, Boehme K, Temelkova-Kurktschiev T. European study on dose-response relationship of acarbose as a first-line drug in non-insulin-dependent diabetes mellitus: efficacy and safety of low and high doses. Acta Diabetologica 1998;35 (1):34-40. 128.

Gentile 1999 \{published data only\}

* Gentile S, Turco S, Guarino G, Oliviero B, Rustici A, Torella R. Non-insulin-dependent diabetes mellitus associated with nonalcoholic liver cirrhosis: an evaluation of treatment with the intestinal alpha-glucosidase inhibitor acarbose [Diabete mellito non insulinodipendente associato a cirrosi epatica non etilica: valutazione del trattamento con un inhibitore delle alpha-glucosidasi intestinali, acarbose]. Annali Italiani di Medicina Interna 1999;14(1):7-14. 130.

Gentile S, Turco S, Persico M, Pananello A, Conte S, Gesuè L, et al. Efficacy of acarbose in the control of diabetes mellitus associated with liver cirrhosis. Journal of Hepatology 1997;26(Suppl 1):S101. 500.

Gentile S, Turco S, Persico M, Panariello A, Conte S, De Seta M, Gesuè $\mathrm{L}$, et al. The acarbose tretament of type 2 diabetes mellitus associated with liver cirrhosis. Diabetologia 1997;40:A306. 497.

Haffner 1997 \{published data only\}

Fischer S, Patzak A, Rietzsch H, Schwanebeck U, Kohler C, Wildbrett $\mathrm{J}$, et al. Influence of treatment with acarbose or glibenclamide on insulin sensitivity in type 2 diabetic patients. Diabetes, Obesity and Metabolism 2003;5(1):38-44. 485.

* Haffner SM, Hanefeld M, Fischer S, Fucker K, Leonhardt W. Glibenclamide, but not acarbose, increases leptin concentrations parallel to changes in insulin in subjects with NIDDM. Diabetes Care 1997;20(9):1430-1434. 137.

Hanefeld M, Haffner SM, Menschikowski M, Koehler C, Temelkova-Kurktschiev T, Wildbrett J, Fischer S. Different effects of acarbose and glibenclamide on proinsulin and insulin profiles in people with Type 2 diabetes. Diabetes Research and Clinical Practice 2002;55(3):221-227. 481.

Hanefeld 1991 \{published and unpublished data\}

* Hanefeld M, Fischer S, Schulze J, Spengler M, Wargenau M, Schollberg K, et al. Therapeutic potentials of acarbose as first-line drug in NIDDM insufficiently treated with diet alone. Diabetes Care 1991; 14(8):732-737. 81.

Leonhardt W, Hanefeld M, Fischer S, Schulze J, Spengler M. Beneficial effects on serum lipids in noninsulin dependent diabetics by acarbose treatment. Arzneimittelforschung 1991;41(7):735-738. 109.

Hillebrand 1987 \{published data only\}

Hillebrand I, Englert R. Efficacy and tolerability of a 12-week treatment with acarbose (BAY g5421), miglitol (BAY m1099) and glibenclamid. Diabetes 1987;26:134A. 515

Hoffmann 1990 \{published and unpublished data\}

* Fölsch UR, Spengler M, Boehme K, Sommerauer B. Efficacy of glucosidase inhibitors compared to sulphonylureas in the treatment and metabolic control of diet treated Type II diabetic subjects: Two long- term comparative studies. Diabetes, Nutrition \& Metabolism 1990;3 (Suppl. 1):63-68. 82.

Hoffmann J. Acarbose and Glibenclamid in Type-II Diabetes. A Comparative Study on Efficacy and Side Effects [Acarbose und Glibenclamid bei Typ-II-Diabetes. Eine Vergleichsstudie zu Wirksamkeit und Nebenwirkungen]. Münchener Medizinische Wochenschrift 1990;132(31-32):487-490. 10.

Hoffmann, J. Adjustment of metabolism and eating behaviour of type II diabetics. Results of a six-months treatment with glibenclamide, respectively with acarbose [Stoffwechseleinstellung und Essverhalten von Typ-II-Diabetikern. Ergebnisse einer sechsmonatigen Behandlung mit Glibenclamid bzw. mit Acarbose]. Zeitschrift für Allgemeinmedizin 1992;68(29):970-977. 8.

Hoffmann 1994 \{published and unpublished data\}

${ }^{*}$ Hoffmann J, Spengler M. Efficacy of 24-week monotherapy with acarbose, glibenclamide, or placebo in NIDDM patients. The Essen Study. Diabetes Care 1994;17(6):561-566. 20.

Hoffmann 1997 \{published and unpublished data\}

* Hoffmann J, Spengler M. Efficacy of 24-week monotherapy with acarbose, metformin, or placebo in dietary-treated NIDDM patients: the Essen-II Study. American Journal of Medicine 1997;103(6):483490. 13.

Holman 1999 \{published and unpublished data\}

* Holman RR, Cull CA, Turner RC. A randomized double-blind trial of acarbose in type 2 diabetes shows improved glycemic control over 3 years (U.K. Prospective Diabetes Study 44) [see comments] [published erratum appears in Diabetes Care 1999 Nov;22(11):1922]. Diabetes Care 1999;22(6):960-4. 4.

Holmes 2001 \{published and unpublished data\}

* Holmes D, Raccah D, Escobar-Jimenez F, Standl E. Targeting postprandial hyperglycemia to achieve glycemic control in patients with type 2 diabetes: a comparison of nateglinide and acarbose [Poster presentation]. EASD Congress 9-13 september 2001, Glasgow (UK) [MedLine: 486.

Holmes D, Raccah D, Escobar-Jimenez F, Standl E. Targeting postprandial hyperglycemia in patients with type 2 diabetes: nateglinide vs acarbose. Diabetologia 2001;44(Suppl 1):A215. 487.

Raccah D, Escobar-Jimenez F, Gomis R, Holmes D, Standl E. Targeting prandial glucose with nateglinide and acarbose in the treatment of type 2 diabetes: a double-blind clinical comparison. Unpublished Document.

Hotta 1993 \{published and unpublished data\}

* Hotta N, Kakuta H, Sano T, Matsumae H, Yamada H, Kitazawa $S$, et al. Long-term effect of acarbose on glycaemic control in noninsulin-dependent diabetes mellitus: a placebo-controlled doubleblind study. Diabetic Medicine 1993;10(2):134-138. 21.

Sakamoto N, Hotta N, Kakuta H, Sano T, Yamada H, Matsumae $\mathrm{H}$, et al. An investigation into the efficacy of long term usage of Bay g 5421 (acarbose) for non-insulin dependent diabetes. A placebo controlled, double blind trial [japanese]. Rinshou to Kenkyu 1990;67 (1):219-233. 504.

Johnston 1998 \{published data only\}

* Johnston PS, Lebovitz HE, Coniff RF, Simonson DC, Raskin P, Munera CL. Advantages of alpha-glucosidase inhibition as 
monotherapy in elderly type 2 diabetic patients. The Journal of Clinical Endocrinology and Metabolism 1998;83(5):1515-1522. 141.

Johnston 1998a \{published data only\}

* Johnston PS, Feig PU, Coniff RF, Krol A, Davidson JA, Haffner SM. Long-term titrated-dose alpha-glucosidase inhibition in noninsulin-requiring Hispanic NIDDM patients. Diabetes Care 1998; 21(3):409-415. 143.

Johnston 1998b \{published data only\}

* Johnston PS, Feig PU, Coniff RF, Krol A, Kelley DE, Mooradian AD. Chronic treatment of African-American type 2 diabetic patients with alpha-glucosidase inhibition. Diabetes Care 1998;21(3):416422. 142 .

Kawamori 2003 \{published data only\}

* Kawamori R, Toyota T, Oka Y, Yamada A, Iwamoto Y, Tajima N, et al. Improvement of glycaemic control following 12-week treatment with miglitol in Japanese type 2 diabetics: a double-blind, randomized, placebo- and voglibose-controlled trial. Poster display, IDF Congress Paris august 25 2003. [MedLine: 510.

Kovacevic 1997 \{published and unpublished data\}

* Kovacevic I, Profozic V, Skrabalo Z, Cabrijan T, Zjacic-Rotkvic $\mathrm{V}$, Goldoni V, et al. Multicentric clinical trial to assess efficacy and tolerability of acarbose (BAY G 5421) in comparison to glibenclamide and placebo. Diabetologia Croatica 1997;26(2):83-89. 316.

Meneilly 2000 \{published data only\}

Josse RG, Chiasson JL, Ryan EA, Lau DC, Ross SA, Yale JF, et al. Acarbose in the treatment of elderly patients with type 2 diabetes. Diabetes Research and Clinical Practice 2003;59(1):37-42. 483.

* Meneilly GS, Ryan EA, Radziuk J, Lau DC, Yale JF, Morais J, et al. Effect of acarbose on insulin sensitivity in elderly patients with diabetes. Diabetes Care 2000;23(8):1162-1167. 101.

Pagano 1995 \{published and unpublished data\}

Marena S, Pagani A, Montegrosso G, Boella G, Pagano A, De Michieli $\mathrm{F}$, et al. Comparison of miglitol and glibenclamide in non insulindependent diabetic patients. [Italian]. Giornale Italiano di Diabetologia 1993;13(4):383-388. 463.

Marena S, Pagani A, Montegrosso G, Boella G, Pagano A, De Michieli F, et al. Miglitol vs Glibenclamide in non-insulin dependent diabete mellitus. European Journal of Clinical Investigation 1993;23(Suppl 1): A43. 496.

* Pagano G, Marena S, Corgiat-Mansin L, Cravero F, Giorda C, Bozza M, et al. Comparison of miglitol and glibenclamide in diettreated type 2 diabetic patients. Diabete \& Metabolisme 1995;21 (3): 162-167. 147.

Rosenthal 2002 \{published and unpublished data\}

Mauersberger $\mathrm{H}$, Rosenthal JH. Wirkung von endogenem Insulin sowie Acarbose oder Glibenclamide in der Therapie der Hypertonie bei Typ-2-Diabetikern. CF-Journal 2001;(1):26-28. 502.

* Rosenthal JH, Mauersberger H. Effects on blood pressure of the alpha-glucosidase inhibitor acarbose compared with the insulin enhancer glibenclamide in patients with hypertension and type 2 diabetes mellitus. Clinical Drug Investigation 2002;22(10):695-701. 492.
Rosenthal JH, Mauersberger $\mathrm{H}$. Hypertension in type 2-diabetic patients - Effects of endogenous insulin and antidiabetic therapies. American Journal of Hypertension 2000;13(4 Suppl 1):S81. 495.

Rybka 1999 \{published data only\}

Bayer Vital GmbH, Company KH. Efficacy and tolerability of miglitol (Bay m 1099) and acarbose (Bay g 5421) in type II diabetes, Report no: R6245 (Data on File). 1994.

* Rybka J, Goke B, Sissmann J. European comparative study of 2 alpha-glucosidase inhibitors, miglitol and acarbose. Diabetes 1999; 48(Suppl. 1):101. 513.

Salman 2001 \{published and unpublished data\}

* Salman S, Salman F, Satman I, Yilmaz Y, Ozer E, Sengul A, et al. Comparison of acarbose and gliclazide as first-line agents in patients with type 2 diabetes. Current Medical Research and Opinion 2001;16 (4):296-306. 112

Santeusanio 1993 \{published and unpublished data\}

* Santeusanio F, Ventura MM, Contadini S, Compagnucci P, Moriconi V, Zaccarini P, et al. Efficacy and safety of two different dosages of acarbose in non-insulin dependent diabetic patients treated by diet alone. Diabetes, Nutrition \& Metabolism - Clinical \& Experimental 1993;6(3):147-154. 468.

Scott 1999 \{published and unpublished data\}

* Scott R, Lintott CJ, Zimmet P, Campbell L, Bowen K, Welborn T. Will acarbose improve the metabolic abnormalities of insulin-resistant type 2 diabetes mellitus?. Diabetes Research and Clinical Practice 1999;43(3):179-185. 5.

Segal 1997 \{published data only\}

* Segal P, Feig PU, Schernthaner G, Ratzmann KP, Rybka J, Petzinna $\mathrm{D}$, et al. The efficacy and safety of miglitol therapy compared with glibenclamide in patients with NIDDM inadequately controlled by diet alone. Diabetes Care 1997;20(5):687-691. 150.

Spengler 1992 \{published and unpublished data\}

Fölsch UR, Spengler M, Boehme K, Sommerauer B. Efficacy of glucosidase inhibitors compared to sulphonylureas in the treatment and metabolic control of diet treated Type II diabetic subjects: Two longterm comparative studies. Diabetes, Nutrition \& Metabolism 1990;3 (Suppl. 1):63-68. 82.

* Spengler M, Hansel G, Boehme K. Efficacy of 6 months monotherapy with glucosidase inhibitor acarbose versus sulphonylurea glibenclamide on metabolic control of dietary treated type II diabetics (NIDDM). Hormone \& Metabolic Research 1992;(Supp 26):50-51. 479 .

Spengler M, Hansel G, Boehme K. 6 Months monotherapy of NIDDM with acarbose or glibenclamide. Lefebvre PJ, Standl E, editor(s). New Aspects in Diabetes. Treatment Strategies with AlphaGlucosidase Inhibitors. Third International Symposium on Acarbose. Berlin - New York: Walter de Gruyter, 1992:243-6. 501.

Spengler M, Hänsel G, Boehme K. Efficacy of 6 months monotherapy with glucosidase inhibitor acarbose versus sulphonylurea glibenclamid on metabolic control of dietary treated type II diabetics. European Journal of Clinical Investigation. 19 Edition. 1989;19(2 part II):A71. 498.

Alpha-glucosidase inhibitors for type 2 diabetes mellitus (Review) 
Spengler M, Hänsel, M, Boehme, K. Acarbose and glibenclamide in type II diabetes [Acarbose und Glibenclamid bei Typ-II-Diabetes]. Zeitschrift für Allgemeinmedizin 1990;65(22):606-610. 480.

Takami 2002 \{published data only\}

* Takami K, Takeda N, Nakashima K, Takami R, Hayashi M, Ozeki $S$, et al. Effects of dietary treatment alone or diet with voglibose or glyburide on abdominal adipose tissue and metabolic abnormalities in patients with newly diagnosed type 2 diabetes. Diabetes Care 2002; 25(4):658-662. 482

Van de Laar 2004a \{published and unpublished data\} Van de Laar FA, Lucassen PLBJ, Kemp J, Van de Lisdonk EH, Van Weel C, Rutten GEHM. Is acarbose equivalent to tolbutamide as first treatment for newly diagnosed diabetes in general practice? A randomised controlled trial. Diabetes Research and Clinical Practice 2004;63(1):57-65. 136.

Zheng 1995 \{published data only\}

* Zheng GF, Wang JP, Zhang H, Hu ZX, Liu J, Xiao JZ, et al. Clinical observation on glucobay treatment for NIDDM. [Chinese]. Chinese Journal of Endocrinology 1995;11(3):163-164. 488.

\section{References to studies excluded from this review}

\section{Bachmann 2003}

* Bachmann W, Petzinna D, Sotiros A, Wascher T. Long-Term Improvement of Metabolic Control by Acarbose in Type 2 Diabetes Patients Poorly Controlled with Maximum Sulfonylurea Therapy. Clinical Drug Investigation 2003;23(10):679-686. 508.

Bayer 2003

* Bayer AG. Study No. 541. Data on file, Bayer.

Bayer 2003a

* Bayer AG. Study No. 656. Data on file, Bayer.

Coniff 1995a

* Coniff RF, Shapiro JA, Seaton TB, Hoogwerf BJ, Hunt JA. A double-blind placebo-controlled trial evaluating the safety and efficacy of acarbose for the treatment of patients with insulin-requiring type II diabetes. Diabetes Care 1995;18(7):928-932. 430.

\section{De Leiva 1993}

* de Leiva A, Piñón F, Tébar J, Escobar-Jiménez F, De la Calle H, Herrera-Pombo JL, et al. Clinical efficacy and tolerance to acarbose in the treatment of non-insulin-dependent diabetic patients [Eficacia clínica y tolerancia de la acarbosa en el tratamiento de pacientes diabéticos no dependientes de la insulina (tipo II)]. Medicina clinica 1993;100(10):368-371. 126.

Escobar-Jimenez 1995

* Escobar-Jimenez F, Barajas C, de Leiva A, Cano FJ, Masoliver R, Herrera-Pombo JL, et al. Efficacy and tolerability of miglitol in the treatment of patients with non-insulin-dependent diabetes mellitus. Current Therapeutic Research, Clinical \& Experimental 1995;56(3): 258-268. 2

\section{Fujita 2001}

* Fujita H, Yamagamu T, Ahshima K. Long-term ingestion of a fermented soybean-derived Touchi-extract with alpha-glucosidase inhibitory activity is safe and effective in humans with borderline and mild type-2 diabetes. Journal of Nutrition 2001;131(8):2105-2108. 499.

\section{Hasche 1999}

* Hasche H, Mertes G, Bruns C, Englert R, Genthner P, Heim D, et al. Effects of acarbose treatment in Type 2 diabetic patients under dietary training: a multicentre, double-blind, placebo-controlled, 2year study. Diabetes, Nutrition \& Metabolism 1999;12(4):277-285. 1.

\section{Holman 1991}

* Holman RR, Steemson J, Turner RC. Post-prandial glycaemic reduction by an alpha-glucosidase inhibitor in type 2 diabetic patients with therapeutically attained basal normoglycaemia. Diabetes Research (Edinburgh, Lothian) 1991;18(4):149-153. 139.

\section{Ikeda 1998}

* Ikeda T, Murao A, Santou Y, Murakami H, Yamamoto R. Comparison of the clinical effect of acarbose and voglibose on blood glucose in non-obese, non-insulin dependent diabetes mellitus [Japanese]. Therapeutic Research 1998;19(9):271-278. 226.

\section{Jenney 1993}

* Jenney A, Proietto J, O'Dea K, Nankervis A, Traianedes K, D'Embden H. Low-dose acarbose improves glycemic control in NIDDM patients without changes in insulin sensitivity. Diabetes Care 1993;16(2):499-502. 140.

\section{Rosak 2002}

${ }^{*}$ Rosak C, Haupt E, Walter T, Werner J. The effect of combination treatment with acarbose and glibenclamide on postprandial glucose and insulin profiles: additive blood glucose lowering effect and decreased hypoglycaemia. Diabetes, Nutrition \& Metabolism 2002;15 (3):143-151. 491.

\section{Rosenbaum 2002}

* Rosenbaum P, Peres RB, Zanella MT, Ferreira SRG. Improved glycemic control by acarbose therapy in hypertensive diabetic patients: effects on blood pressure and hormonal parameters. Brazilian Journal of Medical and Biological Research 2002;35(8):877-884. 490.

\section{Soonthornpun 1998}

* Soonthornpun S, Rattarasarn C, Thamprasit A, Leetanaporn K Effect of acarbose in treatment of type II diabetes mellitus: a doubleblind, crossover, placebo-controlled trial. Journal of the Medical Association of Thailand 1998;81(3):195-200. 12

Wang 2000

Wang H, Xu WH, Wang GY. An evalualion on efficacy of acarbose interfering treatment on IGT. Shanxi Clinical Medicine Journal 2000; 9(2):116-117. 503.

\section{References to ongoing studies}

\section{Holman 2003}

Early Diabetes Intervention Study (EDIT). Ongoing study 01 / 04 / 1998; end date: 30 / 04 / 2003

* Holman R. Early Diabetes Intervention Study (EDIT). The National Research Register 2003; (1).

\section{Sa-adu 2003}

A one-year multicentre, international, randomised, double-blind comparison of Mitiglinide (10to40mgTID) and Acarbose (50mgODto100mgTID) administered orally for the treatment of elderly type 2 diabetic patients. Ongoing study $01 / 12$ / 2--1; end date: $01 / 06 / 2003$ 
* Sa-adu A. A one-year multicentre, international, randomised, double-blind comparison of Mitiglinide (10to40mgTID) and Acarbose (50mgODto100mgTID) administered orally for the treatment of elderly type 2 diabetic patients. The National Research Register 2003; (1).

\section{Whitby 1998}

A long-term study to investigate the effects of acarbose (glucobay) in preventing or delaying deterioration in glycaemic status in noninsulin diabetes will controlled on diet alone.. Ongoing study 28 / 09 / 1993; end date: 31 / 07 / 1996.

Ryder REJ. BIOS - A long-term study to investigate the effects of acarbose (Glucobay) in preventing or delaying deterioration in glycaemic status in non-insulin dependent diabetes well controlled on diet alone. The National Research Register 2003; (1).

* Whitby RJ. A long-term study to investigate the effects of acarbose (glucobay) in preventing or delaying deterioration in glycaemic status in non-insulin diabetes well controlled on diet alone. The National Research Register 2003; (1):Publication ID: B0201167.

\section{Additional references}

\section{ADA 1997}

American Diabetic Association. Report of the Expert Committee on the Diagnosis and Classification of Diabetes Mellitus. Diabetes Care 1997;20:1183-97.

\section{ADA 1999}

American Diabetic Association. The Expert Committee on the Diagnosis and Classification of Diabetes Mellitus. Diabetes Care 1999; 22(Suppl 1):S1-114.

Begg 1994

Begg CB, Mazumbar M. Operating characteristics of a rank correlation test for publication bias. Biometrics 1994;50:1088-1101.

Breuer 2003

Breuer HW. Review of acarbose therapeutic strategies in the longterm treatment and in the prevention of type 2 diabetes. International Journal of Clinical Pharmacology and Therapeutics 2003;41(10):421440. 113.

Campbell 1996

Campbell LK, White JR, Campbell RK. Acarbose: its role in the treatment of diabetes mellitus [see comments]. The Annals of Pharmacotherapy 1996;30(11):1255-62. 104

\section{Campbell 2000}

Campbell LK, Baker DE, Campbell RK. Miglitol: assessment of its role in the treatment of patients with diabetes mellitus. The Annals of Pharmacotherapy 2000;34(11):1291-1301. 7.

\section{Chiasson 2002}

Chiasson JL, Josse RG, Gomis R, Hanefeld M, Karasik A, Laakso M. Acarbose for prevention of type 2 diabetes mellitus: the STOPNIDDM randomised trial. Lancet 2002;359(9323):2072-2077. 169.

Chiasson 2003

Chiasson JL, Josse RG, Gomis R, Hanefeld M, Karasik A, Laakso M. Acarbose treatment and the risk of cardiovascular disease and hypertension in patients with impaired glucose tolerance: the STOP-
NIDDM trial. JAMA : the journal of the American Medical Association 2003;290(4):486-494. 168.

\section{Cohen 1960}

Cohen J. A coefficient of agreement for nominal scales. Educational and Psychological Measurement 1960;20:37-46.

\section{Concato 2000}

Concato J, Shah N, Horwitz RI. Randomized, controlled trials, observational studies, and the hierarchy of research designs. The New England Journal of Medicine 2000;342(25):1887-1892. 24.

\section{EDPG 1999}

Anonymous. A desktop guide to Type 2 diabetes mellitus. European Diabetes Policy Group 1999. Diabetic Medicine 1999;16(9):716730. 135.

Egger 1997

Egger M, Davey SG, Schneider M, Minder C. Bias in meta-analysis detected by a simple, graphical test. British Medical Journal 1997;315 (7109):629-34. 16.

Fölsch 1990

Fölsch UR, Spengler M, Boehme K, Sommerauer B. Efficacy of glucosidase inhibitors compared to sulphonylureas in the treatment and metabolic control of diet treated Type II diabetic subjects: Two longterm comparative studies. Diabetes, Nutrition \& Metabolism 1990;3 (Suppl. 1):63-68. 82.

\section{Hanefeld 2003}

Hanefeld M, Petzinna D, Cagatay M. MeRIA Study: Acarbose Reduces the Incidence of Infarction in Patients with Type 2 Diabetes Metaanalysis of Placebo-Controlled Long-Term Studies. Poster presentation, IDF Paris August 25th 2003. [MedLine: 163.

\section{Hanefeld 2004}

Hanefeld M, Cagatay M, Petrowitsch T, Neuser D, Petzinna D, Rupp M. Acarbose reduces the risk for myocardial infarction in type 2 diabetic patients: meta-analyses of seven long-term studies. European Heart Journal 2004;25:10-16. 163.

Hedges 1992

Hedges LV. Modeling publication selection effects in meta-analysis. Statistical Science 1992;7:246-255.

\section{Kaiser 2004}

Kaiser T, Sawicki PT. Acarbose for prevention of diabetes, hypertension and cardiovascular events? A critical analysis of the STOPNIDDM data. Diabetologia 2004. 114.

\section{Laube 2002}

Laube H. Acarbose. An Update of Its Therapeutic Use in Diabetes Treatment. Clinical Drug Investigation 2002;22(3):141-156. 111.

\section{Lebovitz 1998}

Lebovitz HE. Alpha-Glucosidase inhibitors as agents in the treatment of diabetes. Diabetes Reviews 1998;6(2):132-145. 112.

\section{Lexchin 2003}

Lexchin J, Bero LA, Djulbegovic B, Clark O. Pharmaceutical industry sponsorship and research outcome and quality: systematic review. British Medical Journal 2003;326(7400):1167-1170. 23.

\section{Martin 1996}

Martin AE, Montgomery PA. Acarbose: an alpha-glucosidase inhibitor. American Journal of Health-system Pharmacy 1996;53(19): 2277-2290. 34 . 


\section{Navarro 2003}

Navarro J, Valdivieso M, Bonet A, Navarro A, Gosalbes V. Oral combination therapy for type 2 diabetes mellitus (Protocol for a Cochrane Review). In: The Cochrane Library, 4. Chichester,UK: John Wiley \& Sons,Ltd. [MedLine: 167].

\section{NDDG 1979}

National Diabetes Data Group. Classification and diagnosis of diabetes mellitus and other categories of glucose intolerance. Diabetes 1979;28:1039-57.

\section{Reaven 1990}

Reaven GM, Lardinois CK, Greenfield MS, Schwartz HC, Vreman HJ. Effect of acarbose on carbohydrate and lipid metabolism in NIDDM patients poorly controlled by sulfonylureas. Diabetes Care 1990;13 Suppl 3:32-36. 105.

\section{Rutten 2000}

Rutten GEHM, Verhoeven S, Heine RJ, De Grauw WJC, Cromme PVM, Reenders K, et al. Dutch College of General Practitioners.Guidelines on Type 2 Diabetes [NHG Standaard diabetes mellitus type 2]. Huisarts en Wetenschap 2000;42(2):67-84. 119.

\section{Scott 2000}

Scott LJ, Spencer CM. Miglitol: a review of its therapeutic potential in type 2 diabetes mellitus. Drugs 2000;59(3):521-549. 11.
Van de Laar 2004b

Van de Laar FA, Lucassen PLBJ. No evidence for a reduction of myocardial infarctions by acarbose. European Heart Journal 2004;25 (13): 1179 .

WHO 1980

WHO Expert Committee on Diabetes Mellitus. Second report. Technical Report Series 646. 1980.

\section{WHO 1985}

World Health Organisation. Diabetes Mellitus: Report of a WHO Study Group. Technical Report Series No. 727. 1985.

\section{WHO 1998}

Alberti KM, Zimmet PZ. Definition, diagnosis and classification of diabetes mellitus and its complications. Part I: diagnosis and classification of diabetes mellitus. Provisional report of a WHO consultation. Diabetic Medicine 1998;15:539-53.

\section{References to other published versions of this review}

\section{Van de Laar 2005}

Van de Laar FA, Lucassen PL, Akkermans RP, Van de Lisdonk EH, Rutten GE, Van Weel C. Alpha-glucosidase inhibitors for patients with type 2 diabetes. Results from a Cochrane systematic review and meta-analysis. Diabetes Care 2005;28(1):154-163.

* Indicates the major publication for the study

T A B LE S

\section{Characteristics of included studies}

\begin{tabular}{ll} 
Study & Braun $\mathbf{1 9 9 6}$ \\
\hline Methods & DESIGN: karallel study \\
& RANDOMISATION \\
& PROCEDURE: unclear \\
& BLINDING: double-blind \\
& DURATION: 24 weeks \\
\hline Participants & COUNTRY: Germany \\
& SETTING: general practice \\
& NUMBER: randomised: AGI 80, CONTROL 72, analysed: AGI 42, CONTROL 44 \\
& SEX (F/M): AGI 16/26, CONTROL 20/24 \\
& AGE (YEARS (MEAN)): analysed patients: AGI 60, CONTROL 61 \\
& DURATION OF DIABETES (MONTHS (MEAN)): analysed patients: AGI 16, CONTROL 17 \\
\hline Dietary reinforcement: unclear \\
AGI: acarbose, week 1-2 50 mg TID, week 3-24 100 mg TID \\
CONTROL: placebo TID \\
\hline 1. Mortality: ND \\
2. Diabetes related complications: ND \\
3. Quality of life: ND \\
4. Glycaemic control: glycated haemoglobin (HbA1c), fasting \& post-load blood glucose
\end{tabular}




\section{Characteristics of included studies (Continued)}

5. Lipids: total cholesterol, HDL-cholesterol, triglycerides

6. Insulin levels: ND

7. Weight: body weight

8. Adverse effects: yes

\begin{tabular}{ll}
\hline Notes & $\begin{array}{l}\text { Sponsor: oharmaceutical } \\
\text { Author contacted: chief of department replied, data not in file, original authors were no longer working there } \\
\text { Study retrieved: CENTRAL, EMBASE, manufacturer }\end{array}$ \\
\hline Allocation concealment & B \\
\hline
\end{tabular}

\begin{tabular}{|c|c|}
\hline Study & Buchanan 1988 \\
\hline Methods & $\begin{array}{l}\text { DESIGN: parallel study } \\
\text { RANDOMISATION PROCEDURE: unclear } \\
\text { BLINDING: double-blind } \\
\text { DURATION: } 16 \text { weeks }\end{array}$ \\
\hline Participants & $\begin{array}{l}\text { COUNTRY: Scotland } \\
\text { SETTING: outpatient } \\
\text { NUMBER: randomised 28, analysed } 20 \text { (AGI 9, CONTROL 11) } \\
\text { SEX (F/M): AGI 3/6, CONTROL } 3 / 8 \\
\text { AGE (YEARS (MEAN, SD)): analysed patients: AGI 60,1 }(6,8) \text {, CONTROL } 57,6(8,2) \\
\text { DURATION OF DIABETES (MONTHS (MEAN, SD)): analysed patients: AGI 44,9 }(28,6), \text { CONTROL } \\
\text { 50,6 }(30,1)\end{array}$ \\
\hline Interventions & $\begin{array}{l}\text { Dietary reinforcement: unclear; high complex carbohydrates / low-fat diet generally advised. } \\
\text { AGI: acarbose, week 0-2 } 50 \mathrm{mg} \text { TID, week 3-8 } 100 \mathrm{mg} \text { TID, week 9-12: 200-100-100 mg, week 13-16 } \\
\text { 200-100-200 mg, in case of adverse effects patients were instructed to reduce the dosage of acarbose to that } \\
\text { which could be tolerated. } \\
\text { CONTROL: placebo TID }\end{array}$ \\
\hline Outcomes & $\begin{array}{l}\text { 1. Mortality: ND } \\
\text { 2. Diabetes related complications: ND } \\
\text { 3. Quality of life: ND } \\
\text { 4. Glycaemic control: glycated haemoglobin (HbA1), fasting blood glucose } \\
\text { 5. Lipids: total cholesterol, triglycerides } \\
\text { 6. Insulin levels: ND } \\
\text { 7. Weight: body weight } \\
\text { 8. Adverse effects: yes }\end{array}$ \\
\hline Notes & $\begin{array}{l}\text { Sponsor: pharmaceutical } \\
\text { Author contacted: co-author replied but could not give detailed answers } \\
\text { Study retrieved: CENTRAL, MEDLINE, EMBASE }\end{array}$ \\
\hline location concealment & $\mathrm{B}$ \\
\hline
\end{tabular}

\begin{tabular}{ll} 
Study & Calle-Pascual 1996 \\
\hline Methods & DESIGN: parallel study \\
& RANDOMISATION PROCEDURE: unclear \\
& BLINDING: double-blind \\
& DURATION: 16 weeks \\
\hline Participants & COUNTRY: Spain \\
& SETTING: outpatient \\
& NUMBER: randomised AGI 20, control 20; dropout AGI 3/20, control 4/20 \\
& SEX: data missing \\
& AGE: data missing
\end{tabular}




\section{Characteristics of included studies (Continued)}

\begin{tabular}{ll} 
DURATION OF DIABETES: data missing \\
\hline Interventions & Dietary reinforcement: yes, patients included in a behaviour modification program. \\
& AGI: acarbose, week $1-450 \mathrm{mg}$ TID, week 5-16 $100 \mathrm{mg}$ TID \\
CONTROL: placebo & 1. Mortality: ND \\
2. Diabetes related complications: ND \\
3. Quality of life: ND \\
4. Glycaemic control: glycated haemoglobin (HbA1c), fasting blood glucose \\
5. Lipids: total- and HDL-cholesterol, triglycerides \\
6. Insulin levels: fasting insulin \\
7. Weight: bodyweight, BMI \\
8. Adverse effects: yes \\
Sponsor: not sponsored \\
Author contacted: additional data on design, quality and outcomes send by author \\
Study retrieved: CENTRAL, MEDLINE, EMBASE \\
Short report, published as letter to the editor \\
\hline Notes
\end{tabular}

\begin{tabular}{|c|c|}
\hline Study & Campbell 1998 \\
\hline Methods & $\begin{array}{l}\text { DESIGN: parallel study } \\
\text { RANDOMISATION } \\
\text { PROCEDURE: adequate } \\
\text { BLINDING: double-blind } \\
\text { DURATION: } 3 \text { years }\end{array}$ \\
\hline Participants & $\begin{array}{l}\text { COUNTRY: UK } \\
\text { SETTING: general practice } \\
\text { NUMBER: randomised: } 789 \text { (baseline data: AGI 236, CONTROL1 254, CONTROL2 243) } \\
\text { SEX (F/M): AGI 87/150, CONTROL1 98/156, CONTROL2 71/172 } \\
\text { AGE (YEARS (MEAN)): AGI 62, CONTROL1 62, CONTROL2 } 62 \\
\text { DURATION OF DIABETES (MONTHS (MEAN)): AGI 34.7, CONTROL1 37.8, CONTROL2 } 41.6\end{array}$ \\
\hline Interventions & $\begin{array}{l}\text { Dietary reinforcement: unclear } \\
\text { AGI: acarbose } 100 \mathrm{MG} \text { TID } \\
\text { CONTROL1: placebo } \\
\text { CONTROL2: acarbose } 50 \mathrm{mg} \text { TID }\end{array}$ \\
\hline$\overline{\text { Outcomes }}$ & $\begin{array}{l}\text { 1. Mortality: ND } \\
\text { 2. Diabetes related complications: ND } \\
\text { 3. Quality of life: ND } \\
\text { 4. Glycaemic control: glycated haemoglobin (HbA1c) } \\
\text { 5. Lipids: ND } \\
\text { 6. Insulin levels: ND } \\
\text { 7. Weight: ND } \\
\text { 8. Adverse effects: yes }\end{array}$ \\
\hline Notes & $\begin{array}{l}\text { Sponsor: Pharmaceutical } \\
\text { Author contacted: addtional data on design, quality and outcomes via manufacturer. The sparse outcome } \\
\text { data of insufficient quality to be included in meta-analysis } \\
\text { Study retrieved: handsearch } \\
\text { Published as an abstract only. Patients were followed-up and an interim analysis was planned when the HbA1c } \\
\text { progressed to }>=8.0 \text { on two consecutive visits or }>10.6 \% \text { at any time. Therefore the results are not suitable } \\
\text { for meta-analysis. }\end{array}$ \\
\hline
\end{tabular}




\section{Characteristics of included studies (Continued)}

Allocation concealment B

\begin{tabular}{|c|c|}
\hline Study & Chan 1998 \\
\hline Methods & $\begin{array}{l}\text { DESIGN: parallel study } \\
\text { RANDOMISATION PROCEDURE: unclear } \\
\text { BLINDING: double-blind } \\
\text { DURATION: } 24 \text { weeks }\end{array}$ \\
\hline Participants & $\begin{array}{l}\text { COUNTRIES: China, Taiwan, Hong Kong, Philippines, Korea, Singapore, Malaysia } \\
\text { SETTING: outpatient } \\
\text { NUMBER: randomised AGI 63, CONTROL 63, analysed AGI 59, CONTROL } 62 \\
\text { SEX (F/M): AGI 31/32, CONTROL } 31 / 32 \\
\text { AGE (YEARS (MEAN, SD)): randomised patients: AGI 52,8 }(10,2) \text {, CONTROL 54,0 }(10,0) \\
\text { DURATION OF DIABETES (MONTHS (MEAN, SD)): randomised patients: AGI 32,4 (42), CON- } \\
\text { TROL 25,2 (40,8) }\end{array}$ \\
\hline Interventions & $\begin{array}{l}\text { Dietary reinforcement: unclear } \\
\text { AGI: acarbose, week 1-4 } 50 \mathrm{mg} \text { TID, week 5-24 } 100 \mathrm{mg} \text { TID } \\
\text { CONTROL: placebo TID }\end{array}$ \\
\hline Outcomes & $\begin{array}{l}\text { 1. Mortality: ND } \\
\text { 2. Diabetes related complications: ND } \\
\text { 3. Quality of life: ND } \\
\text { 4. Glycaemic control: glycated haemoglobin (HbA1c), fasting \& post-load blood glucose } \\
\text { 5. Lipids: total-, HDL- \& LDL-cholesterol, triglycerides } \\
\text { 6. Insulin levels: fasting \& post-load insulin } \\
\text { 7. Weight: body weight, BMI } \\
\text { 8. Adverse effects: yes }\end{array}$ \\
\hline Notes & $\begin{array}{l}\text { Sponsor: pharmaceutical } \\
\text { Author contacted: no reply } \\
\text { Study retrieved: CENTRAL, MEDLINE, EMBASE, Current Contents }\end{array}$ \\
\hline location concealment & $\mathrm{B}$ \\
\hline
\end{tabular}

\section{Study}

Chiasson 1994

Methods

DESIGN: parallel study

RANDOMISATION PROCEDURE: unclear

BLINDING: double-blind

DURATION: 1 year

Participants

COUNTRY: Canada

SETTING: outpatient

NUMBER: 354 patients randomised, 77 treated with diet alone; 67 (of 77) analysed

SEX (F/M): 29/48

AGE (YEARS (MEAN, SD)): all randomised patients in diet-only group 57,2 (9.7)

DURATION OF DIABETES (MONTHS (MEAN, SD)): all randomised patients in diet-only group 62,4 $(63,6)$

Interventions Dietary reinforcement: yes, according to Canadian Association Nutritional guidelines (1993).

AGI: acarbose 50, 100 or $200 \mathrm{mg}$ TID, dose adjusted according to blood glucose values and / or tolerance, main target to achieve a postprandial blood glucose $<12 \mathrm{mmol} / \mathrm{l}$

CONTROL: placebo

Outcomes 1 Mortality: ND

2. Diabetes related complications: ND

Alpha-glucosidase inhibitors for type 2 diabetes mellitus (Review)

Copyright @2005 The Cochrane Collaboration. Published by John Wiley \& Sons, Ltd 


\section{Characteristics of included studies (Continued)}

\begin{tabular}{ll} 
3. Quality of life: ND \\
4. Glycaemic control: glycated haemoglobin (HbA1c), fasting \& 90 minutes post-load blood glucose \\
5. Lipids: ND \\
6. Insulin levels: ND \\
7. Weight: ND \\
8. Adverse effects: ND \\
\hline Sponsor: pharmaceutical \\
Author contacted: author requested us to send questions again, no reply since \\
Study retrieved: CENTRAL, MEDLINE, EMBASE, Current Contents, manufacturer, handsearch \\
For this review the reported data from the 'diet only' subgroup is used. \\
\hline Allocation concealment & B \\
\hline
\end{tabular}

\begin{tabular}{ll} 
Study & Chiasson 2001 \\
\hline Methods & DESIGN: parallel study \\
& RANDOMISATION PROCEDURE: unclear \\
& BLINDING: double-blind \\
& DURATION: 36 weeks \\
\hline Participants & COUNTRY: Canada \\
& SETTING: outpatient \\
& NUMBER: total: randomised 324, analysed 318; AGI 82, CONTROL1 83, CONTROL2 83, CONTROL3 \\
& 76 \\
& SEX (F/M): AGI 18/64, CONTROL1 27/56, CONTROL2 22/61, CONTROL3 17/59 \\
& AGE (YEARS (MEAN, SD)): AGI 57,3 (9,0), CONTROL1 57,7 (9,9), CONTROL12 57,9 (8,6), CON- \\
& TROL3 58,9 (7,9) \\
& DURATION OF DIABETES (MONTHS (MEAN, SD)): AGI 62,4 (56,4), CONTROL1 61,2 (58,8), \\
& CONTROL2 90,0 (88,8), CONTROL3 73,2 (66,0)
\end{tabular}

Interventions Dietary reinforcement: yes, 'well-balanced weight-reducing diet' (reference Diabetes Care 1994, 17(5) 490-519).

AGI: miglitol, week 1-4 25 mg TID, week 5-12 $50 \mathrm{mg}$ TID, week 13-36 $100 \mathrm{mg}$ TID

CONTROL1: placebo

CONTROL2: metformin $500 \mathrm{mg}$ TID

CONTROL4: combination of miglitol $100 \mathrm{mg}$ TID and metformin $500 \mathrm{mg}$ TID

\begin{tabular}{ll}
\hline Outcomes & 1. Mortality: ND \\
& 2. Diabetes related complications: ND \\
& 3. Quality of life: ND \\
& 4. Glycaemic control: glycated haemoglobin (HbA1c), fasting \& post-load blood glucose \\
& 5. Lipids: ND \\
& 6. Insulin levels: fasting \& post-load insulin \\
& 7. Weight: body weight \\
& 8. Adverse effects: any AE, gastrointestinal AE \\
\hline Notes & Sponsor: pharmaceutical \\
& Author contacted: author requested us to send questions again, no reply since (4 months) \\
& Study retrieved: CENTRAL, MEDLINE, EMBASE, Current Contents \\
\hline Allocation concealment & B \\
\hline & \\
Study & Coniff 1994 \\
\hline Methods & DESIGN: parallel study \\
& RANDOMISATION PROCEDURE: adequate \\
& BLINDING: double-blind \\
\hline
\end{tabular}




\section{Characteristics of included studies (Continued)}

\begin{tabular}{|c|c|}
\hline & DURATION: 24 weeks \\
\hline Participants & $\begin{array}{l}\text { COUNTRY: USA } \\
\text { SETTING: outpatient } \\
\text { NUMBER: randomised: AGI 105, CONTROL 107; analysed: AGI 91, CONTROL } 98 \\
\text { SEX (F/M): analysed group: AGI 50/41, CONTROL 45/53 } \\
\text { AGE (YEARS (MEAN, SD)): analysed group: AGI 56,0 (9,5), CONTROL 55,6 (9,9) } \\
\text { DURATION OF DIABETES (MONTHS (MEDIAN, RANGE)): analysed group: AGI 48 (6-396), CON- } \\
\text { TROL } 36 \text { (6-252) }\end{array}$ \\
\hline Interventions & $\begin{array}{l}\text { Dietary reinforcement: yes, standard diabetic diet containing at least } 50 \% \text { carbohydrates. } \\
\text { AGI: acarbose titrated to a maximum of } 300 \mathrm{mg} \text { TID: dose in- or decreased according to fasting blood } \\
\text { glucose and tolerance (cut-off point fasting blood glucose }>11.1 \mathrm{mmol} / \mathrm{l} \text { ) } \\
\text { CONTROL: placebo TID }\end{array}$ \\
\hline Outcomes & $\begin{array}{l}\text { 1. Mortality: ND } \\
\text { 2. Diabetes related complications: ND } \\
\text { 3. Quality of Life: ND } \\
\text { 4. Glycaemic control: glycated haemoglobin (HbA1c), fasting \& post-load blood glucose } \\
\text { 5. Lipids: triglycerides, total-, HDL- \& LDL-cholesterol } \\
\text { 6. Insulin levels: ND } \\
\text { 7. Weight: body weight } \\
\text { 8. Adverse effects: yes }\end{array}$ \\
\hline Notes & $\begin{array}{l}\text { Sponsor: pharmaceutical } \\
\text { Author contacted: additional data on design, quality and outcomes via manufacturer } \\
\text { Study retrieved: CENTRAL, MEDLINE, EMBASE, manufacturer, handsearch }\end{array}$ \\
\hline lment & $\mathrm{A}$ \\
\hline
\end{tabular}

\begin{tabular}{|c|c|}
\hline Study & Coniff 1995 \\
\hline Methods & $\begin{array}{l}\text { DESIGN: parallel study } \\
\text { RANDOMISATION PROCEDURE: adequate } \\
\text { BLINDING: double-blind } \\
\text { DURATION: } 24 \text { weeks }\end{array}$ \\
\hline Participants & $\begin{array}{l}\text { COUNTRY: USA } \\
\text { SETTING: outpatient } \\
\text { NUMBER: randomised: AGI 76, CONTROL1 72, CONTROL2 72, CONTROL3 70; analysed: AGI 67, } \\
\text { CONTROL1 62, CONTROL2 66, CONTROL3 } 60 \\
\text { SEX (F/M): analysed group: AGI 41/26, CONTROL1 30/32, CONTROL2 29/37, CONTROL3 29/31 } \\
\text { AGE (YEARS (MEAN)): analysed group: AGI 56,2, CONTROL1 56,3, CONTROL2 55,4, CONTROL3 } \\
\text { 55,7 } \\
\text { DURATION OF DIABETES (MONTHS (MEAN, SD)): }\end{array}$ \\
\hline Interventions & $\begin{array}{l}\text { Dietary reinforcement: yes, standard diabetic diet with } 50 \% \text { energy as carbohydrates. } \\
\text { AGI: acarbose } 200 \mathrm{mg} \text { TID } \\
\text { CONTROL1: placebo } \\
\text { CONTROL2: tolbutamide, individually adjusted in steps of } 250 \mathrm{mg} \text { TID, maximum dose unclear } \\
\text { CONTROL4: acarbose \& tolbutamide combination (data not used in this review) }\end{array}$ \\
\hline Outcomes & $\begin{array}{l}\text { 1. Mortality: yes } \\
\text { 2. Diabetes related complications: ND } \\
\text { 3. Quality of life: ND } \\
\text { 4. Glycaemic control: glycated haemoglobin (HbAlc), fasting \& post-load blood glucose } \\
\text { 5. Lipids: triglycerides, total-, HDL- \& LDL-cholesterol } \\
\text { 6. Insulin levels: fasting \& post-load insulin }\end{array}$ \\
\hline
\end{tabular}




\section{Characteristics of included studies (Continued)}

\begin{tabular}{|c|c|}
\hline & $\begin{array}{l}\text { 7. Weight: body weight } \\
\text { 8. Adverse effects: yes }\end{array}$ \\
\hline$\overline{\text { Notes }}$ & $\begin{array}{l}\text { Sponsor: pharmaceutical } \\
\text { Author contacted: additional data on design, quality and outcomes via manufacturer } \\
\text { Study retrieved: CCRCT, Medline, Embase, manufacturer }\end{array}$ \\
\hline Allocation concealment & $\mathrm{A}$ \\
\hline Study & Coniff 1995b \\
\hline Methods & $\begin{array}{l}\text { DESIGN: parallel study } \\
\text { RANDOMISATION PROCEDURE: adequate } \\
\text { BLINDING: double-blind } \\
\text { DURATION: } 16 \text { weeks }\end{array}$ \\
\hline Participants & $\begin{array}{l}\text { COUNTRY: USA } \\
\text { SETTING: outpatient } \\
\text { NUMBER: randomised: AGI 73, CONTROL1 73, CONTROL2 72, CONTROL3 72; analysed: AGI 58, } \\
\text { CONTROL1 64, CONTROL2 54, CONTROL3 } 53 \\
\text { SEX (F/M): analysed group: AGI 28/30, CONTROL1 27/37, CONTROL2 22/32, CONTROL3 22/31 } \\
\text { AGE (YEARS (MEAN)): analysed group: AGI 55, CONTROL1 54, CONTROL2 56, CONTROL3 } 54 \\
\text { DURATION OF DIABETES (MONTHS (MEAN)): analysed group: AGI 72, CONTROL1 60, CON- } \\
\text { TROL2 60, CONTROL3 } 60\end{array}$ \\
\hline Interventions & $\begin{array}{l}\text { Dietary reinforcement: yes, weight stable ADA diet (1979): 50\% carbohydrate, } 30 \% \text { fat, } 20 \% \text { protein. } \\
\text { AGI: acarbose } 100 \mathrm{mg} \text { TID } \\
\text { CONTROL1: placebo TID } \\
\text { CONTROL2: acarbose, week 1-2 } 100 \mathrm{mg} \text { TID, week 3-16 } 200 \mathrm{mg} \text { TID } \\
\text { CONTROL3: acarbose, week 1-2 } 100 \mathrm{mg} \text { TID, week 3-4 } 200 \mathrm{mg} \text { TID, week 5-16 } 300 \mathrm{mg} \text { TID }\end{array}$ \\
\hline Outcomes & $\begin{array}{l}\text { 1. Mortality: ND } \\
\text { 2. Diabetes Related Complications: ND } \\
\text { 3. Quality of Life: ND } \\
\text { 4. Glycaemic control: glycated haemoglobin }(\mathrm{HbAlc}) \text {, fasting \& post-load blood glucose } \\
\text { 5. Lipids: total cholesterol, triglycerides } \\
\text { 6. Insulin levels: fasting \& post-load insulin levels } \\
\text { 7. Weight: body weight } \\
\text { 8. Adverse effects: yes }\end{array}$ \\
\hline Notes & $\begin{array}{l}\text { Sponsor: pharmaceutical } \\
\text { Author contacted: additional data on design, quality and outcomes via manufacturer } \\
\text { Study retrieved: CENTRAL, MEDLINE, EMBASE, manufacturer }\end{array}$ \\
\hline Allocation concealment & $\mathrm{A}$ \\
\hline
\end{tabular}

\begin{tabular}{ll} 
Study & Dedov 1995 \\
\hline Methods & DESIGN: parallel study \\
& RANDOMISATION PROCEDURE: unclear \\
& BLINDING: double-blind \\
& DURATION: 24 weeks \\
\hline Participants & COUNTRY: Russia \\
& SETTING: outpatient \\
& NUMBER: randomised 180 patients, analysed 155 (AGI 82, CONTROL 73). Baseline values are given for \\
& 61 patients \\
& SEX (F/M): baseline group AGI 50/33, CONTROL 50/28 \\
& AGE (YEARS (MEAN, SD)): baseline group AGI 52,6 (9,5), CONTROL 49,2 (9,5) \\
\hline
\end{tabular}




\section{Characteristics of included studies (Continued)}

DURATION OF DIABETES: ND

\begin{tabular}{ll}
\hline Interventions & Dietary reinforcement: unclear \\
& AGI: acarbose, week 1-2 $50 \mathrm{mg}$ TID, week 3-24 wk $100 \mathrm{mg}$ TID \\
& CONTROL: placebo TID \\
\hline Outcomes & 1. Mortality: ND \\
& 2. Diabetes related complications: ND \\
& 3. Quality of life: ND \\
& 4. Glycaemic control: glycated haemoglobin (HbA1), fasting \& post-load blood glucose \\
& 5. Lipids: ND \\
& 6. Insulin levels: ND \\
& 7. Weight: body weight \\
& 8. Adverse effects: yes \\
\hline Sponsor: not specified & Author contacted: no reply \\
& Study retrieved: CENTRAL, EMBASE \\
\hline Allocation concealment & B \\
\hline
\end{tabular}

\begin{tabular}{|c|c|}
\hline Study & Delgado 2002 \\
\hline Methods & $\begin{array}{l}\text { DESIGN: parallel study } \\
\text { RANDOMISATION PROCEDURE: unclear } \\
\text { BLINDING: double-blind } \\
\text { DURATION: } 16 \text { weeks }\end{array}$ \\
\hline Participants & $\begin{array}{l}\text { COUNTRY: Switzerland } \\
\text { SETTING: outpatient } \\
\text { NUMBER: AGI 9, CONTROL } 8 \\
\text { SEX (F/M): AGI 3/6, CONTROL } 3 / 5 \\
\text { AGE: ND } \\
\text { DURATION OF DIABETES (MONTHS (MEAN, SD)): all patients } 26 \text { (6) }\end{array}$ \\
\hline Interventions & $\begin{array}{l}\text { Dietary reinforcement: yes, for details article referred to article in French (Journeés de diabétologie Hôtel } \\
\text { Dieu 1998: 51-69). } \\
\text { AGI: acarbose, week 1-2 } 50 \mathrm{mg} \text { once daily, week 3-16 } 50 \mathrm{mg} \text { BID } \\
\text { CONTROL1: placebo BID }\end{array}$ \\
\hline Outcomes & $\begin{array}{l}\text { 1. Mortality: ND } \\
\text { 2. Diabetes related complications: ND } \\
\text { 3. Quality of life: ND } \\
\text { 4. Glycaemic control: glycated haemoglobin (HbA1c), fasting \& post-load blood glucose } \\
\text { 5. Lipids: total cholesterol, HDL-cholesterol, triglycerides } \\
\text { 6. Insulin levels: Reaven's triple test } \\
\text { 7. Weight: body weight, BMI } \\
\text { 8. Adverse effects: ND }\end{array}$ \\
\hline Notes & $\begin{array}{l}\text { Sponsor: Not specified } \\
\text { Author contacted: no reply } \\
\text { Study retrieved: CENTRAL, MEDLINE, EMBASE, Current Contents, handsearch } \\
\text { Study mainly about insulin insulin resistance \& secretion }\end{array}$ \\
\hline llocation cone & B \\
\hline
\end{tabular}

\section{Study Drent 2002}

Methods DESIGN: parallel study

Alpha-glucosidase inhibitors for type 2 diabetes mellitus (Review)

Copyright @2005 The Cochrane Collaboration. Published by John Wiley \& Sons, Ltd 


\section{Characteristics of included studies (Continued)}

RANDOMISATION PROCEDURE: unclear

BLINDING: double-blind

DURATION: 24 weeks

Participants

COUNTRY: The Netherlands

SETTING: patients recruited in general practice, study performed in 'study centres'

NUMBER: 599 enrolled, 468 randomised, 384 analysed (AGI 71, CONTROL1 87, CONTROL2 84, CONTROL3 58, CONTROL4 84)

SEX (F/M): AGI 34/37, CONTROL1 38/49, CONTROL2 37/47, CONTROL3 21/37, CONTROL4 $43 / 41$

AGI (YEARS (MEAN, SD)): AGI 63 (11), CONTROL1 63 (11), CONTROL2 63 (9), CONTROL3 64

(10), CONTROL4 64 (10)

DURATION OF DIABETES (MONTHS (MEAN)): AGI 36, CONTROL1 30, CONTROL2 48, CONTROL3 46, CONTROL4 41.5

Interventions Dietary reinforcement: when patients were not using diet, advice was given during screening period, ADA/EASD guidelines, at least $40 \%$ carbohydrates .

AGI: miglitol, week 1-2 $50 \mathrm{mg}$ TID, week 3-24 $100 \mathrm{mg}$ TID

CONTROL1: placebo TID

CONTROL2: miglitol $50 \mathrm{mg}$ TID

CONTROL3: miglitol, week 1-2 $100 \mathrm{mg}$ TID, week 3-24 $200 \mathrm{mg}$ TID

CONTROL4: miglitol $25 \mathrm{mg}$ TID

\begin{tabular}{ll}
\hline Outcomes & 1. Mortality: ND \\
& 2. Diabetes related complications: ND \\
& 3. Quality of life: ND \\
& 4. Glycaemic control: glycated haemoglobin (HbA1c), fasting \& post-load blood glucose \\
& 5. Lipids: "blood lipids" \\
& 6. Insulin levels: fasting \& post-load insulin \\
& 7. Weight: weight \& BMI \\
& 8. Adverse effects: yes \\
\hline Notes & Sponsor: pharmaceutical \\
& Author contacted: additional data on design, quality and outcomes send by author \\
& Study retrieved: CENTRAL, MEDLINE, EMBASE, Current Contents (2nd reference via author) \\
\hline Allocation concealment & A \\
\hline
\end{tabular}

Study

Fischer 1998

Methods

DESIGN: parallel study

RANDOMISATION PROCEDURE: unclear

BLINDING: double-blind

DURATION: 24 weeks

Participants

COUNTRY: Germany, Austria, Croatia, Hungary, Italy

SETTING: outpatient

NUMBER: randomised 495, analysed 420 (AGI 25 mg 86, AGI 50 mg 88, AGI 100 mg 78, AGI 200 mg 87, CONTROL 81)

SEX (F/M): AGI 25 mg 40/46, AGI 50 mg 45/43, AGI 100 mg 32/46, AGI 200 mg 43/44, CONTROL $38 / 43$

AGE (YEARS (MEAN, SD)): analysed group: AGI 25 mg 58,5 (8,4), AGI 50 mg 55,5 (9,6), AGI 100 mg 56,8 (9,4), AGI $200 \mathrm{mg}$ 59,4 (8,6), CONTROL 52,7 (8,7)

DURATION OF DIABETES (MONTHS (MEDIAN)): AGI 25 mg 26, AGI 50 mg 20, AGI 100 mg 17, AGI $200 \mathrm{mg}$ 21, CONTROL 24

Interventions Dietary reinforcement: yes, ADA nutritional recommendations 1986

Alpha-glucosidase inhibitors for type 2 diabetes mellitus (Review) 


\section{Characteristics of included studies (Continued)}

AGI: acarbose divided in 4 groups: $25 \mathrm{mg}, 50 \mathrm{mg}, 100 \mathrm{mg}$ (week 1-2 $50 \mathrm{mg}$ TID) and $200 \mathrm{mg}$ TID (week 1-2 $100 \mathrm{mg}$ TID)

CONTROL: placebo TID

\begin{tabular}{ll}
\hline Outcomes & 1. Mortality: ND \\
& 2. Diabetes related complications: ND \\
& 3. Quality of life: ND \\
& 4. Glycaemic control: glycated haemoglobin (HbA1c), fasting blood glucose \\
& 5. Lipids: ND \\
& 6. Insulin levels: ND \\
& 7. Weight: body weight \\
& 8. Adverse effects: yes \\
\hline Notes & Sponsor: pharmaceutical \\
& Author contacted: additional data on design, quality and outcomes via manufacturer \\
& Study retrieved: CENTRAL, MEDLINE, EMBASE, Current Contents, manufacturer \\
\hline Allocation concealment & A \\
\hline
\end{tabular}

\begin{tabular}{|c|c|}
\hline Study & Gentile 1999 \\
\hline Methods & $\begin{array}{l}\text { DESIGN: cross-over study } \\
\text { RANDOMISATION PROCEDURE: unclear } \\
\text { BLINDING: double-blind } \\
\text { DURATION: } 2 \text { x } 12 \text { weeks } \\
\end{array}$ \\
\hline Participants & $\begin{array}{l}\text { COUNTRY: Italy } \\
\text { SETTING: outpatient } \\
\text { NUMBER: } 76 \\
\text { SEX (F/M): } 33 / 43 \\
\text { AGE: ND } \\
\text { DURATION OF DIABETES (MONTHS (MEAN, SD)): 110,4 }(49,2)\end{array}$ \\
\hline Interventions & $\begin{array}{l}\text { Dietary reinforcement: unclear, general advice } 60 \% \text { carbohydrates, } 20-22 \% \text { fat, } 18-20 \% \text { protein. } \\
\text { AGI: acarbose, week } 150 \mathrm{mg} \text { TID, week } 2-12100 \mathrm{mg} \text { TID } \\
\text { CONTROL: placebo }\end{array}$ \\
\hline Outcomes & $\begin{array}{l}\text { 1. Mortality: ND } \\
\text { 2. Diabetes related complications: ND } \\
\text { 3. Quality of life: ND } \\
\text { 4. Glycaemic control: glycated haemoglobin, fasting blood glucose } \\
\text { 5. Lipids: ND } \\
\text { 6. Insulin levels: ND } \\
\text { 7. Weight: ND } \\
\text { 8. Adverse effects: yes }\end{array}$ \\
\hline Notes & $\begin{array}{l}\text { Sponsor: "Fundi MURST", not clear whether this is a pharmaceutical sponsor } \\
\text { Author contacted: no reply } \\
\text { Study retrieved: CENTRAL, MEDLINE, EMBASE } \\
\text { This study is done with patients suffering from non-alcoholic liver cirrhosis }\end{array}$ \\
\hline Allocation concealment & $\mathrm{B}$ \\
\hline
\end{tabular}

\section{Study}

Haffner 1997

Methods

DESIGN: parallel study RANDOMISATION PROCEDURE: unclear

BLINDING: double-blind

DURATION: 16 weeks 


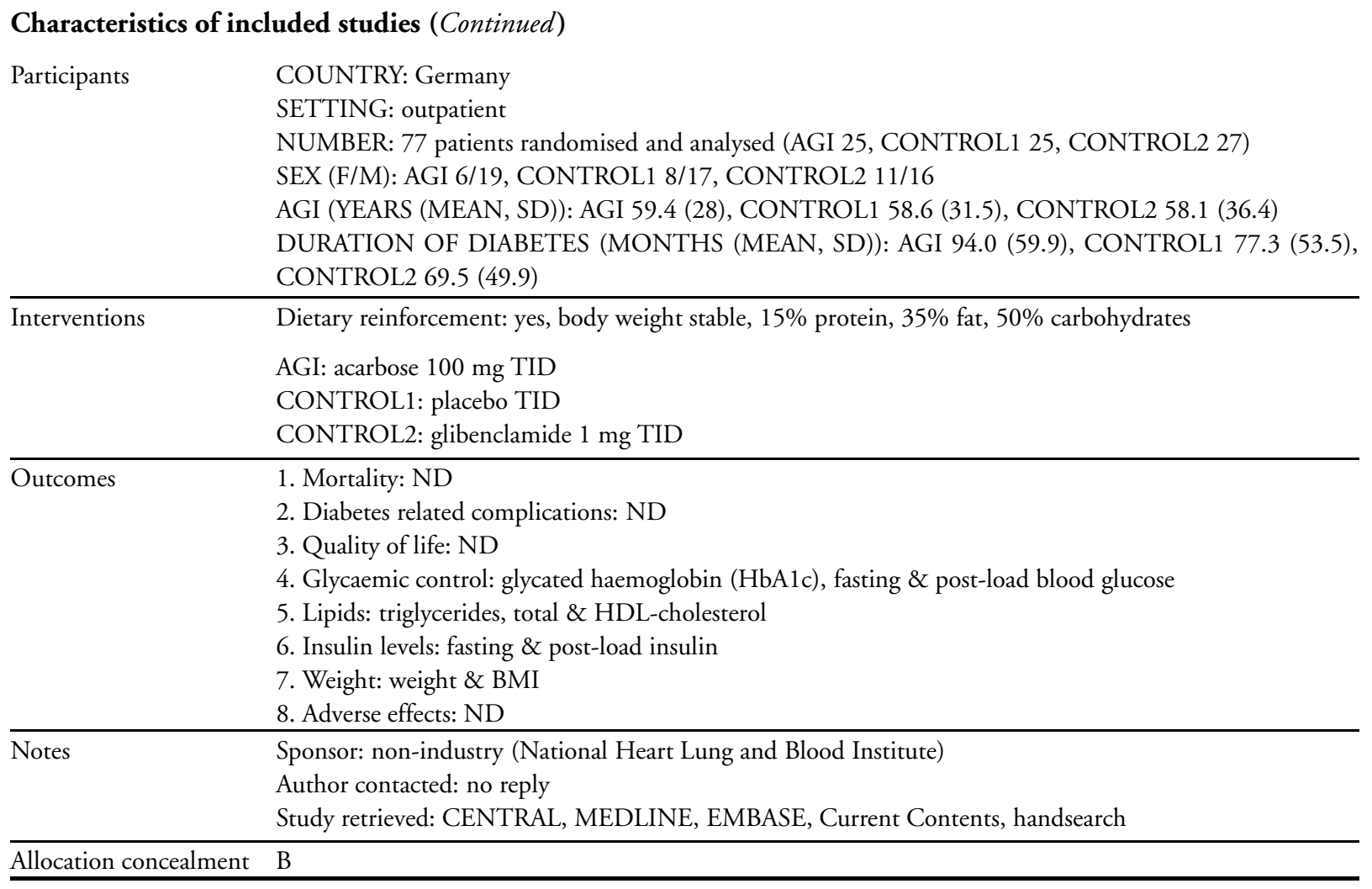

\begin{tabular}{|c|c|}
\hline Study & Hanefeld 1991 \\
\hline Methods & $\begin{array}{l}\text { DESIGN: parallel study } \\
\text { RANDOMISATION PROCEDURE: adequate } \\
\text { BLINDING: double-blind } \\
\text { DURATION: } 24 \text { weeks }\end{array}$ \\
\hline Participants & $\begin{array}{l}\text { COUNTRY: Germany } \\
\text { SETTING: outpatient } \\
\text { NUMBER: randomised 100, analysed 94; AGI 47, CONTROL } 47 \\
\text { SEX (F/M): AGI 24/23, CONTROL 22/25 } \\
\text { AGE (YEARS (MEAN)): analysed patients AGI 60, CONTROL } 59 \\
\text { DURATION OF DIABETES (MONTHS (MEAN)): analysed patients AGI 70, CONTROL } 49\end{array}$ \\
\hline Interventions & $\begin{array}{l}\text { Dietary reinforcement: yes, specification diet unclear. } \\
\text { AGI: acarbose } 100 \mathrm{mg} \text { TID } \\
\text { CONTROL: placebo }\end{array}$ \\
\hline Outcomes & $\begin{array}{l}\text { 1. Mortality: ND } \\
\text { 2. Diabetes related Complications: ND } \\
\text { 3. Quality of life: ND } \\
\text { 4. Glycaemic control: glycated haemoglobin (HbA1), fasting \& } 1 \text { hour post-load blood glucose } \\
\text { 5. Lipids: triglycerides, total- and HDL-cholesterol } \\
\text { 6. Insulin levels: fasting \& } 1 \text { hour post-load insulin } \\
\text { 7. Weight: body weight } \\
\text { 8. Adverse effects: yes }\end{array}$ \\
\hline Notes & $\begin{array}{l}\text { Sponsor: pharmaceutical } \\
\text { Author contacted: additional data on design, quality and outcomes via manufacturer } \\
\text { Study retrieved: CENTRAL, MEDLINE, EMBASE, manufacturer }\end{array}$ \\
\hline
\end{tabular}




\section{Characteristics of included studies (Continued)}

Allocation concealment A

\begin{tabular}{|c|c|}
\hline Study & Hillebrand 1987 \\
\hline Methods & $\begin{array}{l}\text { DESIGN: cross-over study } \\
\text { RANDOMISATION PROCEDURE: unclear } \\
\text { BLINDING: double-blind } \\
\text { DURATION: treatment periods of } 12 \text { weeks }\end{array}$ \\
\hline Participants & $\begin{array}{l}\text { COUNTRY: Germany } \\
\text { SETTING: outpatient } \\
\text { NUMBER: } 76 \\
\text { SEX (F/M): } 33 / 43 \\
\text { AGE: ND } \\
\text { DURATION OF DIABETES (MONTHS (MEAN, SD)): 110,4 }(49,2)\end{array}$ \\
\hline Interventions & $\begin{array}{l}\text { Dietary reinforcement: unclear } \\
\text { AGI: acarbose } 200 \mathrm{mg} \text { BID } \\
\text { CONTROL1: miglitol } 200 \mathrm{mg} \text { BID } \\
\text { CONTROL2: glibenclamide } 7 \mathrm{mg} \text { once daily }\end{array}$ \\
\hline Outcomes & $\begin{array}{l}\text { 1. Mortality: ND } \\
\text { 2. Diabetes related complications: ND } \\
\text { 3. Quality of life: ND } \\
\text { 4. Glycaemic control: glycated haemoglobin (HbA1), fasting \& post-load blood glucose } \\
\text { 5. Lipids: ND } \\
\text { 6. Insulin levels: ND } \\
\text { 7. Weight: ND } \\
\text { 8. Adverse effects: yes }\end{array}$ \\
\hline Notes & $\begin{array}{l}\text { Sponsor: not specified } \\
\text { Author contacted: authors could not be retrieved } \\
\text { Study retrieved: handsearch } \\
\text { Published as abstract only. }\end{array}$ \\
\hline Allocation concealment & $\mathrm{B}$ \\
\hline Study & Hoffmann 1990 \\
\hline Methods & $\begin{array}{l}\text { DESIGN: parallel study } \\
\text { RANDOMISATION PROCEDURE: adequate } \\
\text { BLINDING: no blinding } \\
\text { DURATION: } 24 \text { weeks }\end{array}$ \\
\hline Participants & $\begin{array}{l}\text { COUNTRY: Germany } \\
\text { SETTING: outpatient } \\
\text { NUMBER: } 95 \text { patients included; AGI 48, CONTROL } 47 \\
\text { SEX (F/M): AGI 30/18, CONTROL 26/21 } \\
\text { AGE (YEARS (MEAN, SD)): AGI } 61.8 \text { (5.6), CONTROL } 61.2(5.5) \\
\text { DURATION OF DIABETES (MONTHS (MEAN (SD)): AGI } 22.4 \text { (16.2), CONTROL } 30.7 \text { (29.2) }\end{array}$ \\
\hline Interventions & $\begin{array}{l}\text { Dietary reinforcement: yes, normocaloric diet of } 1500 \mathrm{kcal} \text { with } 120 \mathrm{~g} \text { carbohydrates, } 50 \mathrm{~g} \text { protein, } 55 \mathrm{~g} \text { fat } \\
\text { AGI: acarbose, week } 1-450 \mathrm{mg} \text { TID, week } 5-25100 \mathrm{mg} \text { TID (for one patient dose reduced to } 100 \mathrm{mg} \text { BID) } \\
\text { CONTROL: glibenclamide } 3,5 \mathrm{mg} \text { administered individually } 1-3 \text { times per day }\end{array}$ \\
\hline$\overline{\text { Outcomes }}$ & $\begin{array}{l}\text { 1. Mortality: ND } \\
\text { 2. Diabetes related complications: ND } \\
\text { 3. Quality of life: ND }\end{array}$ \\
\hline
\end{tabular}




\section{Characteristics of included studies (Continued)}

4. Glycaemic control: glycated haemoglobin ( $\mathrm{HbA} 1)$, fasting \& post-load blood glucose

5. Lipids: triglycerides, total-, HDL and LDL-cholesterol

6. Insulin levels: ND

7. Weight: body weight, Broca index

8. Adverse effects: yes

\begin{tabular}{ll}
\hline Notes & $\begin{array}{l}\text { Sponsor: pharmaceutical } \\
\text { Author contacted: additional data on design, quality and outcomes via manufacturer } \\
\text { Study retrieved: CENTRAL, experts }\end{array}$ \\
\hline Allocation concealment & B \\
\hline
\end{tabular}

\begin{tabular}{|c|c|}
\hline Study & Hoffmann 1994 \\
\hline Methods & $\begin{array}{l}\text { DESIGN: parallel study } \\
\text { RANDOMISATION PROCEDURE: adequate } \\
\text { BLINDING: double-blind regarding comparison acarbose / placebo, glibenclamide single-blind } \\
\text { DURATION: } 24 \text { weeks }\end{array}$ \\
\hline Participants & $\begin{array}{l}\text { COUNTRY: Germany } \\
\text { SETTING: outpatient } \\
\text { NUMBER: } 96 \text { patients randomised, } 85 \text { analysed for efficacy (AGI 28, control1 30, control2 27) } \\
\text { SEX (F/M): AGI 15/13, CONTROL1 18/12, CONTROL2 14/13 } \\
\text { AGE (YEARS (MEAN, SD)): analysed patients: AGI 58,8 }(6,9) \text {, CONTROL1 56,9 }(6,7) \text {, CONTROL2 } \\
\text { 59,9 }(5,7) \\
\text { DURATION OF DIABETES (MONTHS (MEAN, SD)): analysed patients: AGI } 12,7(10,8) \text {, CON- } \\
\text { TROL1 12,1 }(10,8) \text {, CONTROL2 17,6 }(13,1)\end{array}$ \\
\hline Interventions & $\begin{array}{l}\text { Dietary reinforcement: yes, } 50 \% \text { carbohydrates, } 35 \% \text { fat, } 15 \% \text { protein. } \\
\text { AGI: acarbose } 100 \mathrm{mg} \text { TID } \\
\text { CONTROL1: placebo TID } \\
\text { CONTROL2: glibenclamide } 3,5 \mathrm{mg} \text { administered individually } 1-3 \text { times per day }\end{array}$ \\
\hline Outcomes & $\begin{array}{l}\text { 1. Mortality: ND } \\
\text { 2. Diabetes related complications: ND } \\
\text { 3. Quality of life: ND } \\
\text { 4. Glycaemic control: glycated haemoglobin }(\mathrm{HbA1c}) \text {, fasting \& post-load blood glucose } \\
\text { 5. Lipids: triglycerides, total- and HDL-cholesterol } \\
\text { 6. Insulin levels: fasting \& post-load insulin } \\
\text { 7. Weight: body weight, BMI } \\
\text { 8. Adverse effects: yes }\end{array}$ \\
\hline$\overline{\text { Notes }}$ & $\begin{array}{l}\text { Sponsor: pharmaceutical } \\
\text { Author contacted: additional data on design, quality and outcomes via manufacturer } \\
\text { Study retrieved: CENTRAL, MEDLINE, EMBASE, manufacturer }\end{array}$ \\
\hline Allocation concealment & $\mathrm{A}$ \\
\hline Study & Hoffmann 1997 \\
\hline Methods & $\begin{array}{l}\text { DESIGN: parallel study } \\
\text { RANDOMISATION PROCEDURE: adequate } \\
\text { BLINDING: double blind regarding comparison acarbose / placebo, metformin single-blind } \\
\text { DURATION: } 24 \text { weeks }\end{array}$ \\
\hline Participants & $\begin{array}{l}\text { COUNTRY: Germany } \\
\text { SETTING: outpatient } \\
\text { NUMBER: } 96 \text { patients randomised; } 94 \text { analysed for efficacy (AGI 31, CONTROL1 32, CONTROL2 31) } \\
\text { SEX (F/M): AGI 25/6, CONTROL1 20/12, CONTROL2 17/14 }\end{array}$ \\
\hline
\end{tabular}




\section{Characteristics of included studies (Continued)}

AGE (YEARS (MEAN, SD)): analysed patients: AGI 58,9 (9,4), CONTROL1 60,2 (8,6), CONTROL2 $55,9(7,8)$

DURATION OF DIABETES (MONTHS (MEAN, SD)): analysed patients: AGI 36,9 (27,2), CONTROL1 43,2 $(33,9)$, CONTROL2 25,0 $(17,4)$

\begin{tabular}{|c|c|}
\hline Interventions & $\begin{array}{l}\text { Dietary reinforcement: yes, } 50 \% \text { carbohydrates, } 35 \% \text { fat, } 15 \% \text { protein } \\
\text { AGI: acarbose } 100 \mathrm{mg} \text { TID } \\
\text { CONTROL1: placebo TID } \\
\text { CONTROL2: metformin } 850 \mathrm{mg} \text { BID }\end{array}$ \\
\hline Outcomes & $\begin{array}{l}\text { 1. Mortality: ND } \\
\text { 2. Diabetes related complications: ND } \\
\text { 3. Quality of life: ND } \\
\text { 4. Glycaemic control: glycated haemoglobin (HbAlc), fasting post-load blood glucose } \\
\text { 5. Lipids: triglycerides, total-, HDL- \& LDL-cholesterol } \\
\text { 6. Insulin levels: fasting \& post-load insulin } \\
\text { 7. Weight: body weight } \\
\text { 8. Adverse effects: yes }\end{array}$ \\
\hline Notes & $\begin{array}{l}\text { Sponsor: pharmaceutical } \\
\text { Author contacted: additional data on design, quality and outcomes via manufacturer } \\
\text { Study retrieved: CENTRAL, MEDLINE, EMBASE, Current Contents, manufacturer }\end{array}$ \\
\hline Allocation concealment & $\mathrm{A}$ \\
\hline Study & Holman 1999 \\
\hline Methods & $\begin{array}{l}\text { DESIGN: parallel study } \\
\text { RANDOMISATION PROCEDURE: adequate } \\
\text { BLINDING: double-blind } \\
\text { DURATION: } 3 \text { years }\end{array}$ \\
\hline Participants & $\begin{array}{l}\text { COUNTRY: England } \\
\text { SETTING: outpatient, part of the United Kingdom Prospective Diabetes Study } \\
\text { NUMBER: } 1946 \text { patients randomised, total } 1624 \text { analysed (intention-to-treat): diet only group randomised } \\
\text { 256, diet only group analysed (HbA1c) AGI 83, CONTROL } 107 . \\
\text { SEX (F/M): AGI 36/84, CONTROL 38/98 } \\
\text { AGE (YEARS (MEAN, SD)): AGI } 60.0(8.2) \text {, CONTROL } 60.9(9.0) \\
\text { DURATION OF DIABETES (MONTHS (MEAN, SD)): AGI } 82.6(33.3) \text {, CONTROL } 91.3 \text { (34.9) }\end{array}$ \\
\hline Interventions & $\begin{array}{l}\text { Dietary reinforcement: no (dietary advice according to UKPDS protocol) } \\
\text { AGI: acarbose, } 50 \mathrm{mg} \text { once, BID \& TID at two-week intervals; } 4 \text { months after start dosage increased in } 3 \\
\text { weeks period with } 50 \mathrm{mg} \text { per step to } 100 \mathrm{mg} \text { TID. In case of side effects patients were allowed to reduce the } \\
\text { dose. } \\
\text { CONTROL: placebo }\end{array}$ \\
\hline Outcomes & $\begin{array}{l}\text { 1. Mortality: yes } \\
\text { 2. Diabetes related complications: yes } \\
\text { 3. Quality of life: ND } \\
\text { 4. Glycaemic control: glycated haemoglobin (HbA1c) } \\
\text { 5. Lipids: ND } \\
\text { 6. Insulin levels: ND } \\
\text { 7. Weight: body weight, BMI } \\
\text { 8. Adverse effects: yes }\end{array}$ \\
\hline Notes & $\begin{array}{l}\text { Sponsor: pharmaceutical } \\
\text { Author contacted: additional data on design, quality and outcomes send by authors } \\
\text { Study retrieved: CENTRAL, MEDLINE, EMBASE, Current Contents, Manufacturer }\end{array}$ \\
\hline
\end{tabular}




\section{Characteristics of included studies (Continued)}

For this review the reported data from the 'diet only' subgroup is used.

Allocation concealment A

\begin{tabular}{|c|c|}
\hline Study & Holmes 2001 \\
\hline Methods & $\begin{array}{l}\text { DESIGN: parallel study } \\
\text { RANDOMISATION PROCEDURE: adequate } \\
\text { BLINDING: double-blind } \\
\text { DURATION: } 24 \text { weeks }\end{array}$ \\
\hline Participants & $\begin{array}{l}\text { COUNTRY: Germany, France and Spain } \\
\text { SETTING: outpatient } \\
\text { NUMBER: } 260 \text { patients entered run-in period, } 179 \text { randomised (AGI 92, CONTROL 87). analysed (for } \\
\text { HbA1c) AGI 90, CONTROL } 85 \\
\text { SEX (F/M): randomised group AGI 33/59; CONTROL 30/57 } \\
\text { AGE (YEARS (MEAN, SD)): randomised patients AGI 60,6 (10.2); CONTROL } 64.3(10.4) \\
\text { DURATION OF DIABETES (MONTHS (MEAN (SD)): randomised patients AGI } 53.9(62.4 \text { or } 64.4 \text { ); } \\
\text { CONTROL } 63.4(66.5)\end{array}$ \\
\hline Interventions & $\begin{array}{l}\text { Dietary reinforcement: no ("patients continued with their normal dietary habits'). } \\
\text { AGI: acarbose, week } 0-450 \mathrm{mg} \text { TID, week } 4-8100 \mathrm{mg} \text { TID, in case of side-effects to be reduced to } 50 \mathrm{mg} \\
\text { CONTROL: nateglinide } 120 \mathrm{mg} \text { TID }\end{array}$ \\
\hline$\overline{\text { Outcomes }}$ & $\begin{array}{l}\text { 1. Mortality: ND } \\
\text { 2. Diabetes related complications: ND } \\
\text { 3. Quality of life: ND } \\
\text { 4. Glycaemic control: glycated haemoglobin (HbA1c), fasting blood glucose } \\
\text { 5. Lipids: ND } \\
\text { 6. Insulin levels: ND } \\
\text { 7. Weight: body weight } \\
\text { 8. Adverse effects: yes }\end{array}$ \\
\hline Notes & $\begin{array}{l}\text { Sponsor: pharmaceutical } \\
\text { Author contacted: additional data on design, quality and outcomes send by author } \\
\text { Study retrieved: handsearch }\end{array}$ \\
\hline location concealment & $\mathrm{A}$ \\
\hline
\end{tabular}

\section{Study}

Hotta 1993

\begin{tabular}{ll}
\hline Methods & DESIGN: parallel study \\
& RANDOMISATION PROCEDURE: unclear \\
& BLINDING: double-blind \\
& DURATION: 24 weeks \\
\hline Participants & COUNTRY: Japan \\
& SETTING: outpatient \\
& NUMBER: randomised: AGI 20, CONTROL 20, analysed: AGI 16, CONTROL 15, (baseline values given \\
& for 37 patients) \\
& SEX (F/M): AGI 5/14, CONTROL 4/14 \\
& AGE (YEARS (MEAN)): AGI 49,8, CONTROL 47,9 \\
& DURATION OF DIABETES (MONTHS (MEAN)): AGI 55,2, CONTROL 57,6 \\
\hline Interventions & Dietary reinforcement: yes, specification unclear \\
& AGI: acarbose 100 mg TID \\
CONTROL: placebo TID \\
\hline Outcomes & 1. Mortality: ND \\
\hline Alpha-glucosidase inhibitors for type 2 diabetes mellitus (Review) \\
Copyright @2005 The Cochrane Collaboration. Published by John Wiley \& Sons, Ltd
\end{tabular}




\section{Characteristics of included studies (Continued)}

\begin{tabular}{|c|c|}
\hline & $\begin{array}{l}\text { 2. Diabetes related complications: ND } \\
\text { 3. Quality of life: ND } \\
\text { 4. Glycaemic control: glycated haemoglobin (HbA1c), fasting \& post-load blood glucose } \\
\text { 5. Lipids: total- \& HDL-cholesterol, triglycerides } \\
\text { 6. Insulin levels: ND } \\
\text { 7. Weight: body weight } \\
\text { 8. Adverse effects: yes }\end{array}$ \\
\hline Notes & $\begin{array}{l}\text { Sponsor: pharmaceutical } \\
\text { Author contacted: additional data on design, quality and outcomes send by author } \\
\text { Study retrieved: CENTRAL, MEDLINE, EMBASE, manufacturer, (2nd reference via author) }\end{array}$ \\
\hline Allocation concealment & $\mathrm{A}$ \\
\hline Study & Johnston 1998 \\
\hline Methods & $\begin{array}{l}\text { DESIGN: parallel study } \\
\text { RANDOMISATION PROCEDURE: unclear } \\
\text { BLINDING: double-blind } \\
\text { DURATION: } 56 \text { weeks }\end{array}$ \\
\hline Participants & $\begin{array}{l}\text { COUNTRY: USA } \\
\text { SETTING: outpatient } \\
\text { NUMBER: randomised: AGI 102, CONTROL1 104, CONTROL2 104, CONTROL3 101, analysed: } \\
\text { AGI 85, CONTROL1 95, CONTROL2 92, CONTROL3 92 } \\
\text { SEX(F/M): analysed patients: AGIN24/61, CONTROL1 35/60, CONTROL2 33/59, CONTROL3 26/66 } \\
\text { AGE (YEARS (MEAN, SD)): analysed group: AGI 67,8 (5,5), CONTROL1 67,2 (5,8), CONTROL2 67,7 } \\
\text { (5,8), CONTROL3 68,5 (5,8) } \\
\text { DURATION OF DIABETES (MONTHS (MEAN, SD)): AGI 81,6 (88,8), CONTROL1 } 90(93,6) \text {, } \\
\text { CONTROL2 86,4 (92,4), CONTROL3 } 84(92,4)\end{array}$ \\
\hline Interventions & $\begin{array}{l}\text { Dietary reinforcement: yes, ADA approved diet }>=50 \% \text { carbohydrates } \\
\text { AGI: miglitol } 50 \mathrm{mg} \text { TID } \\
\text { CONTROL1: miglitol } 25 \mathrm{mg} \text { TID } \\
\text { CONTROL2: glyburide } 20 \mathrm{mg} \text { once daily, step up \& individually titrated: every } 2 \text { weeks increase: } \\
\text { 2,5/5/7,5/10/15/20 mg } \\
\text { CONTROL4: placebo TID and once daily }\end{array}$ \\
\hline$\overline{\text { Outcomes }}$ & $\begin{array}{l}\text { 1. Mortality: yes } \\
\text { 2. Diabetes related complications: yes } \\
\text { 3. Quality of life: ND } \\
\text { 4. Glycaemic control: glycated haemoglobin (HbA1c), fasting \& post-load blood glucose } \\
\text { 5. Lipids: triglycerides } \\
\text { 6. Insulin levels: fasting \& post-load insulin } \\
\text { 7. Weight: BMI } \\
\text { 8. Adverse effects: yes }\end{array}$ \\
\hline$\overline{\text { Notes }}$ & $\begin{array}{l}\text { Sponsor: pharmaceutical } \\
\text { Author contacted: Bayer replied that the data from this study was transferred to Pfizer. Pfizer didn't reply to } \\
\text { our requests do far. } \\
\text { Study retrieved: CENTRAL, MEDLINE, EMBASE, Current Contents }\end{array}$ \\
\hline Allocation concealment & $\mathrm{B}$ \\
\hline Study & Johnston 1998a \\
\hline Methods & $\begin{array}{l}\text { DESIGN: parallel study } \\
\text { RANDOMISATION PROCEDURE: unclear }\end{array}$ \\
\hline
\end{tabular}




\section{Characteristics of included studies (Continued)}

BLINDING: double-blind

DURATION: 52 weeks, main outcomes measured at 26 weeks

\begin{tabular}{|c|c|}
\hline Participants & $\begin{array}{l}\text { COUNTRY: USA } \\
\text { SETTING: outpatient } \\
\text { NUMBER: total randomised: AGI 254, CONTROL 131, diet only group } 55 \text { (AGI), } 14 \text { (CONTROL); } \\
\text { analysed: AGI 19, CONTROL } 10 \\
\text { SEX: no data for diet only group } \\
\text { AGE: no data for diet only group } \\
\text { DURATION OF DIABETES: no data for diet only group }\end{array}$ \\
\hline Interventions & $\begin{array}{l}\text { Dietary reinforcement: yes, at least } 50 \% \text { carbohydrates, intended to maintain weight. } \\
\text { AGI: miglitol } 50 \text { mg: when tolerant the patient increased the dose to 100/150/200 TID at wk 13/26 and } 39 \\
\text { respectively. Backtitration allowed (in case of intolerance). } \\
\text { CONTROL: placebo TID }\end{array}$ \\
\hline Outcomes & $\begin{array}{l}\text { 1. Mortality: ND } \\
\text { 2. Diabetes related complications: ND } \\
\text { 3. Quality of life: ND } \\
\text { 4. Glycaemic control: glycated haemoglobin }(\mathrm{HbAlc}) \\
\text { 5. Lipids: no data for diet only group } \\
\text { 6. Insulin levels: no data for diet only group } \\
\text { 7. Weight: no data for diet only group } \\
\text { 8. Adverse effects: yes }\end{array}$ \\
\hline$\overline{\text { Notes }}$ & $\begin{array}{l}\text { Sponsor: pharmaceutical } \\
\text { Author contacted: Bayer replied that the data from this study was transferred to Pfizer. Pfizer didn't reply to } \\
\text { our requests so far. } \\
\text { Study retrieved: CENTRAL, MEDLINE, EMBASE, Current Contents } \\
\text { Both patients using diet only and patients receiving additional sulphonylurea therapy were included in this } \\
\text { study. }\end{array}$ \\
\hline Allocation & $B$ \\
\hline
\end{tabular}

\begin{tabular}{ll} 
Study & Johnston $1998 \mathbf{b}$ \\
\hline Methods & DESIGN: parallel study \\
& RANDOMISATION PROCEDURE: unclear \\
& BLINDING: double-blind \\
& DURATION: 52 weeks, primary efficacy criterion measured at 28 weeks \\
\hline
\end{tabular}

\begin{tabular}{ll}
\hline Participants & COUNTRY: USA \\
& SETTING: outpatient \\
& NUMBER: total randomised: AGI 229, CONTROL 116; valid for efficacy diet only group: AGI 32, \\
& CONTROL 13; analysed for HbA1c: AGI 30, CONTROL 9 \\
& SEX (F/M): diet only group valid for efficacy: AGI 12/20, CONTROL 7/6 \\
& AGE (YEARS (MEAN, SD)): diet only group valid for efficacy: AGI 57,3 (10,2), CONTROL 54,9 (12,6) \\
& DURATION OF DIABETES (MONTHS (MEAN, SD)): diet only group valid for efficacy: AGI 57,6 \\
& (95,0), CONTROL 30 (38,9) \\
\hline Interventions & Dietary reinforcement: yes, overweight patients received counselling to produce gradual (1 lb./week) weight \\
& loss. \\
& AGI: miglitol, week 1-12 50 mg TID, week 12-52 100 mg TID. In case of intolerance to be decreased to \\
& 50 mg \\
& CONTROL: placebo TID \\
\hline Outcomes & 1. Mortality: ND \\
\hline Alpha-glucosidase inhibitors for type 2 diabetes mellitus (Review) \\
Copyright @2005 The Cochrane Collaboration. Published by John Wiley \& Sons, Ltd
\end{tabular}




\section{Characteristics of included studies (Continued)}

\begin{tabular}{l} 
3. Quality of life: ND \\
4. Glycaemic control: glycated haemoglobin (HbAlc) \\
5. Lipids: no data for diet only group \\
6. Insulin levels: no data for diet only group \\
7. Weight: no data for diet only group \\
8. Adverse effects: no data for diet only group \\
Sponsor: pharmaceutical \\
Author contacted: Bayer replied that the data from this study was transferred to Pfizer. Pfizer didn't reply to \\
our requests so far. \\
Study retrieved: CENTRAL, MEDLINE, EMBASE, Current Contents \\
Study among African-American patients. Both patients using diet only and patients receiving additional \\
sulphonylurea therapy were included in this study. \\
\hline Allocation concealment
\end{tabular}

\begin{tabular}{ll} 
Study & Kawamori $\mathbf{2 0 0 3}$ \\
\hline Methods & DESIGN: parallel study \\
& RANDOMISATION PROCEDURE: unclear \\
& BLINDING: double-blind \\
& DURATION: 12 weeks \\
\hline Participants & COUNTRY: Japan \\
& SETTING: unclear \\
& NUMBER: 445 patients enrolled, efficacy data for 396 patients (AGI1 158, AGI2 154, CONTROL 84) \\
& SEX: Data missing \\
& AGE: Data missing \\
& DURATION OF DIABETES: Data missing \\
\hline
\end{tabular}

\begin{tabular}{|c|c|}
\hline \multirow[t]{4}{*}{ Interventions } & Dietary reinforcement: unclear \\
\hline & AGI1: miglitol $50 \mathrm{mg}$ TID \\
\hline & AGI2: voglibose $0.2 \mathrm{mg}$ TID \\
\hline & CONTROL: placebo \\
\hline \multirow[t]{8}{*}{ Outcomes } & 1. Mortality: ND \\
\hline & 2. Diabetes related complications: ND \\
\hline & 3. Quality of life: ND \\
\hline & 4. Glycaemic control: glycated haemoglobin (HbA1c), fasting \& post-load blood glucose \\
\hline & 5. Lipids: ND \\
\hline & 6. Insulin levels: post-load insulin \\
\hline & 7. Weight: ND \\
\hline & 8. Adverse effects: yes \\
\hline \multirow[t]{4}{*}{ Notes } & Sponsor: not specified \\
\hline & Author contacted: no additional data before study was published as journal article \\
\hline & Study retrieved: handsearch \\
\hline & $\begin{array}{l}\text { Data extracted from a congress abstract and a copy of a poster presentation. Authors refused to give more } \\
\text { data before this study was published. }\end{array}$ \\
\hline Allocation concealment & $\mathrm{B}$ \\
\hline
\end{tabular}

\begin{tabular}{ll} 
Study & Kovacevic $\mathbf{1 9 9 7}$ \\
\hline Methods & DESIGN: parallel study \\
& RANDOMISATION PROCEDURE: unclear \\
BLINDING: double-blind with respect to acarbose and placebo, single blind with respect to glibenclamide & DURATION: 24 weeks \\
\hline \hline Alpha-glucosidase inhibitors for type 2 diabetes mellitus (Review) \\
Copyright @2005 The Cochrane Collaboration. Published by John Wiley \& Sons, Ltd
\end{tabular}




\begin{tabular}{|c|c|}
\hline \multicolumn{2}{|c|}{ Characteristics of included studies (Continued) } \\
\hline Participants & $\begin{array}{l}\text { COUNTRY: Croatia } \\
\text { SETTING: outpatient } \\
\text { NUMBER: randomised: AGI 34, CONTROL1 34, CONTROL2 34; analysed AGI 33, CONTROL1 31, } \\
\text { CONTROL2 } 33 \\
\text { SEX (F/M): total group 55/47; analysed AGI 16/17, CONTROL1 18/13, CONTROL2 20/13 } \\
\text { AGE (YEARS (MEAN, SD)): total group 57,5 (8,1), analysed AGI 58.42 (7.76), CONTROL1 } 59.35 \text { (8.61), } \\
\text { CONTROL2 54.73 (7.80) } \\
\text { DURATION OF DIABETES (MONTHS (MEAN)): total group } 54\end{array}$ \\
\hline Interventions & $\begin{array}{l}\text { Dietary reinforcement: yes, } 40-50 \% \text { carbohydrates, } 35-40 \% \text { fat, } 15 \% \text { protein } \\
\text { AGI: acarbose } 100 \mathrm{mg} \text { TID } \\
\text { CONTROL1: placebo TID } \\
\text { CONTROL2: glibenclamide } 3.5 \mathrm{mg} \text { adjusted individually, maximum TID }\end{array}$ \\
\hline Outcomes & $\begin{array}{l}\text { 1. Mortality: ND } \\
\text { 2. Diabetes related complications: ND } \\
\text { 3. Quality of life: ND } \\
\text { 4. Glycaemic control: glycated haemoglobin (HbAlc), fasting \& post-load blood-glucose } \\
\text { 5. Lipids: tot cholesterol, HDL and triglycerides } \\
\text { 6. Insulin levels: fasting \& post-load insulin } \\
\text { 7. Weight: BMI } \\
\text { 8. Adverse effects: yes }\end{array}$ \\
\hline Notes & $\begin{array}{l}\text { Sponsor: pharmaceutical } \\
\text { Author contacted: additional data on design, quality and outcomes send by author } \\
\text { Study retrieved: CENTRAL, EMBASE, manufacturer }\end{array}$ \\
\hline miment & \\
\hline
\end{tabular}

\begin{tabular}{|c|c|}
\hline Study & Meneilly 2000 \\
\hline Methods & $\begin{array}{l}\text { DESIGN: parallel study } \\
\text { RANDOMISATION PROCEDURE: unclear } \\
\text { BLINDING: double-blind } \\
\text { DURATION: } 12 \text { months }\end{array}$ \\
\hline Participants & $\begin{array}{l}\text { COUNTRY: Canada } \\
\text { SETTING: outpatient } \\
\text { NUMBER: AGI 93, CONTROL } 99 \\
\text { SEX (F/M): AGI 28/65, CONTROL } 39 / 60 \\
\text { AGE (YEARS (MEAN, SD)): AGI } 69.7(4,8) \text {, CONTROL } 70.3(5,0) \\
\text { DURATION OF DIABETES (MONTHS (MEAN, SD)): AGI 69,6 }(81,6) \text {, CONTROL } 57,6(60)\end{array}$ \\
\hline Interventions & $\begin{array}{l}\text { Dietary reinforcement: yes, advised to maintain diet to ensure that calorie intake was consistent throughout } \\
\text { the study. } \\
\text { AGI: acarbose, week 1: } 50 \mathrm{mg} \text { once daily, week } 2: 50 \mathrm{mg} \mathrm{BID} \text {, week } 3: 50 \mathrm{mg} \text { TID, week } 4-52 \text { titrated } \\
\text { upward to } 100 \mathrm{mg} \text { TID when post-load blood glucose > } 12 \mathrm{mmol} / \mathrm{l} \text {, downtitrated in case of intolerance. } \\
\text { CONTROL: placebo TID }\end{array}$ \\
\hline Outcomes & $\begin{array}{l}\text { 1. Mortality: ND } \\
\text { 2. Diabetes related complications: ND } \\
\text { 3. Quality of life: SF } 36 \& \text { Boyer quality of life rating instrument } \\
\text { 4. Glycaemic control: glycated haemoglobin (HbA1c), fasting \& post-load blood glucose } \\
\text { 5. Lipids: ND } \\
\text { 6. Insulin levels: fasting \& post-load insulin } \\
\text { 7. Weight: body weight } \\
\text { 8. Adverse effects: yes }\end{array}$ \\
\hline
\end{tabular}




\section{Characteristics of included studies (Continued)}

Notes

Sponsor: pharmaceutical

Author contacted: no reply

Study retrieved: CENTRAL, MEDLINE, EMBASE, Current Contents, manufacturer, handsearch

Study conducted in older patients

Allocation concealment B

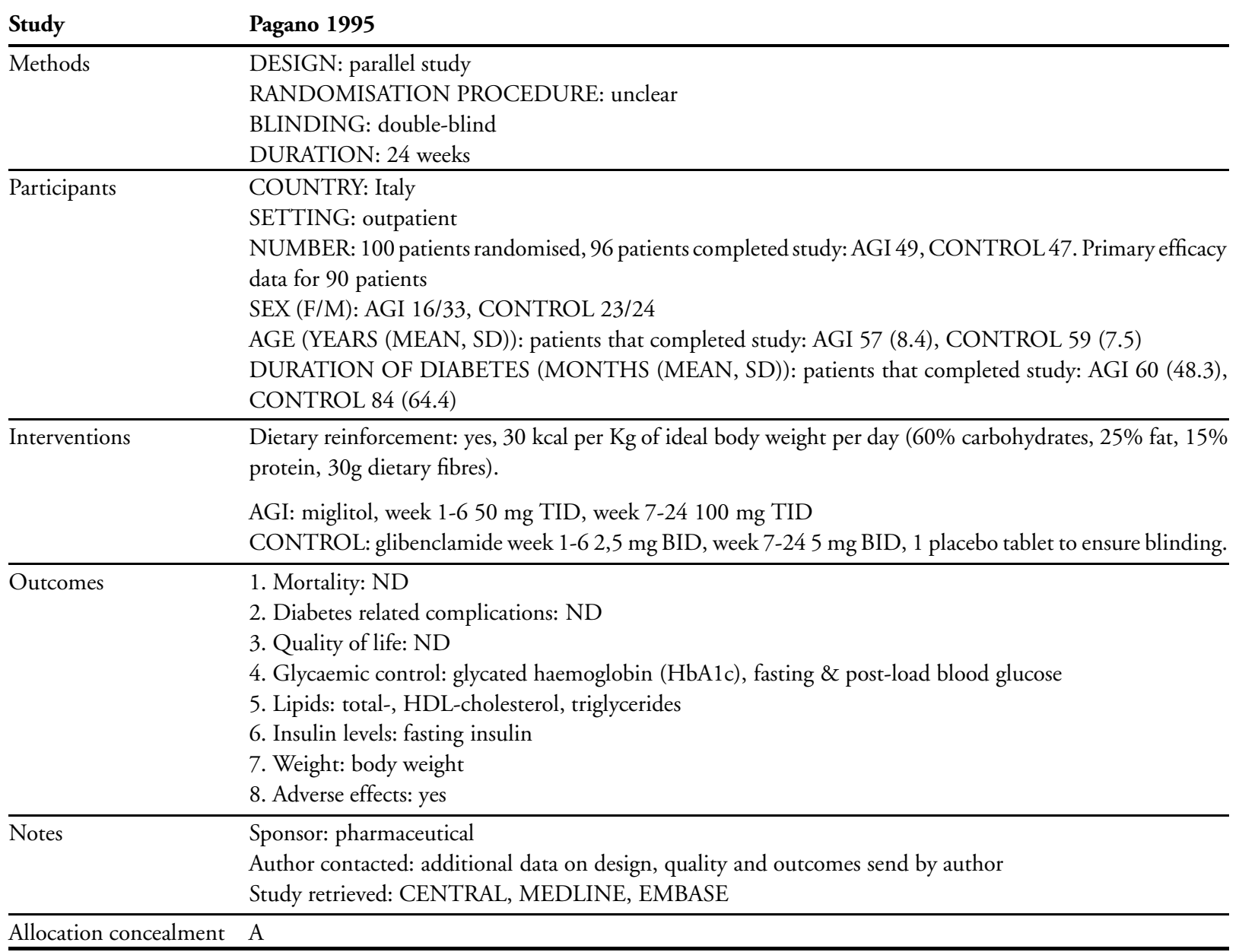

\begin{tabular}{ll} 
Study & Rosenthal $\mathbf{2 0 0 2}$ \\
\hline Methods & DESIGN: parallel study \\
& RANDOMISATION PROCEDURE: adequate \\
& BLINDING: no blinding \\
& DURATION: 24 weeks \\
\hline Participants & COUNTRY: Germany \\
& SETTING: general practice \\
& NUMBER: selected: AGI 39, CONTROL 37, analysed: AGI 32, CONTROL 31 \\
& SEX: data missing \\
& AGE (YEARS (MEAN, SD)): AGI 57.4 (8.6), CONTROL 57.7 (10.5) \\
& DURATION OF DIABETES (MONTHS (MEAN, SD)): AGI 20.2 (31.2), CONTROL 35.6 (44.8) \\
\hline Dietary reinforcement: no \\
AGI: acarbose, 50 mg TID, uptitrated to 100 mg TID (exact scheme not reported)
\end{tabular}




\section{Characteristics of included studies (Continued)}

CONTROL: glibenclamide, maximum $10.5 \mathrm{mg}$ daily $(7 \mathrm{mg}-0-3.5 \mathrm{mg})$, step-up scheme as long as fasting blood glucose remained $>8.9 \mathrm{mmol} / \mathrm{l}$

\begin{tabular}{|c|c|}
\hline Outcomes & $\begin{array}{l}\text { 1. Mortality: ND } \\
\text { 2. Diabetes related complications: ND } \\
\text { 3. Quality of life: ND } \\
\text { 4. Glycaemic control: glycated haemoglobin (HbA1c), fasting \& post-load blood-glucose } \\
\text { 5. Lipids: total cholesterol, HDL, triglycerides } \\
\text { 6. Insulin levels: fasting \& post-load insulin } \\
\text { 7. Weight: body weight, BMI } \\
\text { 8. Adverse effects: yes }\end{array}$ \\
\hline Notes & $\begin{array}{l}\text { Sponsor: pharmaceutical } \\
\text { Author contacted: additional data on design, quality and outcomes via manufacturer } \\
\text { Study retrieved: EMBASE, Current Contents, manufacturer, ( } 2 \text { additional references via authors) } \\
\text { Main outcome is blood pressure. } \\
\text { According to the statistical report, the changes for lipids are calculated with standardised values (using a } \\
\text { linear transformation to the interval [0,1] with respect to normal range), and therefore cannot be used for } \\
\text { the meta-analysis. }\end{array}$ \\
\hline Allocation concealment & $\mathrm{B}$ \\
\hline Study & Rybka 1999 \\
\hline Methods & $\begin{array}{l}\text { DESIGN: parallel study } \\
\text { RANDOMISATION PROCEDURE: unclear } \\
\text { BLINDING: double-blind } \\
\text { DURATION: } 24 \text { weeks }\end{array}$ \\
\hline Participants & $\begin{array}{l}\text { COUNTRY: multiple European countries, not further specification } \\
\text { SETTING: unclear } \\
\text { NUMBER: } 603 \text { patients included } \\
\text { SEX: data missing } \\
\text { AGE: data missing } \\
\text { DURATION OF DIABETES: data missing }\end{array}$ \\
\hline Interventions & $\begin{array}{l}\text { Dietary reinforcement: yes, specifications unclear } \\
\text { AGI: acarbose } 100 \mathrm{mg} \text { TID } \\
\text { CONTROL1: placebo } \\
\text { CONTROL2: miglitol } 50 \mathrm{mg} \text { TID } \\
\text { CONTROL3: miglitol } 100 \mathrm{mg} \text { TID }\end{array}$ \\
\hline Outcomes & $\begin{array}{l}\text { 1. Mortality: ND } \\
\text { 2. Diabetes related complications: ND } \\
\text { 3. Quality of life: ND } \\
\text { 4. Glycaemic control: glycated haemoglobin (HbA1c), fasting \& post-load blood glucose } \\
\text { 5. Lipids: ND } \\
\text { 6. Insulin levels: ND } \\
\text { 7. Weight: body weight } \\
\text { 8. Adverse effects: yes }\end{array}$ \\
\hline
\end{tabular}

\begin{tabular}{ll}
\hline Notes & Sponsor: pharmaceutical \\
& Author contacted: no reply \\
& Study retrieved: handsearch \\
& Published as an abstract. A non-systematic review on miglitol cited this study also as an unpublished document \\
& (Scott 2000). Bayer referred to Pfizer being the current owner of this data, but wen received no reply from \\
& Pfizer so far. \\
\hline
\end{tabular}




\section{Characteristics of included studies (Continued)}

Allocation concealment $\mathrm{B}$

\begin{tabular}{|c|c|}
\hline Study & Salman 2001 \\
\hline Methods & $\begin{array}{l}\text { DESIGN: parallel study } \\
\text { RANDOMISATION PROCEDURE: adequate } \\
\text { BLINDING: no blinding } \\
\text { DURATION: } 24 \text { weeks }\end{array}$ \\
\hline Participants & $\begin{array}{l}\text { COUNTRY: Turkey } \\
\text { SETTING: outpatient } \\
\text { NUMBER: randomised 72; analysed: AGI 27, CONTROL } 30 \\
\text { SEX (F/M): analysed patients: AGI 10/17, CONTROL 14/16 } \\
\text { AGE (YEARS (MEAN, SD)): analysed group: AGI 52,6 }(9,1) \text {, CONTROL 56,1 }(8,7) \\
\text { DURATION OF DIABETES (MONTHS (MEAN, SD)): analysed group: AGI 50,4 }(40,8) \text {, CONTROL } \\
56,4(67,2)\end{array}$ \\
\hline Interventions & $\begin{array}{l}\text { Dietary reinforcement: patients under dietary recommendations for at least } 3 \text { months, controlled for diet } \\
\text { compliance before study inclusion. } \\
\text { AGI: acarbose, week } 1 \text { to } 4 \text { every week } 50 \mathrm{mg} \text { increase to } 100 \mathrm{mg} \text { BID, week } 4-24100 \mathrm{mg} \text { TID, dose reduced } \\
\text { to } 100 \mathrm{mg} \text { BID in case of adverse events } \\
\text { CONTROL: gliclazide maximum } 80 \mathrm{mg} \text { BID, depending on degree of glycemic control; in general maximum } \\
\text { dose was not recommended }\end{array}$ \\
\hline Outcomes & $\begin{array}{l}\text { 1. Mortality: ND } \\
\text { 2. Diabetes related complications: ND } \\
\text { 3. Quality of life: ND } \\
\text { 4. Glycaemic Control: glycated haemoglobin (HbAlc), fasting \& post-load blood glucose } \\
\text { 5. Lipids: triglycerides, total-, HDL- \& LDL-cholesterol } \\
\text { 6. Insulin levels: fasting \& post-load insulin, fasting \& post-load C-peptide } \\
\text { 7. Weight: body weight, BMI } \\
\text { 8. Adverse effects: yes }\end{array}$ \\
\hline$\overline{\text { Notes }}$ & $\begin{array}{l}\text { Sponsor: pharmaceutical } \\
\text { Author contacted: additional data on design, quality and outcomes send by author } \\
\text { Study retrieved: CENTRAL, MEDLINE, EMBASE, Current Contents, manufacturer }\end{array}$ \\
\hline location concealment & A \\
\hline
\end{tabular}

\begin{tabular}{ll} 
Study & Santeusanio $\mathbf{1 9 9 3}$ \\
\hline Methods & DESIGN: parallel study \\
& RANDOMISATION PROCEDURE: adequate \\
& BLINDING: double-blind \\
& DURATION: 16 weeks \\
\hline Participants & COUNTRY: Italy \\
& SETTING: outpatient \\
& NUMBER: randomised: AGI 27, CONTROL1 29, CONTROL2 28; evaluated in ITT-analysis: AGI 23, \\
& CONTROL1 23, CONTROL2 18 \\
& SEX (F/M): ITT: AGI 8/15, CONTROL1 7/16, CONTROL2 8/10 \\
& AGE (YEARS (MEAN, SD)): ITT: AGI 53,8 (11,0), CONTROL1 55,5 (11,5), CONTROL2 58,9 (9,8) \\
& DURATION OF DIABETES (MONTHS (MEAN, SD)): ITT: AGI 60,6 (57,6), CONTROL1 46,4 (51,6), \\
& CONTROL2 46,4 (36,0)
\end{tabular}

Interventions Dietary reinforcement: yes, iso-caloric diet to maintain stable body weight $(50-55 \%$ carbohydrates, $<30 \%$ lipids, $15-20 \%$ protein and $<10 \mathrm{~g} / 1000 \mathrm{kcal}$ as fibre).

AGI: acarbose m100 mg TID 


\section{Characteristics of included studies (Continued)}

CONTROL1: placebo TID

CONTROL2: acarbose $50 \mathrm{mg}$ TID

\begin{tabular}{|c|c|}
\hline Outcomes & $\begin{array}{l}\text { 1. Mortality: ND } \\
\text { 2. Diabetes related complications: ND } \\
\text { 3. Quality of life: ND } \\
\text { 4. Glycaemic control: glycated haemoglobin (HbAlc), fasting \& post-load blood glucose } \\
\text { 5. Lipids: ND } \\
\text { 6. Insulin levels: fasting \& post-load insulin } \\
\text { 7. Weight: ND } \\
\text { 8. Adverse effects: yes }\end{array}$ \\
\hline Notes & $\begin{array}{l}\text { Sponsor: pharmaceutical } \\
\text { Author contacted: additional data on design, quality and outcomes via manufacturer } \\
\text { Study retrieved: CENTRAL, MEDLINE, EMBASE, Current Contents, manufacturer, handsearch }\end{array}$ \\
\hline Allocation concealment & $\mathrm{B}$ \\
\hline Study & Scott 1999 \\
\hline Methods & $\begin{array}{l}\text { DESIGN: parallel study } \\
\text { RANDOMISATION PROCEDURE: unclear } \\
\text { BLINDING: double-blind } \\
\text { DURATION: } 16 \text { weeks }\end{array}$ \\
\hline Participants & $\begin{array}{l}\text { COUNTRY: New Zealand / Australia } \\
\text { SETTING: outpatient } \\
\text { NUMBER: AGI 53, CONTROL } 52 \\
\text { SEX (F/M): AGI 20/33, CONTROL 18/34 } \\
\text { AGE (YEARS (MEAN, SD)): AGI } 56 \text { (9), CONTROL 57 (8) } \\
\text { DURATION OF DIABETES (MONTHS (MEAN, SD)): AGI } 21 \text { (15), CONTROL } 26 \text { (17) }\end{array}$ \\
\hline Interventions & $\begin{array}{l}\text { Dietary reinforcement: yes, 'conforming to current recommendations for type } 2 \text { diabetes' } \\
\text { AGI: acarbose, week 1-2 } 50 \mathrm{mg} \text { TID, wk 3-16 } 100 \mathrm{mg} \text { TID, dose reduced to } 50 \mathrm{mg} \text { TID in case of adverse } \\
\text { events } \\
\text { CONTROL: placebo TID }\end{array}$ \\
\hline$\overline{\text { Outcomes }}$ & $\begin{array}{l}\text { 1. Mortality: ND } \\
\text { 2. Diabetes related complications: ND } \\
\text { 3. Quality of life: ND } \\
\text { 4. Glycaemic control: glycated haemoglobin (HbA1c), fasting blood glucose } \\
\text { 5. Lipids: triglycerides, total- and HDL-cholesterol } \\
\text { 6. Insulin levels: fasting insulin } \\
\text { 7. Weight: ND } \\
\text { 8. Adverse effects: yes }\end{array}$ \\
\hline$\overline{\text { Notes }}$ & $\begin{array}{l}\text { Sponsor: pharmaceutical } \\
\text { Author contacted: author replied that he passed our queries through to Bayer Australia, but we received no } \\
\text { reply from Bayer Australia since. } \\
\text { Study retrieved: CENTRAL, MEDLINE, EMBASE, Current Contents }\end{array}$ \\
\hline & $\mathrm{A}$ \\
\hline
\end{tabular}

\begin{tabular}{ll} 
Study & Segal $\mathbf{1 9 9 7}$ \\
\hline Methods & DESIGN: parallel study \\
& RANDOMISATION PROCEDURE: unclear \\
& BLINDING: double-blind \\
& DURATION: 24 weeks \\
\hline Alpha-glucosidase inhibitors for type 2 diabetes mellitus (Review)
\end{tabular}




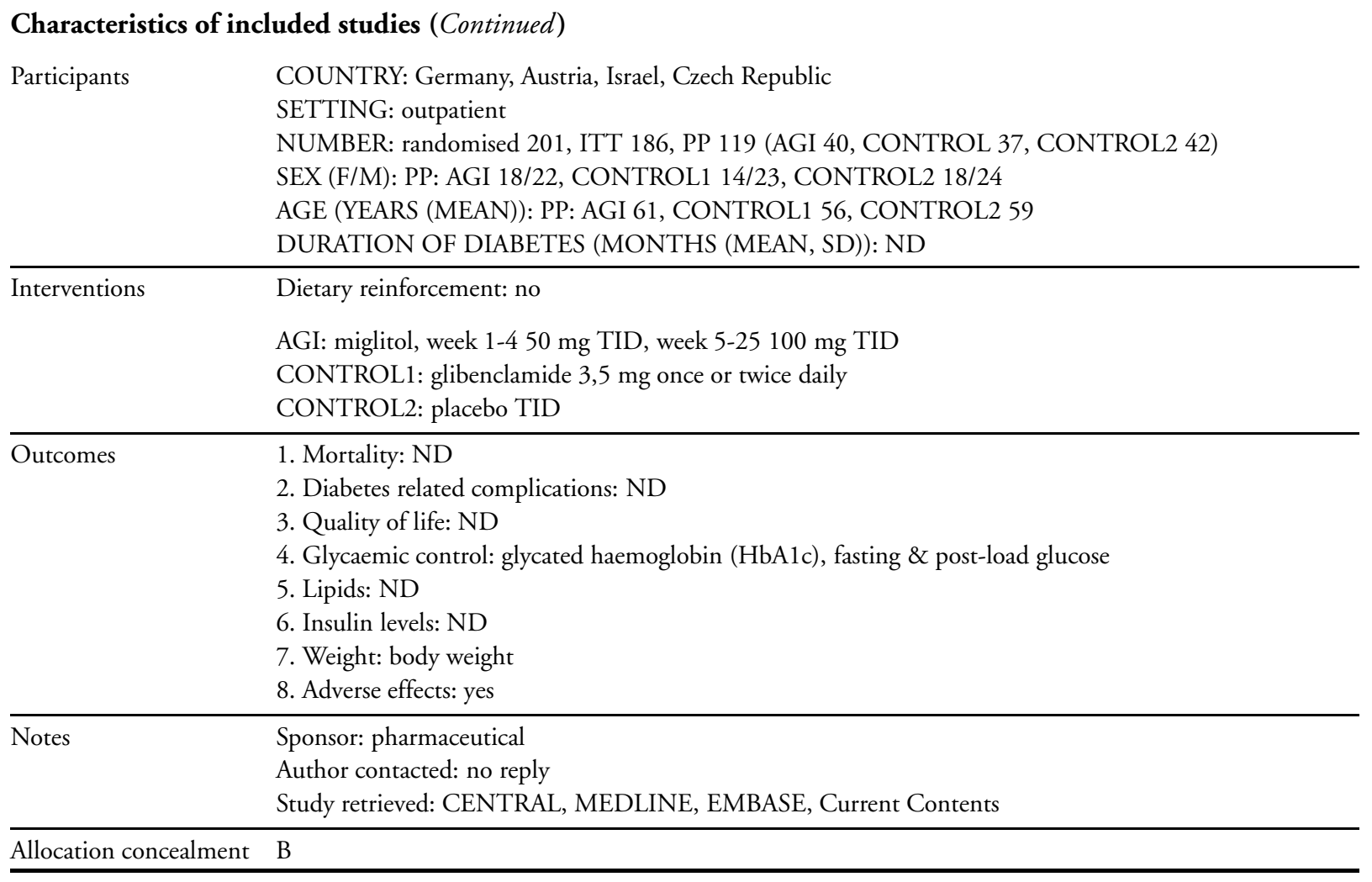

\begin{tabular}{|c|c|}
\hline Study & Spengler 1992 \\
\hline Methods & $\begin{array}{l}\text { DESIGN: Parallel study } \\
\text { RANDOMISATION PROCEDURE: adequate } \\
\text { BLINDING: no blinding } \\
\text { DURATION: } 24 \text { weeks }\end{array}$ \\
\hline Participants & $\begin{array}{l}\text { COUNTRY: Germany } \\
\text { SETTING: outpatient } \\
\text { NUMBER: randomised 72, analysed: AGI 26, CONTROL } 29 \\
\text { SEX (F/M): AGI 15/11, CONTROL 18/11 } \\
\text { AGE (YEARS (MEAN, SD)): analysed: AGI } 59 \text { (5), CONTROL } 60 \text { (7) } \\
\text { DURATION OF DIABETES (MONTHS (MEDIAN)): analysed: AGI 12.0, CONTROL } 8.4\end{array}$ \\
\hline Interventions & $\begin{array}{l}\text { Dietary reinforcement: unclear } \\
\text { AGI: acarbose, week 1-2 } 50 \mathrm{mg} \text { TID, week 3-24 } 100 \mathrm{mg} \text { TID } \\
\text { CONTROL: glibenclamide maximum 3,5 mg TID }\end{array}$ \\
\hline Outcomes & $\begin{array}{l}\text { 1. Mortality: ND } \\
\text { 2. Diabetes related complications: ND } \\
\text { 3. Quality of life: ND } \\
\text { 4. Glycaemic control: glycated haemoglobin (HbA1c), fasting \& post-load blood glucose } \\
\text { 5. Lipids: ND } \\
\text { 6. Insulin levels: ND } \\
\text { 7. Weight: body weight } \\
\text { 8. Adverse effects: yes }\end{array}$ \\
\hline Notes & $\begin{array}{l}\text { Sponsor: pharmaceutical } \\
\text { Author contacted: additional data on design, quality and outcomes via manufacturer } \\
\text { Study retrieved: CENTRAL, MEDLINE, EMBASE, experts ( } 1 \text { additional reference via author) }\end{array}$ \\
\hline
\end{tabular}




\section{Characteristics of included studies (Continued)}

For all outcomes except body weight, geometric means are reported; true means not available from articles and statistical reports.

Allocation concealment $\mathrm{B}$

Study

Methods

Takami 2002

DESIGN: parallel study

RANDOMISATION PROCEDURE: unclear

BLINDING: no blinding

DURATION: 3 months

Participants

COUNTRY: Japan

SETTING: outpatient

NUMBER: Analysed: AGI 12, CONTROL1 11, CONTROL2 9

SEX (F/M): AGI 3/9, CONTROL1 4/7, CONTROL2 3/10

AGE (YEARS (MEAN, SD)): total group $(\mathrm{n}=36$ !) men 48,7 (8,3), women 55,0 $(7,8)$

DURATION OF DIABETES: Newly diagnosed patients

Intervention

Dietary reinforcement: yes, $30 \mathrm{kcal} / \mathrm{Kg}$ of ideal body weight per day, $60 \%$ carbohydrate, $20 \%$ fat, $20 \%$ protein.

AGI: voglibose $0,3 \mathrm{mg}$ TID

CONTROL1: diet therapy

CONTROL2: glyburide $1,25 \mathrm{mg}$ once daily

\begin{tabular}{ll}
\hline Outcomes & 1. Mortality: ND \\
& 2. Diabetes related complications: ND \\
3. Quality of life: ND & 4. Glycaemic control: glycated haemoglobin (HbA1c), fasting bloodglucose \\
& 5. Lipids: Total \& HDL-cholesterol, triglycerides \\
& 6. Insulin levels: fasting insulin \\
& 7. Weight: weight \& BMI \\
& 8. Adverse effects: ND \\
& Sponsor: not specified \\
& Author contacted: no reply \\
& Study retrieved: CENTRAL, MEDLINE, Current Contents, handsearch \\
& 36 'study subjects', 32 randomised and 4 patients assigned to diet group after random phase to 'facilitate \\
& analysis of correlations between the changes in abdominal adipose tissue and glycemic control with diet'. \\
\hline Allocation concealment & B \\
\hline
\end{tabular}

\begin{tabular}{ll} 
Study & Van de Laar 2004a \\
\hline Methods & DESIGN: Parallel study RANDOMISATION PROCEDURE: adequate BLINDING: double-blind DU- \\
& RATION: 30 weeks \\
\hline Participants & COUNTRY: The Netherlands SETTING: general practice NUMBER: randomised: AGI 48, CONTROL \\
& 48, ITT: AGI 32, CONTROL 43 SEX (F/M): ITT: AGI 16/16, CONTROL 20/23 AGE (YEARS (MEAN, \\
& SD)): ITT: AGI 58.6 (7.7), CONTROL 58.6 (7.1) DURATION OF DIABETES (MONTHS (MEDIAN)): \\
& analysed: AGI 12.0, CONTROL 8.4
\end{tabular}

Interventions

Dietary reinforcement: yes, advice tailored to individual food habits by dietician with access to current recommendations AGI: acarbose, maximum dosage schedule at week 0, 2, 4 and 6-30 was (mg): 50 - 0 0, 50 - 0 - 50, 50 - 50 - 50 and $100-100-100$ respectively CONTROL: tolbutamide, maximum dosage schedule at week 0, 2, 4 and 6-30 (mg) was $500-0-0,500-0-500,500-500-500$ and $1000-500-500$ respectively.

Alpha-glucosidase inhibitors for type 2 diabetes mellitus (Review)

Copyright @2005 The Cochrane Collaboration. Published by John Wiley \& Sons, Ltd 


\section{Characteristics of included studies (Continued)}

Outcomes 1. Mortality: ND 2. Diabetes related complications: ND 3. Quality of Life: ND 4. Glycaemic Control: glycated haemoglobin (HbA1c), fasting \& post-load blood glucose 5. Lipids: triglycerides, total-, LDL- \& HDL-cholesterol 6. Insulin levels: fasting \& post-load insulin 7. Weight: BMI 8. Adverse effects: yes

\begin{tabular}{|c|c|}
\hline Notes & $\begin{array}{l}\text { Sponsor: pharmaceutical Author contacted: data possessed by authors review Study retrieved: experts Equiv- } \\
\text { alence study }\end{array}$ \\
\hline Allocation concealment & A \\
\hline Study & Zheng 1995 \\
\hline Methods & $\begin{array}{l}\text { DESIGN: parallel study } \\
\text { RANDOMISATION PROCEDURE: unclear } \\
\text { BLINDING: double-blind } \\
\text { DURATION: } 24 \text { weeks }\end{array}$ \\
\hline Participants & $\begin{array}{l}\text { COUNTRY: China } \\
\text { SETTING: outpatient } \\
\text { NUMBER: AGI 39, CONTROL } 38 \\
\text { SEX (F/M): AGI 19/20, CONTROL 18/20 } \\
\text { AGE (YEARS (MEAN, SD)): AGI } 49.6 \text { (6.9), CONTROL } 49.0(6.6) \\
\text { DURATION OF DIABETES (MONTHS (MEAN, SD)): AGI 49.2 (33.6), CONTROL } 50.4 \text { (43.2) }\end{array}$ \\
\hline$\overline{\text { Interventions }}$ & $\begin{array}{l}\text { Dietary reinforcement: unclear ('diet and level of activity had to remain stable) } \\
\text { AGI: acarbose, week 1-3 } 50 \mathrm{mg} \text { TID, wk 4-24 } 100 \mathrm{mg} \text { TID } \\
\text { CONTROL: placebo }\end{array}$ \\
\hline Outcomes & $\begin{array}{l}\text { 1. Mortality: ND } \\
\text { 2. Diabetes related complications: ND } \\
\text { 3. Quality of life: ND } \\
\text { 4. Glycaemic control: glycated haemoglobin (HbA1c), fasting \& post-load blood glucose } \\
\text { 5. Lipids: triglycerides, total- and HDL-cholesterol } \\
\text { 6. Insulin levels: fasting \& post-load insulin } \\
\text { 7. Weight: BMI } \\
\text { 8. Adverse effects: yes }\end{array}$ \\
\hline$\overline{\text { Notes }}$ & $\begin{array}{l}\text { Sponsor: pharmaceutical } \\
\text { Author contacted: no reply } \\
\text { Study retrieved: CENTRAL }\end{array}$ \\
\hline Allocation concealment & $\mathrm{B}$ \\
\hline \multicolumn{2}{|c|}{$\begin{array}{l}\mathrm{BID}=\text { two times per day; } \mathrm{BMI}=\text { body mass index } \\
\text { lipoprotein; ITT = intention-to-treat analysis; LD } \\
=\text { three times per day, } \\
\text { For interventions the maximum dosage is given } \\
\text { For outcomes: Outome measures that are reporte }\end{array}$} \\
\hline
\end{tabular}

\section{Characteristics of excluded studies}

\begin{tabular}{ll}
\hline Bachmann 2003 & Use of additional anti-diabetic medication \\
\hline Bayer 2003 & Use of additional anti-diabetic medication \\
\hline Bayer 2003a & Use of additional anti-diabetic medication, included patients with type 1 and type 2 diabetes \\
\hline Coniff 1995a & $\begin{array}{l}\text { Falsely included on basis of Embase search (excluded from Medline search) acarbose given as additional therapy } \\
\text { (added to insulin therapy) }\end{array}$ \\
\hline De Leiva 1993 & Use of additional anti-diabetic medication, reported data does not allow subgroup analysis of AGI only group \\
\hline $\begin{array}{l}\text { Alpha-glucosidase inhibitors for type 2 diabetes mellitus (Review) } \\
\text { Copyright @2005 The Cochrane Collaboration. Published by John Wiley \& Sons, Ltd }\end{array}$
\end{tabular}




\section{Characteristics of excluded studies (Continued)}

Escobar-Jimenez 1995 Use of additional anti-diabetic medication, reported data does not allow subgroup analysis of AGI only group Fujita $2001 \quad$ Use of additional anti-diabetic medication, reported data does not allow subgroup analysis of AGI only group

Hasche $1999 \quad$ Use of additional medication, reported data does not allow subgroup analysis of AGI only group

\begin{tabular}{ll}
\hline Holman 1991 & Duration of AGI treatment $<12 \mathrm{wk}(4 \mathrm{wk})$ \\
\hline Ikeda 1998 & Use of additional anti-diabetic medication, reported data does not allow subgroup analysis of AGI only group \\
\hline Jenney 1993 & No randomisation; Acarbose not given as monotherapy \\
\hline Rosak 2002 & Study duration < 12 wk (1 day) \\
\hline Rosenbaum 2002 & Us of additional anti-diabetic medication, reported data does not allow subgroup analysis of AGI only group \\
\hline Soonthornpun 1998 & Use of additional anti-diabetic medication \\
\hline Wang 2000 & Patients with impaired glucose tolerance (in stead of type 2 diabetes mellitus) \\
\hline
\end{tabular}

\section{Characteristics of ongoing studies}

\begin{tabular}{|c|c|}
\hline Study & Holman 2003 \\
\hline Trial name or title & Early Diabetes Intervention Study (EDIT) \\
\hline Participants & $\begin{array}{l}\text { Subjects were selected on the basis of two consecutive fasting plasma glucose values of } 5.5 \text { to } 7.7 \mathrm{mmol} / \mathrm{l} \text {. They } \\
\text { all underwent OGTTs at entry into the study but if the } 2 \text {-h glucose was found to be in the diabetic range (i.e. } \\
11.1 \text { or above) they were not excluded, provided that the fasting remained below } 7.8 \mathrm{mmol} / \mathrm{l} \text {. }\end{array}$ \\
\hline Interventions & $\begin{array}{l}\text { Acarbose (50mg TID), metformin (500mg TID) and placebo; Design: prospective, parallel group, double blind, } \\
\text { double dummy, randomised, factorial design, multicentre study; Duration } 6 \text { years }\end{array}$ \\
\hline Outcomes & Progression to frank diabetes; Glycaemic reduction \\
\hline Starting date & 01 / 04 / 1998; end date: 30 / 04 / 2003 \\
\hline Contact information & $\begin{array}{l}\text { Dr Rury Holman } \\
\text { Diabetes Research Laboratories } \\
\text { Radcliffe Infirmary } \\
\text { Woodstock Rd } \\
\text { Oxford } \\
\text { OX2 6HE } \\
\text { UK } \\
\text { rury.holman@dtu.ox.ac.uk }\end{array}$ \\
\hline Notes & $\begin{array}{l}\text { A subgroup of } 106 \text { patients had postprandial blood glucose in the diabetic range }(>11.1 \mathrm{mmol} / \mathrm{l} \text {, but fasting } \\
\text { blood glucose }<7.8 \mathrm{mmol} / \mathrm{l}) \text {. Data from this sub-group might be possible included in the review }\end{array}$ \\
\hline Study & Sa-adu 2003 \\
\hline Trial name or title & $\begin{array}{l}\text { A one-year multicentre, international, randomised, double-blind comparison of } \\
\text { Mitiglinide (10to } 40 \mathrm{mgTID}) \text { and Acarbose (50mgODto100mgTID) administered orally for the treatment of } \\
\text { elderly type } 2 \text { diabetic patients }\end{array}$ \\
\hline Participants & Elderly type 2 diabetic patients suboptimally controlled with diet alone. \\
\hline Interventions & $\begin{array}{l}\text { Mitiglinide (10 to } 40 \mathrm{mg} \text { TID) and Acarbose ( } 50 \mathrm{mg} \text { OD to } 100 \mathrm{mg} \text { TID); Design: comparative, randomised, } \\
\text { double blind, parallel group phase III }\end{array}$ \\
\hline Outcomes & HbA1c \\
\hline Starting date & $01 / 12$ / 2--1; end date: $01 / 06 / 2003$ \\
\hline Contact information & $\begin{array}{l}\text { Prof Alan Sinclair, The University of Warwick; Dr Alfa Sa-adu } \\
\text { Care of the Elderly }\end{array}$ \\
\hline
\end{tabular}




\section{Characteristics of ongoing studies (Continued)}

\begin{tabular}{|c|c|}
\hline & $\begin{array}{l}\text { Watford General Hospital } \\
\text { Vicarage Road } \\
\text { Watford } \\
\text { Herts } \\
\text { WD18 0HB } \\
\text { UK } \\
\text { Telephone: } 01923217227 \\
\text { E-mail: a.saadu.btinternet.com }\end{array}$ \\
\hline Notes & $\begin{array}{l}\text { Two e-mails to prof. Sinclair were not answered. Dr Sa-adu replied that he was not a contributor to this study } \\
\text { and that recruitment was taken to East European Countries. }\end{array}$ \\
\hline Study & Whitby 1998 \\
\hline Trial name or title & $\begin{array}{l}\text { A long-term study to investigate the effects of acarbose (glucobay) in } \\
\text { preventing or delaying deterioration in glycaemic status in non-insulin diabetes } \\
\text { will controlled on diet alone. }\end{array}$ \\
\hline Participants & Non-insulin dependent diabetics, either newly diagnosed or well controlled on diet alone. \\
\hline Interventions & Acarbose versus placebo \\
\hline Outcomes & Not specified \\
\hline Starting date & 28 / 09 / 1993; end date: $31 / 07 / 1996$ \\
\hline Contact information & $\begin{array}{l}\text { Dr Robert E J Ryder } \\
\text { Department of Diabetes } \\
\text { City Hospital } \\
\text { Dudley Road } \\
\text { Birmingham } \\
\text { West Midlands } \\
\text { B18 7QH } \\
\text { England } \\
\text { Telephone: } 01215543801 \\
\text { Dr R J Whitby } \\
\text { Linden Medical Centre } \\
\text { Linden Ave } \\
\text { Kettering } \\
\text { NN15 7NX } \\
\text { Northants }\end{array}$ \\
\hline Notes & $\begin{array}{l}\text { Dr Ryder and dr. Whitby were contacted. Dr Ryder referred to prof. Holman as leading investigator, but } \\
\text { Professor Holman did not reply to our e-mails regarding questions about this study. }\end{array}$ \\
\hline
\end{tabular}

TID $=$ three times per day

A D D I T I O AL TABLES

Table 01. Methods post-load glucose / insulin measurement

\begin{tabular}{lllll} 
Study & Type of test & Interval & Data used & Medication given? \\
Braun 1996 & $\begin{array}{l}\text { Breakfast ('no special } \\
\text { meals') }\end{array}$ & 1 hour & 1 hour glucose & unclear \\
Buchanan 1988 & No post-load test & & & \\
\hline
\end{tabular}


Table 01. Methods post-load glucose / insulin measurement (Continued)

\begin{tabular}{|c|c|c|c|c|}
\hline Study & Type of test & Interval & Data used & Medication given? \\
\hline Calle-Pascual 1996 & No post-load test & & & \\
\hline Campbell 1998 & No post-load test & & & \\
\hline Chan 1998 & $\begin{array}{l}\text { Individually tailored } \\
\text { meal recommended } \\
\text { by dietician }(60 \% \\
\text { carbohydrate, }<30 \% \text { fat, } \\
12-20 \% \text { protein })\end{array}$ & 1 hour & 1 hour glucose $\&$ insulin & $\begin{array}{l}\text { yes (at least at } 24 \text { weeks } \\
\text { measurement) }\end{array}$ \\
\hline Chiasson 1994 & $\begin{array}{l}\text { Standard breakfast: } 450 \\
\text { kcal, } 55 \% \text { carbohydrates, } \\
30.5 \% \text { lipids, } 14.5 \% \\
\text { protein }\end{array}$ & $\begin{array}{l}1,1.5 \text { and } 2 \text { hours } \\
\text { measured }\end{array}$ & Data not reported & yes \\
\hline Chiasson 2001 & $\begin{array}{l}\text { Standardised liquid } \\
\text { test breakfast }(55 \% \\
\text { carbohydrate, } 30 \% \\
\text { fat, and } 15 \% \text { protein; } \\
\text { providing }-450 \mathrm{kcal})\end{array}$ & $\begin{array}{l}1,1.5 \text { and } 2 \text { hours } \\
\text { measured and reported }\end{array}$ & $\begin{array}{l}1 \text { hour ( } 2 \text { hours value } \\
\text { in sensitivity analysis) } \\
\text { glucose } \& \text { insulin }\end{array}$ & yes \\
\hline Coniff 1994 & $\begin{array}{l}\text { Breakfast, } 2520 \mathrm{~kJ} \text {, with } \\
50 \% \text { carbohydrates, } 30 \% \\
\text { fat, } 20 \% \text { protein. }\end{array}$ & $\begin{array}{l}1,1.5 \text { and } 2 \text { hours } \\
\text { measured and reported }\end{array}$ & $\begin{array}{l}1 \text { hour ( } 2 \text { hours value } \\
\text { in sensitivity analysis) } \\
\text { glucose }\end{array}$ & yes \\
\hline Coniff 1995 & $\begin{array}{l}\text { Full-meal tolerance test: } \\
600 \text { kcal breakfast }(50 \% \\
\text { carbohydrate, } 30 \% \text { fat, } \\
20 \% \text { protein }\end{array}$ & $\begin{array}{l}1,1.5 \text { and } 2 \text { hours } \\
\text { measured and reported }\end{array}$ & $\begin{array}{l}1 \text { hour ( } 2 \text { hours value } \\
\text { in sensitivity analysis) } \\
\text { glucose } \& \text { insulin }\end{array}$ & yes \\
\hline Coniff 1995b & $\begin{array}{l}\text { Standardised meal } \\
\text { tolerance test, } 600- \\
\text { kcal breakfast of } 50 \% \\
\text { carbohydrates }(75 \mathrm{~g}), 30 \% \\
\text { fat }(20 \mathrm{~g}), 20 \% \text { protein } \\
(30 \mathrm{~g})\end{array}$ & $\begin{array}{l}1,1.5 \text { and } 2 \text { hours } \\
\text { measured and reported }\end{array}$ & $\begin{array}{l}1 \text { hour ( } 2 \text { hours value } \\
\text { in sensitivity analysis) } \\
\text { glucose } \& \text { insulin }\end{array}$ & yes \\
\hline Dedov 1995 & $\begin{array}{l}\text { Post-load test performed, } \\
\text { type of test unclear }\end{array}$ & 1 hour & 1 hour glucose & unclear \\
\hline Delgado 2002 & $\begin{array}{l}\text { Post-load test performed, } \\
\text { type of test unclear }\end{array}$ & Not reported & post-load glucose & unclear \\
\hline Drent 2002 & $\begin{array}{l}\text { White bread, margarine, } \\
\text { diet jam and cheese, } 1556 \\
\mathrm{~kJ}, 49 \% \text { carbohydrate, } \\
40 \% \text { fat, } 11 \% \text { protein, } \\
2,5 \mathrm{~g} \text { fibre. }\end{array}$ & $\begin{array}{l}1,1.5 \text { and } 2 \text { hours } \\
\text { measured }\end{array}$ & Data not reported & yes \\
\hline Fischer 1998 & $\begin{array}{l}\text { Test meal } 1562 \mathrm{~kJ}, 49 \% \\
\text { carbohydrate, } 40 \% \text { fat, } \\
11 \% \text { protein ( } 80 \mathrm{~g} \text { white } \\
\text { bread, } 10 \mathrm{~g} \text { spread, } 25 \mathrm{~g} \\
\text { diet jam, } 20 \mathrm{~g} 45 \% \mathrm{fat} \\
\text { cheese) }\end{array}$ & $\begin{array}{l}1 \text { hour measured and } \\
\text { reported ( } 2 \text { hours } \\
\text { value measured but not } \\
\text { reported adequately) }\end{array}$ & 1 hour glucose & yes \\
\hline
\end{tabular}


Table 01. Methods post-load glucose / insulin measurement (Continued)

\begin{tabular}{|c|c|c|c|c|}
\hline Study & Type of test & Interval & Data used & Medication given? \\
\hline Gentile 1999 & $\begin{array}{l}\text { Home cooked breakfast, } \\
\text { lunch and diner }\end{array}$ & $\begin{array}{l}2 \text { hours (after diner also } \\
\text { after } 4 \text { hours) measured, } \\
\text { not reported adequately }\end{array}$ & Data not reported & unclear \\
\hline Haffner 1997 & $\begin{array}{l}\text { Standardised breakfast } \\
(370 \mathrm{kcal} ; 49 \% \\
\text { carbohydrates, } 40 \% \text { fat, } \\
11 \% \text { protein })\end{array}$ & $\begin{array}{l}1 \text { hour measured and } \\
\text { reported }\end{array}$ & 1 hour glucose $\&$ insulin & unclear \\
\hline Hanefeld 1991 & $\begin{array}{l}\text { Testmeal: } 400 \mathrm{kcal}(50 \% \\
\text { carbohydrates, } 35 \% \mathrm{fat}, \\
15 \% \text { protein })\end{array}$ & $\begin{array}{l}1 \text { hour measured and } \\
\text { reported (2, 3, } 4 \text { and } 5 \\
\text { hours also measured but } \\
\text { not reported) }\end{array}$ & 1 hour glucose $\&$ insulin & yes \\
\hline Hillebrand 1987 & Unclear & $\begin{array}{l}\text { Measurement at } 11 \mathrm{AM} \\
\text { and } 5 \mathrm{AM} \text {, interval not } \\
\text { clear }\end{array}$ & $\begin{array}{l}\text { Data not adequately } \\
\text { reported }\end{array}$ & unclear \\
\hline Hoffmann 1990 & $\begin{array}{l}\text { Standard breakfast: } 80 \mathrm{~g} \\
\text { bread, } 20 \mathrm{~g} \text { low fat spread, } \\
25 \mathrm{~g} \text { marmalade, } 20 \mathrm{~g} \\
\text { cheese ( } 45 \% \text { fat), } 1 \mathrm{egg}\end{array}$ & $\begin{array}{l}1 \text { hour measured and } \\
\text { reported }\end{array}$ & 1 hour glucose & yes \\
\hline Hoffmann 1994 & $\begin{array}{l}\text { Standardised breakfast: } \\
1,569 \mathrm{~kJ}(372 \mathrm{Kcal}) \text {, } \\
49 \% \text { energy as (mainly } \\
\text { complex) carbohydrates, } \\
40 \% \text { fat, } 11 \% \text { protein }\end{array}$ & $\begin{array}{l}1 \text { hour measured and } \\
\text { reported }\end{array}$ & 1 hour glucose $\&$ insulin & yes \\
\hline Hoffmann 1997 & $\begin{array}{l}\text { Standardised breakfast: } \\
1,569 \mathrm{~kJ}(372 \mathrm{Kcal}) \text {, } \\
49 \% \text { energy as (mainly } \\
\text { complex) carbohydrates, } \\
40 \% \text { fat, } 11 \% \text { protein }\end{array}$ & $\begin{array}{l}1 \text { hour measured and } \\
\text { reported }\end{array}$ & 1 hour glucose $\&$ insulin & yes \\
\hline Holman 1999 & No post-load test & & & \\
\hline Holmes 2001 & No post-load test & & & \\
\hline Hotta 1993 & $\begin{array}{l}75 \text { grams Oral Glucose } \\
\text { Tolerance Test }\end{array}$ & $\begin{array}{l}0.5,1,2 \text { and } 3 \text { hours } \\
\text { measured }\end{array}$ & $\begin{array}{l}2 \text { hours glucose, } 0.5,1 \\
\text { and } 3 \text { hours not reported } \\
\text { adequately }\end{array}$ & yes \\
\hline Johnston 1998 & $\begin{array}{l}\text { Standardised test meal: } \\
480 \text { calories, } 51 \% \\
\text { carbohydrates }\end{array}$ & $\begin{array}{l}1,1.5 \text { and } 2 \text { hours } \\
\text { measured }\end{array}$ & $\begin{array}{l}\text { Data not reported } \\
\text { adequately }\end{array}$ & unclear \\
\hline Johnston 1998a & $\begin{array}{l}\text { Standard } 483 \mathrm{kcal}, 51 \% \\
\text { carbohydrate mixed-meal } \\
\text { breakfast }\end{array}$ & 2 hours measured & $\begin{array}{l}\text { Data not reported } \\
\text { adequately }\end{array}$ & unclear \\
\hline Johnston $1998 \mathrm{~b}$ & $\begin{array}{l}\text { Standard } 438 \mathrm{kcal}, 51 \% \\
\text { carbohydrate, } 14 \% \\
\text { protein, } 35 \% \text { fat meal }\end{array}$ & 2 hours measured & $\begin{array}{l}\text { Data not reported } \\
\text { adequately }\end{array}$ & unclear \\
\hline Kawamori 2003 & 'meal-loading test' & 1 and 2 hours measured & 1 hour ( 2 hours value & unclear \\
\hline
\end{tabular}

Alpha-glucosidase inhibitors for type 2 diabetes mellitus (Review)

Copyright @2005 The Cochrane Collaboration. Published by John Wiley \& Sons, Ltd 
Table 01. Methods post-load glucose / insulin measurement (Continued)

\begin{tabular}{|c|c|c|c|c|}
\hline Study & Type of test & $\begin{array}{l}\text { Interval } \\
\text { and reported }\end{array}$ & $\begin{array}{l}\text { Data used } \\
\text { in sensitivity analysis) } \\
\text { glucose } \& \text { insulin }\end{array}$ & Medication given? \\
\hline Kovacevic 1997 & $\begin{array}{l}\text { Full meal tolerance } \\
\text { test: } 80 \mathrm{~g} \text { white bread; } \\
10 \mathrm{~g} \text { butter, } 25 \mathrm{~g} \text { diet } \\
\text { marmalade (with } 23 \% \\
\text { fructose); } 20 \mathrm{~g} \text { cheese } \\
\text { ( } 45 \% \mathrm{fat}) ; 250 \mathrm{ml} \text { coffee } \\
\text { or tea }\end{array}$ & $\begin{array}{l}1 \text { hour measured and } \\
\text { reported }\end{array}$ & 1 hour glucose $\&$ insulin & unclear \\
\hline Meneilly 2000 & $\begin{array}{l}400 \mathrm{ml} \text { Ensure } \mathrm{TM} \text { with } \\
\text { fibre ( } 450 \mathrm{kcal}, 55 \% \\
\text { carbohydrate, } 30 \% \text { fat } \\
\text { and } 15 \% \text { protein) }\end{array}$ & $\begin{array}{l}1,1.5 \text { and } 2 \text { hours } \\
\text { measured }\end{array}$ & $\begin{array}{l}\text { Data not reported } \\
\text { adequately }\end{array}$ & yes \\
\hline Pagano 1995 & $\begin{array}{l}\text { Standard breakfast, with } \\
125 \mathrm{~g} \text { fruit juice, } 75 \mathrm{~g} \\
\text { ham and } 80 \mathrm{~g} \text { white } \\
\text { bread }(590 \mathrm{kcal}, 44 \% \\
\text { carbohydrates, } 41 \% \\
\text { lipids, } 15 \% \text { protein) }\end{array}$ & $\begin{array}{l}0.5,1,2 \text { and } 3 \text { hours } \\
\text { measured and reported, } \\
0.5,1 \text {, and } 3 \text { hours } \\
\text { measured }\end{array}$ & $\begin{array}{l}2 \text { hour glucose, } 0.5,1 \\
\text { and } 3 \text { hours not reported } \\
\text { adequately }\end{array}$ & $\begin{array}{l}\text { yes (not with respect to } \\
\text { glibencamide) }\end{array}$ \\
\hline Rosenthal 2002 & $\begin{array}{l}\text { Standard breakfast: } 80 \mathrm{~g} \\
\text { bread, } 20 \mathrm{~g} \text { low fat spread, } \\
25 \mathrm{~g} \text { marmalade, } 20 \mathrm{~g} \\
\text { cheese }(45 \%), 1 \mathrm{egg}\end{array}$ & $\begin{array}{l}1 \text { hour measured and } \\
\text { reported }\end{array}$ & 1 hour glucose $\&$ insulin & yes \\
\hline Rybka 1999 & Unclear & 1 hour measured & $\begin{array}{l}\text { Data not reported } \\
\text { adequately }\end{array}$ & unclear \\
\hline Salman 2001 & $\begin{array}{l}\text { Breakfast which } \\
\text { was prepared by an } \\
\text { experienced dietician } \\
\text { according to individual } \\
\text { needs }\end{array}$ & $\begin{array}{l}1.5 \text { hours measured and } \\
\text { reported }\end{array}$ & $\begin{array}{l}1.5 \text { hours glucose, insulin } \\
\& \text { c-peptide }\end{array}$ & no \\
\hline Santeusanio 1993 & $\begin{array}{l}\text { Mixed meal test, } \\
\text { consisting } 440 \text { calories, as } \\
30 \% \text { protein, } 20 \% \text { lipid } \\
\text { and } 50 \% \text { carbohydrate }\end{array}$ & $\begin{array}{l}1,2 \text { and } 3 \text { hours measured } \\
\text { and reported ( } 0.5 \text { hours } \\
\text { not reported) }\end{array}$ & $\begin{array}{l}1 \text { hour ( } 2 \text { hours value } \\
\text { in sensitivity analysis) } \\
\text { glucose } \& \text { insulin }\end{array}$ & unclear \\
\hline Scott 1999 & $\begin{array}{l}\text { Standardised breakfast } \\
\text { meal }(1.6 \mathrm{MJ})\end{array}$ & 1 and 2 hours measured & $\begin{array}{l}\text { Data not reported } \\
\text { adequately }\end{array}$ & unclear \\
\hline Segal 1997 & $\begin{array}{l}\text { Standardised breakfast } \\
\text { test meal ( } 372 \mathrm{kcal} ; 49 \% \\
\text { carbohydrate, } 40 \% \text { fat, } \\
11 \% \text { protein) }\end{array}$ & 1 and 2 hour measured & $\begin{array}{l}\text { Data not reported } \\
\text { adequately }\end{array}$ & unclear \\
\hline Spengler 1992 & $\begin{array}{l}\text { Standard breakfast: } 80 \mathrm{~g}, \\
20 \mathrm{~g} \text { low fat spread, } 25 \mathrm{~g} \\
\text { marmelade, } 20 \mathrm{~g} \text { cheese, } \\
1 \text { egg }\end{array}$ & 1 hour measured & $\begin{array}{l}\text { Data not reported } \\
\text { adequately }\end{array}$ & yes \\
\hline
\end{tabular}

Alpha-glucosidase inhibitors for type 2 diabetes mellitus (Review) 
Table 01. Methods post-load glucose / insulin measurement (Continued)

$\begin{array}{lllll}\text { Study } & \text { Type of test } & \text { Interval } & \text { Data used } & \text { Medicatior } \\ \text { Takami 2002 } & \text { No post-load test } & & & \\ \text { Van de Laar 2004a } & \begin{array}{l}\text { 75 grams Oral Glucose } \\ \text { Tolerance Test }\end{array} & \begin{array}{l}1 \text { hour mesured and } \\ \text { reported }\end{array} & 1 \text { hour glucose \& insulin } & \text { no } \\ \text { Zheng 1995 } & \text { 'meal' } & \begin{array}{l}1 \text { hour measured and } \\ \text { reported }\end{array} & 1 \text { hour glucose \& insulin } & \text { unclear }\end{array}$

\section{G R A P H S}

\section{Comparison 01. Acarbose versus placebo}

\begin{tabular}{|c|c|c|c|c|}
\hline Outcome title & $\begin{array}{l}\text { No. of } \\
\text { studies }\end{array}$ & $\begin{array}{c}\text { No. of } \\
\text { participants }\end{array}$ & Statistical method & Effect size \\
\hline $\begin{array}{l}01 \text { Change in glycated } \\
\text { haemoglobin }(\%)\end{array}$ & 28 & 2831 & Weighted Mean Difference (Random) 95\% CI & $-0.77[-0.90,-0.64]$ \\
\hline $\begin{array}{l}02 \text { Change in fasting blood glucose } \\
(\mathrm{mmol} / \mathrm{l})\end{array}$ & 28 & 2838 & Weighted Mean Difference (Random) 95\% CI & $-1.09[-1.36,-0.83]$ \\
\hline $\begin{array}{l}03 \text { Change in post-load blood } \\
\text { glucose }(\mathrm{mmol} / \mathrm{l})\end{array}$ & 22 & 2238 & Weighted Mean Difference (Random) 95\% CI & $-2.32[-2.73,-1.92]$ \\
\hline $\begin{array}{l}04 \text { Change in total cholesterol } \\
(\mathrm{mmol} / \mathrm{l})\end{array}$ & 23 & 2133 & Weighted Mean Difference (Random) 95\% CI & $0.00[-0.10,0.09]$ \\
\hline $\begin{array}{l}05 \text { Change in HDL-cholesterol } \\
(\mathrm{mmol} / \mathrm{l})\end{array}$ & 14 & 924 & Weighted Mean Difference (Random) 95\% CI & $0.00[-0.04,0.04]$ \\
\hline $\begin{array}{l}06 \text { Change in LDL-cholesterol } \\
(\mathrm{mmol} / \mathrm{l})\end{array}$ & 4 & 402 & Weighted Mean Difference (Random) 95\% CI & $-0.08[-0.41,0.25]$ \\
\hline $\begin{array}{l}07 \text { Change in triglycerides } \\
(\mathrm{mmol} / \mathrm{l})\end{array}$ & 21 & 1969 & Weighted Mean Difference (Random) 95\% CI & $-0.09[-0.18,0.00]$ \\
\hline $\begin{array}{l}08 \text { Change in fasting insulin levels } \\
(\mathrm{pmol} / \mathrm{l})\end{array}$ & 15 & 1264 & Weighted Mean Difference (Random) 95\% CI & $-0.52[-7.90,6.86]$ \\
\hline $\begin{array}{l}09 \text { Change in post-load insulin } \\
\text { levels (pmol/l) }\end{array}$ & 13 & 1050 & Weighted Mean Difference (Random) 95\% CI & $\begin{array}{l}-40.82[-60.64 \\
-21.01]\end{array}$ \\
\hline $\begin{array}{l}10 \text { Change in fasting C-peptide } \\
\text { levels }(\mathrm{nmol} / \mathrm{l})\end{array}$ & 1 & 94 & Weighted Mean Difference (Random) 95\% CI & $-0.05[-0.18,0.08]$ \\
\hline $\begin{array}{l}11 \text { Change in post-load C-peptide } \\
\text { levels }(\mathrm{nmol} / \mathrm{l})\end{array}$ & 1 & 94 & Weighted Mean Difference (Random) 95\% CI & $-0.10[-0.34,0.14]$ \\
\hline 12 Change in body weight $(\mathrm{Kg})$ & 16 & 1451 & Weighted Mean Difference (Random) 95\% CI & $-0.13[-0.46,0.20]$ \\
\hline $\begin{array}{l}13 \text { Change in body mass index } \\
(\mathrm{Kg} / \mathrm{m} 2)\end{array}$ & 14 & 1430 & Weighted Mean Difference (Random) 95\% CI & $-0.17[-0.25,-0.08]$ \\
\hline 15 Total deaths & 2 & 385 & Odds Ratio (Random) 95\% CI & $1.11[0.29,4.22]$ \\
\hline 16 Disease related deaths & 1 & 129 & Odds Ratio (Random) 95\% CI & Not estimable \\
\hline 20 Occurence of morbidity (total) & 0 & 0 & Odds Ratio (Random) 95\% CI & Not estimable \\
\hline $\begin{array}{l}21 \text { Occurence of morbidity } \\
\text { (disease specific) }\end{array}$ & 0 & 0 & Odds Ratio (Random) 95\% CI & Not estimable \\
\hline 30 Occurence of adverse effects & 23 & 3819 & Odds Ratio (Random) 95\% CI & $3.37[2.60,4.36]$ \\
\hline $\begin{array}{l}31 \text { Occurence of gastro-intestinal } \\
\text { adverse effects }\end{array}$ & 4 & 1442 & Odds Ratio (Random) 95\% CI & $3.30[2.31,4.71]$ \\
\hline 50 Quality of life & 0 & 0 & Weighted Mean Difference (Random) 95\% CI & Not estimable \\
\hline
\end{tabular}


90 Change in post-load blood glucose (mmol/l) (2-hours)

91 Change in post-load insulin levels (pmol/l) (2-hours)
Weighted Mean Difference (Random) 95\% CI $\quad-2.27$ [-2.67, -1.88]

Weighted Mean Difference (Random) 95\% CI $\quad-38.83$ [-58.77,

\section{Comparison 02. Acarbose versus sulphonylurea (SU)}

\begin{tabular}{|c|c|c|c|c|}
\hline Outcome title & $\begin{array}{l}\text { No. of } \\
\text { studies }\end{array}$ & $\begin{array}{c}\text { No. of } \\
\text { participants }\end{array}$ & Statistical method & Effect size \\
\hline $\begin{array}{l}01 \text { Change in glycated } \\
\text { haemoglobin (\%) }\end{array}$ & 8 & 596 & Weighted Mean Difference (Random) 95\% CI & $0.38[-0.02,0.77]$ \\
\hline $\begin{array}{l}02 \text { Change in fasting blood glucose } \\
(\mathrm{mmol} / \mathrm{l})\end{array}$ & 8 & 596 & Weighted Mean Difference (Random) 95\% CI & $0.69[0.16,1.23]$ \\
\hline $\begin{array}{l}03 \text { Change in post-load blood } \\
\text { glucose }(\mathrm{mmol} / \mathrm{l})\end{array}$ & 8 & 591 & Weighted Mean Difference (Random) 95\% CI & $-0.10[-0.43,0.22]$ \\
\hline $\begin{array}{l}04 \text { Change in total cholesterol } \\
(\mathrm{mmol} / \mathrm{l})\end{array}$ & 7 & 499 & Weighted Mean Difference (Random) 95\% CI & $-0.09[-0.23,0.05]$ \\
\hline $\begin{array}{l}05 \text { Change in HDL-cholesterol } \\
(\mathrm{mmol} / \mathrm{l})\end{array}$ & 7 & 485 & Weighted Mean Difference (Random) 95\% CI & $0.02[-0.02,0.06]$ \\
\hline $\begin{array}{l}06 \text { Change in LDL-cholesterol } \\
(\mathrm{mmol} / \mathrm{l})\end{array}$ & 4 & 312 & Weighted Mean Difference (Random) 95\% CI & $0.10[-0.07,0.27]$ \\
\hline $\begin{array}{l}07 \text { Change in triglycerides } \\
(\mathrm{mmol} / \mathrm{l})\end{array}$ & 8 & 591 & Weighted Mean Difference (Random) 95\% CI & $0.01[-0.18,0.20]$ \\
\hline $\begin{array}{l}08 \text { Change in fasting insulin levels } \\
(\mathrm{pmol} / \mathrm{l})\end{array}$ & 7 & 486 & Weighted Mean Difference (Random) 95\% CI & $\begin{array}{l}-24.78[-43.30 \\
-6.26]\end{array}$ \\
\hline $\begin{array}{l}09 \text { Change in post-load insulin } \\
\text { levels }(\mathrm{pmol} / \mathrm{l})\end{array}$ & 7 & 483 & Weighted Mean Difference (Random) 95\% CI & $\begin{array}{l}-133.17[-184.53 \\
-81.82]\end{array}$ \\
\hline $\begin{array}{l}10 \text { Change in fasting C-peptide } \\
\text { levels }(\mathrm{nmol} / \mathrm{l})\end{array}$ & 1 & 57 & Weighted Mean Difference (Random) 95\% CI & $-0.18[-0.51,0.15]$ \\
\hline $\begin{array}{l}11 \text { Change in post-load C-peptide } \\
\text { levels }(\mathrm{nmol} / \mathrm{l})\end{array}$ & 1 & 57 & Weighted Mean Difference (Random) 95\% CI & $-0.36[-0.94,0.22]$ \\
\hline 12 Change in body weight $(\mathrm{Kg})$ & 5 & 397 & Weighted Mean Difference (Random) 95\% CI & $-1.90[-4.01,0.21]$ \\
\hline $\begin{array}{l}13 \text { Change in body mass index } \\
(\mathrm{Kg} / \mathrm{m} 2)\end{array}$ & 4 & 230 & Weighted Mean Difference (Random) 95\% CI & $-0.39[-0.83,0.05]$ \\
\hline 15 Total deaths & 1 & 133 & Odds Ratio (Random) 95\% CI & $0.32[0.01,8.08]$ \\
\hline 16 Disease related deaths & 1 & 133 & Odds Ratio (Random) 95\% CI & $0.32[0.01,8.08]$ \\
\hline 30 Occurence of adverse effects & 7 & 607 & Odds Ratio (Random) 95\% CI & $3.95[2.00,7.80]$ \\
\hline $\begin{array}{l}31 \text { Occurence of gastro-intestinal } \\
\text { adverse effects }\end{array}$ & 1 & 145 & Odds Ratio (Random) 95\% CI & $7.70[3.64,16.31]$ \\
\hline $\begin{array}{l}90 \text { Change in post-load blood } \\
\text { glucose (mmol/l) ( } 2 \text { hours) }\end{array}$ & 8 & 591 & Weighted Mean Difference (Random) 95\% CI & $0.06[-0.42,0.53]$ \\
\hline $\begin{array}{l}91 \text { Change in post-load insulin } \\
\text { levels ( } \mathrm{pmol} / \mathrm{l}) \text { ( } 2 \text { hours) }\end{array}$ & 7 & 484 & Weighted Mean Difference (Random) 95\% CI & $\begin{array}{l}-115.84[-152.52 \\
-79.15]\end{array}$ \\
\hline
\end{tabular}

\section{Comparison 03. Acarbose versus Metformin}

\begin{tabular}{lcccc} 
Outcome title & $\begin{array}{c}\text { No. of } \\
\text { studies }\end{array}$ & $\begin{array}{c}\text { No. of } \\
\text { participants }\end{array}$ & Statistical method & Effect size \\
\hline $\begin{array}{l}\text { 01 Change in glycated } \\
\text { haemoglobin (\%) }\end{array}$ & 1 & 62 & Weighted Mean Difference (Random) 95\% CI & $-0.25[-0.61,0.11]$ \\
$\begin{array}{l}02 \text { Change in fasting blood glucose } \\
(\mathrm{mmol} / \mathrm{l})\end{array}$ & 1 & 62 & Weighted Mean Difference (Random) 95\% CI & $-0.39[-0.74,-0.04]$ \\
\hline
\end{tabular}

Alpha-glucosidase inhibitors for type 2 diabetes mellitus (Review) 


\begin{tabular}{|c|c|c|c|c|}
\hline $\begin{array}{l}03 \text { Change in post-load blood } \\
\text { glucose }(\mathrm{mmol} / \mathrm{l})\end{array}$ & 1 & 62 & Weighted Mean Difference (Random) 95\% CI & $-0.42[-0.79,-0.05]$ \\
\hline $\begin{array}{l}04 \text { Change in total cholesterol } \\
(\mathrm{mmol} / \mathrm{l})\end{array}$ & 1 & 62 & Weighted Mean Difference (Random) 95\% CI & $-0.94[-1.66,-0.22]$ \\
\hline $\begin{array}{l}05 \text { Change in HDL-cholesterol } \\
(\mathrm{mmol} / \mathrm{l})\end{array}$ & 1 & 62 & Weighted Mean Difference (Random) 95\% CI & $0.24[-0.02,0.50]$ \\
\hline $\begin{array}{l}06 \text { Change in LDL-cholesterol } \\
(\mathrm{mmol} / \mathrm{l})\end{array}$ & 1 & 62 & Weighted Mean Difference (Random) 95\% CI & $-0.94[-1.52,-0.36]$ \\
\hline $\begin{array}{l}07 \text { Change in triglycerides } \\
(\mathrm{mmol} / \mathrm{l})\end{array}$ & 1 & 62 & Weighted Mean Difference (Random) 95\% CI & $-0.28[-0.80,0.24]$ \\
\hline $\begin{array}{l}08 \text { Change in fasting insulin levels } \\
(\mathrm{pmol} / \mathrm{l})\end{array}$ & 1 & 61 & Weighted Mean Difference (Random) 95\% CI & $\begin{array}{l}33.80[-28.24 \\
95.84]\end{array}$ \\
\hline $\begin{array}{l}09 \text { Change in post-load insulin } \\
\text { levels (pmol/l) }\end{array}$ & 1 & 61 & Weighted Mean Difference (Random) 95\% CI & $\begin{array}{l}115.30[-13.22, \\
243.82]\end{array}$ \\
\hline 12 Change in body weight $(\mathrm{Kg})$ & 1 & 62 & Weighted Mean Difference (Random) 95\% CI & $-0.30[-5.45,4.85]$ \\
\hline 30 Occurence of adverse effects & 1 & 64 & Odds Ratio (Random) 95\% CI & $15.00[3.06,73.58]$ \\
\hline
\end{tabular}

\section{Comparison 04. Acarbose versus nateglinide / repaglinide}

\begin{tabular}{|c|c|c|c|c|}
\hline Outcome title & $\begin{array}{l}\text { No. of } \\
\text { studies }\end{array}$ & $\begin{array}{c}\text { No. of } \\
\text { participants }\end{array}$ & Statistical method & Effect size \\
\hline $\begin{array}{l}01 \text { Change in glycated } \\
\text { haemoglobin }(\%)\end{array}$ & 1 & 179 & Weighted Mean Difference (Random) 95\% CI & $0.03[-0.19,0.25]$ \\
\hline $\begin{array}{l}02 \text { Change in fasting blood glucose } \\
(\mathrm{mmol} / \mathrm{l})\end{array}$ & 1 & 175 & Weighted Mean Difference (Random) 95\% CI & $-0.02[-1.10,1.06]$ \\
\hline 12 Change in body weight $(\mathrm{Kg})$ & 1 & 169 & Weighted Mean Difference (Random) 95\% CI & $-0.68[-1.30,-0.06]$ \\
\hline 30 Occurence of adverse effects & 1 & 179 & Odds Ratio (Random) 95\% CI & $1.92[1.05,3.50]$ \\
\hline $\begin{array}{l}31 \text { Occurence of gastro-intestinal } \\
\text { adverse effects }\end{array}$ & 1 & 179 & Odds Ratio (Random) 95\% CI & $3.22[1.66,6.24]$ \\
\hline
\end{tabular}

\section{Comparison 05. Miglitol versus placebo}

\begin{tabular}{|c|c|c|c|c|}
\hline Outcome title & $\begin{array}{l}\text { No. of } \\
\text { studies }\end{array}$ & $\begin{array}{c}\text { No. of } \\
\text { participants }\end{array}$ & Statistical method & Effect size \\
\hline $\begin{array}{l}01 \text { Change in glycated } \\
\text { haemoglobin }(\%)\end{array}$ & 7 & 1088 & Weighted Mean Difference (Random) 95\% CI & $-0.68[-0.93,-0.44]$ \\
\hline $\begin{array}{l}02 \text { Change in fasting blood glucose } \\
(\mathrm{mmol} / \mathrm{l})\end{array}$ & 2 & 398 & Weighted Mean Difference (Random) 95\% CI & $-0.52[-0.88,-0.16]$ \\
\hline $\begin{array}{l}03 \text { Change in post-load blood } \\
\text { glucose }(\mathrm{mmol} / \mathrm{l})\end{array}$ & 2 & 398 & Weighted Mean Difference (Random) 95\% CI & $-2.70[-5.54,0.14]$ \\
\hline $\begin{array}{l}08 \text { Change in fasting insulin levels } \\
(\mathrm{pmol} / \mathrm{l})\end{array}$ & 1 & 162 & Weighted Mean Difference (Random) 95\% CI & $\begin{array}{l}-18.20[-57.01 \\
20.61]\end{array}$ \\
\hline $\begin{array}{l}09 \text { Change in post-load insulin } \\
\text { levels }(\mathrm{pmol} / \mathrm{l})\end{array}$ & 2 & 398 & Weighted Mean Difference (Random) 95\% CI & $\begin{array}{l}-16.62[-39.23, \\
6.00]\end{array}$ \\
\hline 12 Change in body weight $(\mathrm{Kg})$ & 1 & 162 & Weighted Mean Difference (Random) 95\% CI & $0.27[-0.50,1.04]$ \\
\hline 15 Total deaths & 2 & 408 & Odds Ratio (Random) 95\% CI & $2.97[0.31,28.80]$ \\
\hline 16 Disease related deaths & 2 & 408 & Odds Ratio (Random) 95\% CI & $2.94[0.12,73.07]$ \\
\hline 30 Occurence of adverse effects & 7 & 1304 & Odds Ratio (Random) 95\% CI & $4.01[1.69,9.52]$ \\
\hline $\begin{array}{l}31 \text { Occurence of gastro-intestinal } \\
\text { adverse effects }\end{array}$ & 2 & 428 & Odds Ratio (Random) 95\% CI & $3.12[1.62,6.02]$ \\
\hline $\begin{array}{l}90 \text { Change in post-load blood } \\
\text { glucose ( } \mathrm{mmol} / \mathrm{l}) \text { (2-hours) }\end{array}$ & 2 & 398 & Weighted Mean Difference (Random) 95\% CI & $-1.66[-2.25,-1.07]$ \\
\hline
\end{tabular}




\section{Comparison 06. Miglitol versus sulphonylurea (SU)}

\begin{tabular}{|c|c|c|c|c|}
\hline Outcome title & $\begin{array}{l}\text { No. of } \\
\text { studies }\end{array}$ & $\begin{array}{c}\text { No. of } \\
\text { participants }\end{array}$ & Statistical method & Effect size \\
\hline $\begin{array}{l}01 \text { Change in glycated } \\
\text { haemoglobin }(\%)\end{array}$ & 1 & 90 & Weighted Mean Difference (Random) 95\% CI & $0.40[-0.16,0.96]$ \\
\hline $\begin{array}{l}02 \text { Change in fasting blood glucose } \\
(\mathrm{mmol} / \mathrm{l})\end{array}$ & 1 & 90 & Weighted Mean Difference (Random) 95\% CI & $0.27[-0.74,1.28]$ \\
\hline $\begin{array}{l}03 \text { Change in post-load blood } \\
\text { glucose }(\mathrm{mmol} / \mathrm{l})\end{array}$ & 1 & 88 & Weighted Mean Difference (Random) 95\% CI & $-0.60[-3.43,2.23]$ \\
\hline $\begin{array}{l}04 \text { Change in total cholesterol } \\
(\mathrm{mmol} / \mathrm{l})\end{array}$ & 1 & 88 & Weighted Mean Difference (Random) 95\% CI & $0.08[-0.29,0.45]$ \\
\hline $\begin{array}{l}05 \text { Change in HDL-cholesterol } \\
(\mathrm{mmol} / \mathrm{l})\end{array}$ & 1 & 86 & Weighted Mean Difference (Random) 95\% CI & $-0.01[-0.26,0.24]$ \\
\hline $\begin{array}{l}07 \text { Change in triglycerides } \\
(\mathrm{mmol} / \mathrm{l})\end{array}$ & 1 & 89 & Weighted Mean Difference (Random) 95\% CI & $-0.04[-0.40,0.32]$ \\
\hline $\begin{array}{l}08 \text { Change in fasting insulin levels } \\
(\mathrm{pmol} / \mathrm{l})\end{array}$ & 1 & 90 & Weighted Mean Difference (Random) 95\% CI & $\begin{array}{l}-44.75[-53.72 \\
-35.78]\end{array}$ \\
\hline 12 Change in body weight $(\mathrm{Kg})$ & 1 & 90 & Weighted Mean Difference (Random) 95\% CI & $0.46[-0.48,1.40]$ \\
\hline 15 Total deaths & 2 & 414 & Odds Ratio (Random) 95\% CI & $0.50[0.09,2.76]$ \\
\hline 16 Disease related deaths & 2 & 414 & Odds Ratio (Random) 95\% CI & $0.63[0.08,5.14]$ \\
\hline 30 Occurence of adverse effects & 2 & 232 & Odds Ratio (Random) 95\% CI & $1.29[0.69,2.41]$ \\
\hline
\end{tabular}

\section{Comparison 07. Miglitol versus metformin}

\begin{tabular}{|c|c|c|c|c|}
\hline Outcome title & $\begin{array}{l}\text { No. of } \\
\text { studies }\end{array}$ & $\begin{array}{c}\text { No. of } \\
\text { participants }\end{array}$ & Statistical method & Effect size \\
\hline $\begin{array}{l}01 \text { Change in glycated } \\
\text { haemoglobin }(\%)\end{array}$ & 1 & 161 & Weighted Mean Difference (Random) 95\% CI & $0.87[0.56,1.18]$ \\
\hline $\begin{array}{l}02 \text { Change in fasting blood glucose } \\
(\mathrm{mmol} / \mathrm{l})\end{array}$ & 1 & 161 & Weighted Mean Difference (Random) 95\% CI & $1.00[0.18,1.82]$ \\
\hline $\begin{array}{l}03 \text { Change in post-load blood } \\
\text { glucose }(\mathrm{mmol} / \mathrm{l})\end{array}$ & 1 & 161 & Weighted Mean Difference (Random) 95\% CI & $0.70[-0.43,1.83]$ \\
\hline $\begin{array}{l}08 \text { Change in fasting insulin levels } \\
(\mathrm{pmol} / \mathrm{l})\end{array}$ & 1 & 161 & Weighted Mean Difference (Random) 95\% CI & $\begin{array}{l}-1.10[-30.04 \\
27.84]\end{array}$ \\
\hline $\begin{array}{l}09 \text { Change in post-load insulin } \\
\text { levels ( } \mathrm{pmol} / \mathrm{l})\end{array}$ & 1 & 161 & Weighted Mean Difference (Random) 95\% CI & $\begin{array}{l}-48.30[-94.38 \\
-2.22]\end{array}$ \\
\hline 12 Change in body weight $(\mathrm{Kg})$ & 1 & 161 & Weighted Mean Difference (Random) 95\% CI & $0.37[-0.50,1.24]$ \\
\hline $\begin{array}{l}17 \text { Occurence of gastro-intestinal } \\
\text { side-effects }\end{array}$ & 1 & 165 & Odds Ratio (Random) 95\% CI & $1.59[0.83,3.05]$ \\
\hline 30 Occurence of adverse effects & 1 & 165 & Odds Ratio (Random) 95\% CI & $1.69[0.39,7.31]$ \\
\hline $\begin{array}{l}90 \text { Change in post-load blood } \\
\text { glucose ( } \mathrm{mmol} / \mathrm{l}) \text { ( } 2 \text { hours) }\end{array}$ & 1 & 161 & Weighted Mean Difference (Random) 95\% CI & $0.80[-0.45,2.05]$ \\
\hline $\begin{array}{l}91 \text { Change in post-load insulin } \\
\text { levels ( } \mathrm{pmol} / \mathrm{l}) \text { (2-hours) }\end{array}$ & 1 & 161 & Weighted Mean Difference (Random) 95\% CI & $\begin{array}{l}-67.20[-115.65 \\
-18.75]\end{array}$ \\
\hline
\end{tabular}

Alpha-glucosidase inhibitors for type 2 diabetes mellitus (Review) 


\section{Comparison 08. Voglibose versus placebo}

\begin{tabular}{|c|c|c|c|c|}
\hline Outcome title & $\begin{array}{l}\text { No. of } \\
\text { studies }\end{array}$ & $\begin{array}{c}\text { No. of } \\
\text { participants }\end{array}$ & Statistical method & Effect size \\
\hline $\begin{array}{l}01 \text { Change in glycated } \\
\text { haemoglobin }(\%)\end{array}$ & 1 & 238 & Weighted Mean Difference (Random) 95\% CI & $-0.47[-0.63,-0.31]$ \\
\hline $\begin{array}{l}02 \text { Change in fasting blood glucose } \\
(\mathrm{mmol} / \mathrm{l})\end{array}$ & 1 & 234 & Weighted Mean Difference (Random) 95\% CI & $-0.60[-0.97,-0.23]$ \\
\hline $\begin{array}{l}03 \text { Change in post-load blood } \\
\text { glucose }(\mathrm{mmol} / \mathrm{l})\end{array}$ & 1 & 234 & Weighted Mean Difference (Random) 95\% CI & $-2.40[-2.97,-1.83]$ \\
\hline $\begin{array}{l}08 \text { Change in post-load insulin } \\
\text { levels }(\mathrm{pmol} / \mathrm{l})\end{array}$ & 1 & 234 & Weighted Mean Difference (Random) 95\% CI & $\begin{array}{l}-12.90[-37.06 \\
11.26]\end{array}$ \\
\hline 30 Occurence of adverse effects & 1 & 263 & Odds Ratio (Random) 95\% CI & $1.15[0.67,1.97]$ \\
\hline $\begin{array}{l}31 \text { Occurence of gastro-intestinal } \\
\text { adverse effects }\end{array}$ & 1 & 263 & Odds Ratio (Random) 95\% CI & $1.62[0.96,2.75]$ \\
\hline $\begin{array}{l}90 \text { Change in post-load blood } \\
\text { glucose (mmol/l) (2 hours) }\end{array}$ & 1 & 234 & Weighted Mean Difference (Random) 95\% CI & $-1.70[-2.37,-1.03]$ \\
\hline
\end{tabular}

\section{Comparison 09. Voglibose versus diet therapy}

\begin{tabular}{|c|c|c|c|c|}
\hline Outcome title & $\begin{array}{l}\text { No. of } \\
\text { studies }\end{array}$ & $\begin{array}{c}\text { No. of } \\
\text { participants }\end{array}$ & Statistical method & Effect size \\
\hline $\begin{array}{l}01 \text { Change in glycated } \\
\text { haemoglobin }(\%)\end{array}$ & 1 & 23 & Weighted Mean Difference (Random) 95\% CI & $0.00[-1.15,1.15]$ \\
\hline $\begin{array}{l}02 \text { Change in fasting blood glucose } \\
(\mathrm{mmol} / \mathrm{l})\end{array}$ & 1 & 23 & Weighted Mean Difference (Random) 95\% CI & $-2.40[-4.58,-0.22]$ \\
\hline $\begin{array}{l}04 \text { Change in total cholesterol } \\
(\mathrm{mmol} / \mathrm{l})\end{array}$ & 1 & 23 & Weighted Mean Difference (Random) 95\% CI & $-0.70[-1.64,0.24]$ \\
\hline $\begin{array}{l}05 \text { Change in HDL-cholesterol } \\
(\mathrm{mmol} / \mathrm{l})\end{array}$ & 1 & 23 & Weighted Mean Difference (Random) 95\% CI & $-0.40[-0.81,0.01]$ \\
\hline $\begin{array}{l}08 \text { Change in fasting insulin levels } \\
(\mathrm{pmol} / \mathrm{l})\end{array}$ & 1 & 23 & Weighted Mean Difference (Random) 95\% CI & $6.00[-19.22,31.22]$ \\
\hline 12 Change in body weight $(\mathrm{Kg})$ & 1 & 23 & Weighted Mean Difference (Random) 95\% CI & $0.20[-4.99,5.39]$ \\
\hline $\begin{array}{l}13 \text { Change in body mass index } \\
(\mathrm{Kg} / \mathrm{m} 2)\end{array}$ & 1 & 23 & Weighted Mean Difference (Random) 95\% CI & $0.00[-2.26,2.26]$ \\
\hline
\end{tabular}

Comparison 10. .Voglibose versus sulphonylurea (SU)

\begin{tabular}{|c|c|c|c|c|}
\hline Outcome title & $\begin{array}{l}\text { No. of } \\
\text { studies }\end{array}$ & $\begin{array}{c}\text { No. of } \\
\text { participants }\end{array}$ & Statistical method & Effect size \\
\hline $\begin{array}{l}01 \text { Change in glycated } \\
\text { haemoglobin }(\%)\end{array}$ & 1 & 21 & Weighted Mean Difference (Random) 95\% CI & $1.30[-0.45,3.05]$ \\
\hline $\begin{array}{l}02 \text { Change in fasting blood glucose } \\
(\mathrm{mmol} / \mathrm{l})\end{array}$ & 1 & 21 & Weighted Mean Difference (Random) 95\% CI & $-0.50[-3.15,2.15]$ \\
\hline $\begin{array}{l}04 \text { Change in total cholesterol } \\
(\mathrm{mmol} / \mathrm{l})\end{array}$ & 1 & 21 & Weighted Mean Difference (Random) 95\% CI & $0.10[-1.13,1.33]$ \\
\hline $\begin{array}{l}05 \text { Change in HDL-cholesterol } \\
(\mathrm{mmol} / \mathrm{l})\end{array}$ & 1 & 21 & Weighted Mean Difference (Random) 95\% CI & $-0.20[-0.59,0.19]$ \\
\hline $\begin{array}{l}08 \text { Change in fasting insulin levels } \\
(\mathrm{pmol} / \mathrm{l})\end{array}$ & 1 & 21 & Weighted Mean Difference (Random) 95\% CI & $\begin{array}{l}-11.80[-25.49, \\
1.89]\end{array}$ \\
\hline 12 Change in body weight $(\mathrm{Kg})$ & 1 & 21 & Weighted Mean Difference (Random) 95\% CI & $0.60[-9.73,10.93]$ \\
\hline
\end{tabular}




\begin{tabular}{|c|c|c|c|c|}
\hline Outcome title & $\begin{array}{l}\text { No. of } \\
\text { studies }\end{array}$ & $\begin{array}{c}\text { No. of } \\
\text { participants }\end{array}$ & Statistical method & Effect size \\
\hline $\begin{array}{l}01 \text { Change in glycated } \\
\text { haemoglobin }(\%)\end{array}$ & 1 & 312 & Weighted Mean Difference (Random) 95\% CI & $-0.13[-0.24,-0.02]$ \\
\hline $\begin{array}{l}02 \text { Change in fasting blood glucose } \\
(\mathrm{mmol} / \mathrm{l})\end{array}$ & 1 & 306 & Weighted Mean Difference (Random) 95\% CI & $0.00[-0.31,0.31]$ \\
\hline $\begin{array}{l}03 \text { Change in post-load blood } \\
\text { glucose }(\mathrm{mmol} / \mathrm{l})\end{array}$ & 1 & 306 & Weighted Mean Difference (Random) 95\% CI & $-1.70[-2.27,-1.13]$ \\
\hline $\begin{array}{l}09 \text { Change in post-load insulin } \\
\text { levels }(\mathrm{pmol} / \mathrm{l})\end{array}$ & 1 & 306 & Weighted Mean Difference (Random) 95\% CI & $\begin{array}{l}-2.90[-30.04 \\
24.24]\end{array}$ \\
\hline 30 Occurence of adverse effects & 1 & 348 & Odds Ratio (Random) 95\% CI & $1.53[0.96,2.45]$ \\
\hline $\begin{array}{l}31 \text { Occurence of gastro-intestinal } \\
\text { adverse effects }\end{array}$ & 1 & 348 & Odds Ratio (Random) 95\% CI & $1.41[0.93,2.16]$ \\
\hline $\begin{array}{l}90 \text { Change in post-load blood } \\
\text { glucose (mmol/l) ( } 2 \text { hours })\end{array}$ & 1 & 312 & Weighted Mean Difference (Random) 95\% CI & $0.00[-0.61,0.61]$ \\
\hline
\end{tabular}

\section{INDEX TERMS}

\section{Medical Subject Headings (MeSH)}

Acarbose [therapeutic use]; Diabetes Mellitus, Type 2 [drug therapy]; Enzyme Inhibitors [therapeutic use]; Glucosamine [analogs \& derivatives]; Hypoglycemic Agents [therapeutic use]; Inositol [analogs \& derivatives]; Randomized Controlled Trials; alpha-Glucosidases [antagonists \& inhibitors]

\section{Medical MeSH check words}

Humans

\section{COVERSHEET}

Title

Authors

\section{Contribution of author(s)}

Issue protocol first published

Review first published

Date of most recent amendment
Alpha-glucosidase inhibitors for type 2 diabetes mellitus

Van de Laar FA, Lucassen PLBJ, Akkermans RP, Van de Lisdonk EH, Rutten GEHM, Van Weel C

FLORIS VAN DE LAAR: Protocol development, searching for trials, abstract assessment for eligibility, quality assessment of trials, data extraction, data entry, data analysis, review development

PETER LUCASSEN: Protocol development, abstract assessment for eligibility, quality assessment of trials, data extraction, data analysis, review development

REINIER AKKERMANS: (double) data entry, data analysis, review development ELOY VAN DE LISDONK: Quality assessment of trials (referee), data analysis, translation Italian articles, review development

GUY RUTTEN: Protocol development, data analysis (advisor), review development CHRIS VAN WEEL: Protocol development, data analysis (advisor), review development

$2002 / 2$

$2005 / 2$

25 May 2005 


\section{Date of most recent SUBSTANTIVE amendment}

What's New

Date new studies sought but none found

Date new studies found but not yet included/excluded

Date new studies found and included/excluded

Date authors' conclusions section amended

Contact address

DOI

Cochrane Library number

Editorial group

Editorial group code
23 February 2005

We received additional data for the Holman (1999) study on september 1st 2004. The information is added. (see Table of included studies, comparions tables and study quality)

Information not supplied by author

Information not supplied by author

Information not supplied by author

Information not supplied by author

Floris Van de Laar M.D.

GP / investigator

Department of General Practice, 229 HAG

Radboud University Nijmegen Medical Centre

P.O. Box 9101

Nijmegen

$6500 \mathrm{HB}$

NETHERLANDS

E-mail: f.vandelaar@hag.umcn.nl

Tel: + 31243614411

Fax: + 31243541862

10.1002/14651858.CD003639.pub2

CD003639

Cochrane Metabolic and Endocrine Disorders Group

HM-ENDOC 
GRAPHS AND OTHER TABLES

Fig. I.

Alpha-glucosidase inhibitors for type 2 diabetes mellitus (Review)

Copyright @2005 The Cochrane Collaboration. Published by John Wiley \& Sons, Ltd 
Fig. 2.

Alpha-glucosidase inhibitors for type 2 diabetes mellitus (Review)

Copyright (C2005 The Cochrane Collaboration. Published by John Wiley \& Sons, Ltd 


\section{Fig. 3. Comparison 0I. Acarbose versus placebo}

\subsection{Change in glycated haemoglobin (\%)}

Review: Alpha-glucosidase inhibitors for type 2 diabetes mellitus

Comparison: 01 Acarbose versus placebo

Outcome: 0 l Change in glycated haemoglobin (\%)

\begin{tabular}{|c|c|c|c|c|c|c|c|c|}
\hline \multirow[t]{2}{*}{ Study } & \multicolumn{2}{|c|}{ Acarbose } & \multicolumn{2}{|c|}{ Placebo } & \multirow{2}{*}{\multicolumn{2}{|c|}{$\begin{array}{l}\text { Weighted Mean Difference (Random) } \\
\qquad 95 \% \mathrm{Cl}\end{array}$}} & \multirow{2}{*}{$\begin{array}{c}\text { Weight } \\
(\%)\end{array}$} & \multirow{2}{*}{$\begin{array}{l}\text { Weighted Mean Difference (Random) } \\
\qquad 95 \% \mathrm{Cl}\end{array}$} \\
\hline & $N$ & Mean(SD) & N & Mean(SD) & & & & \\
\hline \multicolumn{9}{|l|}{ 0I Acarbose 25 mg TID } \\
\hline Fischer 1998 & 92 & $0.00(1.07)$ & 86 & $0.48(1.49)$ & $\rightarrow$ & & 4.7 & $-0.48[-0.86,-0.10]$ \\
\hline Subtotal $(95 \% \mathrm{Cl})$ & 92 & & 86 & & - & & 4.7 & $-0.48[-0.86,-0.10]$ \\
\hline \multicolumn{9}{|c|}{ Test for heterogeneity: not applicable } \\
\hline \multicolumn{9}{|c|}{ Test for overall effect $z=2.45 \quad p=0.01$} \\
\hline \multicolumn{9}{|l|}{02 Acarbose 50 mg BID } \\
\hline Delgado 2002 & 9 & $-0.10(1.40)$ & 8 & $0.00(2.90)$ & & & 0.3 & $-0.10[-2.31,2.11]$ \\
\hline Subtotal $(95 \% \mathrm{Cl})$ & 9 & & 8 & & & & 0.3 & $-0.10[-2.31,2.11]$ \\
\hline \multicolumn{9}{|c|}{ Test for heterogeneity: not applicable } \\
\hline \multicolumn{9}{|c|}{ Test for overall effect $z=0.09 p=0.9$} \\
\hline \multicolumn{9}{|l|}{05 Acarbose 50 mg TID } \\
\hline Fischer 1998 & 91 & $-0.40(1.18)$ & 86 & $0.48(1.49)$ & $\rightarrow$ & & 4.6 & $-0.88[-1.28,-0.48]$ \\
\hline Santeusanio 1993 & 18 & $-0.59(0.68)$ & 22 & $0.33(0.88)$ & $\rightarrow$ & & 3.8 & $-0.92[-1.40,-0.44]$ \\
\hline Subtotal $(95 \% \mathrm{Cl})$ & 109 & & 108 & & $\bullet$ & & 8.4 & $-0.90[-1.20,-0.59]$ \\
\hline \multicolumn{9}{|c|}{ Test for heterogeneity chi-square $=0.02 \mathrm{df}=\mid \mathrm{p}=0.90 \mathrm{I}^{2}=0.0 \%$} \\
\hline \multicolumn{9}{|c|}{ Test for overall effect $z=5.72 \quad p<0.0000$ I } \\
\hline \multicolumn{9}{|c|}{10 Acarbose 100 mg TID } \\
\hline Braun 1996 & 42 & $-2.50(1.80)$ & 44 & $-1.10(2.10)$ & 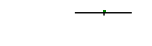 & & 1.9 & $-1.40[-2.23,-0.57]$ \\
\hline Calle-Pascual 1996 & 17 & $-0.30(0.90)$ & 16 & $-0.03(1.50)$ & $\longrightarrow$ & - & 1.8 & $-0.27[-1.12,0.58]$ \\
\hline Chan 1998 & 59 & $-0.70(1.20)$ & 62 & $-0.27(1.10)$ & $\rightarrow$ & & 4.4 & $-0.43[-0.84,-0.02]$ \\
\hline Coniff 1995b & 57 & $-0.46(0.98)$ & 62 & $0.35(1.02)$ & $\rightarrow$ & & 5.0 & $-0.81[-1.17,-0.45]$ \\
\hline Dedov 1995 & 82 & $-2.17(1.80)$ & 73 & $-1.61(2.10)$ & $\longrightarrow$ & & 2.8 & $-0.56[-1.18,0.06]$ \\
\hline Fischer 1998 & 89 & $-0.26(1.43)$ & 86 & $0.48(1.49)$ & $\rightarrow$ & & 4.2 & $-0.74[-1.17,-0.31]$ \\
\hline Haffner 1997 & 25 & $0.00(1.60)$ & 25 & $0.70(1.40)$ & $\longrightarrow$ & & 1.9 & $-0.70[-1.53,0.13]$ \\
\hline Hanefeld |99| & 47 & $-0.65(1.30)$ & 47 & $-0.08(1.40)$ & $\rightarrow$ & & 3.3 & $-0.57[-1.12,-0.02]$ \\
\hline Hoffmann 1994 & 28 & $-0.98(0.45)$ & 30 & $0.16(0.39)$ & + & & 6.6 & $-1.14[-1.36,-0.92]$ \\
\hline Hoffmann 1997 & 31 & $-1.10(0.79)$ & 32 & $0.30(0.27)$ & $\rightarrow$ & & 5.7 & $-1.40[-1.69,-1.11]$ \\
\hline Holman 1999 & 83 & $0.16(1.78)$ & 107 & $0.35(1.56)$ & $\rightarrow$ & & 3.8 & $-0.19[-0.67,0.29]$ \\
\hline \multirow[t]{3}{*}{ Hotta 1993} & 16 & $-1.38(1.75)$ & 13 & $-0.42(1.30)$ & & & 1.2 & $-0.96[-2.07,0.15]$ \\
\hline & & & & & -2.0 & 2.0 & & \\
\hline & & & & & Durs acarbose & Favours placebo & & \\
\hline
\end{tabular}

Alpha-glucosidase inhibitors for type 2 diabetes mellitus (Review) 
(... Continued)

\begin{tabular}{|c|c|c|c|c|c|c|c|c|}
\hline \multirow[t]{2}{*}{ Study } & \multicolumn{2}{|c|}{ Acarbose } & \multicolumn{2}{|c|}{ Placebo } & \multirow{2}{*}{\multicolumn{2}{|c|}{$\begin{array}{l}\text { Weighted Mean Difference (Random) } \\
\qquad 95 \% \mathrm{Cl}\end{array}$}} & \multirow{2}{*}{$\begin{array}{c}\text { Weight } \\
(\%)\end{array}$} & \multirow{2}{*}{$\begin{array}{l}\text { Weighted Mean Difference (Random) } \\
\qquad 95 \% \mathrm{Cl}\end{array}$} \\
\hline & $N$ & Mean(SD) & $N$ & Mean(SD) & & & & \\
\hline Kovacevic 1997 & 33 & $-0.70(0.90)$ & 31 & $0.20(1.60)$ & $\rightarrow$ & & 2.7 & $-0.90[-1.54,-0.26]$ \\
\hline Meneilly 2000 & 80 & $-0.30(1.00)$ & 94 & $0.30(1.00)$ & - & & 5.6 & $-0.60[-0.90,-0.30]$ \\
\hline Santeusanio 1993 & 22 & $-0.73(0.96)$ & 22 & $0.33(0.88)$ & $\rightarrow$ & & 3.3 & $-1.06[-1.60,-0.52]$ \\
\hline Scott 1999 & 41 & $-0.14(0.90)$ & 42 & $0.25(1.20)$ & $\rightarrow$ & & 4.0 & $-0.39[-0.85,0.07]$ \\
\hline Zheng 1995 & 39 & $-0.94(2.20)$ & 38 & $-0.46(2.40)$ & $\longrightarrow$ & + & 1.3 & $-0.48[-1.51,0.55]$ \\
\hline Subtotal $(95 \% \mathrm{Cl})$ & 791 & & 824 & & $\bullet$ & & 59.5 & $-0.76[-0.95,-0.56]$ \\
\hline \multicolumn{9}{|c|}{ Test for heterogeneity chi-square $=45.0 \mathrm{ldf}=16 \mathrm{p}=0.000 \mathrm{l} \mathrm{l}^{2}=64.5 \%$} \\
\hline \multicolumn{9}{|c|}{ Test for overall effect $z=7.55 \quad p<0.0000$ I } \\
\hline \multicolumn{9}{|c|}{19 Acarbose 200-100-200 } \\
\hline Buchanan 1988 & 9 & $1.10(3.50)$ & 11 & $1.60(3.90)$ & & & 0.2 & $-0.50[-3.75,2.75]$ \\
\hline Subtotal $(95 \% \mathrm{Cl})$ & 9 & & 11 & & & & 0.2 & $-0.50[-3.75,2.75]$ \\
\hline \multicolumn{9}{|c|}{ Test for heterogeneity: not applicable } \\
\hline \multicolumn{9}{|c|}{ Test for overall effect $z=0.30 \quad p=0.8$} \\
\hline \multicolumn{9}{|c|}{20 Acarbose $200 \mathrm{mg}$ TID } \\
\hline Chiasson 1994 & 30 & $-0.40(1.50)$ & 37 & $0.50(1.30)$ & $\longrightarrow$ & & 2.5 & $-0.90[-1.58,-0.22]$ \\
\hline Coniff 1995 & 65 & $-0.54(1.05)$ & 62 & $0.04(1.02)$ & + & & 5.0 & $-0.58[-0.94,-0.22]$ \\
\hline Coniff 1995b & 54 & $-0.30(1.03)$ & 62 & $0.35(1.02)$ & $\rightarrow$ & & 4.8 & $-0.65[-1.02,-0.28]$ \\
\hline Fischer 1998 & 90 & $-0.59(1.24)$ & 86 & $0.48(1.49)$ & $\rightarrow$ & & 4.5 & $-1.07[-1.48,-0.66]$ \\
\hline Subtotal $(95 \% \mathrm{Cl})$ & 239 & & 247 & & $\bullet$ & & 16.7 & $-0.77[-1.00,-0.53]$ \\
\hline \multicolumn{9}{|c|}{ Test for heterogeneity chi-square $=3.69 \mathrm{df}=3 p=0.30 \mathrm{I}^{2}=18.8 \%$} \\
\hline \multicolumn{9}{|c|}{ Test for overall effect $z=6.40 \quad p<0.0000$ I } \\
\hline \multicolumn{9}{|c|}{30 Acarbose $300 \mathrm{mg}$ TID } \\
\hline Coniff 1994 & 87 & $-0.06(1.12)$ & 96 & $0.53(1.08)$ & $\rightarrow$ & & 5.4 & $-0.59[-0.91,-0.27]$ \\
\hline Coniff I995b & 53 & $-0.65(1.02)$ & 62 & $0.35(1.02)$ & + & & 4.8 & $-1.00[-1.37,-0.63]$ \\
\hline Subtotal $(95 \% \mathrm{Cl})$ & 140 & & 158 & & 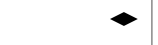 & & 10.2 & $-0.78[-1.18,-0.38]$ \\
\hline \multicolumn{9}{|c|}{ Test for heterogeneity chi-square $=2.67 \mathrm{df}=1 \mathrm{p}=0.10 \mathrm{I}^{2}=62.5 \%$} \\
\hline \multicolumn{9}{|c|}{ Test for overall effect $z=3.83 \quad p=0.000$ I } \\
\hline Total $(95 \% \mathrm{Cl})$ & 1389 & & 1442 & & - & & 100.0 & $-0.77[-0.90,-0.64]$ \\
\hline \multicolumn{9}{|c|}{ Test for heterogeneity chi-square $=55.87 \mathrm{df}=27 \mathrm{p}=0.0009 \mathrm{I}^{2}=51.7 \%$} \\
\hline \multicolumn{9}{|c|}{ Test for overall effect $z=|1.61 \quad p<0.0000|$} \\
\hline & & & & & -2.0 & 2.0 & & \\
\hline
\end{tabular}

Alpha-glucosidase inhibitors for type 2 diabetes mellitus (Review) 


\section{Fig. 4. Comparison 0I. Acarbose versus placebo}

\subsection{Change in fasting blood glucose $(\mathrm{mmol} / \mathrm{l})$}

Review: Alpha-glucosidase inhibitors for type 2 diabetes mellitus

Comparison: 01 Acarbose versus placebo

Outcome: 02 Change in fasting blood glucose $(\mathrm{mmol} / \mathrm{l})$

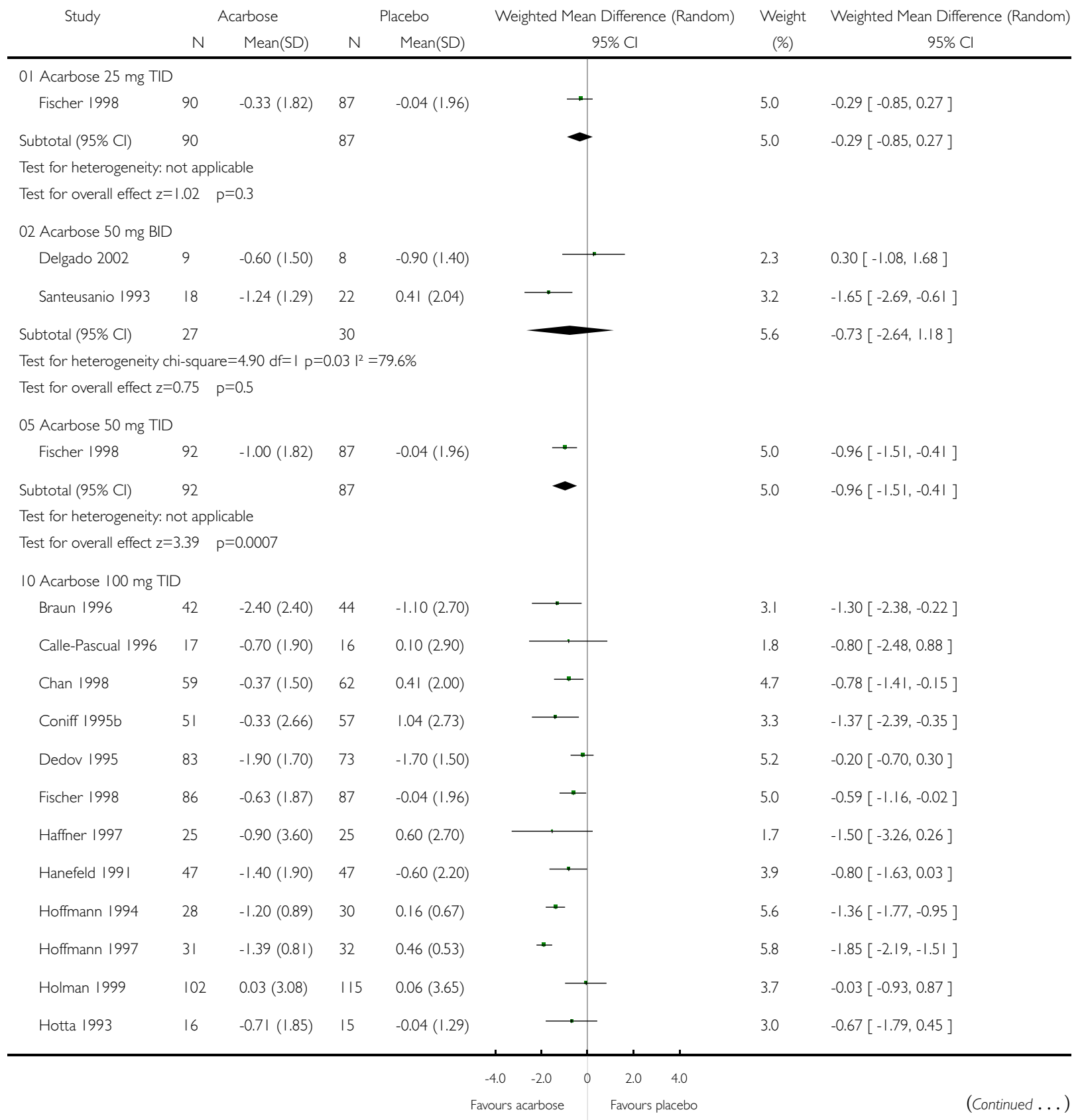

Alpha-glucosidase inhibitors for type 2 diabetes mellitus (Review) 
(... Continued)

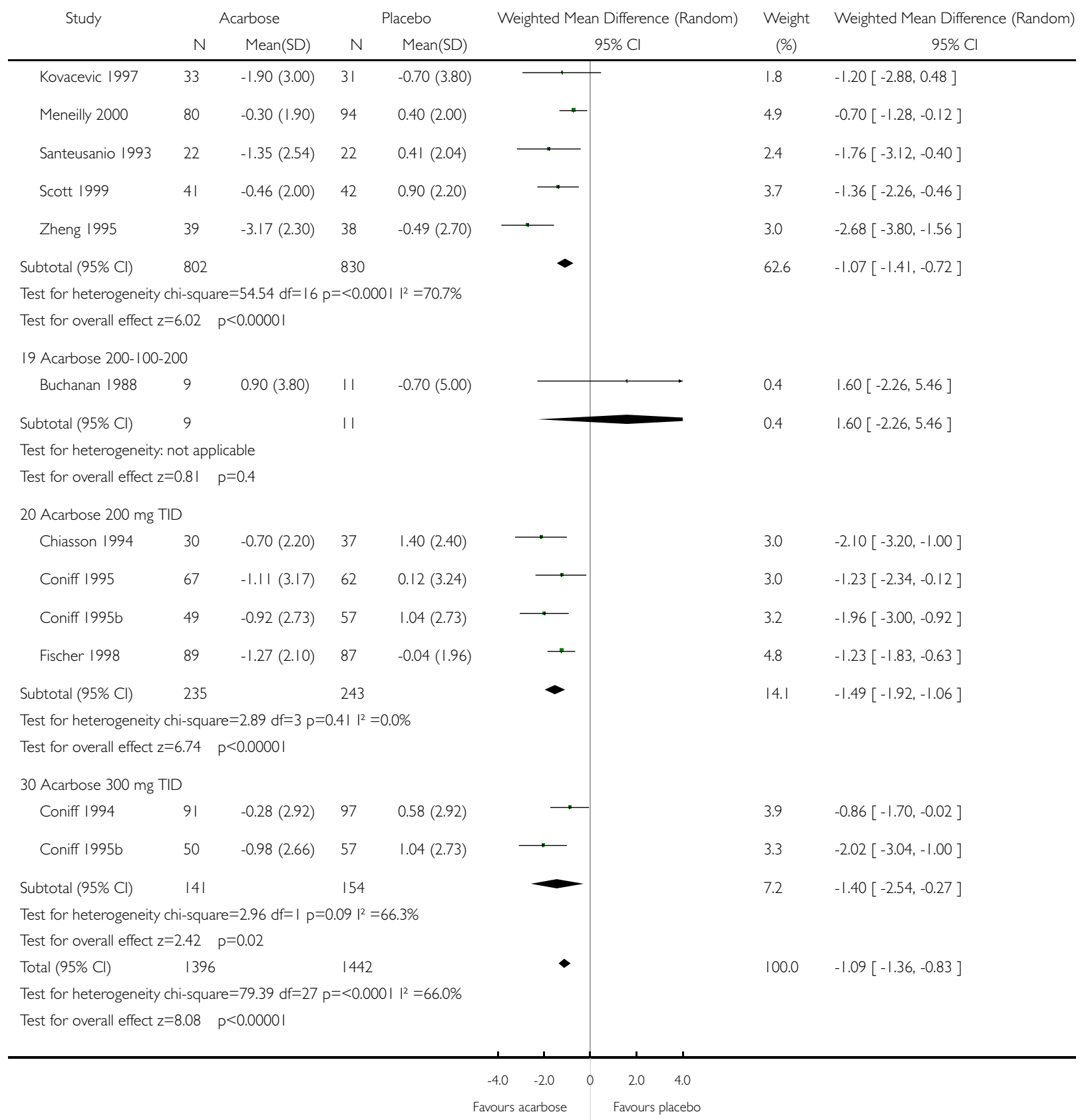

Alpha-glucosidase inhibitors for type 2 diabetes mellitus (Review) 


\section{Fig. 5. Comparison 0I. Acarbose versus placebo}

\subsection{Change in post-load blood glucose $(\mathrm{mmol} / \mathrm{l})$}

Review: Alpha-glucosidase inhibitors for type 2 diabetes mellitus

Comparison: 01 Acarbose versus placebo

Outcome: 03 Change in post-load blood glucose $(\mathrm{mmol} / \mathrm{l})$

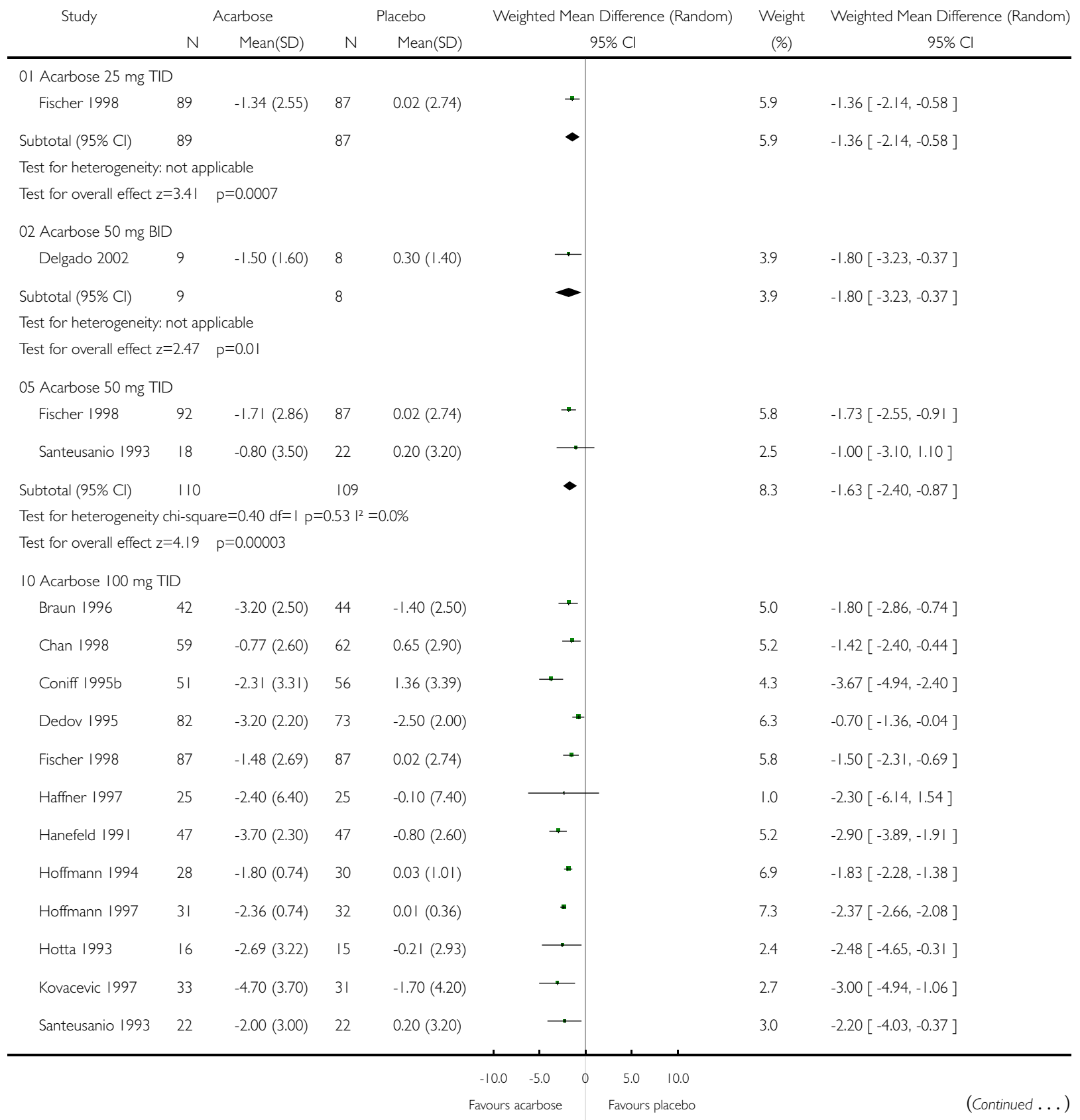

Alpha-glucosidase inhibitors for type 2 diabetes mellitus (Review) 
(... Continued)

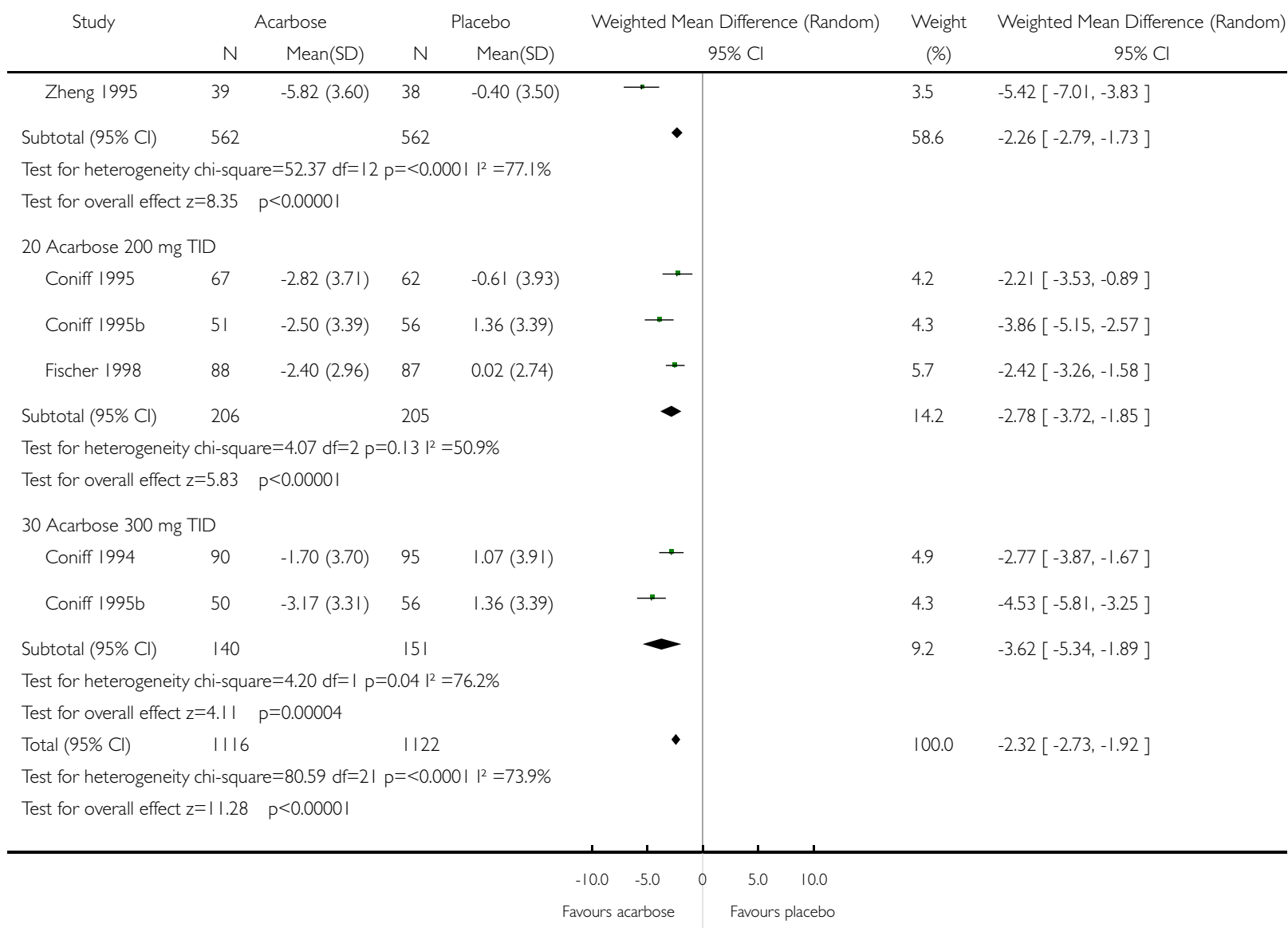

Alpha-glucosidase inhibitors for type $\mathbf{2}$ diabetes mellitus (Review) 


\section{Fig. 6. Comparison 0I. Acarbose versus placebo}

\subsection{Change in total cholesterol ( $\mathrm{mmol} / \mathrm{l})$}

Review: Alpha-glucosidase inhibitors for type 2 diabetes mellitus

Comparison: 01 Acarbose versus placebo

Outcome: 04 Change in total cholesterol $(\mathrm{mmol} / \mathrm{l})$

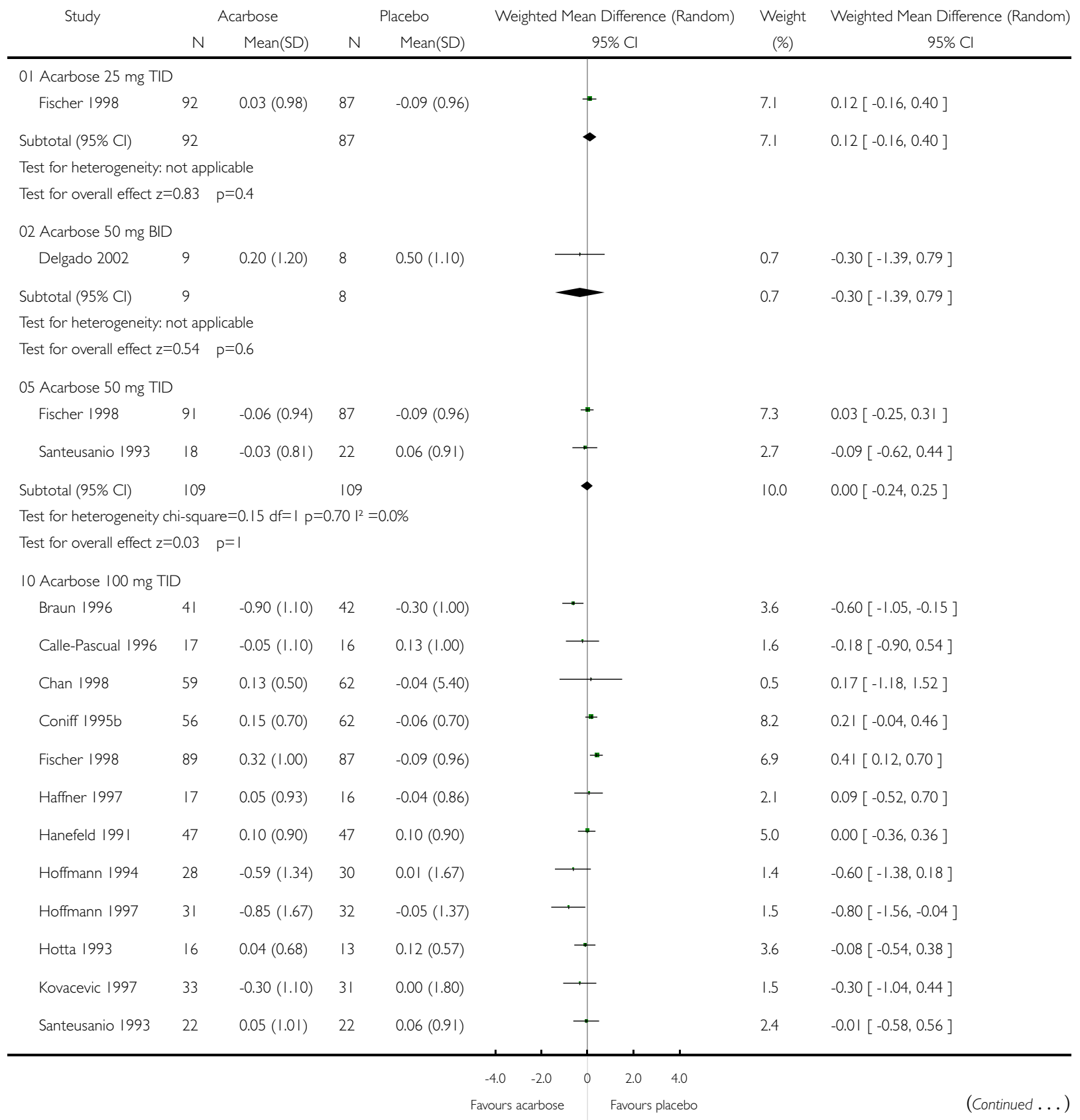

Alpha-glucosidase inhibitors for type 2 diabetes mellitus (Review) 
(... Continued)

\begin{tabular}{|c|c|c|c|c|c|c|c|}
\hline \multirow[t]{2}{*}{ Study } & \multicolumn{2}{|c|}{ Acarbose } & \multicolumn{2}{|c|}{ Placebo } & \multirow{2}{*}{$\begin{array}{l}\text { Weighted Mean Difference (Random) } \\
\qquad 95 \% \mathrm{Cl}\end{array}$} & \multirow{2}{*}{$\begin{array}{l}\text { Weight } \\
(\%)\end{array}$} & \multirow{2}{*}{$\begin{array}{l}\text { Weighted Mean Difference (Random) } \\
\qquad 95 \% \mathrm{Cl} \\
\end{array}$} \\
\hline & $\mathrm{N}$ & Mean(SD) & $\mathrm{N}$ & Mean(SD) & & & \\
\hline Scott 1999 & 41 & $-0.04(1.40)$ & 42 & $0.28(1.30)$ & $\rightarrow$ & 2.3 & $-0.32[-0.90,0.26]$ \\
\hline Subtotal $(95 \% \mathrm{Cl})$ & 497 & & 502 & & $\bullet$ & 40.7 & $-0.10[-0.30,0.11]$ \\
\hline \multicolumn{8}{|c|}{ Test for heterogeneity chi-square $=25.95 \mathrm{df}=12 \mathrm{p}=0.01 \mathrm{I}^{2}=53.8 \%$} \\
\hline \multicolumn{8}{|c|}{ Test for overall effect $z=0.90 \quad p=0.4$} \\
\hline \multicolumn{8}{|c|}{19 Acarbose $200-100-200$} \\
\hline Buchanan 1988 & 9 & $-0.10(1.20)$ & 11 & $0.20(1.80)$ & 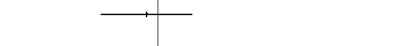 & 0.5 & $-0.30[-1.62,1.02]$ \\
\hline Subtotal $(95 \% \mathrm{Cl})$ & 9 & & 11 & & & 0.5 & $-0.30[-1.62,1.02]$ \\
\hline \multicolumn{8}{|c|}{ Test for heterogeneity: not applicable } \\
\hline \multicolumn{8}{|c|}{ Test for overall effect $z=0.44 \quad p=0.7$} \\
\hline \multicolumn{8}{|c|}{20 Acarbose $200 \mathrm{mg}$ TID } \\
\hline Coniff 1995 & 64 & $-0.21(0.79)$ & 58 & $-0.13(0.80)$ & $t$ & 7.2 & $-0.08[-0.36,0.20]$ \\
\hline Coniff I995b & 51 & $-0.09(0.7 \mathrm{I})$ & 62 & $-0.06(0.70)$ & $t$ & 7.9 & $-0.03[-0.29,0.23]$ \\
\hline Fischer 1998 & 88 & $-0.04(1.00)$ & 87 & $-0.09(0.96)$ & $\rightarrow$ & 6.9 & $0.05[-0.24,0.34]$ \\
\hline Subtotal $(95 \% \mathrm{Cl})$ & 203 & & 207 & & $\bullet$ & 21.9 & $-0.02[-0.18,0.14]$ \\
\hline \multicolumn{8}{|c|}{ Test for heterogeneity chi-square $=0.40 \mathrm{df}=2 \mathrm{p}=0.82 \mathrm{l}^{2}=0.0 \%$} \\
\hline \multicolumn{8}{|c|}{ Test for overall effect $z=0.27 \quad p=0.8$} \\
\hline \multicolumn{8}{|c|}{30 Acarbose $300 \mathrm{mg}$ TID } \\
\hline Coniff 1994 & 80 & $0.09(0.63)$ & 95 & $0.14(0.64)$ & t & 11.0 & $-0.05[-0.24,0.14]$ \\
\hline Coniff 1995b & 53 & $0.09(0.70)$ & 62 & $-0.06(0.70)$ & + & 8.1 & $0.15[-0.11,0.41]$ \\
\hline Subtotal $(95 \% \mathrm{Cl})$ & 133 & & 157 & & $\bullet$ & 19.1 & $0.03[-0.16,0.22]$ \\
\hline \multicolumn{8}{|c|}{ Test for heterogeneity chi-square $=1.5 \mathrm{Idf}=\mid \mathrm{p}=0.22 \mathrm{I}^{2}=33.9 \%$} \\
\hline \multicolumn{8}{|c|}{ Test for overall effect $z=0.31 \quad p=0.8$} \\
\hline Total $(95 \% \mathrm{Cl})$ & 1052 & & 1081 & & i & 100.0 & $0.00[-0.10,0.09]$ \\
\hline \multicolumn{8}{|c|}{ Test for heterogeneity chi-square $=29.29 \mathrm{df}=22 \mathrm{p}=0.14 \mathrm{l}^{2}=24.9 \%$} \\
\hline Test for overall effe & 0.10 & $=0.9$ & & & & & \\
\hline
\end{tabular}

Alpha-glucosidase inhibitors for type 2 diabetes mellitus (Review) 


\section{Fig. 7. Comparison 0I. Acarbose versus placebo}

\subsection{Change in HDL-cholesterol (mmol/l)}

Review: Alpha-glucosidase inhibitors for type 2 diabetes mellitus

Comparison: 01 Acarbose versus placebo

Outcome: 05 Change in HDL-cholesterol ( $\mathrm{mmol} / \mathrm{l})$

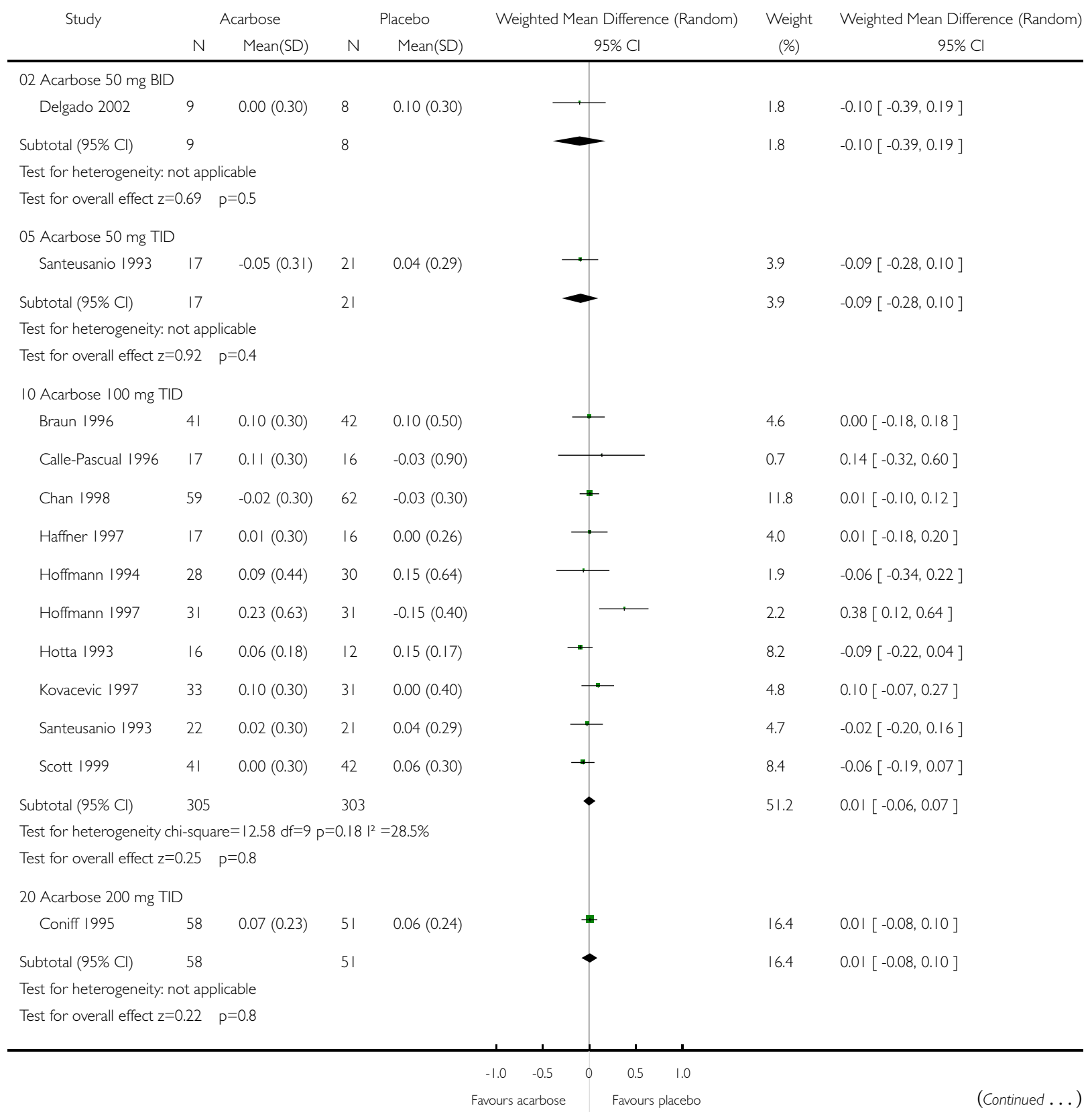

Alpha-glucosidase inhibitors for type 2 diabetes mellitus (Review) 
(... Continued)

Study

Acarbose

Placebo

Weighted Mean Difference (Random)

Weight

Weighted Mean Difference (Random)

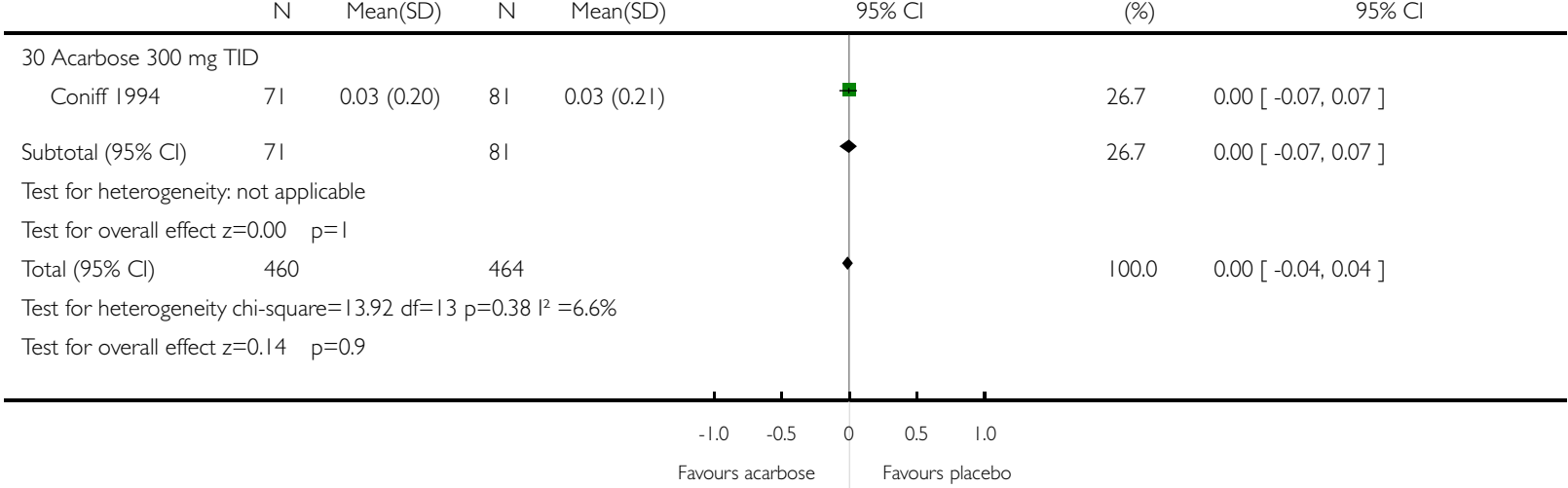

\section{Fig. 8. Comparison 0I. Acarbose versus placebo}

\subsection{Change in LDL-cholesterol ( $\mathrm{mmol} / \mathrm{l})$}

Review: Alpha-glucosidase inhibitors for type 2 diabetes mellitus

Comparison: 01 Acarbose versus placebo

Outcome: 06 Change in LDL-cholesterol $(\mathrm{mmol} / \mathrm{l})$

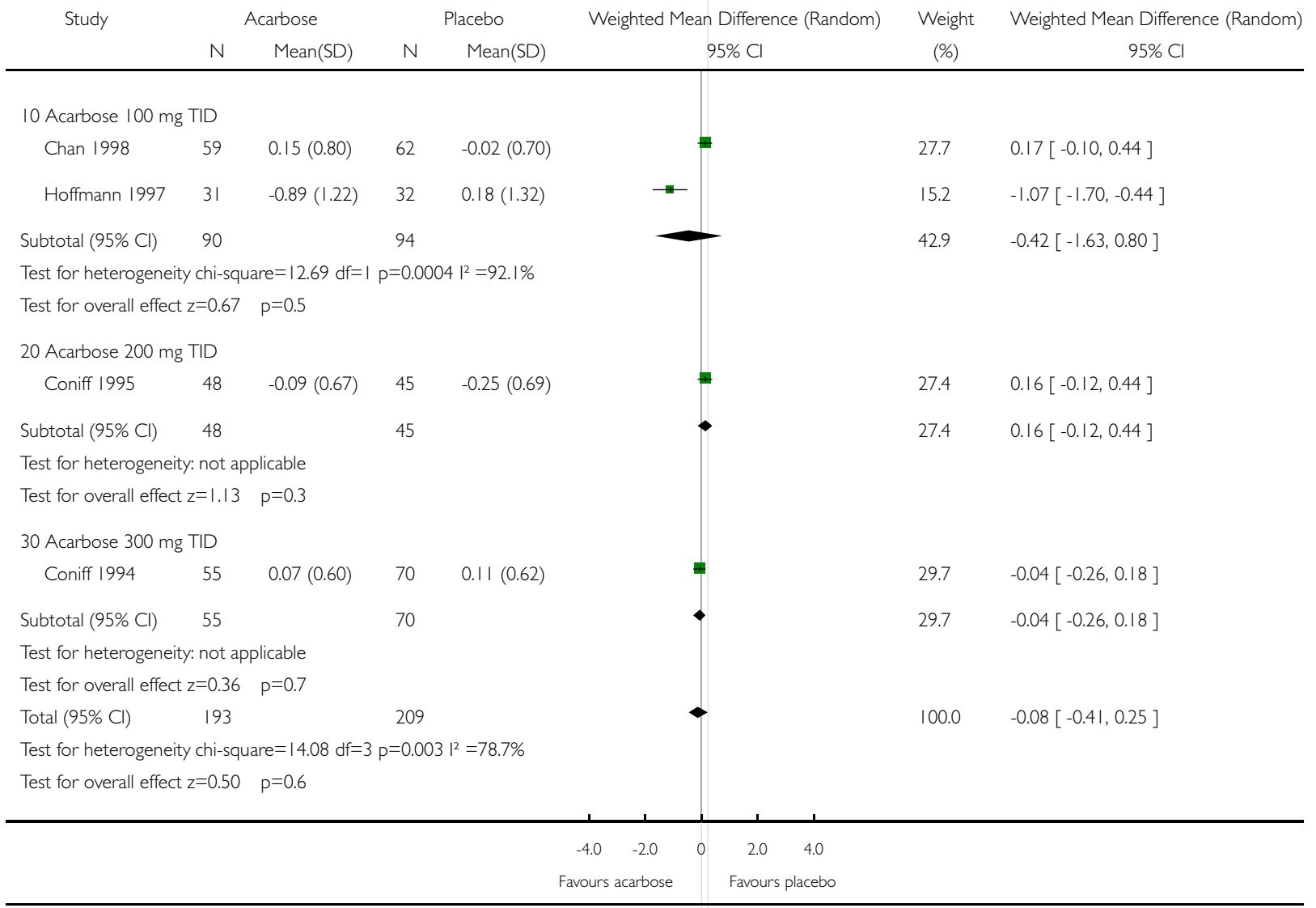

Alpha-glucosidase inhibitors for type 2 diabetes mellitus (Review) 


\section{Fig. 9. Comparison 0I. Acarbose versus placebo}

\subsection{Change in triglycerides $(\mathrm{mmol} / \mathrm{l})$}

Review: Alpha-glucosidase inhibitors for type 2 diabetes mellitus

Comparison: 01 Acarbose versus placebo

Outcome: 07 Change in triglycerides $(\mathrm{mmol} / \mathrm{l})$

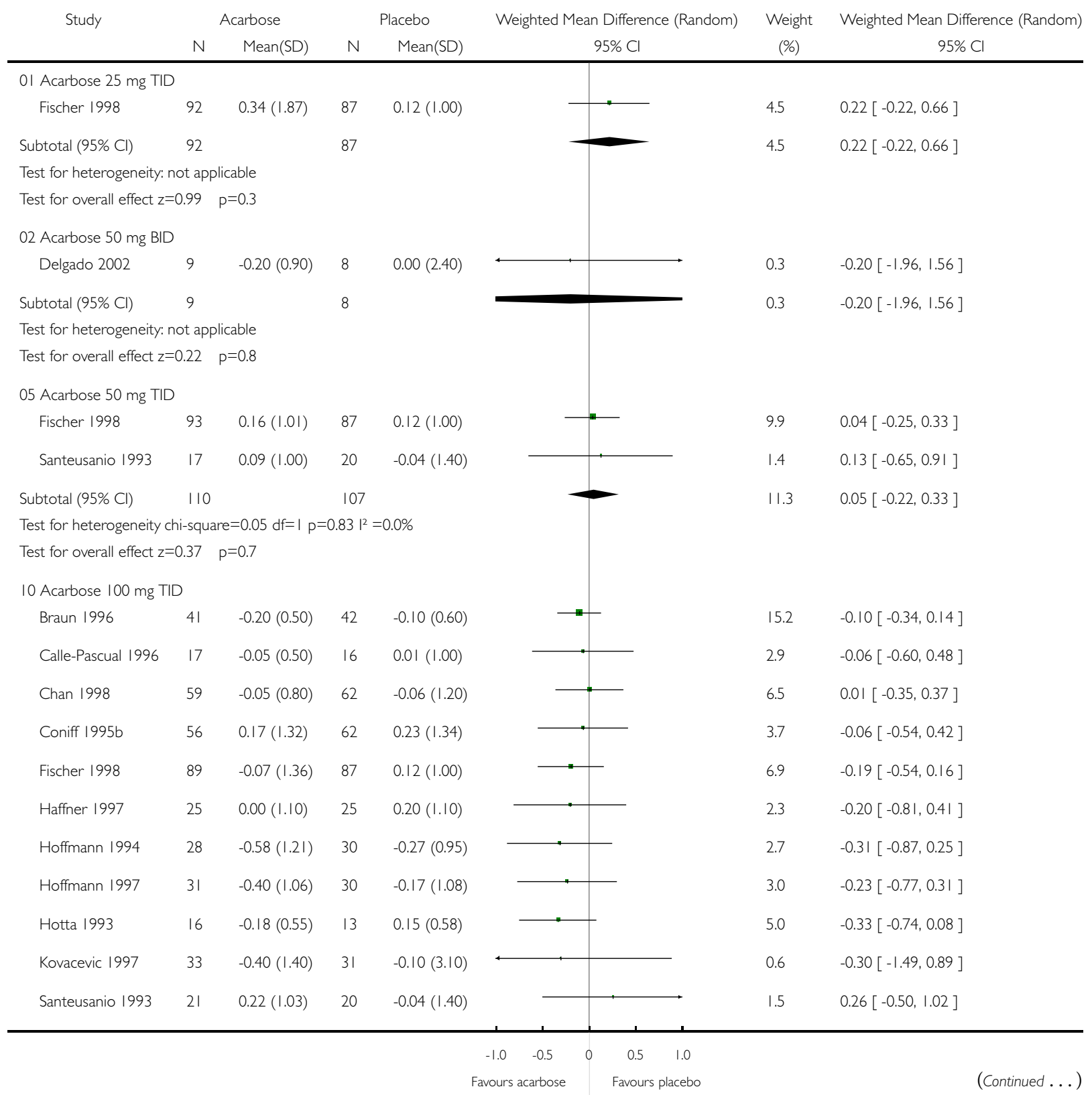

Alpha-glucosidase inhibitors for type 2 diabetes mellitus (Review) 
(... Continued)

\begin{tabular}{|c|c|c|c|c|c|c|c|}
\hline \multirow[t]{2}{*}{ Study } & \multicolumn{2}{|c|}{ Acarbose } & \multicolumn{2}{|r|}{ Placebo } & \multirow{2}{*}{$\begin{array}{l}\text { Weighted Mean Difference (Random) } \\
\qquad 95 \% \mathrm{Cl}\end{array}$} & \multirow{2}{*}{$\begin{array}{c}\text { Weight } \\
(\%)\end{array}$} & \multirow{2}{*}{$\begin{array}{l}\text { Weighted Mean Difference (Random } \\
\qquad 95 \% \mathrm{Cl}\end{array}$} \\
\hline & N & Mean(SD) & $N$ & Mean(SD) & & & \\
\hline Subtotal $(95 \% \mathrm{Cl})$ & 416 & & 418 & & - & 50.2 & $-0.13[-0.26,0.00]$ \\
\hline \multicolumn{8}{|c|}{ Test for heterogeneity chi-square $=3.47 \mathrm{df}=10 \mathrm{p}=0.97 \mathrm{I}^{2}=0.0 \%$} \\
\hline \multicolumn{8}{|c|}{ Test for overall effect $z=1.96 \quad p=0.05$} \\
\hline \multicolumn{8}{|c|}{19 Acarbose 200-100-200 } \\
\hline Buchanan 1988 & 9 & $0.20(0.60)$ & 11 & $-0.20(2.00)$ & $\longrightarrow$ & 0.6 & $0.40[-0.85,1.65]$ \\
\hline Subtotal $(95 \% \mathrm{Cl})$ & 9 & & 11 & & & 0.6 & $0.40[-0.85,1.65]$ \\
\hline \multicolumn{8}{|c|}{ Test for heterogeneity: not applicable } \\
\hline \multicolumn{8}{|c|}{ Test for overall effect $z=0.63 \quad p=0.5$} \\
\hline \multicolumn{8}{|c|}{20 Acarbose $200 \mathrm{mg}$ TID } \\
\hline Coniff 1995 & 64 & $-0.49(1.87)$ & 58 & $-0.31(1.90)$ & & 1.9 & $-0.18[-0.85,0.49]$ \\
\hline Coniff 1995b & 51 & $0.02(1.34)$ & 62 & $0.23(1.34)$ & & 3.5 & $-0.21[-0.71,0.29]$ \\
\hline Fischer 1998 & 90 & $-0.24(1.80)$ & 87 & $0.12(1.00)$ & & 4.7 & $-0.36[-0.79,0.07]$ \\
\hline Subtotal $(95 \% \mathrm{Cl})$ & 205 & & 207 & & & 10.1 & $-0.27[-0.57,0.02]$ \\
\hline \multicolumn{8}{|c|}{ Test for heterogeneity chi-square $=0.30 \mathrm{df}=2 \mathrm{p}=0.86 \mathrm{I}^{2}=0.0 \%$} \\
\hline \multicolumn{8}{|c|}{ Test for overall effect $z=1.84 \quad p=0.07$} \\
\hline \multicolumn{8}{|c|}{30 Acarbose 300 mg TID } \\
\hline Coniff 1994 & 80 & $0.12(0.70)$ & 95 & $0.18(0.7 \mid)$ & & 19.5 & $-0.06[-0.27,0.15]$ \\
\hline Coniff I995b & 53 & $0.20(1.33)$ & 62 & $0.23(1.34)$ & & 3.6 & $-0.03[-0.52,0.46]$ \\
\hline Subtotal $(95 \% \mathrm{Cl})$ & 133 & & 157 & & & 23.0 & $-0.06[-0.25,0.14]$ \\
\hline \multicolumn{8}{|c|}{ Test for heterogeneity chi-square $=0.01 \mathrm{df}=\mid \mathrm{p}=0.91 \mathrm{I}^{2}=0.0 \%$} \\
\hline \multicolumn{8}{|c|}{ Test for overall effect $z=0.56 \quad p=0.6$} \\
\hline Total $(95 \% \mathrm{Cl})$ & 974 & & 995 & & $\bullet$ & 100.0 & $-0.09[-0.18,0.00]$ \\
\hline \multicolumn{8}{|c|}{ Test for heterogeneity chi-square $=9.42 \mathrm{df}=20 \mathrm{p}=0.98 \mathrm{l}^{2}=0.0 \%$} \\
\hline Test for overall effe & 1.88 & $=0.06$ & & & & & \\
\hline
\end{tabular}

Alpha-glucosidase inhibitors for type 2 diabetes mellitus (Review) 


\section{Fig. 10. Comparison 0I. Acarbose versus placebo}

\subsection{Change in fasting insulin levels (pmol/l)}

Review: Alpha-glucosidase inhibitors for type 2 diabetes mellitus

Comparison: 01 Acarbose versus placebo

Outcome: 08 Change in fasting insulin levels (pmol/l)



Alpha-glucosidase inhibitors for type 2 diabetes mellitus (Review) 
(... Continued)

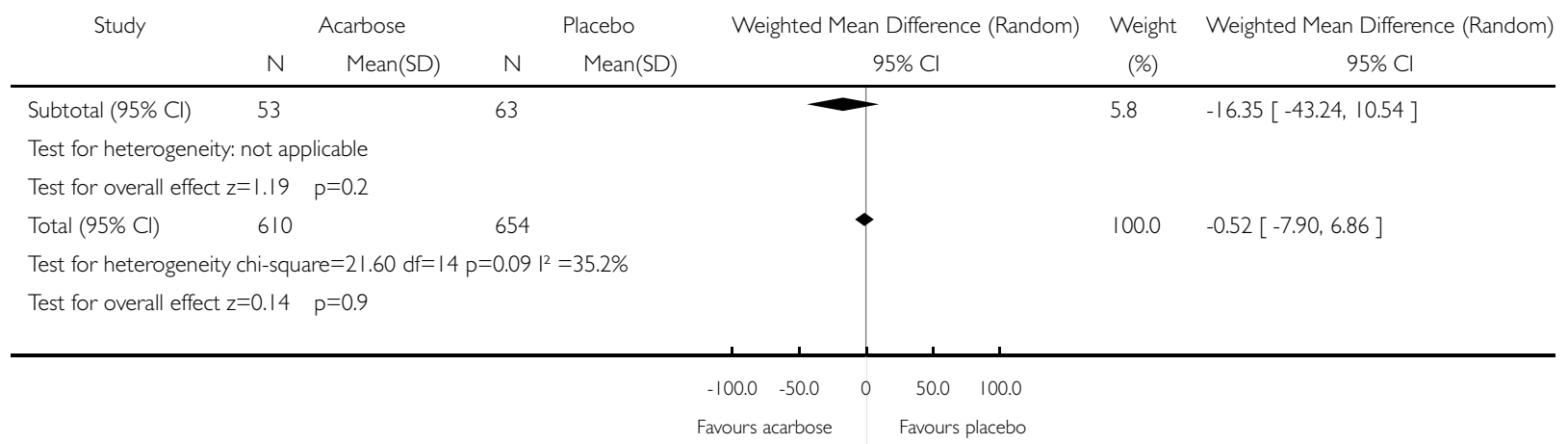

\section{Fig. I I. Comparison 0I. Acarbose versus placebo}

01.09 Change in post-load insulin levels (pmol/l)

Review: Alpha-glucosidase inhibitors for type 2 diabetes mellitus

Comparison: 01 Acarbose versus placebo

Outcome: 09 Change in post-load insulin levels (pmol/l)

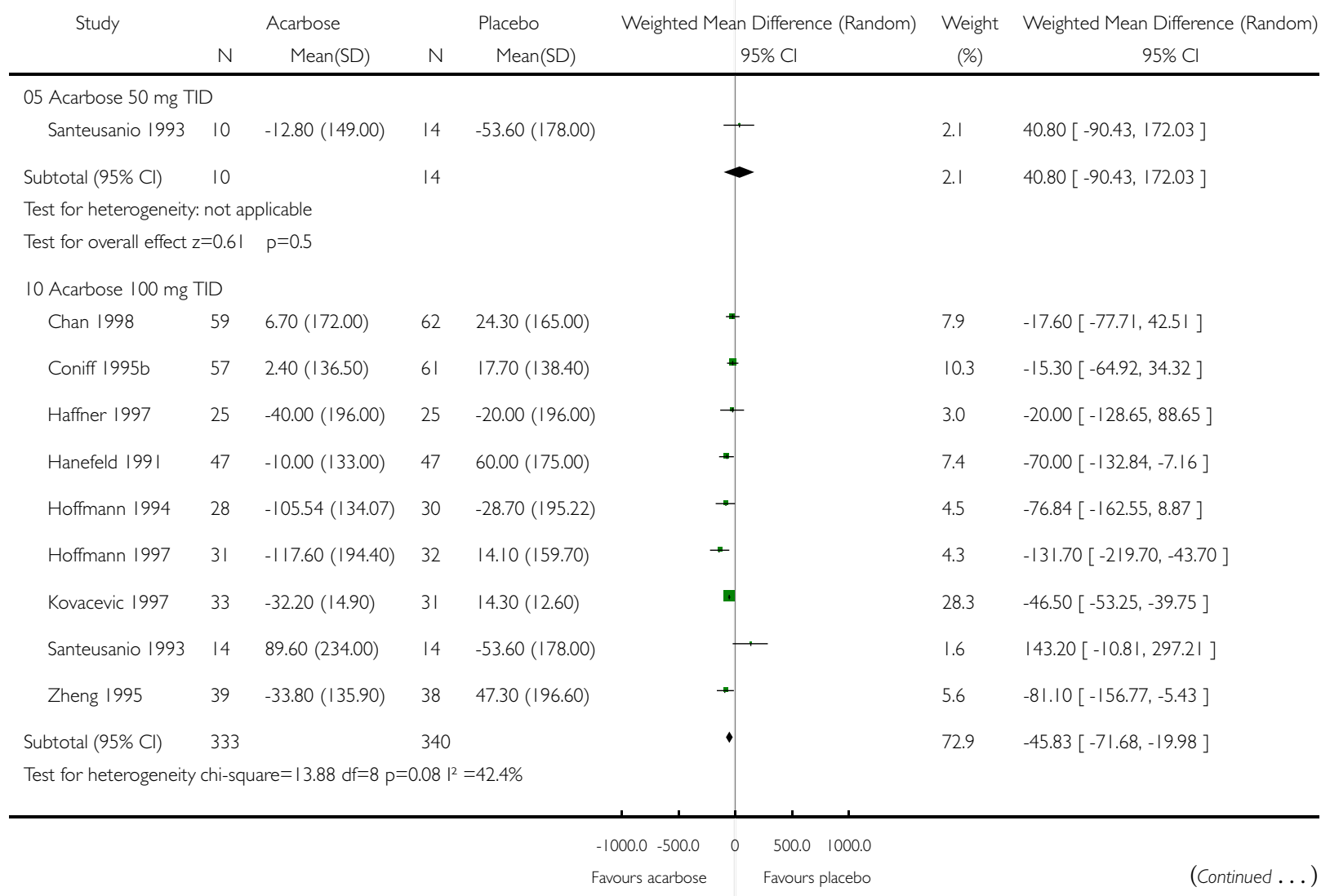

Alpha-glucosidase inhibitors for type 2 diabetes mellitus (Review) 
(... Continued)

\begin{tabular}{|c|c|c|c|c|c|c|c|}
\hline \multirow[t]{2}{*}{ Study } & \multicolumn{2}{|r|}{ Acarbose } & \multicolumn{2}{|r|}{ Placebo } & \multirow{2}{*}{$\begin{array}{l}\text { Weighted Mean Difference (Random) } \\
\qquad 95 \% \mathrm{Cl}\end{array}$} & \multirow{2}{*}{$\begin{array}{l}\text { Weight } \\
(\%)\end{array}$} & \multirow{2}{*}{$\begin{array}{l}\text { Weighted Mean Difference (Random) } \\
\qquad 95 \% \mathrm{Cl}\end{array}$} \\
\hline & $\mathrm{N}$ & Mean(SD) & N & Mean(SD) & & & \\
\hline \multicolumn{8}{|c|}{ Test for overall effect $z=3.47 \quad p=0.0005$} \\
\hline \multicolumn{8}{|c|}{20 Acarbose $200 \mathrm{mg}$ TID } \\
\hline Coniff 1995 & 65 & $-45.10(226.80)$ & 61 & $-51.40(230.90)$ & + & 5.1 & $6.30[-73.68,86.28]$ \\
\hline Coniff I995b & 52 & $-6.70(138.70)$ & 61 & $17.70(138.40)$ & + & 9.9 & $-24.40[-75.66,26.86]$ \\
\hline Subtotal $(95 \% \mathrm{Cl})$ & 117 & & 122 & & $\bullet$ & 15.0 & $-15.46[-58.62,27.69]$ \\
\hline \multicolumn{8}{|c|}{ Test for heterogeneity chi-square $=0.40 \mathrm{df}=\mid \mathrm{p}=0.53 \mathrm{I}^{2}=0.0 \%$} \\
\hline \multicolumn{8}{|c|}{ Test for overall effect $z=0.70 \quad p=0.5$} \\
\hline \multicolumn{8}{|c|}{30 Acarbose 300 mg TID } \\
\hline Coniff 1995b & 53 & $-44.70(137.90)$ & 61 & $17.70(138.40)$ & $=$ & 10.0 & $-62.40[-113.24,-11.56]$ \\
\hline Subtotal $(95 \% \mathrm{Cl})$ & 53 & & 61 & & $\bullet$ & 10.0 & $-62.40[-113.24,-11.56]$ \\
\hline \multicolumn{8}{|c|}{ Test for heterogeneity: not applicable } \\
\hline \multicolumn{8}{|c|}{ Test for overall effect $z=2.41 \quad p=0.02$} \\
\hline Total $(95 \% \mathrm{Cl})$ & 513 & & 537 & & $\cdot$ & 100.0 & $-40.82[-60.64,-21.01]$ \\
\hline \multicolumn{8}{|c|}{ Test for heterogeneity chi-square $=18.29 \mathrm{df}=12 \mathrm{p}=0.1 \mid \mathrm{I}^{2}=34.4 \%$} \\
\hline \multicolumn{8}{|c|}{ Test for overall effect $z=4.04 \quad p=0.00005$} \\
\hline & & & & & $500.0 \quad 1000.0$ & & \\
\hline & & & & & Favours placebo & & \\
\hline
\end{tabular}

Fig. I2. Comparison 0I. Acarbose versus placebo

01.10 Change in fasting C-peptide levels (nmol/l)

Review: Alpha-glucosidase inhibitors for type 2 diabetes mellitus

Comparison: 01 Acarbose versus placebo

Outcome: 10 Change in fasting C-peptide levels (nmol/l)

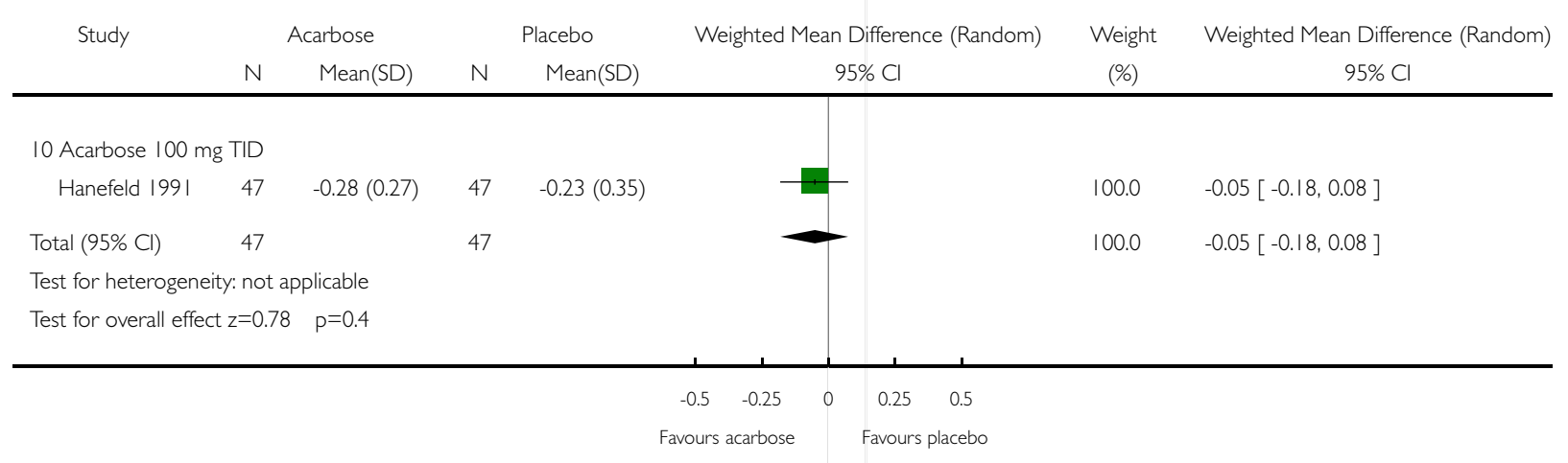




\section{Fig. 13. Comparison 0I. Acarbose versus placebo}

\section{I.I I Change in post-load C-peptide levels (nmol/I)}

Review: Alpha-glucosidase inhibitors for type 2 diabetes mellitus

Comparison: 01 Acarbose versus placebo

Outcome: I I Change in post-load C-peptide levels (nmol/l)

Study

Acarbose

Placebo

Weighted Mean Difference (Random)

Weight

Weighted Mean Difference (Random)

$N \quad M e a n(S D) \quad N \quad M e a n(S D)$ $95 \% \mathrm{Cl}$

$95 \% \mathrm{Cl}$

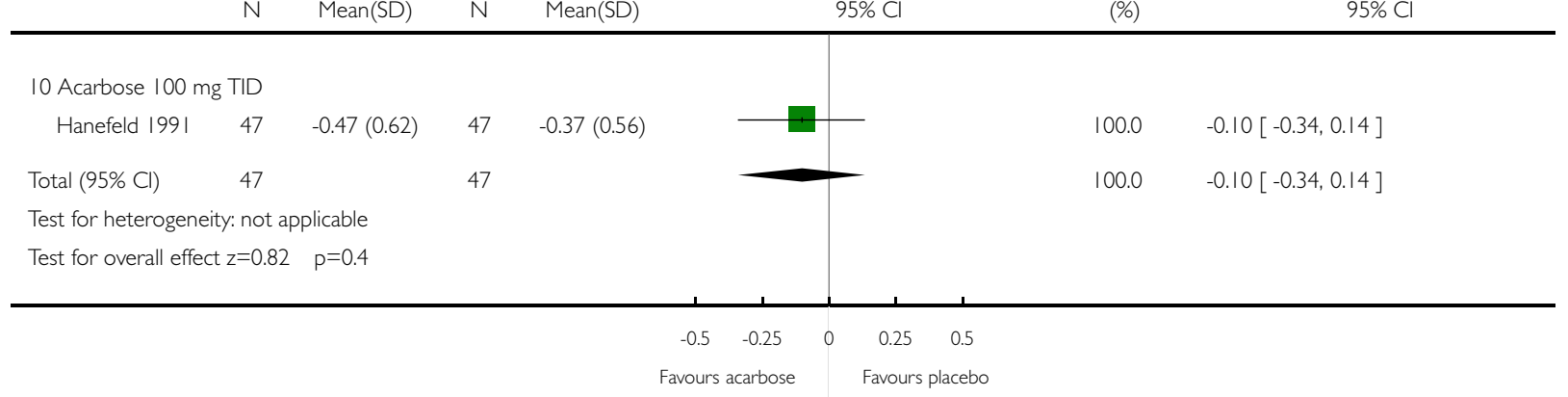

Fig. I4. Comparison 0 I. Acarbose versus placebo

01.12 Change in body weight $(\mathrm{Kg})$

Review: Alpha-glucosidase inhibitors for type 2 diabetes mellitus

Comparison: 01 Acarbose versus placebo

Outcome: 12 Change in body weight $(\mathrm{Kg})$

Study Acarbose

Placebo

Weighted Mean Difference (Random) Weight

Weighted Mean Difference (Random)

N Mean(SD)

Mean(SD)

$95 \% \mathrm{Cl}$

(\%)

$95 \% \mathrm{Cl}$

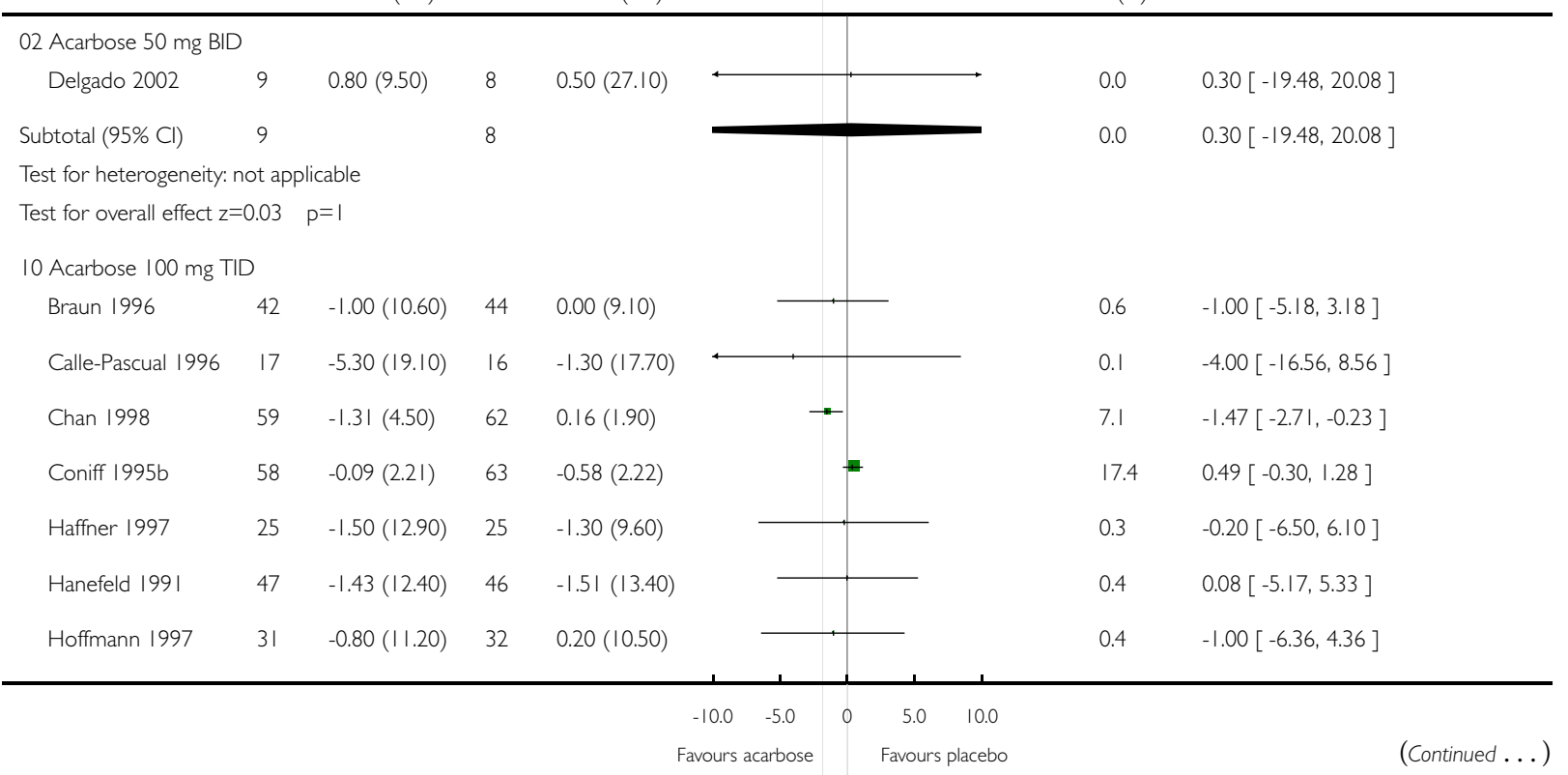

Alpha-glucosidase inhibitors for type 2 diabetes mellitus (Review) 
(... Continued)

\begin{tabular}{|c|c|c|c|c|c|c|c|}
\hline \multirow[t]{2}{*}{ Study } & \multicolumn{2}{|r|}{ Acarbose } & \multicolumn{2}{|r|}{ Placebo } & \multirow{2}{*}{$\begin{array}{l}\text { Weighted Mean Difference (Random) } \\
\qquad 95 \% \mathrm{Cl}\end{array}$} & \multirow{2}{*}{$\begin{array}{c}\text { Weight } \\
(\%)\end{array}$} & \multirow{2}{*}{$\begin{array}{l}\text { Weighted Mean Difference (Random) } \\
\qquad 95 \% \mathrm{Cl}\end{array}$} \\
\hline & N & Mean(SD) & N & Mean(SD) & & & \\
\hline Holman 1999 & 104 & $0.38(4.06)$ & 117 & $0.48(4.85)$ & $\rightarrow$ & 7.9 & $-0.10[-1.28,1.08]$ \\
\hline Hotta 1993 & 16 & $-0.81(3.22)$ & 15 & $-0.82(1.09)$ & $T$ & 3.9 & $0.01[-1.66,1.68]$ \\
\hline Meneilly 2000 & 22 & $-1.90(2.80)$ & 23 & $-1.90(3.80)$ & 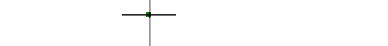 & 2.9 & $0.00[-1.94,1.94]$ \\
\hline Subtotal (95\% Cl) & 421 & & 443 & & - & 40.9 & $-0.09[-0.61,0.42]$ \\
\hline \multicolumn{8}{|c|}{ Test for heterogeneity chi-square $=7.5 \mathrm{Idf}=9 \mathrm{p}=0.58 \mathrm{I}^{2}=0.0 \%$} \\
\hline \multicolumn{8}{|c|}{ Test for overall effect $z=0.36 \quad p=0.7$} \\
\hline \multicolumn{8}{|c|}{19 Acarbose $200-100-200$} \\
\hline Buchanan 1988 & 9 & $-3.20(9.80)$ & 11 & $-2.30(10.80)$ & & 0.1 & $-0.90[-9.94,8.14]$ \\
\hline Subtotal $(95 \% \mathrm{Cl})$ & 9 & & 11 & & & 0.1 & $-0.90[-9.94,8.14]$ \\
\hline \multicolumn{8}{|c|}{ Test for heterogeneity: not applicable } \\
\hline \multicolumn{8}{|c|}{ Test for overall effect $z=0.20 \quad p=0.8$} \\
\hline \multicolumn{8}{|c|}{20 Acarbose $200 \mathrm{mg}$ TID } \\
\hline Coniff 1995 & 66 & $-1.42(2.84)$ & 62 & $-1.40(2.91)$ & $\rightarrow$ & 10.9 & $-0.02[-1.02,0.98]$ \\
\hline Coniff 1995b & 54 & $-0.95(2.20)$ & 63 & $-0.58(2.22)$ & + & 16.9 & $-0.37[-1.17,0.43]$ \\
\hline Subtotal $(95 \% \mathrm{Cl})$ & 120 & & 125 & & $\bullet$ & 27.8 & $-0.23[-0.86,0.39]$ \\
\hline \multicolumn{8}{|c|}{ Test for heterogeneity chi-square $=0.29 \mathrm{df}=\mid \mathrm{p}=0.59 \mathrm{I}^{2}=0.0 \%$} \\
\hline \multicolumn{8}{|c|}{ Test for overall effect $z=0.73 \quad p=0.5$} \\
\hline \multicolumn{8}{|c|}{30 Acarbose $300 \mathrm{mg}$ TID } \\
\hline Coniff 1994 & 91 & $-0.93(3.05)$ & 98 & $-0.77(3.07)$ & 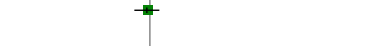 & 14.3 & $-0.16[-1.03,0.71]$ \\
\hline Coniff 1995b & 53 & $-0.59(2.18)$ & 63 & $-0.58(2.22)$ & 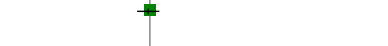 & 16.9 & $-0.01[-0.81,0.79]$ \\
\hline Subtotal $(95 \% \mathrm{Cl})$ & 144 & & 161 & & $\bullet$ & 31.1 & $-0.08[-0.67,0.51]$ \\
\hline \multicolumn{8}{|c|}{ Test for heterogeneity chi-square $=0.06 \mathrm{df}=\mid \mathrm{p}=0.80 \mathrm{I}^{2}=0.0 \%$} \\
\hline \multicolumn{8}{|c|}{ Test for overall effect $z=0.26 \quad p=0.8$} \\
\hline Total $(95 \% \mathrm{Cl})$ & 703 & & 748 & & 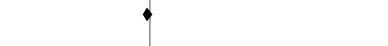 & 100.0 & $-0.13[-0.46,0.20]$ \\
\hline \multicolumn{8}{|c|}{ Test for heterogeneity chi-square $=8.03 \mathrm{df}=15 \mathrm{p}=0.92 \mathrm{I}^{2}=0.0 \%$} \\
\hline Test for overall effe & 0.77 & $=0.4$ & & & & & \\
\hline
\end{tabular}

Alpha-glucosidase inhibitors for type 2 diabetes mellitus (Review) 


\section{Fig. I5. Comparison 0I. Acarbose versus placebo}

\subsection{Change in body mass index $(\mathrm{Kg} / \mathrm{m} 2)$}

Review: Alpha-glucosidase inhibitors for type 2 diabetes mellitus

Comparison: 01 Acarbose versus placebo

Outcome: 13 Change in body mass index $(\mathrm{Kg} / \mathrm{m} 2)$

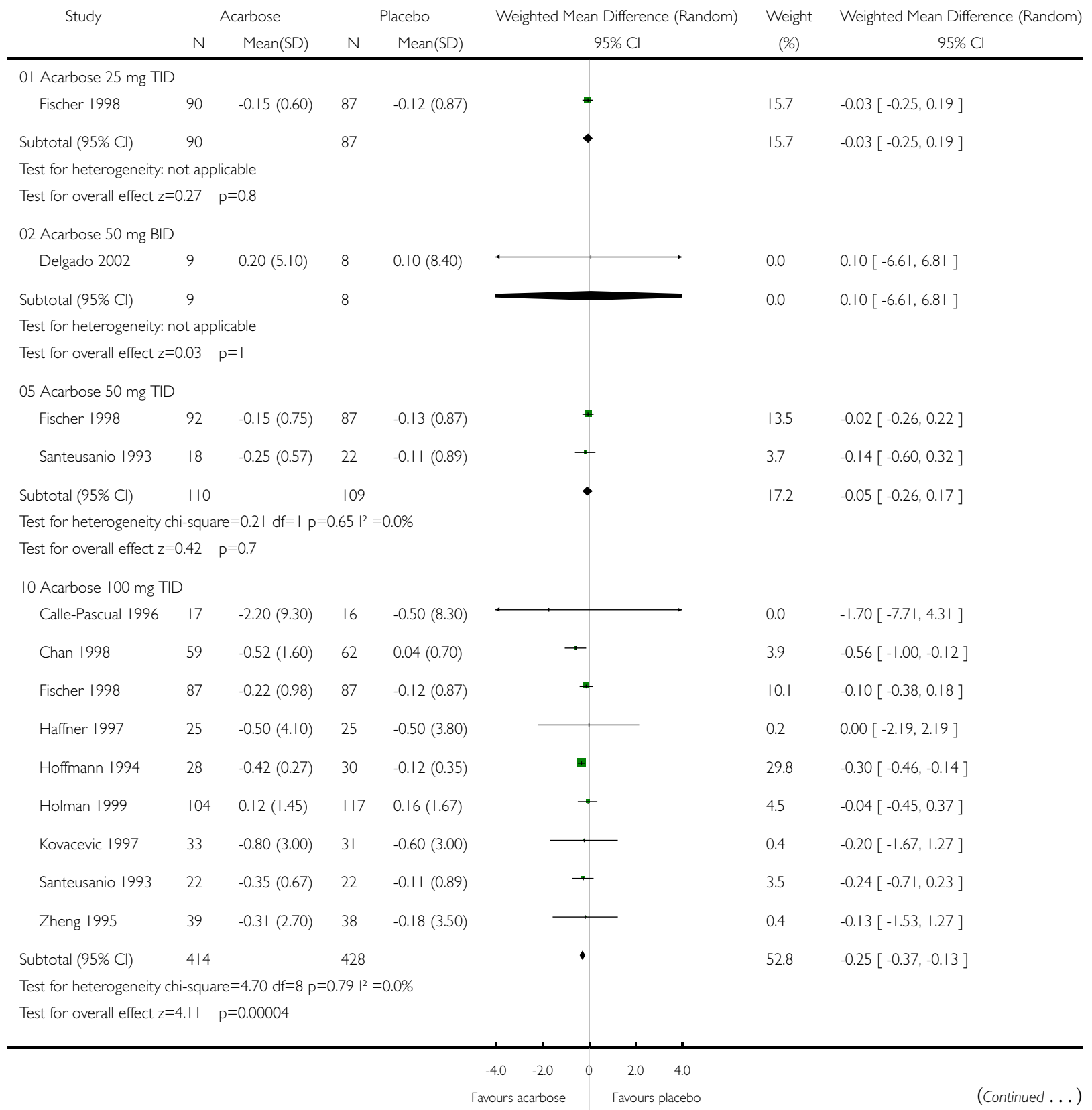

Alpha-glucosidase inhibitors for type 2 diabetes mellitus (Review) 
(... Continued)

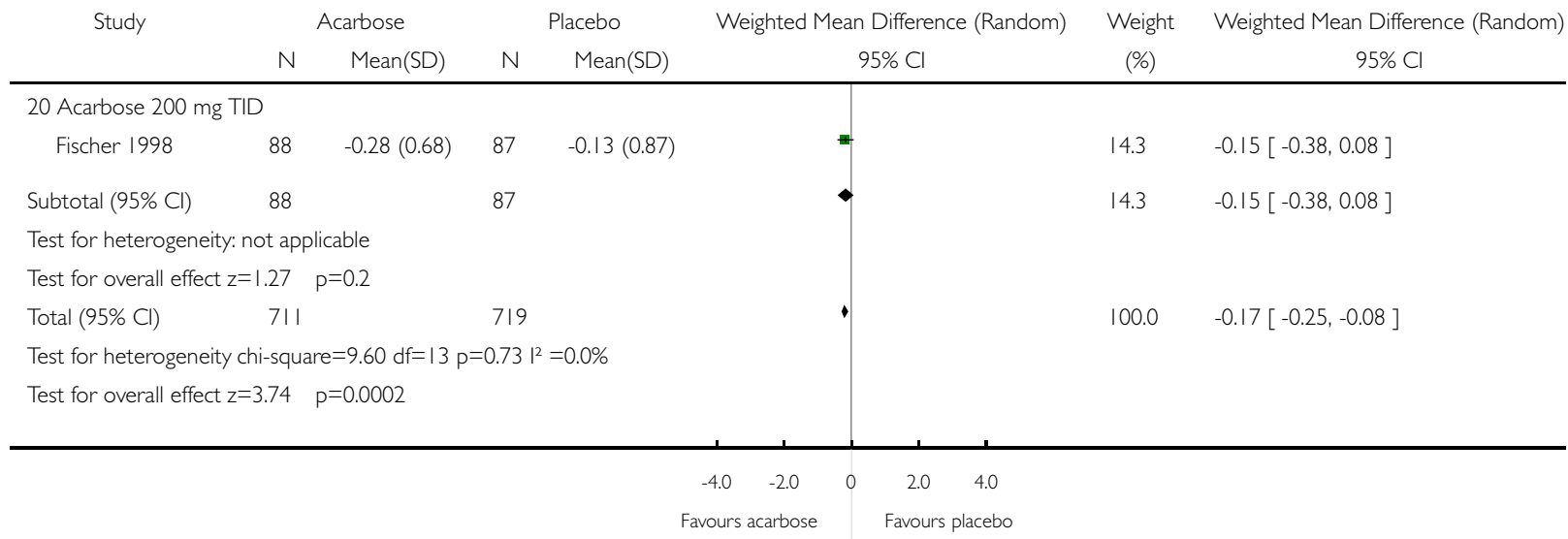

Fig. 16. Comparison 0I. Acarbose versus placebo

\section{OI.I5 Total deaths}

Review: Alpha-glucosidase inhibitors for type 2 diabetes mellitus

Comparison: 0 I Acarbose versus placebo

Outcome: 15 Total deaths

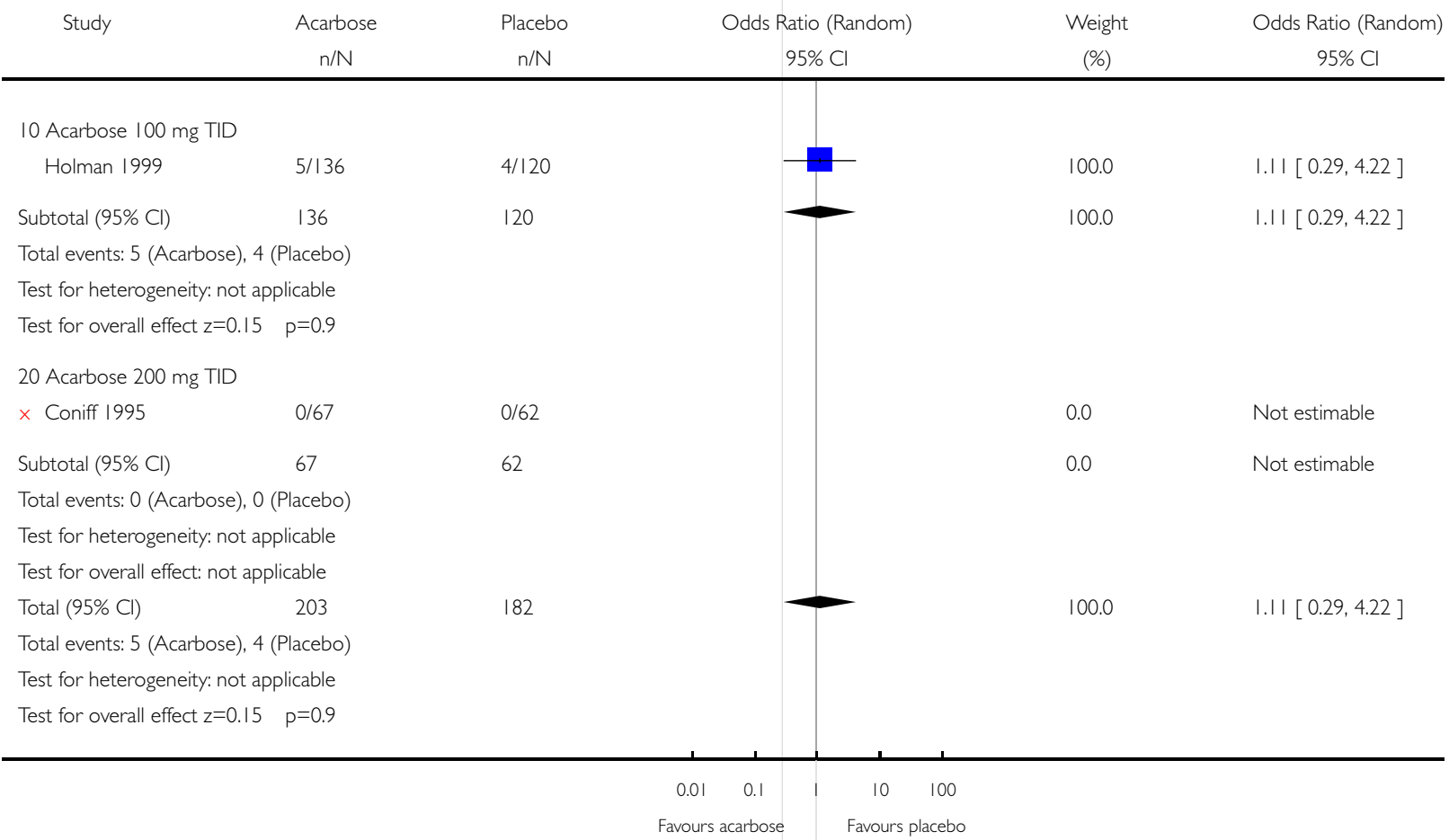




\section{Fig. I7. Comparison 0I. Acarbose versus placebo}

\subsection{Disease related deaths}

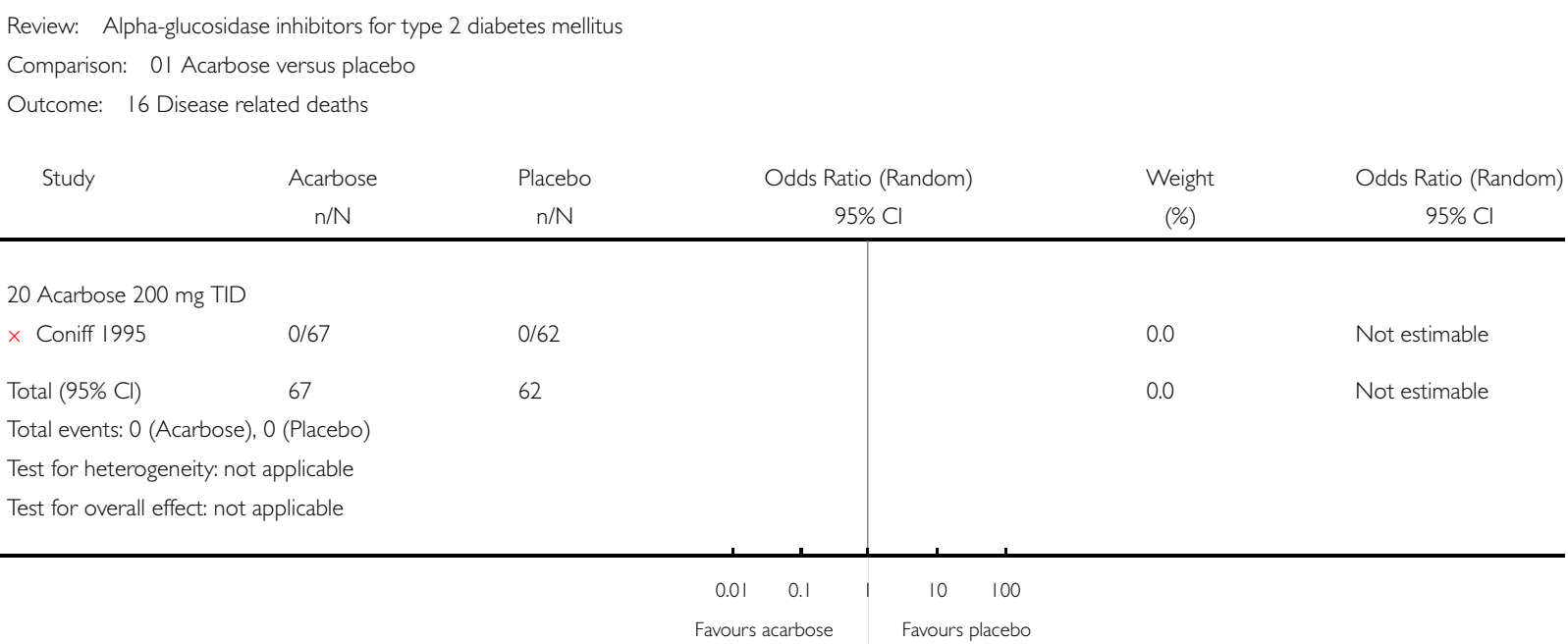

Fig. I 8. Comparison 0I. Acarbose versus placebo

\subsection{Occurence of morbidity (total)}

Review: Alpha-glucosidase inhibitors for type 2 diabetes mellitus

Comparison: 01 Acarbose versus placebo

Outcome: 20 Occurence of morbidity (total)

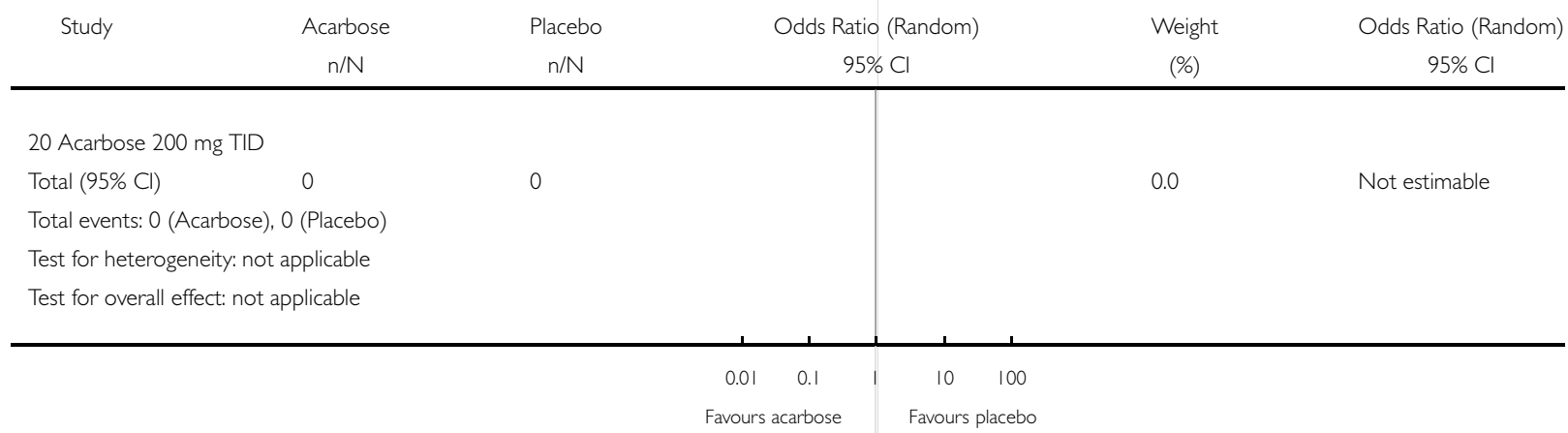




\section{Fig. 19. Comparison 0I. Acarbose versus placebo}

\section{I.2I Occurence of morbidity (disease specific)}

Review: Alpha-glucosidase inhibitors for type 2 diabetes mellitus

Comparison: 01 Acarbose versus placebo

Outcome: 21 Occurence of morbidity (disease specific)

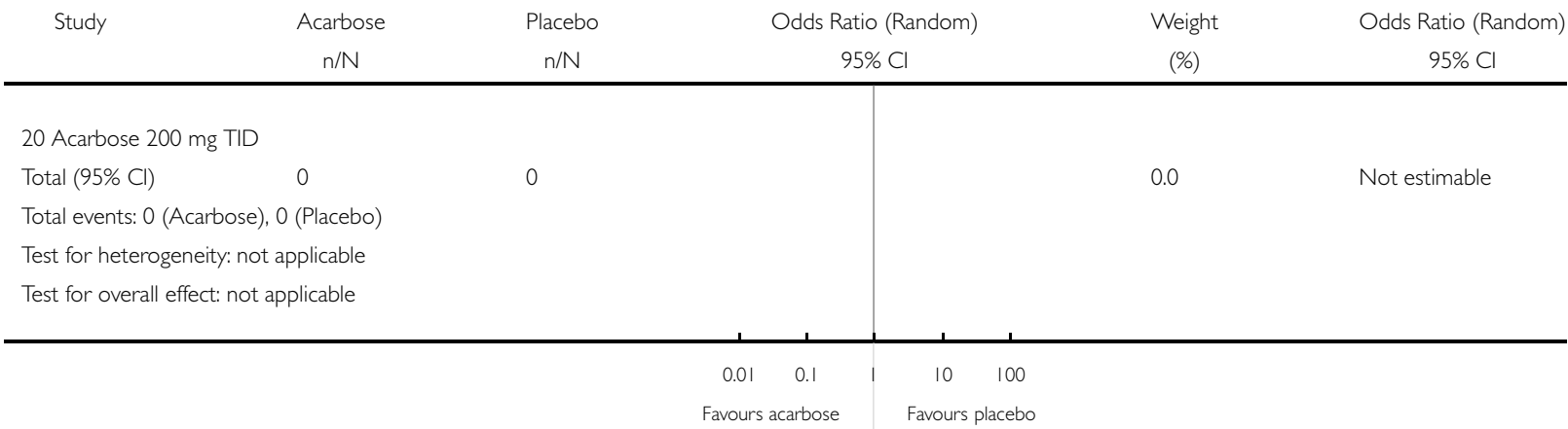

Fig. 20. Comparison 0I. Acarbose versus placebo

01.30 Occurence of adverse effects

Review: Alpha-glucosidase inhibitors for type 2 diabetes mellitus

Comparison: 01 Acarbose versus placebo

Outcome: 30 Occurence of adverse effects

Study Acarbose

Placebo Odds Ratio (Random)

$95 \% \mathrm{Cl}$

Weight

Odds Ratio (Random)

$\mathrm{n} / \mathrm{N}$

$\mathrm{n} / \mathrm{N}$

01 Acarbose 25 mg TID

Fischer 1998

$46 / 102$

$33 / 97$

102

97

Subtotal $(95 \% \mathrm{Cl})$

Placebo)

Total events: 46 (Acarbose), 33 (Placebo)
Test for heterogeneity: not applicable

Test for overall effect $z=1.59 \quad p=0.1$

05 Acarbose 50 mg TID

Campbell 1998

$248 / 259$

$242 / 263$

Fischer 1998

$59 / 99$

$33 / 97$

Santeusanio 1993

$9 / 28$

$9 / 29$

Subtotal $(95 \% \mathrm{Cl})$

386

389

Total events: 316 (Acarbose), 284 (Placebo)

Test for heterogeneity chi-square $=2.55 \mathrm{df}=2 \mathrm{p}=0.28 \mathrm{I}^{2}=21.6 \%$

Test for overall effect $z=2.95 \quad p=0.003$

10 Acarbose $100 \mathrm{mg}$ TID

Braun 1996

$21 / 55$

$4 / 57$

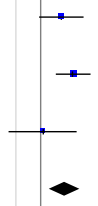

$1.96[0.92,4.14]$

7.0

$2.86[1.60,5.11]$

3.6

$1.05[0.34,3.22]$

16.2

$2.11[1.29,3.47]$

$1.59[0.90,2.83]$

$1.59[0.90,2.83]$

7.1

$[0.90,2.83]$

Alpha-glucosidase inhibitors for type 2 diabetes mellitus (Review) 


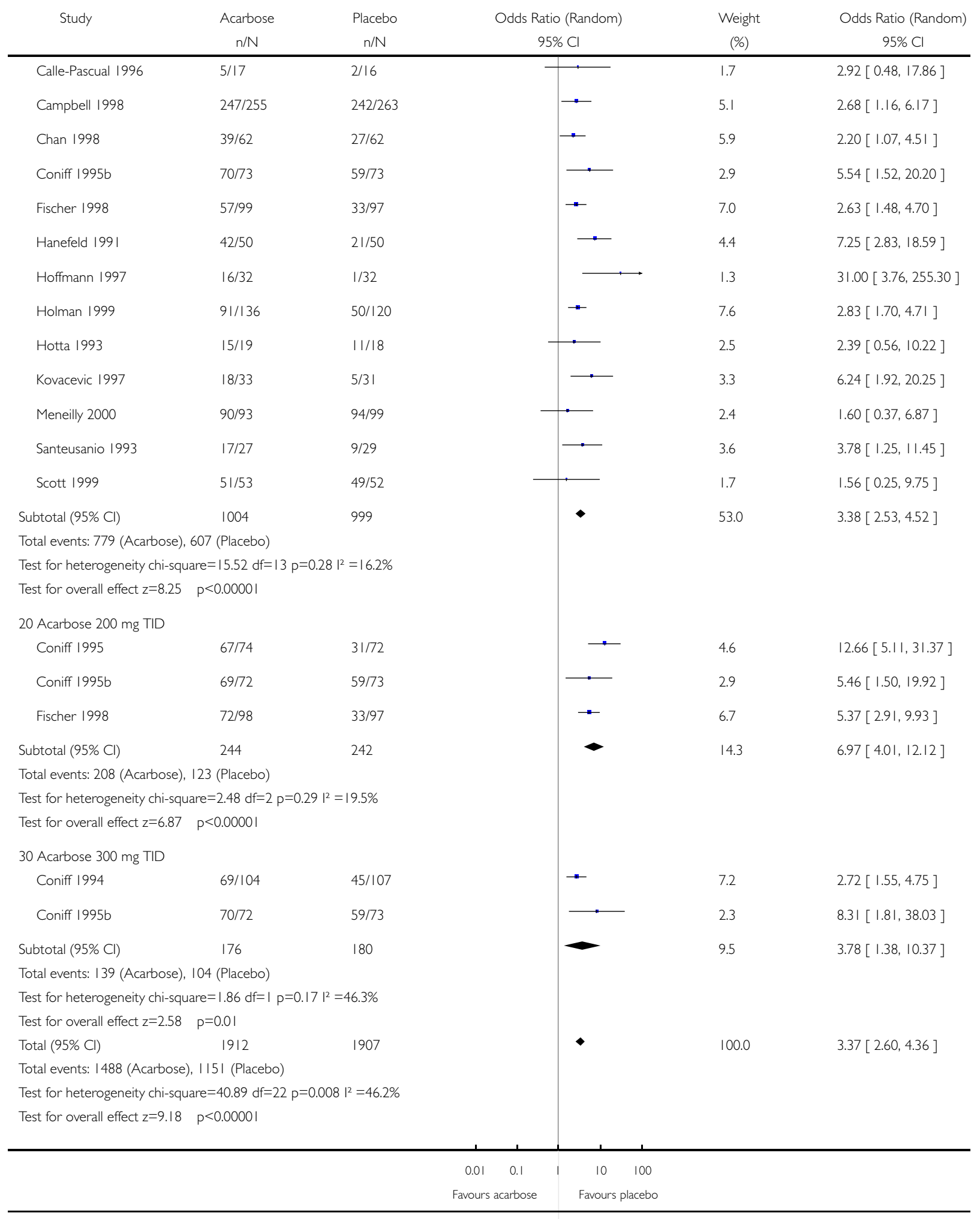

Alpha-glucosidase inhibitors for type 2 diabetes mellitus (Review) 


\section{Fig. 2I. Comparison 0I. Acarbose versus placebo}

\section{I.3 I Occurence of gastro-intestinal adverse effects}

Review: Alpha-glucosidase inhibitors for type 2 diabetes mellitus

Comparison: 01 Acarbose versus placebo

Outcome: 31 Occurence of gastro-intestinal adverse effects

Study

Acarbose

Placebo

Odds Ratio (Random)

Weight

$\mathrm{n} / \mathrm{N}$

$\mathrm{n} / \mathrm{N}$

$95 \% \mathrm{Cl}$

(\%)

$95 \% \mathrm{C}$

05 Acarbose $50 \mathrm{mg}$ TID

Campbell 1998

$160 / 259$

$98 / 263$

Subtotal $(95 \% \mathrm{Cl})$

259

263

Total events: 160 (Acarbose), 98 (Placebo)

Test for heterogeneity: not applicable

Test for overall effect $z=5.54 \quad p<0.0000$ I

10 Acarbose 100 mg TID

Campbell 1998

|55/255

$98 / 263$

Holman 1999

$56 / 136$

$20 / 120$

Subtotal $(95 \% \mathrm{Cl})$

391

383

Total events: 21 I (Acarbose), I 8 (Placebo)

Test for heterogeneity chi-square $=0.70 \mathrm{df}=\mid \mathrm{p}=0.40 \mathrm{I}^{2}=0.0 \%$

Test for overall effect $z=6.69 \quad p<0.0000$ I

20 Acarbose $200 \mathrm{mg}$ TID

$$
\text { Coniff } 1995
$$

$59 / 74$

$25 / 72$

Subtotal $(95 \% \mathrm{Cl})$

74

72

Total events: 59 (Acarbose), 25 (Placebo)

Test for heterogeneity: not applicable

Test for overall effect $z=5.26 \quad p<0.0000$ I

Total $(95 \% \mathrm{Cl})$

724

Total events: 430 (Acarbose), 24I (Placebo)

Test for heterogeneity chi-square $=6.76 \mathrm{df}=3 \mathrm{p}=0.08 \mathrm{I}^{2}=55.6 \%$

Test for overall effect $z=6.56 \quad p<0.0000$ ।

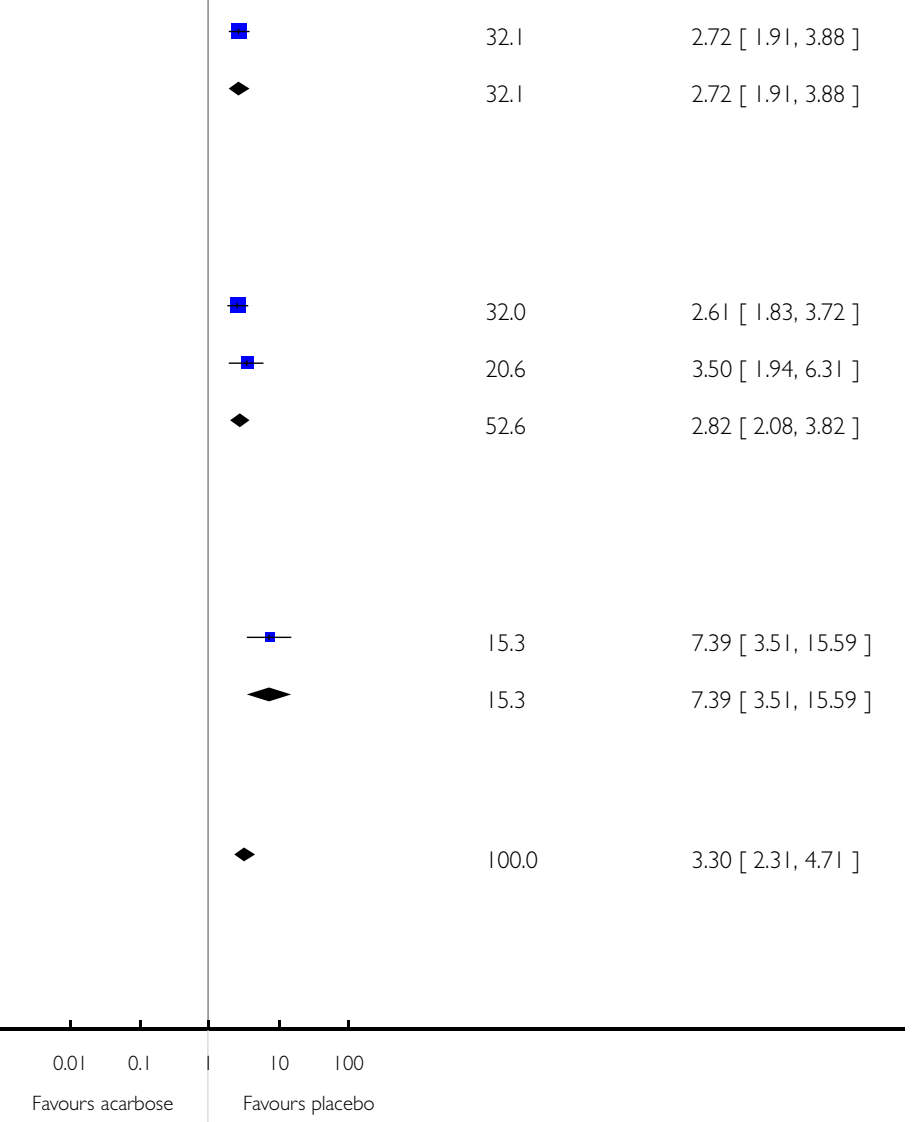

(1)


Fig. 22. Comparison 0I. Acarbose versus placebo

0 I.50 Quality of life

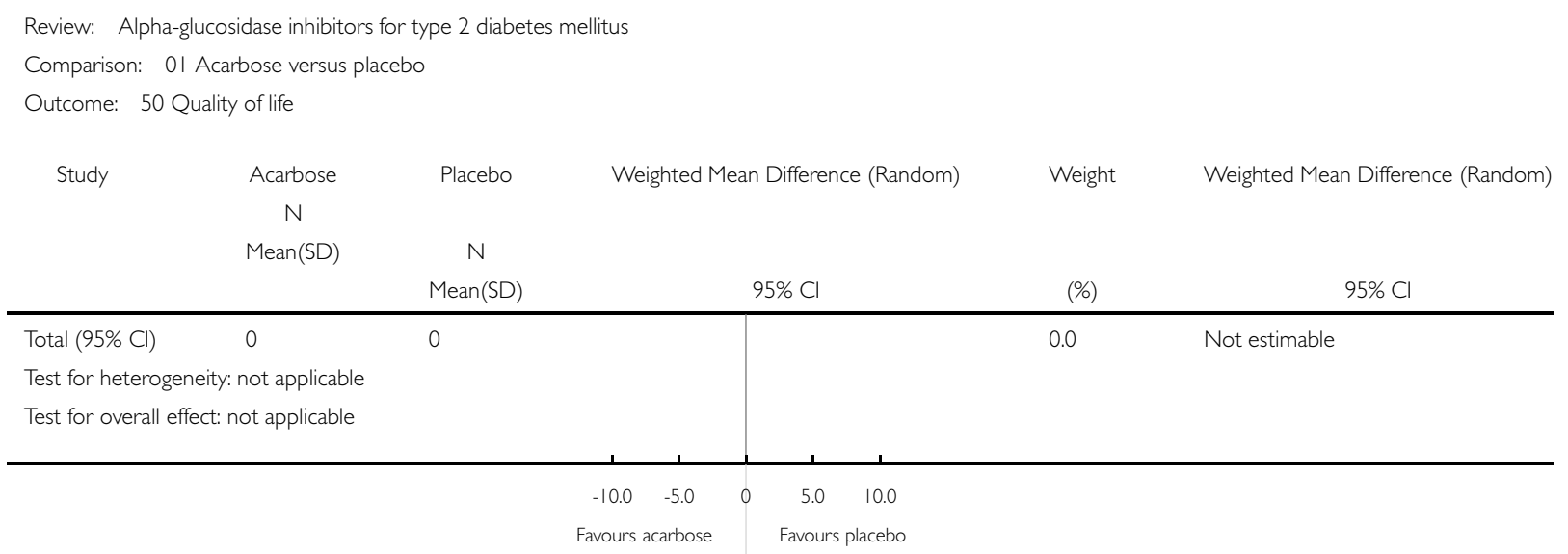

Fig. 23. Comparison 0I. Acarbose versus placebo

01.90 Change in post-load blood glucose ( $\mathrm{mmol} / \mathrm{l})$ (2-hours)

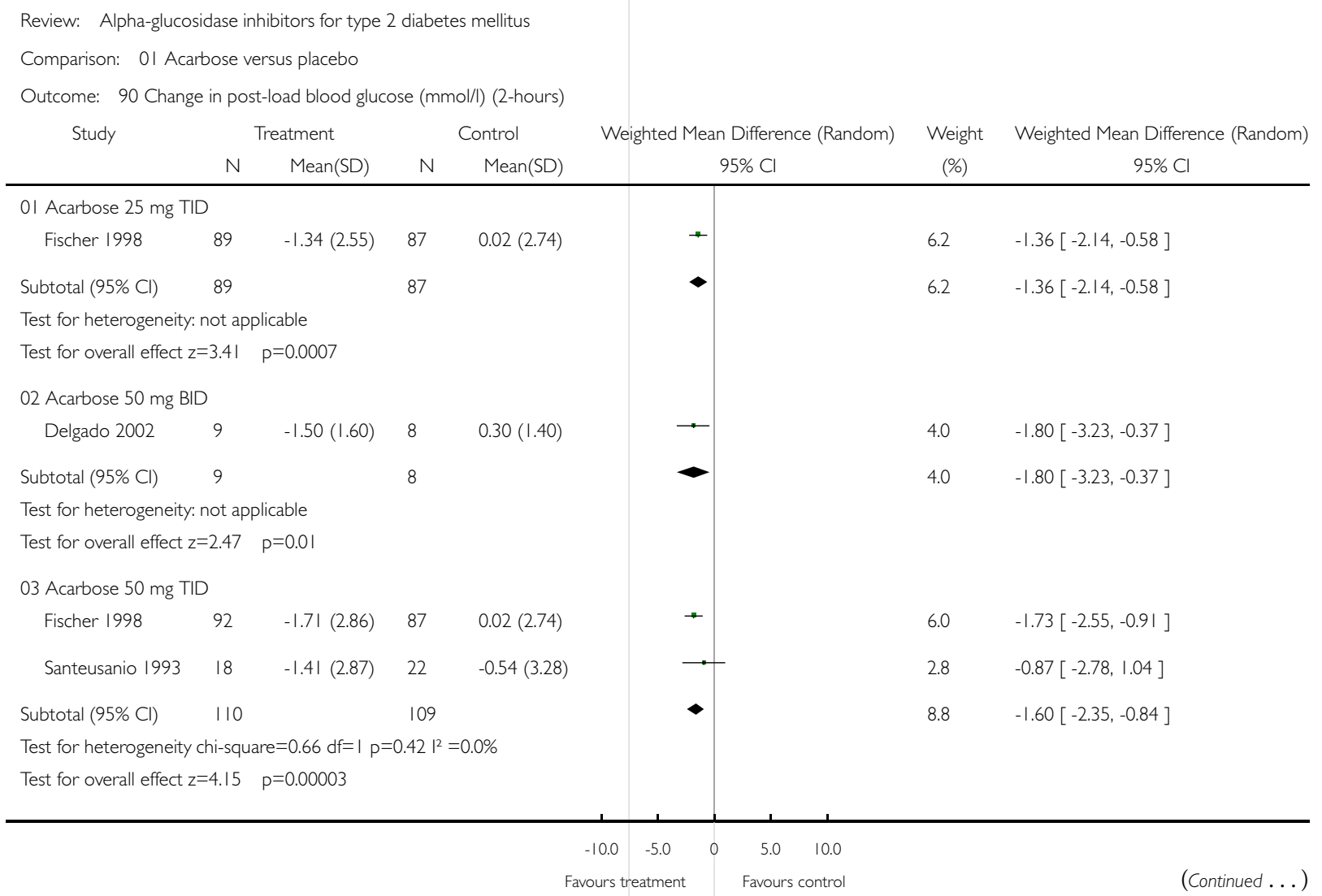


(... Continued)

Study

Treatment

Control

Weighted Mean Difference (Random)

Weight

Weighted Mean Difference (Random)

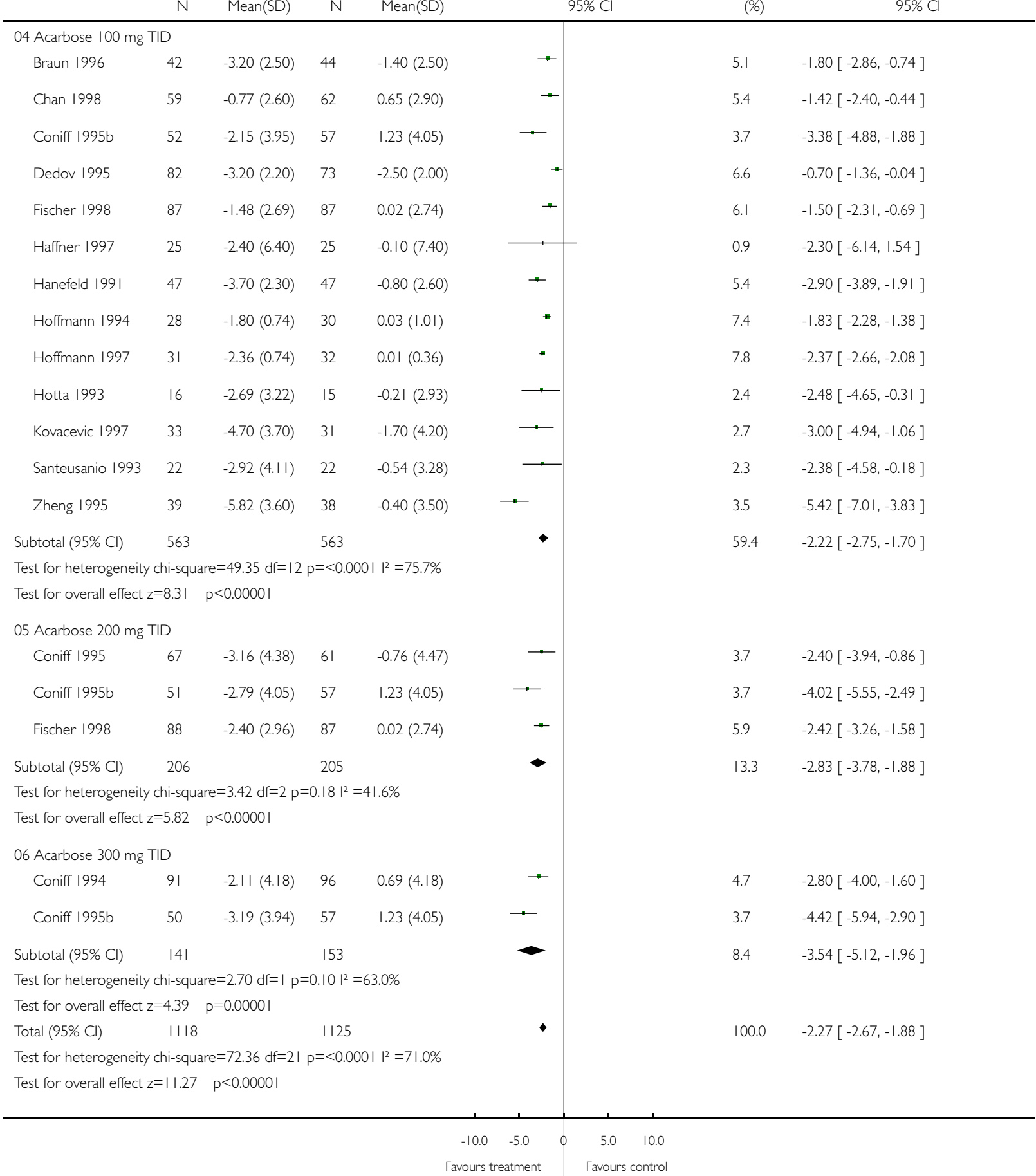

Alpha-glucosidase inhibitors for type 2 diabetes mellitus (Review) 


\section{Fig. 24. Comparison 0I. Acarbose versus placebo}

\subsection{Change in post-load insulin levels (pmol/l) (2-hours)}

Review: Alpha-glucosidase inhibitors for type 2 diabetes mellitus

Comparison: 01 Acarbose versus placebo

Outcome: 91 Change in post-load insulin levels (pmol/l) (2-hours)

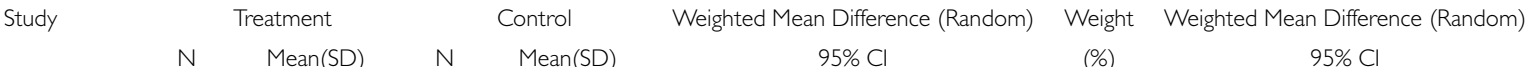

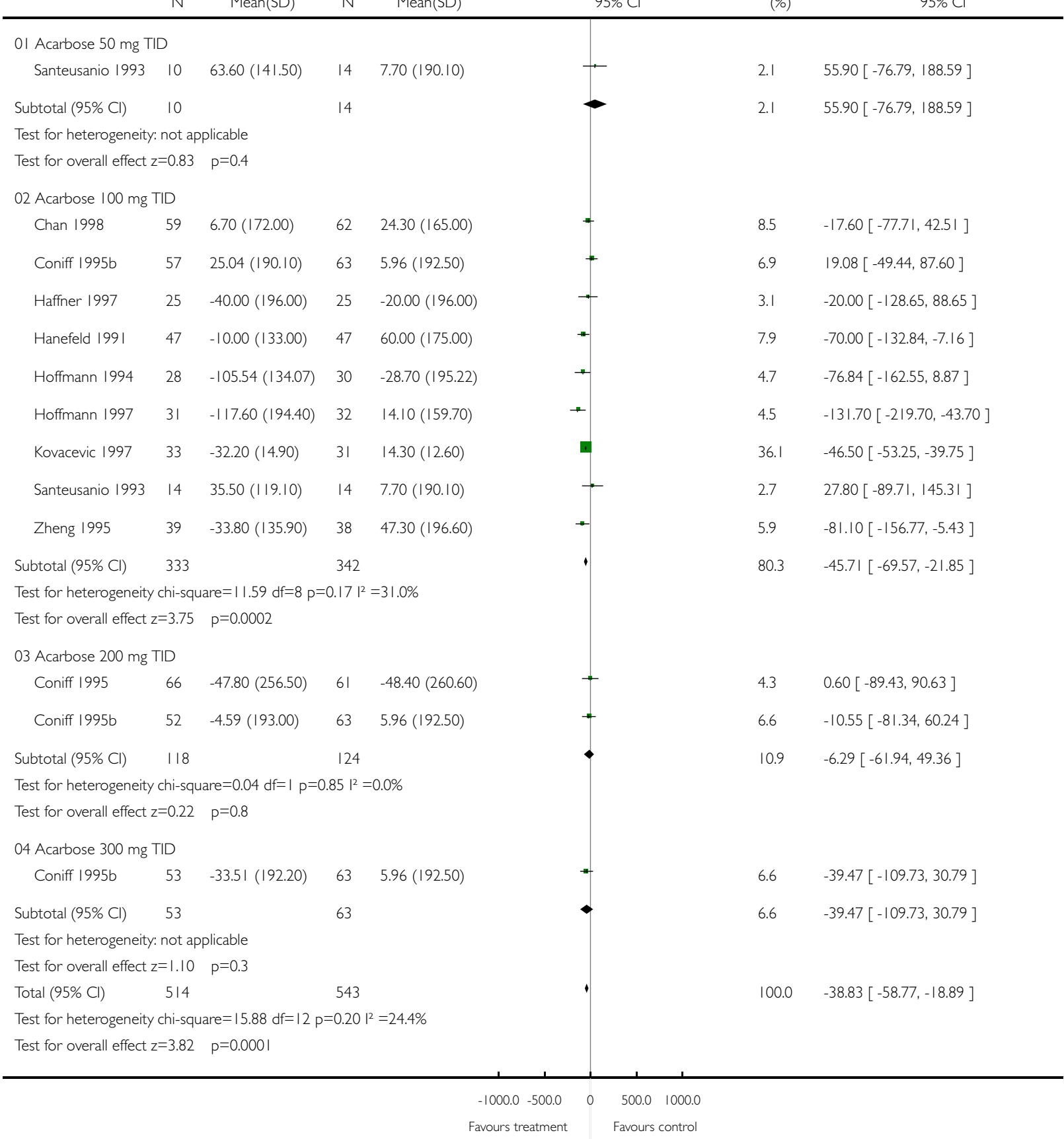

Alpha-glucosidase inhibitors for type 2 diabetes mellitus (Review) 
Fig. 25. Comparison 02. Acarbose versus sulphonylurea (SU)

\subsection{Change in glycated haemoglobin (\%)}

Review: Alpha-glucosidase inhibitors for type 2 diabetes mellitus

Comparison: 02 Acarbose versus sulphonylurea (SU)

Outcome: 0 I Change in glycated haemoglobin (\%)

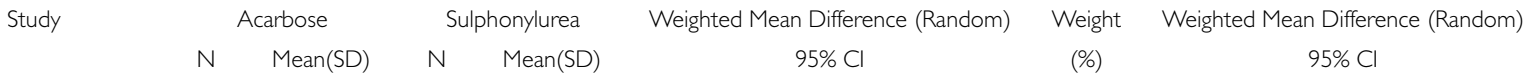

0I Acarbose $100 \mathrm{mg}$ TID vs Tolbutamide $2000 \mathrm{mg}$ in 3 dose

Van de Laar 2004a $32 \quad-1.10(1.00) \quad 43 \quad-1.80(1.30)$

Subtotal $(95 \% \mathrm{Cl}) \quad 32 \quad 43$

Test for heterogeneity: not applicable

Test for overall effect $z=2.64 \quad p=0.008$

10 Acarbose $200 \mathrm{mg}$ TID vs Tolbutamide $1000 \mathrm{mg}$ TID

$\begin{array}{lllll}\text { Coniff } 1995 & 67 & -0.54(1.05) & 66 & -0.93(1.04)\end{array}$

Subtotal $(95 \% \mathrm{Cl}) \quad 67 \quad 66$

Test for heterogeneity: not applicable

Test for overall effect $z=2.15 \quad p=0.03$

18 Acarbose $100 \mathrm{mg}$ TID vs Glibenclamide I mg TID

Haffner $1997 \quad 25 \quad 0.00(1.60) \quad 27 \quad-1.30(1.00)$

Subtotal $(95 \% \mathrm{Cl}) \quad 25 \quad 27$

27

Test for heterogeneity: not applicable

Test for overall effect $z=3.48 \quad p=0.0005$

20 Acarbose 100 mg TID vs Glibenclamide 3,5 mg TID

$\begin{array}{lcccc}\text { Hoffmann 1990 } & 48 & -1.78(3.62) & 47 & -1.87(3.95) \\ \text { Hoffmann 1994 } & 28 & -0.98(0.45) & 27 & -0.76(0.39) \\ \text { Kovacevic 1997 } & 33 & -0.70(0.90) & 33 & -1.60(1.20) \\ \text { Rosenthal 2002 } & 32 & -0.50(0.36) & 31 & -0.20(0.78) \\ \text { Subtotal (95\% Cl) } & |4| & & 138 & \end{array}$

Test for heterogeneity chi-square $=17.48 \mathrm{df}=3 p=0.0006 \mathrm{I}^{2}=82.8 \%$

Test for overall effect $z=0.29 \quad p=0.8$

30 Acarbose $100 \mathrm{mg}$ TID vs Gliclazide 80 mg BID

$\begin{array}{ccccccc}\text { Salman } 2001 & 27 & -1.78(1.64) & 30 & -2.16(1.17) & 10.7 & 0.38[-0.37,1.13] \\ \text { Subtotal }(95 \% \mathrm{Cl}) & 27 & 30 & 10.7 & 0.38[-0.37,1.13]\end{array}$

Test for heterogeneity: not applicable

Test for overall effect $z=1.00 \quad p=0.3$

Total $(95 \% \mathrm{Cl}) \quad 292 \quad 304$

Test for heterogeneity chi-square $=42.6 \mathrm{Idf}=7 \mathrm{p}=<0.000 \mathrm{I} \mathrm{I}^{2}=83.6 \%$

Test for overall effect $z=1.85 \quad p=0.06$

$13.3 \quad 0.70[0.18,1.22]$

$13.3 \quad 0.70[0.18,1.22]$

I5. $0.39[0.03,0.75]$

I5.1 $0.39[0.03,0.75]$

$10.9 \quad 1.30[0.57,2.03]$

$10.9 \quad 1.30[0.57,2.03]$

$4.90 .09[-1.43,1.61]$

$16.3-0.22[-0.44,0.00]$

$13.4 \quad 0.90[0.39,1.41]$

I5.6- $-0.30[-0.60,0.00]$

$50.1 \quad 0.07[-0.43,0.58]$

$10.7 \quad 0.38[-0.37,1.13]$

$100.0 \quad 0.38[-0.02,0.77]$

Alpha-glucosidase inhibitors for type 2 diabetes mellitus (Review) 
Fig. 26. Comparison 02. Acarbose versus sulphonylurea (SU)

\subsection{Change in fasting blood glucose $(\mathrm{mmol} / \mathrm{l})$}

Review: Alpha-glucosidase inhibitors for type 2 diabetes mellitus

Comparison: 02 Acarbose versus sulphonylurea (SU)

Outcome: 02 Change in fasting blood glucose $(\mathrm{mmol} / \mathrm{l})$



0I Acarbose $100 \mathrm{mg}$ TID vs Tolbutamide $2000 \mathrm{mg}$ in 3 dose

Van de Laar 2004a $\quad 32 \quad-1.50(2.10) \quad 43 \quad-2.90(2.60)$

Subtotal $(95 \% \mathrm{Cl}) \quad 32 \quad 43$

Test for heterogeneity: not applicable

Test for overall effect $z=2.58 \quad p=0.0$ I

10 Acarbose 200 mg TID vs Tolbutamide 1000 mg TID

$\begin{array}{lllll}\text { Coniff } 1995 & 67 & -1.11(3.17) & 66 & -2.02(3.13)\end{array}$

Subtotal $(95 \% \mathrm{Cl}) \quad 67 \quad 66$

Test for heterogeneity: not applicable

66

Test for overall effect $z=1.67 \quad p=0.1$

18 Acarbose $100 \mathrm{mg}$ TID vs Glibenclamide I mg TID

Haffner $1997 \quad 25 \quad-0.90(3.60) \quad 27$

$-3.40(3.00)$

Subtotal $(95 \% \mathrm{Cl}) \quad 25 \quad 27$

27

Test for heterogeneity: not applicable

Test for overall effect $z=2.7$ | $\quad p=0.007$

20 Acarbose 100 mg TID vs Glibenclamide 3,5 mg TID

$\begin{array}{lcccc}\text { Hoffmann 1990 } & 48 & -1.70(1.20) & 47 & -1.70(0.90) \\ \text { Hoffmann 1994 } & 28 & -1.20(0.89) & 27 & -1.25(0.89) \\ \text { Kovacevic 1997 } & 33 & -1.90(3.00) & 33 & -4.00(4.00) \\ \text { Rosenthal 2002 } & 32 & -0.70(2.40) & 31 & -0.90(2.50) \\ & 141 & & 138 & \end{array}$

Subtotal $(95 \% \mathrm{Cl}) \quad|4| \quad \mid 38$

Test for heterogeneity chi-square $=5.56 \mathrm{df}=3 \mathrm{p}=0.14 \mathrm{I}^{2}=46.1 \%$

Test for overall effect $z=0.79 \quad p=0.4$

30 Acarbose 100 mg TID vs Gliclazide 80 mg BID

Subtotal $(95 \% \mathrm{Cl}) \quad 27 \quad 30$

Test for heterogeneity: not applicable

Test for overall effect $z=1.07 \quad p=0.3$

Total $(95 \% \mathrm{Cl}) \quad 292 \quad 304$

Test for heterogeneity chi-square $=18.68 \mathrm{df}=7 \mathrm{p}=0.009 \mathrm{I}^{2}=62.5 \%$

Test for overall effect $z=2.54 \quad p=0.01$

$12.3 \quad 1.40[0.34,2.46]$

$12.3 \quad 1.40[0.34,2.46]$

$12.2 \quad 0.91[-0.16,1.98]$

$12.20 .91[-0.16,1.98]$

$6.4 \quad 2.50[0.69,4.31]$

$6.4 \quad 2.50[0.69,4.31]$

20.9

$0.00[-0.43,0.43]$

$20.3 \quad 0.05[-0.42,0.52]$

$7.0 \quad 2.10[0.39,3.81]$

$10.8 \quad 0.20[-1.01,1.41]$

$58.8 \quad 0.20[-0.29,0.69]$

$10.3 \quad 0.69[-0.57,1.95]$

$10.3 \quad 0.69[-0.57,1.95]$

$100.0 \quad 0.69[0.16,1.23]$

Alpha-glucosidase inhibitors for type 2 diabetes mellitus (Review) 
Fig. 27. Comparison 02. Acarbose versus sulphonylurea (SU)

\subsection{Change in post-load blood glucose $(\mathrm{mmol} / \mathrm{l})$}

Review: Alpha-glucosidase inhibitors for type 2 diabetes mellitus

Comparison: 02 Acarbose versus sulphonylurea (SU)

Outcome: 03 Change in post-load blood glucose $(\mathrm{mmol} / \mathrm{l})$

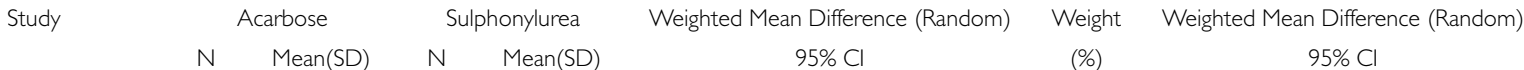

(\%)

$95 \% \mathrm{Cl}$

01 Acarbose $100 \mathrm{mg}$ TID vs Tolbutamide $2000 \mathrm{mg}$ in 3 dose

Van de Laar 2004a $29 \quad-1.20(3.90) \quad 41 \quad-2.20(2.80)$

Subtotal $(95 \% \mathrm{Cl}) \quad 29$

Test for heterogeneity: not applicable 41

Test for overall effect $z=1.18 \quad p=0.2$

10 Acarbose $200 \mathrm{mg}$ TID vs Tolbutamide 1000 mg TID

$\begin{array}{lllll}\text { Coniff } 1995 & 67 & -2.82(3.71) & 66 & -3.15(3.83)\end{array}$

Subtotal $(95 \% \mathrm{Cl}) \quad 67 \quad 66$

Test for heterogeneity: not applicable

Test for overall effect $z=0.50 \quad p=0.6$

18 Acarbose $100 \mathrm{mg}$ TID vs Glibenclamide I mg TID

Haffner $1997 \quad 25 \quad-2.40(6.40) \quad 27$

$-3.20(7.10)$

Subtotal $(95 \% \mathrm{Cl}) \quad 25 \quad 27$

Test for heterogeneity: not applicable

Test for overall effect $z=0.43 \quad p=0.7$

20 Acarbose 100 mg TID vs Glibenclamide 3,5 mg TID

$\begin{array}{lcccc}\text { Hoffmann 1990 } & 48 & -2.20(1.30) & 47 & -1.90(1.20) \\ \text { Hoffmann 1994 } & 28 & -1.80(0.74) & 27 & -1.63(0.90) \\ \text { Kovacevic 1997 } & 33 & -4.70(3.70) & 33 & -5.10(3.90) \\ \text { Rosenthal 2002 } & 32 & -1.40(2.40) & 31 & -2.10(2.70) \\ & 141 & & 138 & \end{array}$

Test for heterogeneity chi-square $=2.44 d f=3 p=\left.0.49\right|^{2}=0.0 \%$

Test for overall effect $z=0.94 \quad p=0.3$

30 Acarbose 100 mg TID vs Gliclazide 80 mg BID

$\begin{array}{lllll}\text { Salman 200I } & 27 & -3.73(3.45) & 30 & -2.16(3.45) \\ & 27 & & 30\end{array}$

$+$

$3.8 \quad 1.00[-0.66,2.66]$

$3.8 \quad 1.00[-0.66,2.66]$

Subtotal $(95 \% \mathrm{Cl}) \quad 27 \quad 30$

Test for heterogeneity: not applicable

Test for overall effect $z=1.72 \quad p=0.09$

Total $(95 \% \mathrm{Cl}) \quad 289 \quad 302$

Test for heterogeneity chi-square $=7.45 \mathrm{df}=7 \mathrm{p}=0.38 \mathrm{I}^{2}=6.0 \%$

Test for overall effect $z=0.62 \quad p=0.5$ 
Fig. 28. Comparison 02. Acarbose versus sulphonylurea (SU)

\subsection{Change in total cholesterol $(\mathrm{mmol} / \mathrm{l})$}

Review: Alpha-glucosidase inhibitors for type 2 diabetes mellitus

Comparison: 02 Acarbose versus sulphonylurea (SU)

Outcome: 04 Change in total cholesterol $(\mathrm{mmol} / \mathrm{l})$

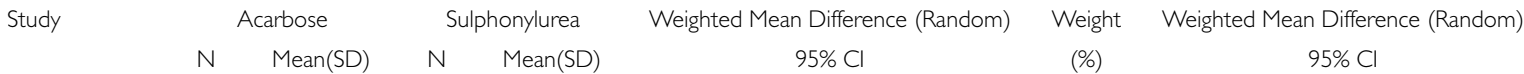

0I Acarbose $100 \mathrm{mg}$ TID vs Tolbutamide $2000 \mathrm{mg}$ in 3 dose

$\begin{array}{lllll}\text { Van de Laar 2004a } & 28 & 0.10(0.50) & 39 & 0.00(0.70)\end{array}$

Subtotal $(95 \% \mathrm{Cl}) \quad 28 \quad 39$

Test for heterogeneity: not applicable

Test for overall effect $z=0.68 \quad p=0.5$

10 Acarbose $200 \mathrm{mg}$ TID vs Tolbutamide $1000 \mathrm{mg}$ TID

$\begin{array}{llllll}\text { Coniff } 1995 & 64 & -0.21 & (0.79) & 61 & 0.05\end{array}(0.77)$

Subtotal $(95 \% \mathrm{Cl}) \quad 64 \quad 61$

Test for heterogeneity: not applicable

Test for overall effect $z=1.86 \quad p=0.06$

18 Acarbose $100 \mathrm{mg}$ TID vs Glibenclamide I mg TID

$\begin{array}{llll}\text { Haffner } 1997 & 17 & 0.05(0.93) & 17\end{array}$

$-0.10(0.70)$

Subtotal $(95 \% \mathrm{Cl}) \quad 17$

Test for heterogeneity: not applicable

Test for overall effect $z=0.53 \quad p=0.6$

20 Acarbose 100 mg TID vs Glibenclamide 3,5 mg TID

$\begin{array}{lllll}\text { Hoffmann 1990 } & 48 & -0.45(0.67) & 47 & -0.33(0.73) \\ \text { Hoffmann 1994 } & 28 & -0.59(1.34) & 27 & -0.18(1.61) \\ \text { Kovacevic 1997 } & 33 & -0.30(1.10) & 33 & -0.20(1.40)\end{array}$

Subtotal $(95 \% \mathrm{Cl}) \quad 109 \quad 107$

Test for heterogeneity chi-square $=0.49 \mathrm{df}=2 \mathrm{p}=0.78 \mathrm{I}^{2}=0.0 \%$

Test for overall effect $z=1.17 \quad p=0.2$

30 Acarbose 100 mg TID vs Gliclazide 80 mg BID

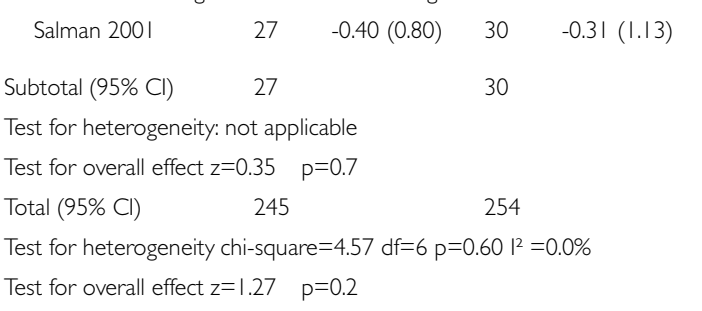

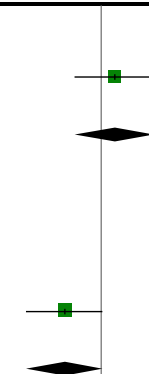

$24.4 \quad 0.10[-0.19,0.39]$

$24.40 .10[-0.19,0.39]$

24

$0.10[-0.19 .0 .39]$

$27.0-0.26[-0.53,0.01]$

$27.0-0.26[-0.53,0.01]$
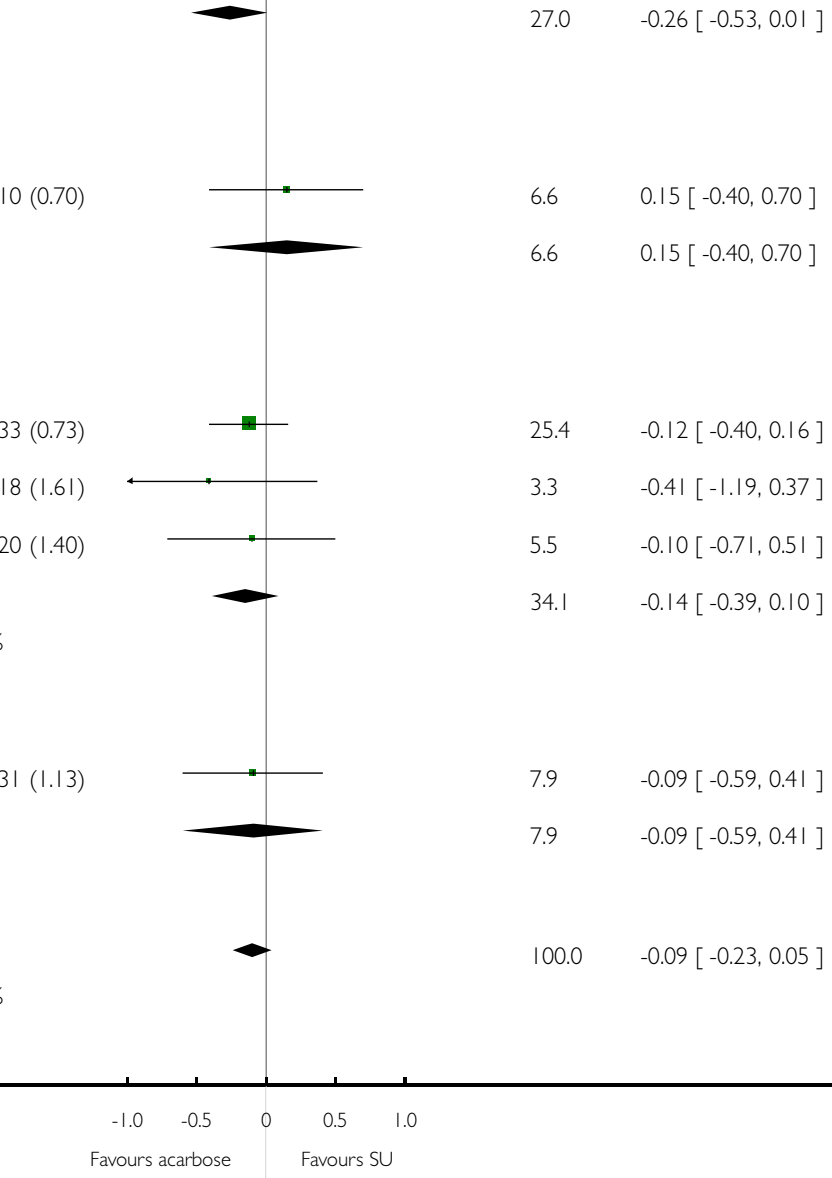

Alpha-glucosidase inhibitors for type 2 diabetes mellitus (Review) 
Fig. 29. Comparison 02. Acarbose versus sulphonylurea (SU)

\subsection{Change in HDL-cholesterol (mmol/l)}

Review: Alpha-glucosidase inhibitors for type 2 diabetes mellitus

Comparison: 02 Acarbose versus sulphonylurea (SU)

Outcome: 05 Change in HDL-cholesterol (mmol/l)

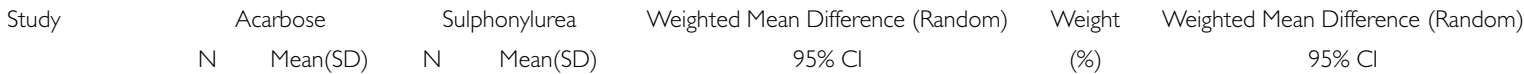

01 Acarbose $100 \mathrm{mg}$ TID vs Tolbutamide $2000 \mathrm{mg}$ in 3 dose

Van de Laar 2004a $28 \quad 0.10(0.20) \quad 38 \quad 0.10(0.40)$

Subtotal $(95 \% \mathrm{Cl}) \quad 28 \quad 38$

Test for heterogeneity: not applicable

Test for overall effect $z=0.00 \quad p=1$

10 Acarbose 200 mg TID vs Tolbutamide 1000 mg TID

$\begin{array}{lllll}\text { Coniff } 1995 & 58 & 0.07(0.23) & 54 & 0.08(0.23)\end{array}$

Subtotal $(95 \% \mathrm{Cl}) \quad 58 \quad 54$

Test for heterogeneity: not applicable

Test for overall effect $z=0.23 \quad p=0.8$

18 Acarbose $100 \mathrm{mg}$ TID vs Glibenclamide I mg TID

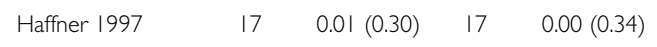

Subtotal $(95 \% \mathrm{Cl}) \quad 17 \quad 17$

Test for heterogeneity: not applicable

Test for overall effect $z=0.09 \quad p=0.9$

20 Acarbose 100 mg TID vs Glibenclamide 3,5 mg TID

$\begin{array}{lcccc}\text { Hoffmann I990 } & 48 & 0.06(0.13) & 47 & 0.02(0.20) \\ \text { Hoffmann 1994 } & 28 & 0.09(0.44) & 27 & -0.07(0.68) \\ \text { Kovacevic 1997 } & 33 & 0.10(0.30) & 33 & 0.10(0.40) \\ \text { Subtotal (95\% Cl) } & 109 & & 107 & \end{array}$

Subtotal $(95 \% \mathrm{Cl})$

Test for heterogeneity chi-square $=0.8 \mathrm{l} d \mathrm{df}=2 \mathrm{p}=0.67 \mathrm{I}^{2}=0.0 \%$

Test for overall effect $z=1.26 \quad p=0.2$

30 Acarbose 100 mg TID vs Gliclazide 80 mg BID

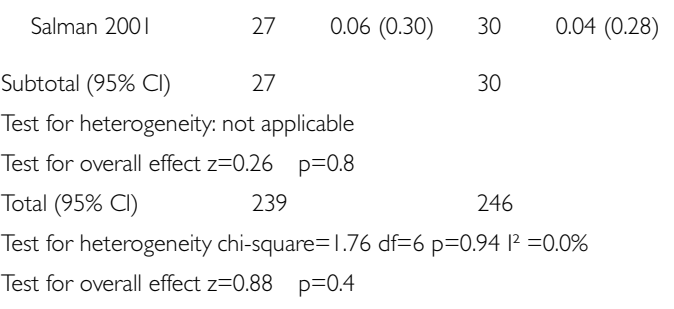

$+$

$9.0 \quad 0.00[-0.15,0.15]$

$9.0 \quad 0.00[-0.15,0.15]$

$-0.01[-0.10,0.08]$

$26.9-0.01[-0.10,0.08]$
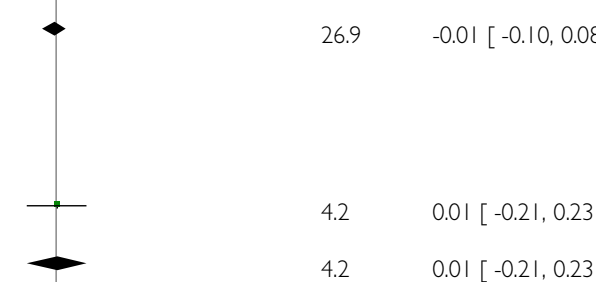

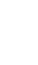


Fig. 30. Comparison 02. Acarbose versus sulphonylurea (SU)

\subsection{Change in LDL-cholesterol ( $\mathrm{mmol} / \mathrm{l})$}

Review: Alpha-glucosidase inhibitors for type 2 diabetes mellitus

Comparison: 02 Acarbose versus sulphonylurea (SU)

Outcome: 06 Change in LDL-cholesterol ( $\mathrm{mmol} / \mathrm{l})$

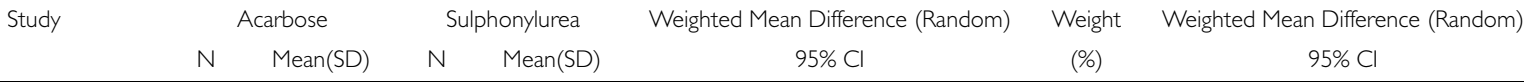

OI Acarbose $100 \mathrm{mg}$ TID vs Tolbutamide $2000 \mathrm{mg}$ in 3 dose

Van de Laar 2004a $\quad 27 \quad 0.10(0.40) \quad 38 \quad-0.10(0.70)$

Subtotal $(95 \% \mathrm{Cl}) \quad 27 \quad 38$

Test for heterogeneity: not applicable

Test for overall effect $z=1.46 \quad p=0.1$

10 Acarbose $200 \mathrm{mg}$ TID vs Tolbutamide $1000 \mathrm{mg}$ TID

$\begin{array}{lllll}\text { Coniff } 1995 & 48 & -0.09(0.67) & 47 & -0.10(0.68)\end{array}$

Subtotal $(95 \% \mathrm{Cl}) \quad 48 \quad 47$

47

Test for heterogeneity: not applicable

Test for overall effect $z=0.07 \quad p=0.9$

20 Acarbose $100 \mathrm{mg}$ TID vs Glibenclamide $3,5 \mathrm{mg}$ TID

Hoffmann $1990 \quad 48 \quad-0.05(1.49) \quad 47 \quad-0.07($ (.74)

Subtotal $(95 \% \mathrm{Cl}) \quad 48 \quad 47$

Test for heterogeneity: not applicable

Test for overall effect $z=0.06 \quad p=1$

30 Acarbose 100 mg TID vs Gliclazide 80 mg BID

$\begin{array}{lllll}\text { Salman 200I } & 27 & -0.33(0.78) & 30 & -0.42(0.94)\end{array}$

Subtotal $(95 \% \mathrm{Cl}) \quad 27 \quad 30$

30

Test for heterogeneity: not applicable

Test for overall effect $z=0.39 \quad p=0.7$

Total $(95 \% \mathrm{Cl}) \quad 150 \quad 162$

Test for heterogeneity chi-square $=1.0 \mathrm{I} d \mathrm{df}=3 \mathrm{p}=0.80 \mathrm{I}^{2}=0.0 \%$

Test for overall effect $z=1.13 \quad p=0.3$

$\begin{array}{lll}39.8 & 0.20[-0.07,0.47] \\ - & 39.8 & 0.20[-0.07,0.47]\end{array}$

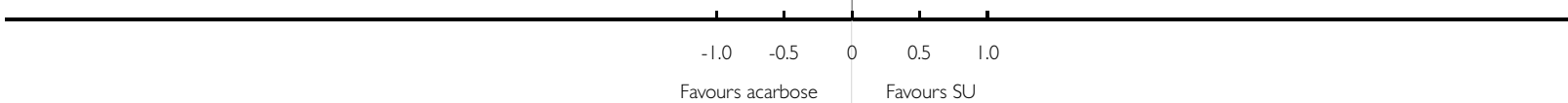

Alpha-glucosidase inhibitors for type 2 diabetes mellitus (Review) 
Fig. 31. Comparison 02. Acarbose versus sulphonylurea (SU)

\subsection{Change in triglycerides $(\mathrm{mmol} / \mathrm{l})$}

Review: Alpha-glucosidase inhibitors for type 2 diabetes mellitus

Comparison: 02 Acarbose versus sulphonylurea (SU)

Outcome: 07 Change in triglycerides $(\mathrm{mmol} / \mathrm{l})$

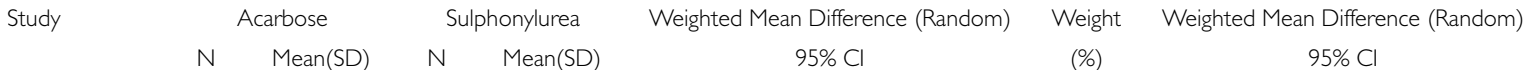

$95 \% \mathrm{Cl}$

(\%)

$95 \% \mathrm{Cl}$

01 Acarbose $100 \mathrm{mg}$ TID vs Tolbutamide $2000 \mathrm{mg}$ in 3 dose

Van de Laar 2004a $\quad 28 \quad-0.30(1.60) \quad 39 \quad-0.40(2.10)$

Subtotal $(95 \% \mathrm{Cl}) \quad 28 \quad 39$

Test for heterogeneity: not applicable

Test for overall effect $z=0.22 \quad p=0.8$

10 Acarbose $200 \mathrm{mg}$ TID vs Tolbutamide 1000 mg TID

$\begin{array}{lllll}\text { Coniff } 1995 & 64 & -0.49(1.87) & 61 & -0.03(1.84)\end{array}$

Subtotal $(95 \% \mathrm{Cl}) \quad 64 \quad 61$

Test for heterogeneity: not applicable

Test for overall effect $z=1.39 p=0.2$

18 Acarbose $100 \mathrm{mg}$ TID vs Glibenclamide I mg TID

Haffner 1997

Subtotal $(95 \% \mathrm{Cl}) \quad 25 \quad 27$

Test for heterogeneity: not applicable

Test for overall effect $z=1.31 \quad p=0.2$

20 Acarbose 100 mg TID vs Glibenclamide 3,5 mg TID

$\begin{array}{lcccc}\text { Hoffmann 1990 } & 48 & -0.10(0.40) & 47 & -0.20(0.90) \\ \text { Hoffmann 1994 } & 28 & -0.58(1.21) & 27 & -0.44(1.36) \\ \text { Kovacevic 1997 } & 33 & -0.40(1.40) & 33 & -0.70(1.50) \\ \text { Rosenthal 2002 } & 38 & -0.13(1.28) & 36 & 0.17(2.04) \\ & 147 & & 143 & \end{array}$

Test for heterogeneity chi-square $=1.68 d f=3 p=\left.0.64\right|^{2}=0.0 \%$

Test for overall effect $z=0.49 \quad p=0.6$

30 Acarbose $100 \mathrm{mg}$ TID vs Gliclazide 80 mg BID

$\begin{array}{lllllll}\text { Salman } 200 \mathrm{I} & 27 & -0.43(1.22) & 30 & -0.12(0.83) & 11.8 & -0.31 \\ & 27 & & 30 & -0.86,0.24]\end{array}$

Subtotal $(95 \% \mathrm{Cl})$ Test for heterogeneity: not applicable

Test for overall effect $z=1.11 \quad p=0.3$

Total $(95 \% \mathrm{Cl}) \quad 291 \quad 300$

Test for heterogeneity chi-square $=6.83 \mathrm{df}=7 \mathrm{p}=0.45 \mathrm{I}^{2}=0.0 \%$

Test for overall effect $z=0.08 \quad p=0.9$

$4.5 \quad 0.10[-0.79,0.99]$

$4.5 \quad 0.10[-0.79,0.99]$

$8.4-0.46[-1.11,0.19]$

$8.4-0.46[-1.11,0.19]$

$9.9 \quad 0.40[-0.20,1.00]$

$9.9 \quad 0.40[-0.20,1.00]$

$44.8 \quad 0.10[-0.18,0.38]$

$7.6-0.14[-0.82,0.54]$

$7.2 \quad 0.30[-0.40,1.00]$

$5.8-0.30[-1.08,0.48]$

$65.4 \quad 0.06[-0.17,0.29]$

$11.8-0.31[-0.86,0.24]$

$100.0 \quad 0.01[-0.18,0.20]$

Alpha-glucosidase inhibitors for type 2 diabetes mellitus (Review) 
Fig. 32. Comparison 02. Acarbose versus sulphonylurea (SU)

02.08 Change in fasting insulin levels (pmol/l)

Review: Alpha-glucosidase inhibitors for type 2 diabetes mellitus

Comparison: 02 Acarbose versus sulphonylurea (SU)

Outcome: 08 Change in fasting insulin levels (pmol/l)

Study Acarbose Sulphonylurea Weighted Mean Difference (Random) Weight Weighted Mean Difference (Random)
N Mean(SD) N Mean(SD)
$95 \% \mathrm{Cl}$
(\%)
95\% Cl

01 Acarbose $100 \mathrm{mg}$ TID vs Tolbutamide $2000 \mathrm{mg}$ in 3 dose

Van de Laar 2004a $28 \quad-4.70(56.00) \quad 35 \quad-3.20(96.10)$

Subtotal $(95 \% \mathrm{Cl}) \quad 28 \quad 35$

Test for heterogeneity: not applicable

Test for overall effect $z=0.08 \quad p=0.9$

10 Acarbose $200 \mathrm{mg}$ TID vs Tolbutamide $1000 \mathrm{mg}$ TID

$$
\begin{array}{lllll}
\text { Coniff } 1995 & 65 & -3.20(112.80) & 65 & 22.20(111.60)
\end{array}
$$

Subtotal $(95 \% \mathrm{Cl}) \quad 65 \quad 65$

Test for heterogeneity: not applicable

Test for overall effect $z=1.29 \quad p=0.2$

18 Acarbose $100 \mathrm{mg}$ TID vs Glibenclamide I mg TID

$$
\begin{array}{lllll}
\text { Haffner } 1997 & 25 & 10.00(92.00) & 27 & 10.00(110.00)
\end{array}
$$

Subtotal $(95 \% \mathrm{Cl}) \quad 25 \quad 27$

Test for heterogeneity: not applicable

Test for overall effect $z=0.00 \quad p=1$

20 Acarbose 100 mg TID vs Glibenclamide 3,5 mg TID

Hoffmann $1994 \quad 28 \quad-33.56(139.81) \quad 27 \quad-52.62(121.54)$

Kovacevic $1997 \quad 33 \quad-14.40($ I I.90) $\quad 33 \quad 7.20$ (13.80)

Rosenthal $2002 \quad 32 \quad-53.00(60.00) \quad 31 \quad 43.00($ I $\quad 36.00)$

Subtotal $(95 \% \mathrm{Cl}) \quad 93 \quad 91$

Test for heterogeneity chi-square $=10.12 \mathrm{df}=2 \mathrm{p}=0.006 \mathrm{I}^{2}=80.2 \%$

Test for overall effect $z=1.28 \quad p=0.2$

30 Acarbose $100 \mathrm{mg}$ TID vs Gliclazide $80 \mathrm{mg}$ BID

$$
\text { Salman 200। } \quad 27 \quad-19.69(67.08) \quad 30
$$

Subtotal $(95 \% \mathrm{Cl}) \quad 27 \quad 30$

Test for heterogeneity: not applicable

Test for overall effect $z=2.19 \quad p=0.03$

Total $(95 \% \mathrm{Cl}) \quad 238 \quad 248$

Test for heterogeneity chi-square $=12.54 \mathrm{df}=6 \mathrm{p}=0.05 \mathrm{I}^{2}=52.2 \%$

Test for overall effect $z=2.62 \quad p=0.009$

$15.12(50.89)$

30
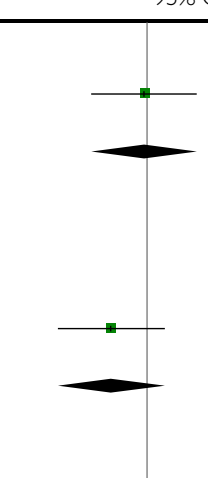
Fig. 33. Comparison 02. Acarbose versus sulphonylurea (SU)

02.09 Change in post-load insulin levels (pmol/l)

Review: Alpha-glucosidase inhibitors for type 2 diabetes mellitus

Comparison: 02 Acarbose versus sulphonylurea (SU)

Outcome: 09 Change in post-load insulin levels (pmol/l)

Study Acarbose Sulphonylurea Weighted Mean Difference (Random) Weight Weighted Mean Difference (Random)
N $\quad \operatorname{Mean}(\mathrm{SD})$
N $\quad$ Mean(SD)
$95 \% \mathrm{Cl}$
(\%)
$95 \% \mathrm{Cl}$

OI Acarbose 100 mg TID vs Tolbutamide 2000 mg in 3 dose (I hour pp)

Van de Laar 2004a $25 \quad 7.50($ (136.50) $\quad 35 \quad 26.40(282.20)$

Subtotal $(95 \% \mathrm{Cl}) \quad 25 \quad 35$

Test for heterogeneity: not applicable

Test for overall effect $z=0.34 \quad p=0.7$

10 Acarbose 200 mg TID vs Tolbutamide 1000 mg TID

$\begin{array}{lllll}\text { Coniff } 1995 & 65 & -45.10(226.80) & 65 & 169.00(225.00)\end{array}$

Subtotal $(95 \% \mathrm{Cl}) \quad 65 \quad 65$

Test for heterogeneity: not applicable

Test for overall effect $z=5.40 \quad p<0.0000$ I

18 Acarbose $100 \mathrm{mg}$ TID vs Glibenclamide I mg TID

Haffner $1997 \quad 25 \quad-40.00(196.00) \quad 27$

Subtotal $(95 \% \mathrm{Cl}) \quad 25 \quad 27$

Test for heterogeneity: not applicable

Test for overall effect $z=2.66 \quad p=0.008$

20 Acarbose 100 mg TID vs Glibenclamide 3,5 mg TID

Hoffmann $1994 \quad 28 \quad-105.54(134.07) \quad 27 \quad 61.92(214.46)$

Kovacevic $1997 \quad 33 \quad-32.20(14.90) \quad 33 \quad 64.60$ (13.90)

Rosenthal $2002 \quad 32 \quad 18.00(304.00) \quad 31 \quad 96.00(381.00)$

Subtotal $(95 \% \mathrm{Cl}) \quad 93 \quad 91$

Test for heterogeneity chi-square $=2.17 \mathrm{df}=2 \mathrm{p}=0.34 \mathrm{I}^{2}=7.7 \%$

Test for overall effect $z=8.24 \quad p<0.0000$ I

30 Acarbose 100 mg TID vs Gliclazide 80 mg BID

$\begin{array}{lllll}\text { Salman 200I } \quad 27 & -69.36(182.74) & 30 & 103.02(232.11)\end{array}$

Subtotal $(95 \% \mathrm{Cl}) \quad 27 \quad 30$

Test for heterogeneity: not applicable

Test for overall effect $z=3.13 \quad p=0.002$

Total $(95 \% \mathrm{Cl}) \quad 235 \quad 248$

Test for heterogeneity chi-square $=16.17 \mathrm{df}=6 \mathrm{p}=0.0 \mathrm{I} \mathrm{I}^{2}=62.9 \%$

Test for overall effect $z=5.08 \quad p<0.0000$ I

30 -

12.4- $172.38[-280.31,-64.45]$

$12.4-172.38[-280.31,-64.45]$

$100.0-133.17[-184.53,-81.82]$

$\bullet$
$14.2-167.46[-262.38,-72.54]$

$27.4-96.80[-103.75,-89.85]$

$6.8 \quad-78.00[-248.54,92.54]$

$48.5-100.66[-124.60,-76.72]$

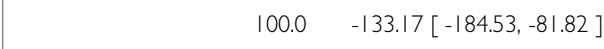

$\begin{array}{lllll}-1000.0 & -500.0 \quad 0 \quad 500.0 \quad 1000.0\end{array}$

Favours acarbose Favours SU

Alpha-glucosidase inhibitors for type 2 diabetes mellitus (Review) 
Fig. 34. Comparison 02. Acarbose versus sulphonylurea (SU)

02.10 Change in fasting C-peptide levels (nmol/l)

Review: Alpha-glucosidase inhibitors for type 2 diabetes mellitus

Comparison: 02 Acarbose versus sulphonylurea (SU)

Outcome: 10 Change in fasting C-peptide levels ( $\mathrm{nmol} / \mathrm{l})$

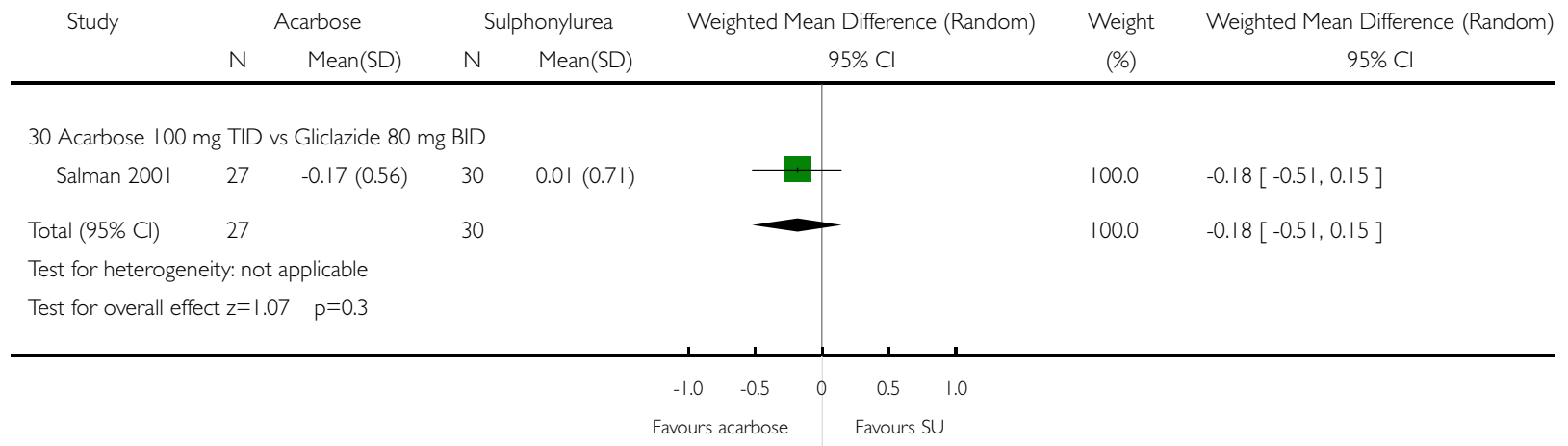

Fig. 35. Comparison 02. Acarbose versus sulphonylurea (SU)

02. I I Change in post-load C-peptide levels (nmol/I)

Review: Alpha-glucosidase inhibitors for type 2 diabetes mellitus

Comparison: 02 Acarbose versus sulphonylurea (SU)

Outcome: I | Change in post-load C-peptide levels (nmol//)

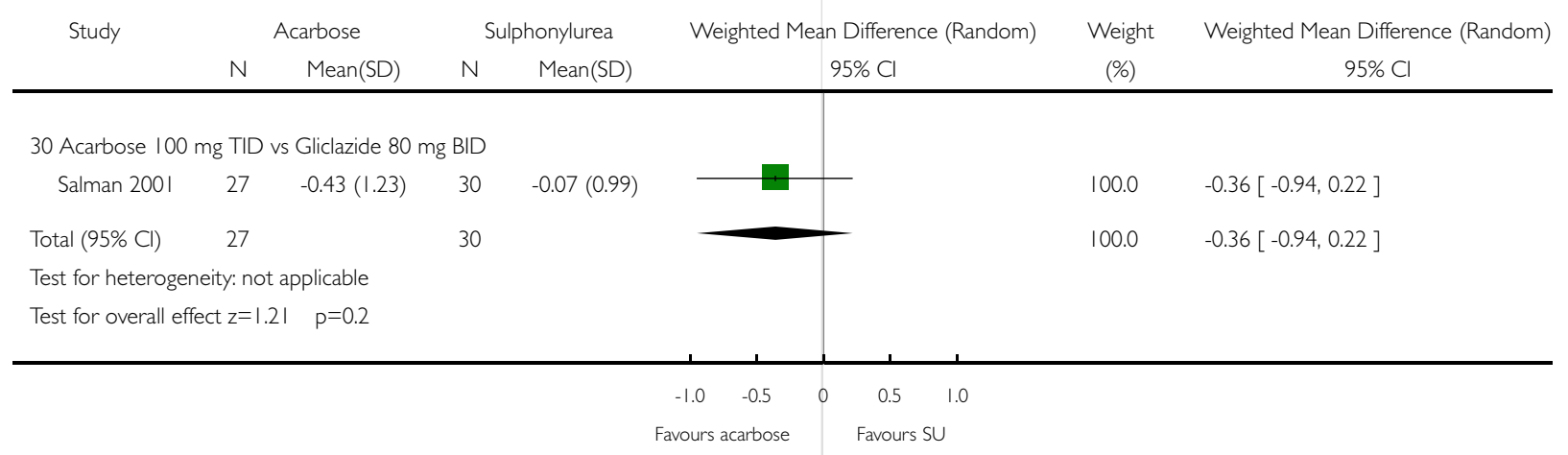


Fig. 36. Comparison 02. Acarbose versus sulphonylurea (SU)

\subsection{Change in body weight $(\mathrm{Kg})$}

Review: Alpha-glucosidase inhibitors for type 2 diabetes mellitus

Comparison: 02 Acarbose versus sulphonylurea (SU)

Outcome: 12 Change in body weight $(\mathrm{Kg})$

Study Acarbose Sulphonylurea Weighted Mean Difference (Random) Weight Weighted Mean Difference (Random) N Mean(SD) N Mean(SD) $95 \% \mathrm{Cl}$

(\%) $95 \% \mathrm{Cl}$

10 Acarbose 200 mg TID vs Tolbutamide 1000 mg TID $\begin{array}{lllll}\text { Coniff } 1995 & 66 & -1.42(2.84) & 66 & 1.84(2.76)\end{array}$

Subtotal $(95 \% \mathrm{Cl}) \quad 66 \quad 66$

Test for heterogeneity: not applicable

Test for overall effect $z=6.69 \quad p<0.0000$ I

18 Acarbose $100 \mathrm{mg}$ TID vs Glibenclamide I mg TID Haffner $1997 \quad 25 \quad-1.50(12.90) \quad 27$

Subtotal $(95 \% \mathrm{Cl}) \quad 25 \quad 27$

Test for heterogeneity: not applicable

Test for overall effect $z=0.84 \quad p=0.4$

20 Acarbose 100 mg TID vs Glibenclamide 3,5 mg TID

Hoffmann $1990-48--1.14(1.59)-47$

Rosenthal $2002 \quad 32 \quad-2.50($ (15.70) $\quad 31$

$0.20(14.60)$

Spengler $1992 \quad 26 \quad-0.70(11.80) \quad 29 \quad 0.00(10.00)$

Subtotal $(95 \% \mathrm{Cl}) \quad 106 \quad 107$

Test for heterogeneity chi-square $=0.32 \mathrm{df}=2 \mathrm{p}=0.85 \mathrm{I}^{2}=0.0 \%$ Test for overall effect $z=1.78 \quad p=0.08$

Total $(95 \% \mathrm{Cl}) \quad 197 \quad 200$

Test for heterogeneity chi-square $=21.90 \mathrm{df}=4 \mathrm{p}=0.0002 \mathrm{I}^{2}=81.7 \%$

Test for overall effect $z=1.77 \quad p=0.08$

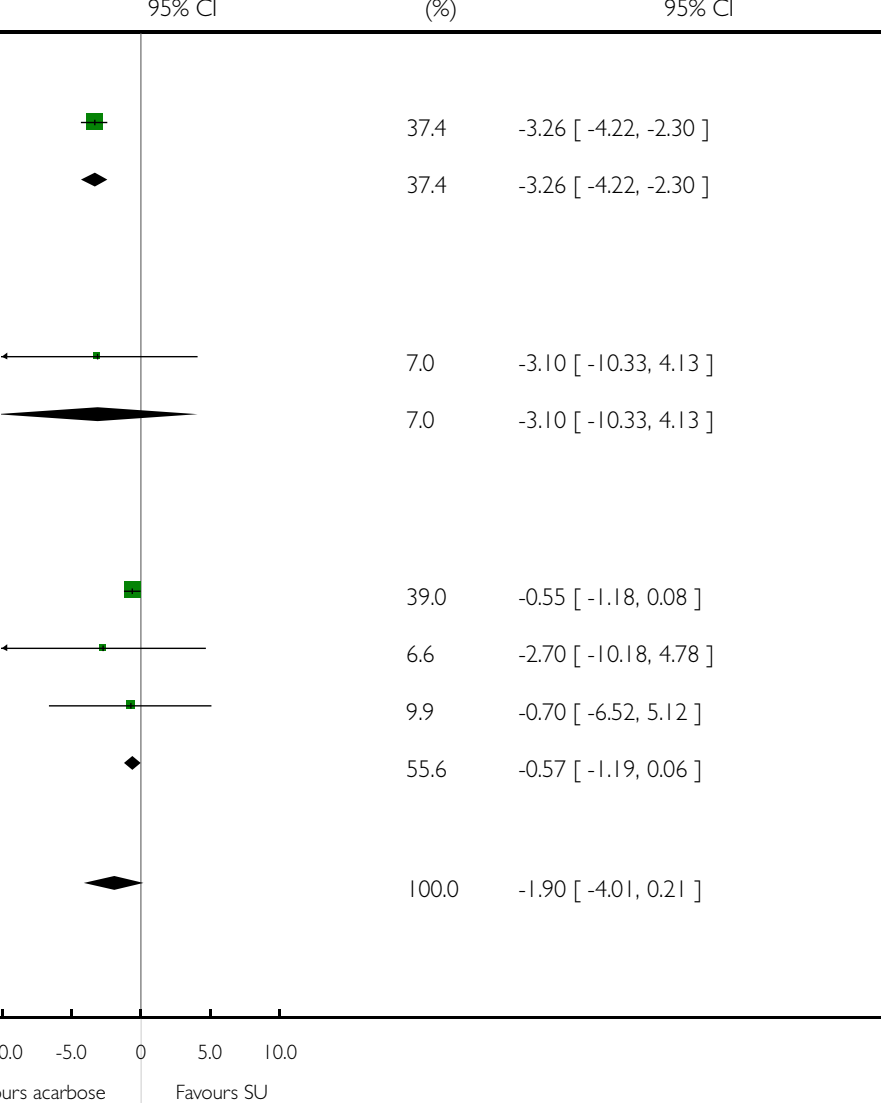


Fig. 37. Comparison 02. Acarbose versus sulphonylurea (SU)

\subsection{Change in body mass index $(\mathrm{Kg} / \mathrm{m} 2)$}

Review: Alpha-glucosidase inhibitors for type 2 diabetes mellitus

Comparison: 02 Acarbose versus sulphonylurea (SU)

Outcome: 13 Change in body mass index $(\mathrm{Kg} / \mathrm{m} 2)$

Study Acarbose Sulphonylurea Weighted Mean Difference (Random) Weight Weighted Mean Difference (Random)

$N \quad M e a n(S D) \quad N \quad M e a n(S D)$

$95 \% \mathrm{Cl}$

(\%)

$95 \% \mathrm{Cl}$

18 Acarbose $100 \mathrm{mg}$ TID vs Glibenclamide I mg TID

Haffner $1997 \quad 25 \quad-0.50(4.10) \quad 27$

$0.60(3.70)$

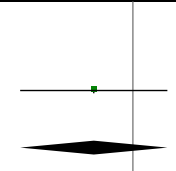

Subtotal $(95 \% \mathrm{Cl}) \quad 25$

4.0

$-1.10[-3.23,1.03]$

Test for heterogeneity: not applicable

Test for overall effect $z=1.01 \quad p=0.3$

20 Acarbose 100 mg TID vs Glibenclamide 3,5 mg TID

Hoffmann $1994 \quad 28 \quad-0.42(0.27) \quad 27 \quad-0.32(0.66)$

Kovacevic $1997 \quad 33 \quad-0.80(3.00) \quad 33 \quad 0.40(3.40)$

Subtotal $(95 \% \mathrm{Cl}) \quad 61 \quad 60$

Test for heterogeneity chi-square $=1.89 \mathrm{df}=\mid \mathrm{p}=0.17 \mathrm{I}^{2}=47.0 \%$

Test for overall effect $z=0.79 \quad p=0.4$

30 Acarbose 100 mg TID vs Gliclazide 80 mg BID

Salman 200I $\quad 27 \quad-0.41(1.03) \quad 30$

$0.19(1.08)$

Subtotal $(95 \% \mathrm{Cl}) \quad 27$

30

Test for heterogeneity: not applicable

Test for overall effect $z=2.15 \quad p=0.03$

Total $(95 \% \mathrm{Cl}) \quad 113 \quad 117$

Test for heterogeneity chi-square $=4.8 \mathrm{I} d f=3 p=\left.0.19\right|^{2}=37.6 \%$

Test for overall effect $z=1.72 \quad p=0.08$

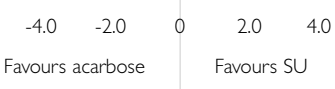

$4.0-1.10[-3.23,1.03]$

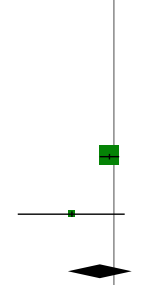

Alpha-glucosidase inhibitors for type 2 diabetes mellitus (Review) 
Fig. 38. Comparison 02. Acarbose versus sulphonylurea (SU)

02.15 Total deaths

\begin{tabular}{|c|c|c|c|c|c|}
\hline \multicolumn{6}{|c|}{ Comparison: 02 Acarbose versus sulphonylurea (SU) } \\
\hline \multirow[t]{2}{*}{ Study } & Acarbose & Sulphonylurea & Odds Ratio (Random) & Weight & Odds Ratio (Random) \\
\hline & $n / N$ & $n / N$ & $95 \% \mathrm{Cl}$ & (\%) & $95 \% \mathrm{Cl}$ \\
\hline \multicolumn{6}{|c|}{ OI Acarbose 200 mg TID vs Tolbutamide 1000 mg TID } \\
\hline Coniff 1995 & $0 / 67$ & $1 / 66$ & 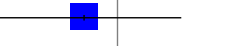 & 100.0 & $0.32[0.01,8.08]$ \\
\hline Total $(95 \% \mathrm{Cl})$ & 67 & 66 & & 100.0 & $0.32[0.01,8.08]$ \\
\hline \multicolumn{6}{|c|}{ Total events: 0 (Acarbose), I (Sulphonylurea) } \\
\hline \multicolumn{6}{|c|}{ Test for heterogeneity: not applicable } \\
\hline \multicolumn{6}{|c|}{ Test for overall effect $z=0.69 \quad p=0.5$} \\
\hline
\end{tabular}

Fig. 39. Comparison 02. Acarbose versus sulphonylurea (SU)

\subsection{Disease related deaths}

Review: Alpha-glucosidase inhibitors for type 2 diabetes mellitus

Comparison: 02 Acarbose versus sulphonylurea (SU)

Outcome: 16 Disease related deaths

\begin{tabular}{|c|c|c|c|c|c|}
\hline Study & $\begin{array}{c}\text { Acarbose } \\
\mathrm{n} / \mathrm{N}\end{array}$ & $\begin{array}{c}\text { Sulphonylurea } \\
n / N\end{array}$ & $\begin{array}{c}\text { Odds Ratio (Random) } \\
95 \% \mathrm{Cl}\end{array}$ & $\begin{array}{c}\text { Weight } \\
(\%)\end{array}$ & $\begin{array}{c}\text { Odds Ratio (Random) } \\
95 \% \mathrm{Cl}\end{array}$ \\
\hline \multicolumn{6}{|c|}{ 0I Acarbose 200 mg TID vs Tolbutamide 1000 mg TID } \\
\hline Coniff 1995 & $0 / 67$ & $1 / 66$ & - & 100.0 & $0.32[0.01,8.08]$ \\
\hline Total $(95 \% \mathrm{Cl})$ & 67 & 66 & & 100.0 & $0.32[0.01,8.08]$ \\
\hline \multicolumn{6}{|c|}{ Total events: 0 (Acarbose), I (Sulphonylurea) } \\
\hline \multicolumn{6}{|c|}{ Test for heterogeneity: not applicable } \\
\hline Test for overall & $9 p=0.5$ & & & & \\
\hline
\end{tabular}


Fig. 40. Comparison 02. Acarbose versus sulphonylurea (SU)

\subsection{Occurence of adverse effects}

Review: Alpha-glucosidase inhibitors for type 2 diabetes mellitus

Comparison: 02 Acarbose versus sulphonylurea (SU)

Outcome: 30 Occurence of adverse effects

Study

Acarbose

Sulphonylurea

Odds Ratio (Random)

Weight

Odds Ratio (Random)

$n / N$

$n / N$

$95 \% \mathrm{Cl}$

$95 \% \mathrm{Cl}$

0I Acarbose $100 \mathrm{mg}$ TID vs Tolbutamide $2000 \mathrm{mg}$ in 3 dose

$\begin{array}{lll}V & \text { Van de Laar 2004a } \quad 22 / 48 & 12 / 48\end{array}$

Subtotal $(95 \% \mathrm{Cl})$

48

48

$-$

Total events: 22 (Acarbose), 12 (Sulphonylurea)

Test for heterogeneity: not applicable

Test for overall effect $z=2.11 \quad p=0.03$

10 Acarbose $200 \mathrm{mg}$ TID vs Tolbutamide $1000 \mathrm{mg}$ TID

Coniff I995 $\quad 67 / 74 \quad 42 / 7$ |

Subtotal $(95 \% \mathrm{Cl})$

74

71

Total events: 67 (Acarbose), 42 (Sulphonylurea)

Test for heterogeneity: not applicable

Test for overall effect $z=4.06 \quad p=0.00005$

20 Acarbose $100 \mathrm{mg}$ TID vs Glibenclamide 3,5 mg TID

$\begin{array}{lll}\text { Hoffmann } 1990 & 14 / 48 & 12 / 47 \\ \text { Kovacevic 1997 } & 18 / 33 & 5 / 33 \\ \text { Rosenthal 2002 } & 8 / 39 & 2 / 37 \\ \text { Spengler 1992 } & 23 / 36 & 3 / 36 \\ \text { Subtotal (95\% Cl) } & 156 & 153\end{array}$

Total events: 63 (Acarbose), 22 (Sulphonylurea)

Test for heterogeneity chi-square $=12.74 \mathrm{df}=3 \mathrm{p}=0.005 \mathrm{l}^{2}=76.5 \%$

Test for overall effect $z=2.45 \quad p=0.0$ l

30 Acarbose $100 \mathrm{mg}$ TID vs Gliclazide $80 \mathrm{mg}$ BID

$\begin{array}{ccc}\text { Salman } 200 \mathrm{I} & 9 / 27 & 6 / 30 \\ \text { Subtotal }(95 \% \mathrm{Cl}) & 27 & 30\end{array}$

Total events: 9 (Acarbose), 6 (Sulphonylurea)

Test for heterogeneity: not applicable

Test for overall effect $z=1.13 \quad p=0.3$

Total $(95 \% \mathrm{Cl}) \quad 305 \quad 302$

Total events: 161 (Acarbose), 82 (Sulphonylurea)

Test for heterogeneity chi-square $=16.02 \mathrm{df}=6 \mathrm{p}=0.0 \mathrm{l} \mathrm{l}^{2}=62.6 \%$

Test for overall effect $z=3.95 \quad p=0.00008$

$6 / 30$

30

48

8

$2 / 71$


Fig. 41. Comparison 02. Acarbose versus sulphonylurea (SU)

02.3 I Occurence of gastro-intestinal adverse effects

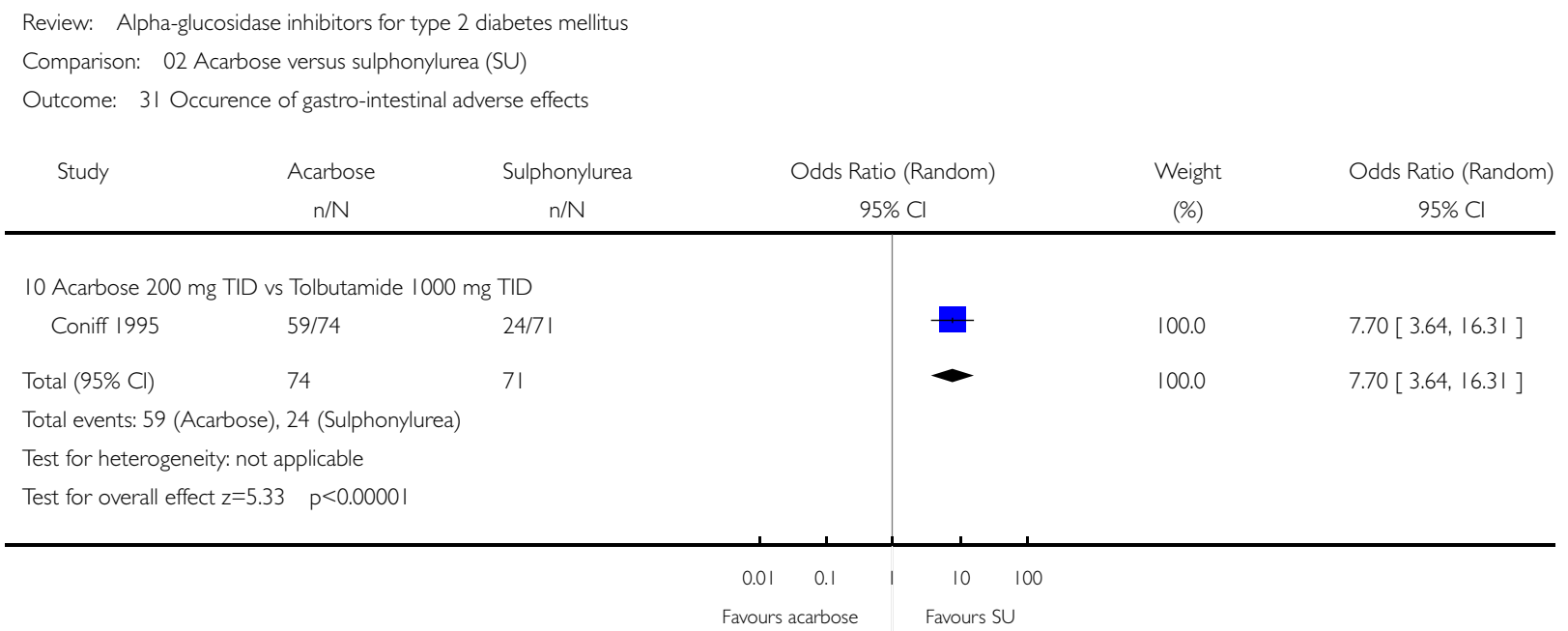

Fig. 42. Comparison 02. Acarbose versus sulphonylurea (SU)

02.90 Change in post-load blood glucose ( $\mathrm{mmol} / \mathrm{l})$ ( 2 hours)

Review: Alpha-glucosidase inhibitors for type 2 diabetes mellitus

Comparison: 02 Acarbose versus sulphonylurea (SU)

Outcome: 90 Change in post-load blood glucose (mmol/l) (2 hours)

\begin{tabular}{|c|c|c|c|c|c|c|c|c|}
\hline \multirow[t]{2}{*}{ Study } & \multicolumn{2}{|c|}{ Treatment } & \multicolumn{2}{|r|}{ Control } & \multicolumn{2}{|c|}{ Weighted Mean Difference (Random) } & \multirow{2}{*}{$\begin{array}{c}\text { Weight } \\
(\%)\end{array}$} & \multirow{2}{*}{$\begin{array}{l}\text { Weighted Mean Difference (Random) } \\
\qquad 95 \% \mathrm{Cl}\end{array}$} \\
\hline & N & Mean(SD) & N & Mean(SD) & & $95 \% \mathrm{Cl}$ & & \\
\hline \multicolumn{9}{|c|}{ 0I Acarbose $100 \mathrm{mg}$ TID vs Tolbutamide $2000 \mathrm{mg}$ in 3 dose } \\
\hline Van de Laar 2004a & 29 & $-1.20(3.90)$ & 41 & $-2.20(2.80)$ & & - & 6.9 & $1.00[-0.66,2.66]$ \\
\hline Subtotal $(95 \% \mathrm{Cl})$ & 29 & & 41 & & & - & 6.9 & $1.00[-0.66,2.66]$ \\
\hline \multicolumn{9}{|c|}{ Test for heterogeneity: not applicable } \\
\hline \multicolumn{9}{|c|}{ Test for overall effect $z=1.18 \quad p=0.2$} \\
\hline \multicolumn{9}{|c|}{02 Acarbose $200 \mathrm{mg}$ TID vs Tolbutamide $1000 \mathrm{mg}$ TID } \\
\hline Coniff 1995 & 67 & $-3.16(4.38)$ & 66 & $-4.55(4.37)$ & & - & 8.2 & $1.39[-0.10,2.88]$ \\
\hline Subtotal $(95 \% \mathrm{Cl})$ & 67 & & 66 & & & - & 8.2 & $1.39[-0.10,2.88]$ \\
\hline \multicolumn{9}{|c|}{ Test for heterogeneity: not applicable } \\
\hline \multicolumn{9}{|c|}{ Test for overall effect $z=1.83 \quad p=0.07$} \\
\hline \multicolumn{9}{|c|}{03 Acarbose $100 \mathrm{mg}$ TID vs Glibenclamide I mg TID } \\
\hline Haffner 1997 & 25 & $-2.40(6.40)$ & 27 & $-3.20(7.10)$ & & 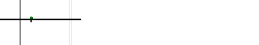 & 1.6 & $0.80[-2.87,4.47]$ \\
\hline Subtotal $(95 \% \mathrm{Cl})$ & 25 & & 27 & & & & 1.6 & $0.80[-2.87,4.47]$ \\
\hline \multicolumn{9}{|c|}{ Test for heterogeneity: not applicable } \\
\hline \multicolumn{9}{|c|}{ Test for overall effect $z=0.43 \quad p=0.7$} \\
\hline & & & & & $-10.0 \quad-5.0$ & $5.0 \quad 10.0$ & & \\
\hline & & & & & vours treatment & Favours control & & (Continu \\
\hline
\end{tabular}

Alpha-glucosidase inhibitors for type 2 diabetes mellitus (Review) 
(... Continued)

Study

Treatment

N Mean(SD)

Mean(SD)

Weighted Mean Difference (Random) $95 \% \mathrm{Cl}$

04 Acarbose 100 mg TID vs Glibenclamide 3,5 mg TID

Hoffmann $1990 \quad 48 \quad-2.20(1.30) \quad 47$

Hoffmann 1994

28

Kovacevic 1997

33

Rosenthal 2002

$-1.80(0.74)$

27

$3-4.70(3.70)$

33

32

$-1.40(2.40) \quad 31$

Subtotal $(95 \% \mathrm{Cl})$

4

138

Test for heterogeneity chi-square $=2.44 \mathrm{df}=3 \mathrm{p}=0.49 \mathrm{p}^{2}=0.0 \%$

Test for overall effect $z=0.94 \quad p=0.3$

05 Acarbose 100 mg TID vs Gliclazide 80 mg BID

Salman 200I $27 \quad-3.73(3.45)$

Subtotal $(95 \% \mathrm{Cl}) \quad 27 \quad 30$

Test for heterogeneity: not applicable

Test for overall effect $z=1.72 \quad p=0.09$

Total $(95 \% \mathrm{Cl}) \quad 289 \quad 302$

Test for heterogeneity chi-square $=10.88 d f=7 p=\left.0.14\right|^{2}=35.7 \%$

Test for overall effect $z=0.24 \quad p=0.8$
Weight Weighted Mean Difference (Random)

(\%) $95 \% \mathrm{Cl}$
$-1.90(1.20)$

$-1.63(0.90)$

$-5.10(3.90)$

$-2.10(2.70)$

$\begin{array}{ll}29.1 & -0.30[-0.80,0.20] \\ 31.7 & -0.17[-0.61,0.27] \\ 5.8 & 0.40[-1.43,2.23] \\ 10.7 & 0.70[-0.56,1.96] \\ 77.2 & -0.15[-0.46,0.16]\end{array}$

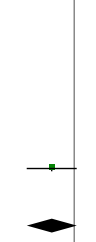

77.2

$-2.16(3.45)$

0

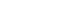

$\longrightarrow$

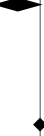

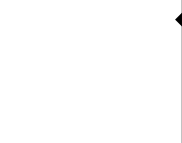
$100.0 \quad 0.06[-0.42,0.53]$
$6.0-1.57[-3.36,0.22]$
$6.0-1.57[-3.36,0.22]$ 
Fig. 43. Comparison 02. Acarbose versus sulphonylurea (SU)

02.9 I Change in post-load insulin levels (pmol/l) (2 hours)

Review: Alpha-glucosidase inhibitors for type 2 diabetes mellitus

Comparison: 02 Acarbose versus sulphonylurea (SU)

Outcome: 9I Change in post-load insulin levels (pmol/l) (2 hours)

Study - Treatment

N Mean(SD) N Mean(SD)

01 Acarbose $100 \mathrm{mg}$ TID vs Tolbutamide $2000 \mathrm{mg}$ in 3 dose (I hour pp)

Van de Laar 2004a $25 \quad 7.50($ (136.50) $\quad 35 \quad 26.40(282.20)$

Subtotal $(95 \% \mathrm{Cl}) \quad 25$

35

Test for heterogeneity: not applicable

Test for overall effect $z=0.34 \quad p=0.7$

02 Acarbose $200 \mathrm{mg}$ TID vs Tolbutamide $1000 \mathrm{mg}$ TID

$\begin{array}{lllll}\text { Coniff } 1995 & 66 & -47.80(256.50) & 65 & 100.20(254.50)\end{array}$ •

Weighted Mean Difference (Random) Weight Weighted Mean Difference (Random)

Subtotal $(95 \% \mathrm{Cl}) \quad 66$

Test for heterogeneity: not applicable

Test for overall effect $z=3.31 \quad p=0.0009$

03 Acarbose 100 mg TID vs Glibenclamide I mg TID

$\begin{array}{lllll}\text { Haffner } 1997 & 25 & -40.00(196.00) & 27 & \mid 40.00(286.00)\end{array}$

Subtotal $(95 \% \mathrm{Cl}) \quad 25 \quad 27$

Test for heterogeneity: not applicable

Test for overall effect $z=2.66 \quad p=0.008$

04 Acarbose 100 mg TID vs Glibenclamide 3,5 mg TID

Hoffmann $1994 \quad 28 \quad-105.54(134.07) \quad 27 \quad 61.92(214.46)$

Kovacevic $1997 \quad 33 \quad-32.20(14.90) \quad 33 \quad 64.60(13.90)$

Rosenthal $2002 \quad 32 \quad 18.00(304.00) \quad 31 \quad 96.00(381.00)$

Subtotal $(95 \% \mathrm{Cl}) \quad 93 \quad 91$

Test for heterogeneity chi-square $=2.17 \mathrm{df}=2 \mathrm{p}=0.34 \mathrm{I}^{2}=7.7 \%$

Test for overall effect $z=8.24 \quad p<0.0000$ I

05 Acarbose $100 \mathrm{mg}$ TID vs Gliclazide $80 \mathrm{mg}$ BID

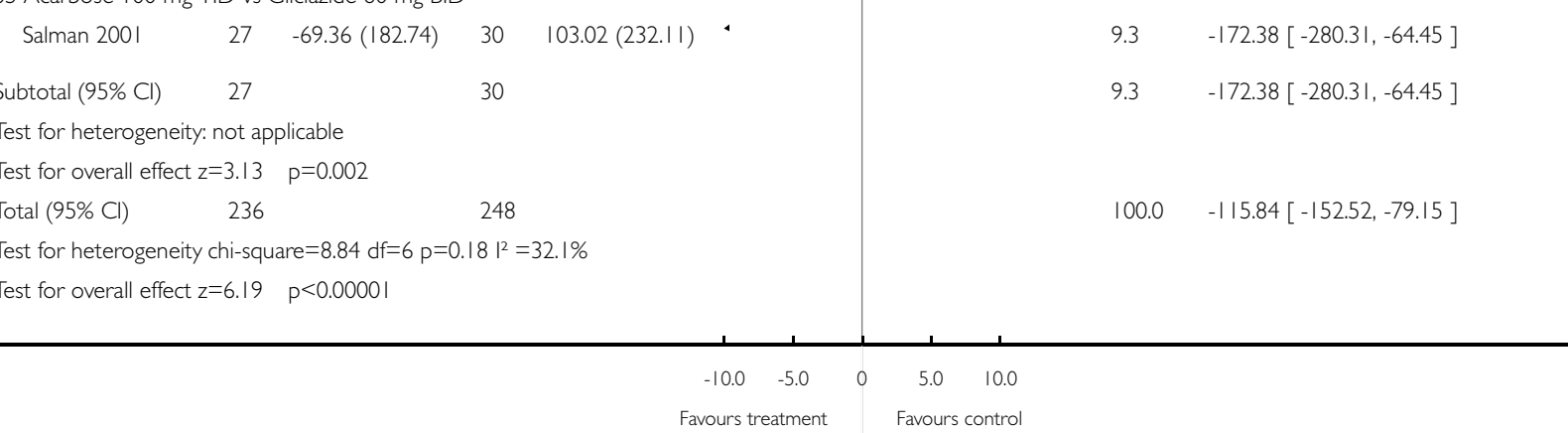

Alpha-glucosidase inhibitors for type 2 diabetes mellitus (Review)

Copyright $@ 2005$ The Cochrane Collaboration. Published by John Wiley \& Sons, Ltd 


\section{Fig. 44. Comparison 03. Acarbose versus Metformin}

03.01 Change in glycated haemoglobin (\%)

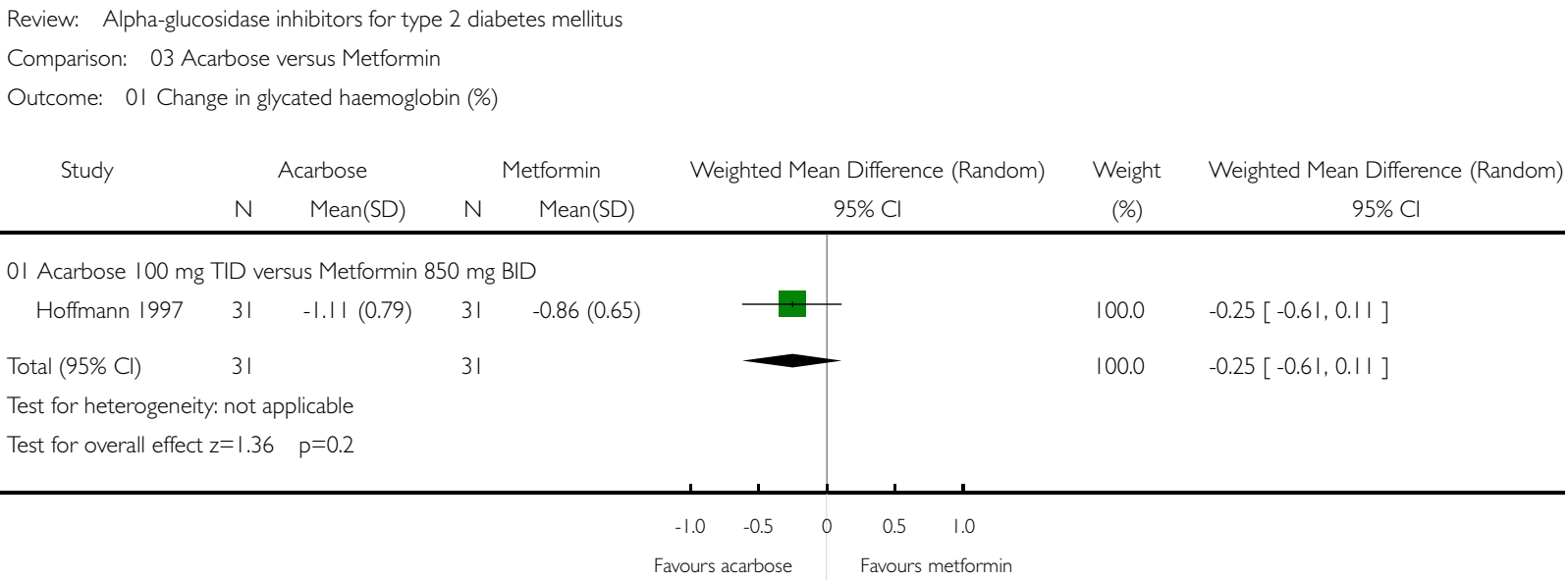

Fig. 45. Comparison 03. Acarbose versus Metformin

03.02 Change in fasting blood glucose $(\mathrm{mmol} / \mathrm{l})$

Review: Alpha-glucosidase inhibitors for type 2 diabetes mellitus

Comparison: 03 Acarbose versus Metformin

Outcome: 02 Change in fasting blood glucose ( $\mathrm{mmol} / \mathrm{l})$

Study Acarbose Metformin Weighted Mean Difference (Random) Weight Weighted Mean Difference (Random)

$\begin{array}{llllll}N & \text { Mean }(\mathrm{SD}) & \mathrm{N} & \mathrm{Mean}(\mathrm{SD}) & 95 \% \mathrm{Cl} & (\%)\end{array}$

0I Acarbose $100 \mathrm{mg}$ TID versus Metformin $850 \mathrm{mg}$ BID

Hoffmann $1997 \quad 31 \quad-1.39(0.81) \quad 31 \quad-1.00(0.59)$

Total $(95 \% \mathrm{Cl}) \quad 31$

31

$100.0-0.39[-0.74,-0.04]$

Test for heterogeneity: not applicable

Test for overall effect $z=2.17 \quad p=0.03$

$100.0-0.39[-0.74,-0.04]$

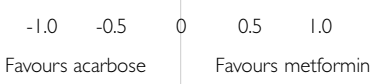


Fig. 46. Comparison 03. Acarbose versus Metformin

03.03 Change in post-load blood glucose $(\mathrm{mmol} / \mathrm{l})$

Review: Alpha-glucosidase inhibitors for type 2 diabetes mellitus

Comparison: 03 Acarbose versus Metformin

Outcome: 03 Change in post-load blood glucose $(\mathrm{mmol} / \mathrm{l})$

Study Acarbose Metformin Weighted Mean Difference (Random) Weight Weighted Mean Difference (Random)

N Mean(SD) N Mean(SD) $95 \% \mathrm{Cl}$

(\%)

95\% Cl

OI Acarbose $100 \mathrm{mg}$ TID versus Metformin $850 \mathrm{mg}$ BID

$\left.\begin{array}{lllllll}\text { Hoffmann } 1997 & 31 & -2.36(0.74) & 31 & -1.94(0.74) & -\end{array}\right]$

$\begin{array}{lllll}\text { Total }(95 \% \mathrm{Cl}) & 31 & 31 & 100.0 & -0.42[-0.79,-0.05]\end{array}$

Test for heterogeneity: not applicable

Test for overall effect $z=2.23 \quad p=0.03$

Fig. 47. Comparison 03. Acarbose versus Metformin

03.04 Change in total cholesterol ( $\mathrm{mmol} / \mathrm{l})$

Review: Alpha-glucosidase inhibitors for type 2 diabetes mellitus

Comparison: 03 Acarbose versus Metformin

Outcome: 04 Change in total cholesterol $(\mathrm{mmol} / \mathrm{l})$

Study Acarbose metformin Weighted Mean Difference (Random) Weight Weighted Mean Difference (Random)

$N \quad \operatorname{Mean}(\mathrm{SD}) \quad \mathrm{N} \quad \operatorname{Mean}(\mathrm{SD})$

$95 \% \mathrm{Cl}$

(\%)

$95 \% \mathrm{Cl}$

OI Acarbose $100 \mathrm{mg}$ TID versus Metformin 850 mg BID

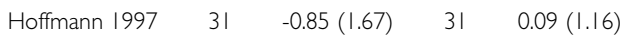

Total $(95 \% \mathrm{Cl}) \quad 31$

Test for heterogeneity: not applicable

Test for overall effect $z=2.57 \quad p=0.0$ I

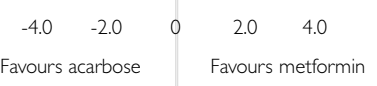




\section{Fig. 48. Comparison 03. Acarbose versus Metformin}

\subsection{Change in HDL-cholesterol (mmol/l)}

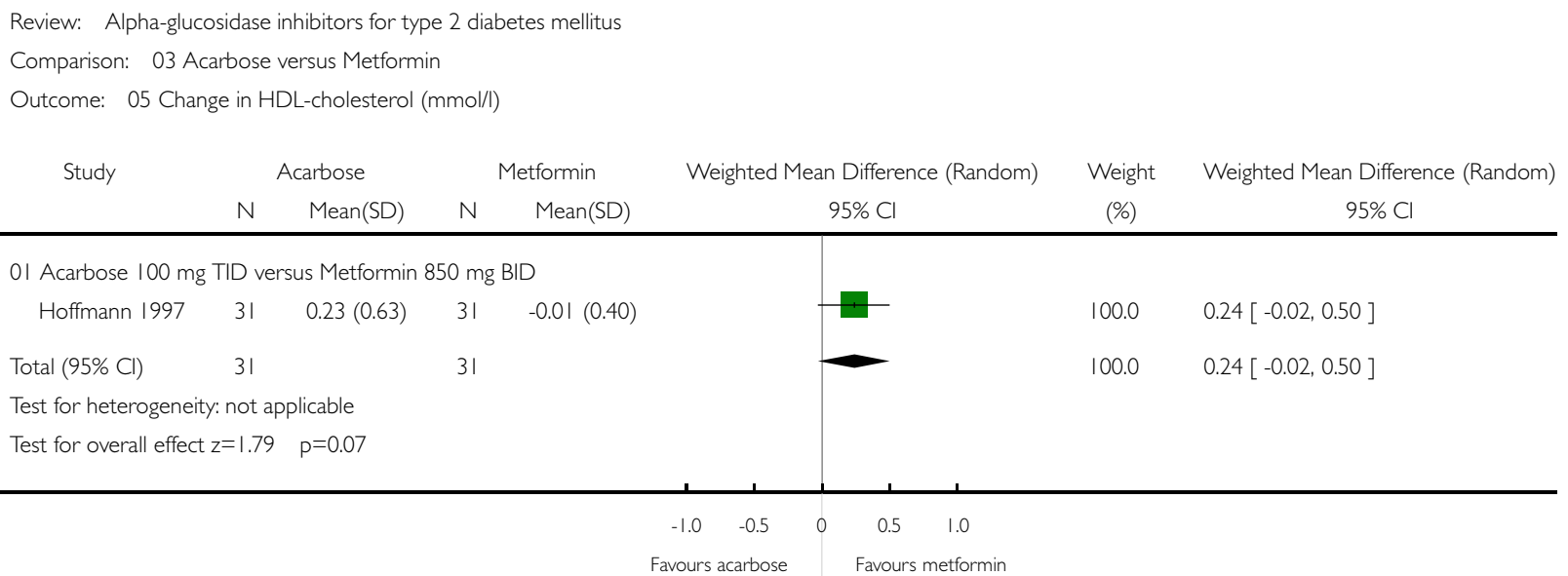

Fig. 49. Comparison 03. Acarbose versus Metformin

03.06 Change in LDL-cholesterol $(\mathrm{mmol} / \mathrm{l})$

Review: Alpha-glucosidase inhibitors for type 2 diabetes mellitus

Comparison: 03 Acarbose versus Metformin

Outcome: 06 Change in LDL-cholesterol $(\mathrm{mmol} / \mathrm{l})$

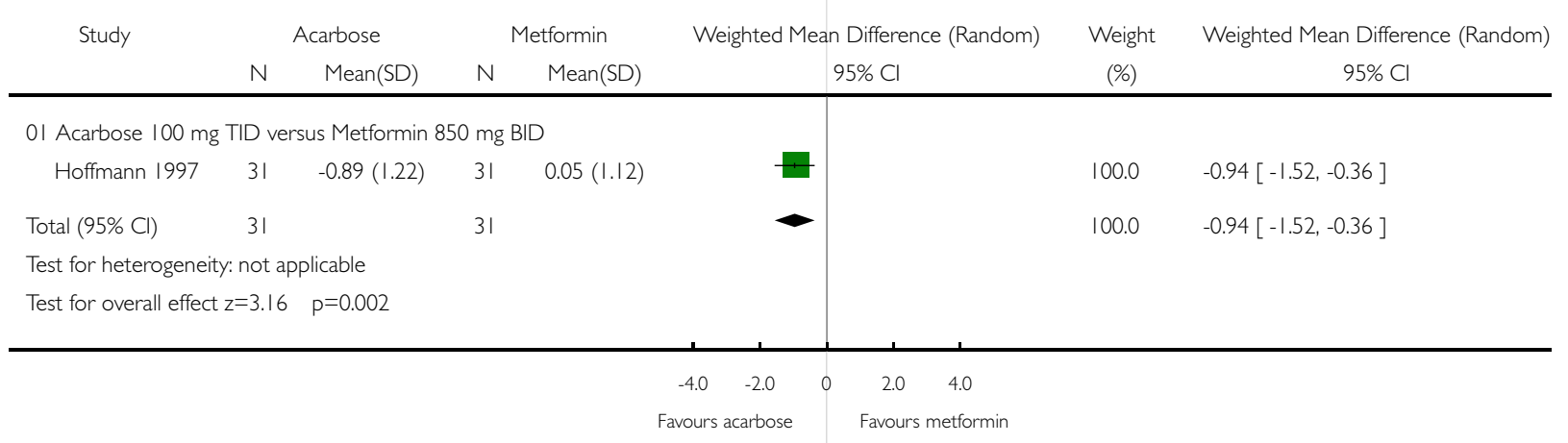




\section{Fig. 50. Comparison 03. Acarbose versus Metformin}

\subsection{Change in triglycerides $(\mathrm{mmol} / \mathrm{l})$}

Review: Alpha-glucosidase inhibitors for type 2 diabetes mellitus

Comparison: 03 Acarbose versus Metformin

Outcome: 07 Change in triglycerides $(\mathrm{mmol} / \mathrm{l})$

$\begin{array}{cccccc}\text { Study } & \text { Acarbose } & \text { Metformin } & \text { Weighted Mean Difference (Random) } & \text { Weight } & \text { Weighted Mean Difference (Random) } \\ & \mathrm{N} & \text { Mean(SD) } & \mathrm{N} & \text { Mean(SD) } & 95 \% \mathrm{Cl}\end{array}$

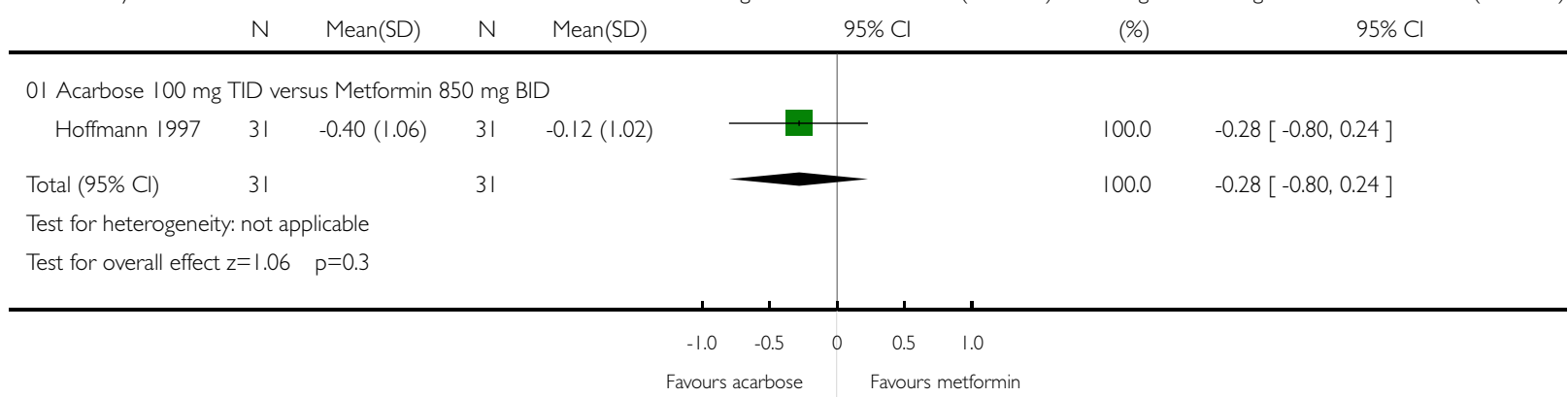

Fig. 51. Comparison 03. Acarbose versus Metformin

03.08 Change in fasting insulin levels (pmol/l)

Review: Alpha-glucosidase inhibitors for type 2 diabetes mellitus

Comparison: 03 Acarbose versus Metformin

Outcome: 08 Change in fasting insulin levels (pmol/l)

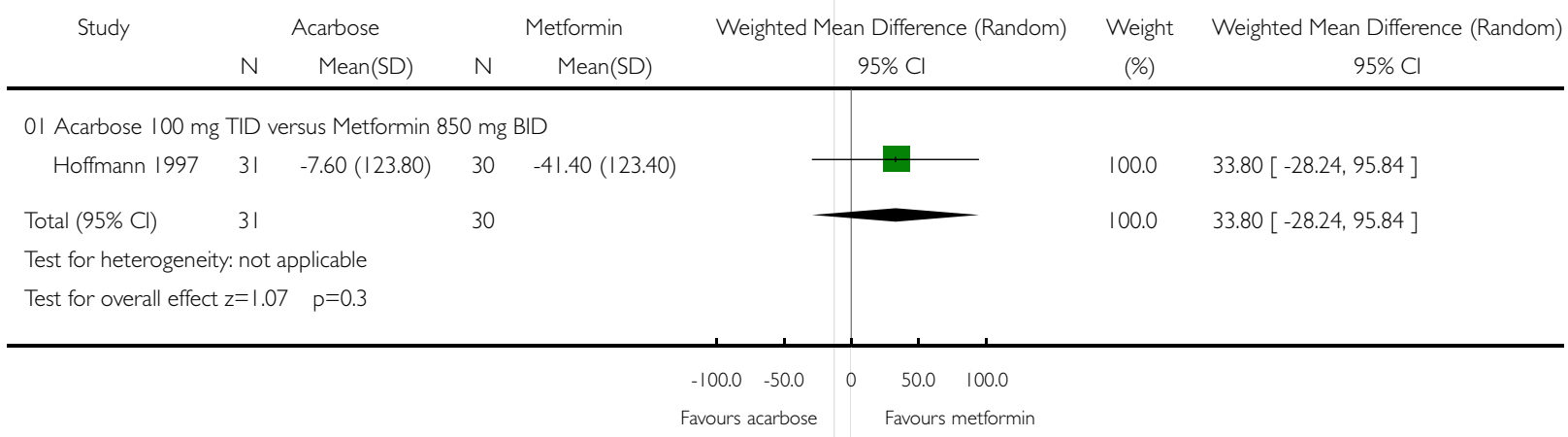




\section{Fig. 52. Comparison 03. Acarbose versus Metformin}

\subsection{Change in post-load insulin levels (pmol/l)}

Review: Alpha-glucosidase inhibitors for type 2 diabetes mellitus

Comparison: 03 Acarbose versus Metformin

Outcome: 09 Change in post-load insulin levels ( $\mathrm{pmol} / \mathrm{l}$ )

$\begin{array}{cccccc} & \text { Acarbose } & \text { Metformin } & \text { Weighted Mean Difference (Random) } & \text { Weight } & \text { Weighted Mean Difference (Random) } \\ \text { N } & \text { Mean(SD) } & \text { N } & \text { Mean(SD) } & 95 \% \mathrm{Cl} & (\%)\end{array}$

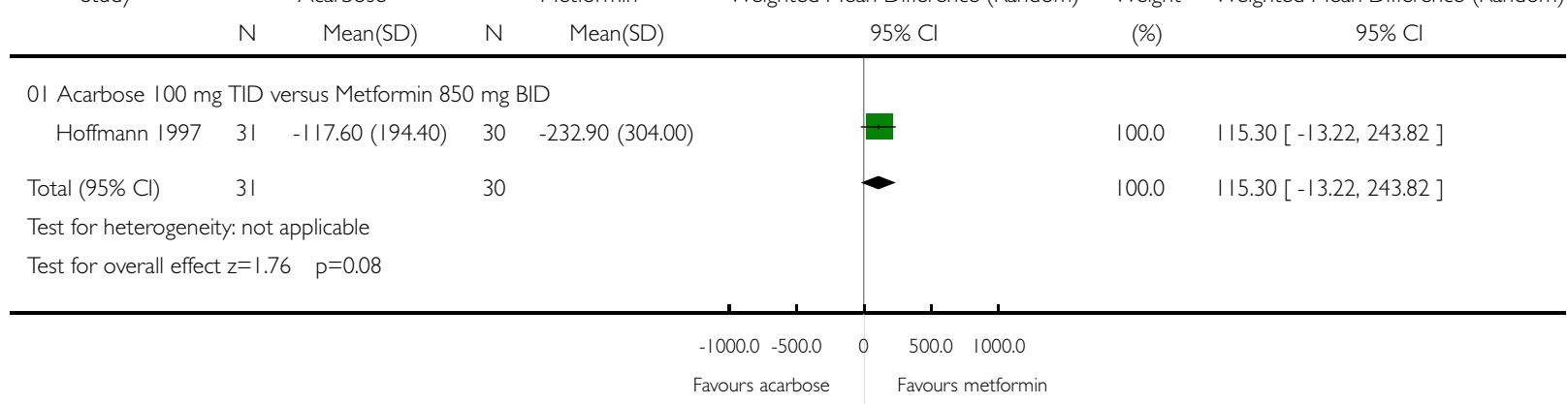

Fig. 53. Comparison 03. Acarbose versus Metformin

03.12 Change in body weight $(\mathrm{Kg})$

Review: Alpha-glucosidase inhibitors for type 2 diabetes mellitus

Comparison: 03 Acarbose versus Metformin

Outcome: 12 Change in body weight $(\mathrm{Kg})$

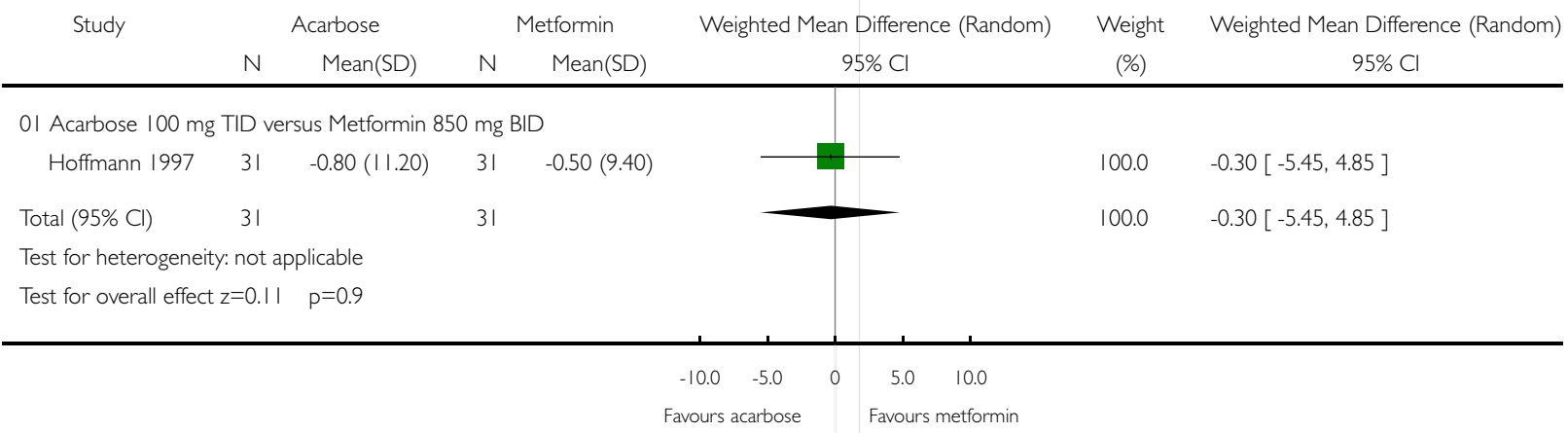




\section{Fig. 54. Comparison 03. Acarbose versus Metformin}

\subsection{Occurence of adverse effects}

Review: Alpha-glucosidase inhibitors for type 2 diabetes mellitus

Comparison: 03 Acarbose versus Metformin

Outcome: 30 Occurence of adverse effects



Fig. 55. Comparison 04. Acarbose versus nateglinide / repaglinide

04.01 Change in glycated haemoglobin (\%)

Review: Alpha-glucosidase inhibitors for type 2 diabetes mellitus

Comparison: 04 Acarbose versus nateglinide / repaglinide

Outcome: 0 I Change in glycated haemoglobin (\%)

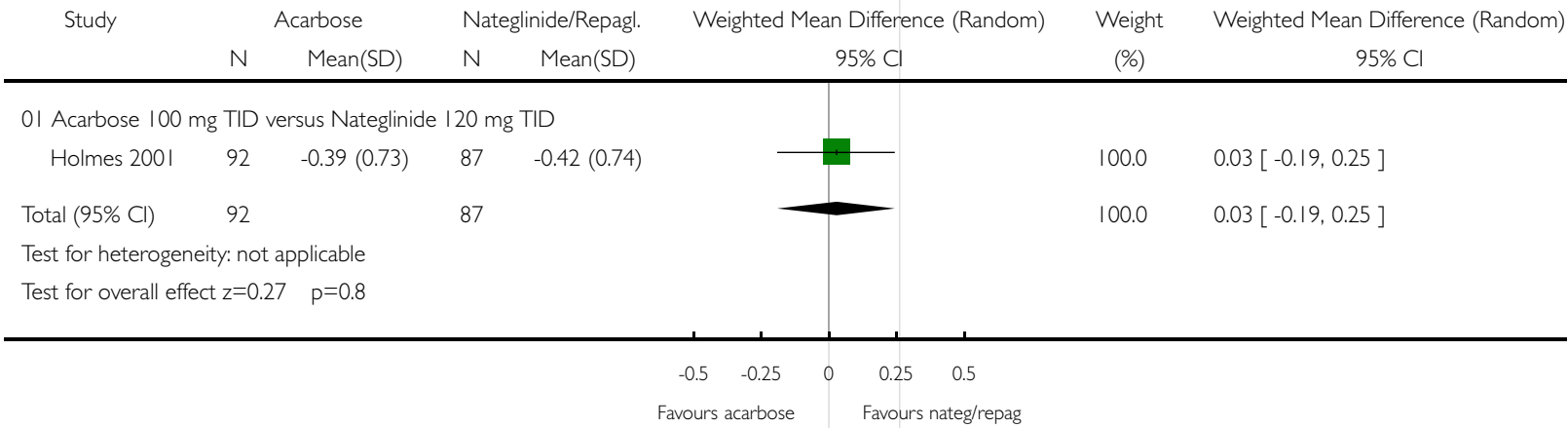




\section{Fig. 56. Comparison 04. Acarbose versus nateglinide / repaglinide}

\subsection{Change in fasting blood glucose ( $\mathrm{mmol} / \mathrm{l})$}

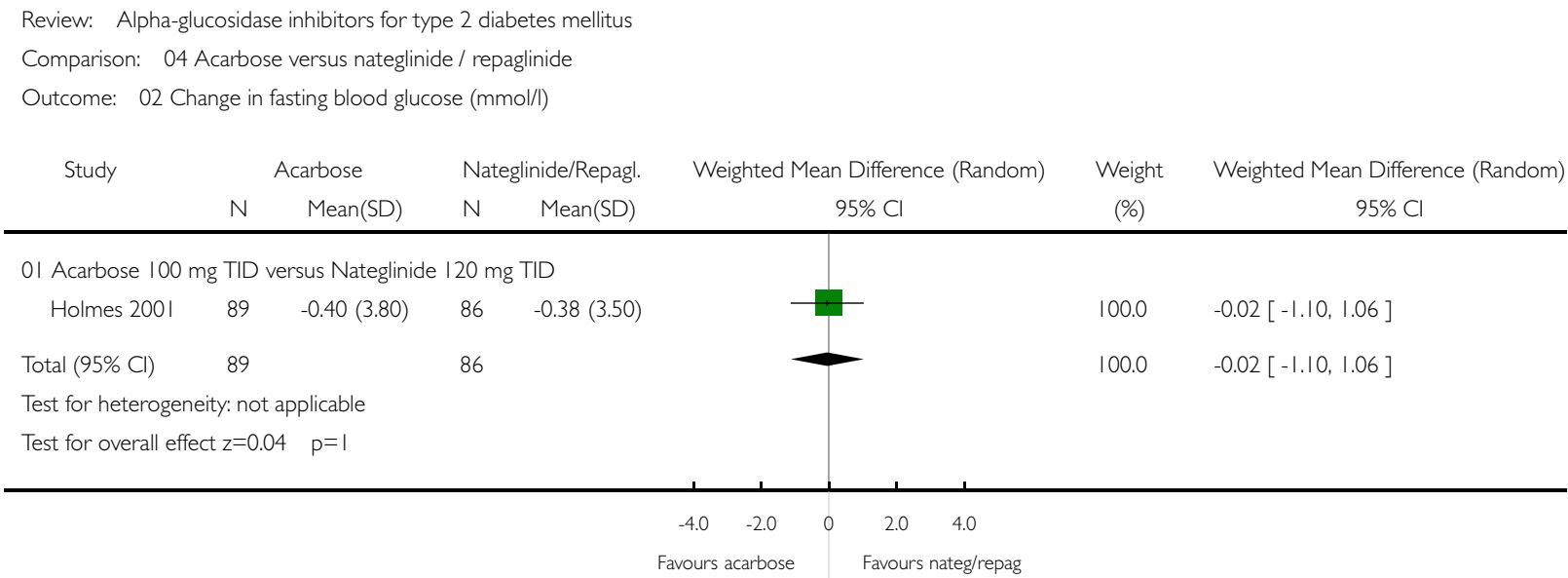

\section{Fig. 57. Comparison 04. Acarbose versus nateglinide / repaglinide}

\subsection{Change in body weight $(\mathrm{Kg})$}

Review: Alpha-glucosidase inhibitors for type 2 diabetes mellitus

Comparison: 04 Acarbose versus nateglinide / repaglinide

Outcome: 12 Change in body weight $(\mathrm{Kg})$

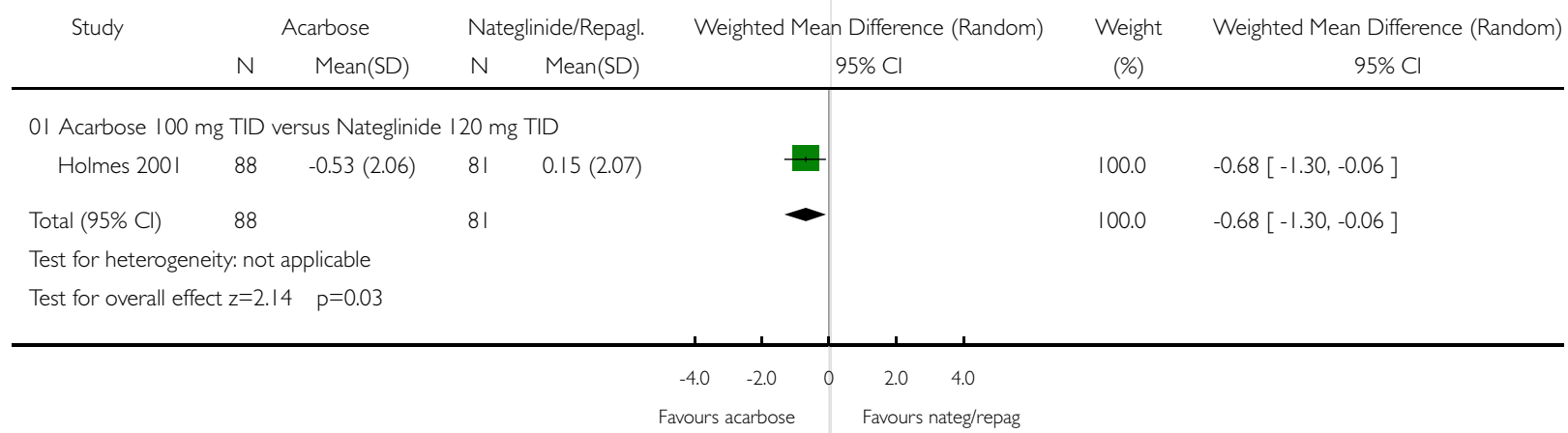


Fig. 58. Comparison 04. Acarbose versus nateglinide / repaglinide

04.30 Occurence of adverse effects

Review: Alpha-glucosidase inhibitors for type 2 diabetes mellitus

Comparison: 04 Acarbose versus nateglinide / repaglinide

Outcome: 30 Occurence of adverse effects

Study

Acarbose

Nateglinide/Repagl.

Odds Ratio (Random)

Weight

Odds Ratio (Random)

$n / N$

$n / N$

$95 \% \mathrm{Cl}$

(\%)

$95 \% \mathrm{Cl}$

0I Acarbose $100 \mathrm{mg}$ TID versus Nateglinide $120 \mathrm{mg}$ TID

Holmes 2001 60/92 $\quad 43 / 87$

$\begin{array}{lll}\text { Total }(95 \% \mathrm{Cl}) & 92 & 87\end{array}$

Total events: 60 (Acarbose), 43 (Nateglinide/Repagl.)

Test for heterogeneity: not applicable

Test for overall effect $z=2.13 \quad p=0.03$

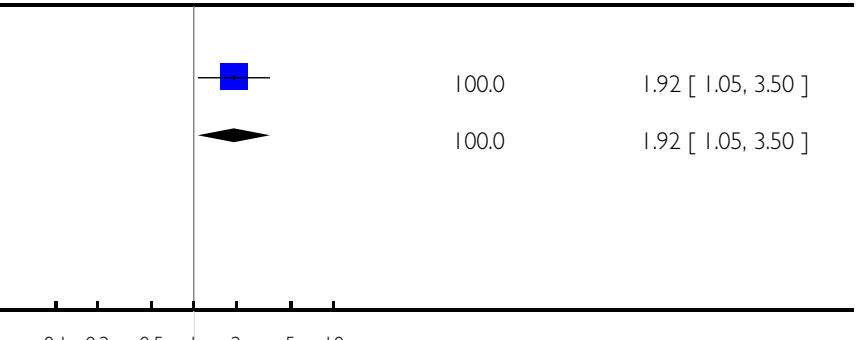

$\begin{array}{lllllll}0.1 & 0.2 & 0.5 & 1 & 2 & 5 & 10\end{array}$

Favours acarbose Favours nategl/repag

Fig. 59. Comparison 04. Acarbose versus nateglinide / repaglinide

04.3 I Occurence of gastro-intestinal adverse effects

Review: Alpha-glucosidase inhibitors for type 2 diabetes mellitus

Comparison: 04 Acarbose versus nateglinide / repaglinide

Outcome: 31 Occurence of gastro-intestinal adverse effects






\section{Fig. 60. Comparison 05. Miglitol versus placebo}

\subsection{Change in glycated haemoglobin (\%)}

Review: Alpha-glucosidase inhibitors for type 2 diabetes mellitus

Comparison: 05 Miglitol versus placebo

Outcome: 01 Change in glycated haemoglobin (\%)

Study

Miglitol

Placebo

Weighted Mean Difference (Random)

Weight

Weighted Mean Difference (Random)

N

Mean(SD)

Mean(SD)

$95 \% \mathrm{Cl}$

$95 \% \mathrm{Cl}$

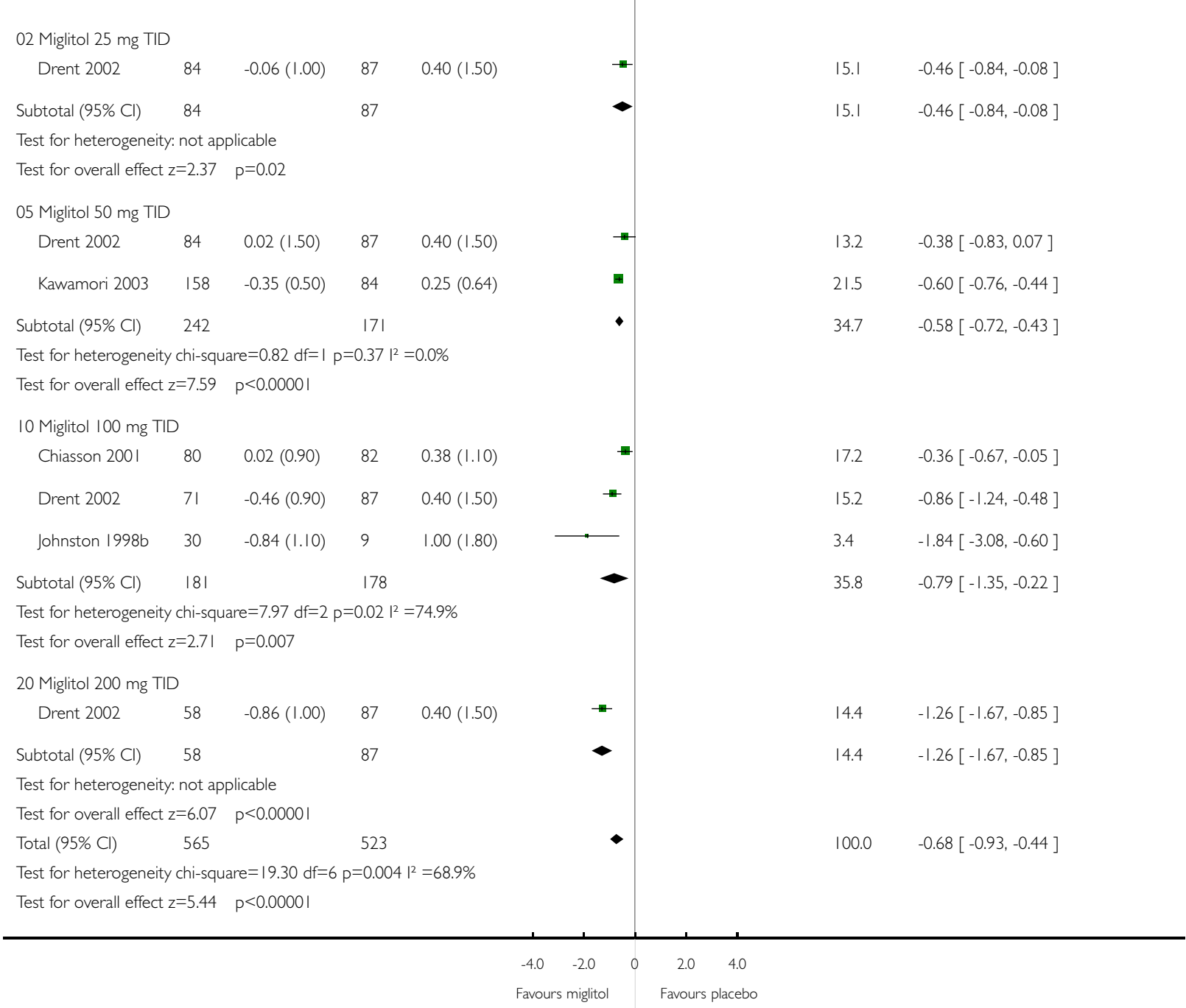

Alpha-glucosidase inhibitors for type 2 diabetes mellitus (Review) 


\section{Fig. 6I. Comparison 05. Miglitol versus placebo}

\subsection{Change in fasting blood glucose $(\mathrm{mmol} / \mathrm{l})$}

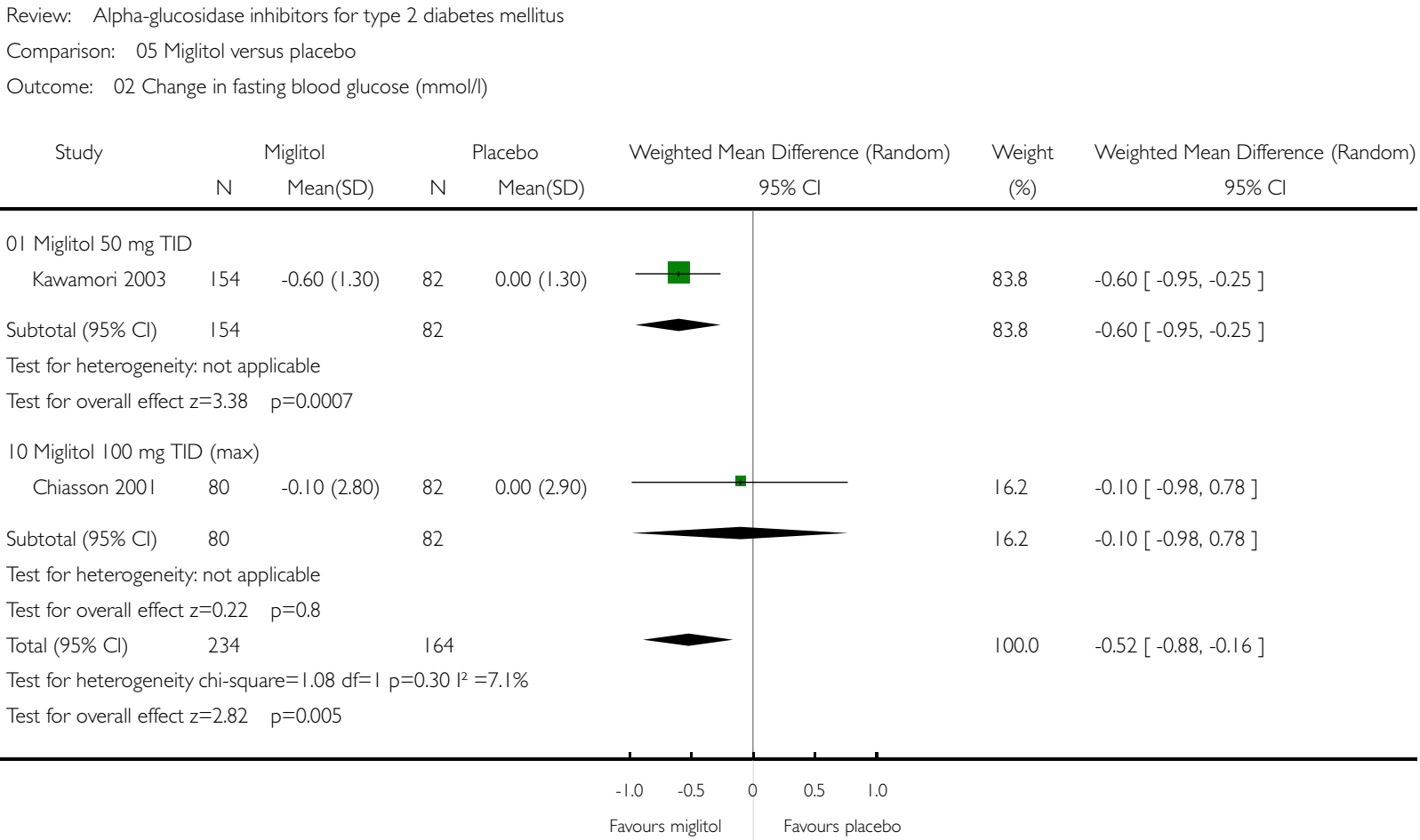


Fig. 62. Comparison 05. Miglitol versus placebo

05.03 Change in post-load blood glucose $(\mathrm{mmol} / \mathrm{l})$

Review: Alpha-glucosidase inhibitors for type 2 diabetes mellitus

Comparison: 05 Miglitol versus placebo

Outcome: 03 Change in post-load blood glucose ( $\mathrm{mmol} / \mathrm{l})$

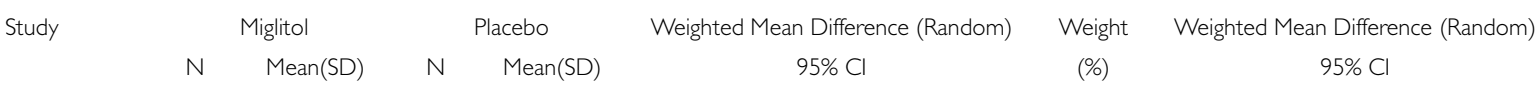

OI Miglitol $50 \mathrm{mg}$ TID

Subtotal $(95 \% \mathrm{Cl})$

154

$82-0.00(1.90)$

82

Test for heterogeneity: not applicable

Test for overall effect $z=|3.83 \quad p<0.0000|$

10 Miglitol $100 \mathrm{mg}$ TID (max)

Chiasson $2001 \quad 80 \quad-0.90(3.80)$

$82 \quad 0.30(3.90)$

Subtotal $(95 \% \mathrm{Cl}) \quad 80$

82

Test for heterogeneity: not applicable

Test for overall effect $z=1.98 \quad p=0.05$

Total $(95 \% \mathrm{Cl}) \quad 234 \quad 164$

Test for heterogeneity chi-square $=18.53 \mathrm{df}=\mid \mathrm{p}=<0.000 \mathrm{I} \mathrm{I}^{2}=94.6 \%$

Test for overall effect $z=1.86 \quad p=0.06$

$51.7-4.10[-4.68,-3.52]$

$51.7-4.10[-4.68,-3.52]$

$\bullet$

$51.7 \quad-4.10[-4.68,-3.52]$




\section{Fig. 63. Comparison 05. Miglitol versus placebo}

\subsection{Change in fasting insulin levels (pmol/l)}

Review: Alpha-glucosidase inhibitors for type 2 diabetes mellitus

Comparison: 05 Miglitol versus placebo

Outcome: 08 Change in fasting insulin levels (pmol/l)

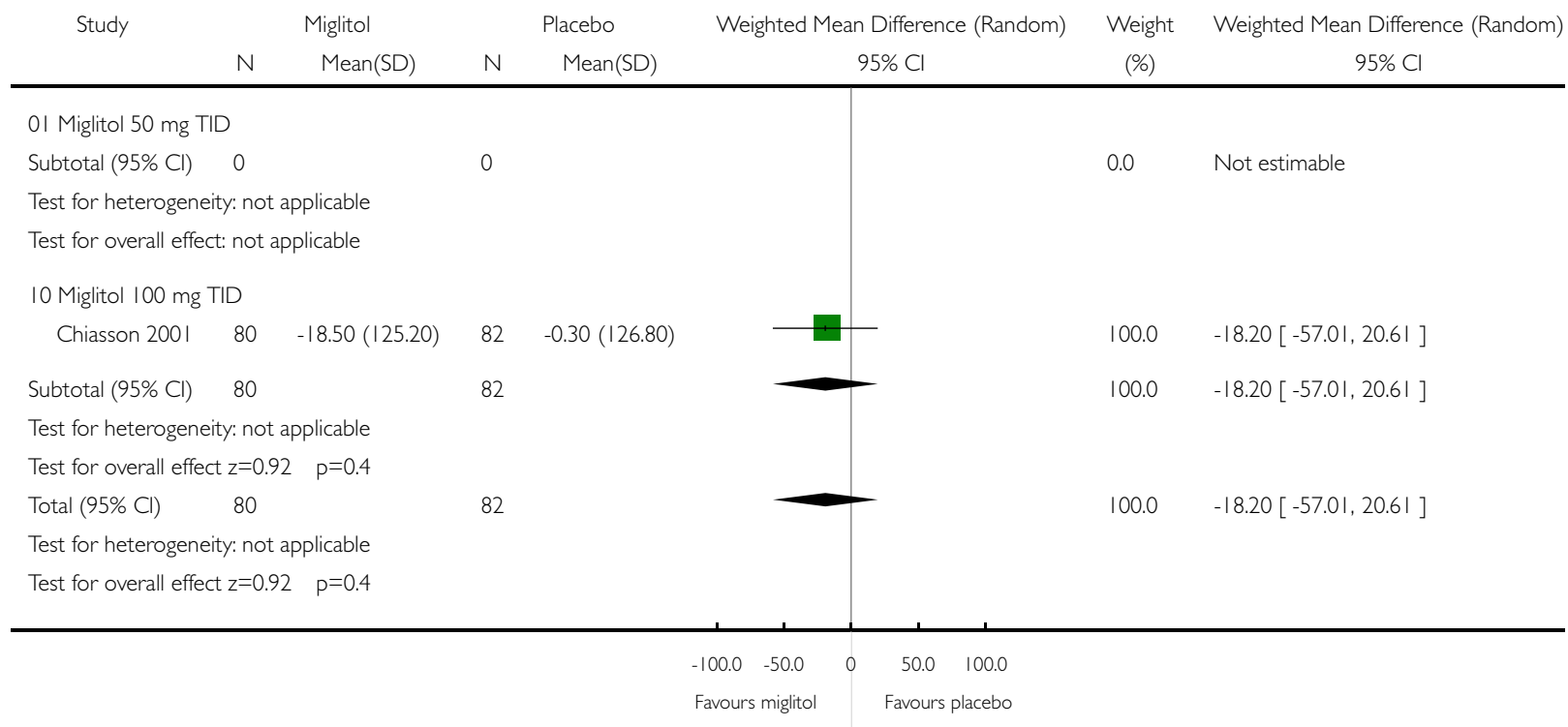

Fig. 64. Comparison 05. Miglitol versus placebo

05.09 Change in post-load insulin levels (pmol/l)

Review: Alpha-glucosidase inhibitors for type 2 diabetes mellitus

Comparison: 05 Miglitol versus placebo

Outcome: 09 Change in post-load insulin levels (pmol/l)

Study Miglitol Placebo Weighted Mean Difference (Random) Weight Weighted Mean Difference (Random)

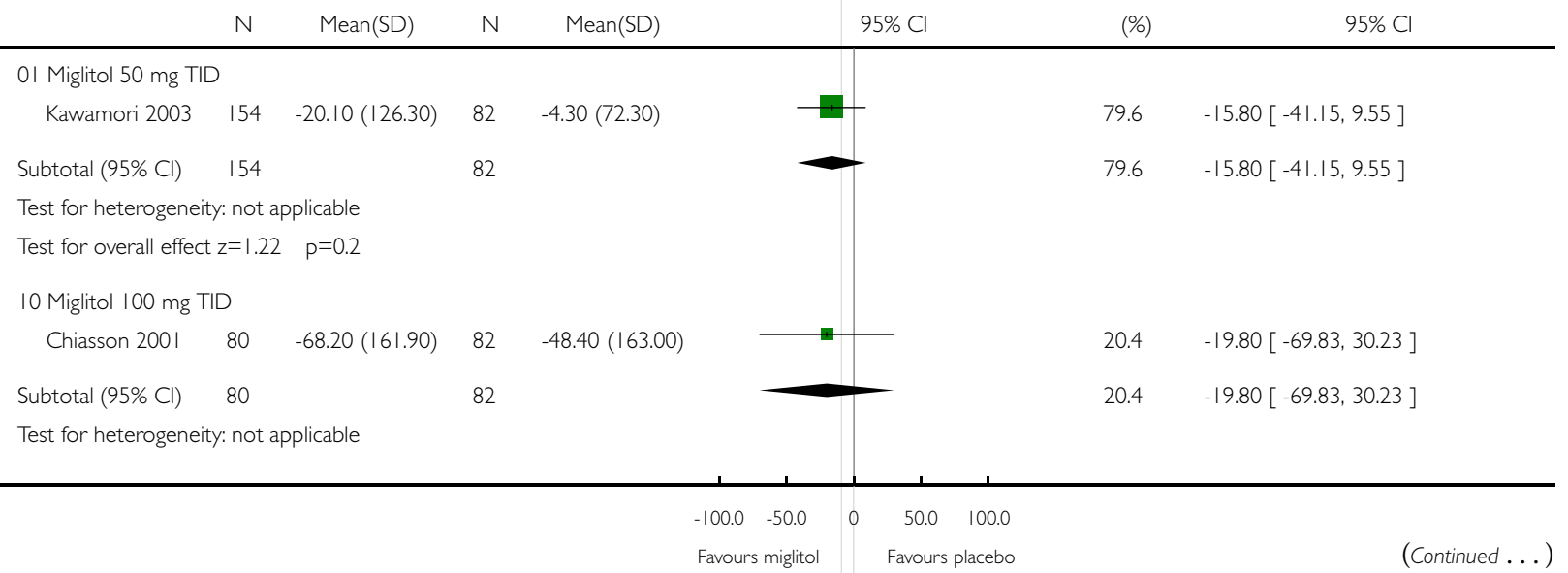


(... Continued)

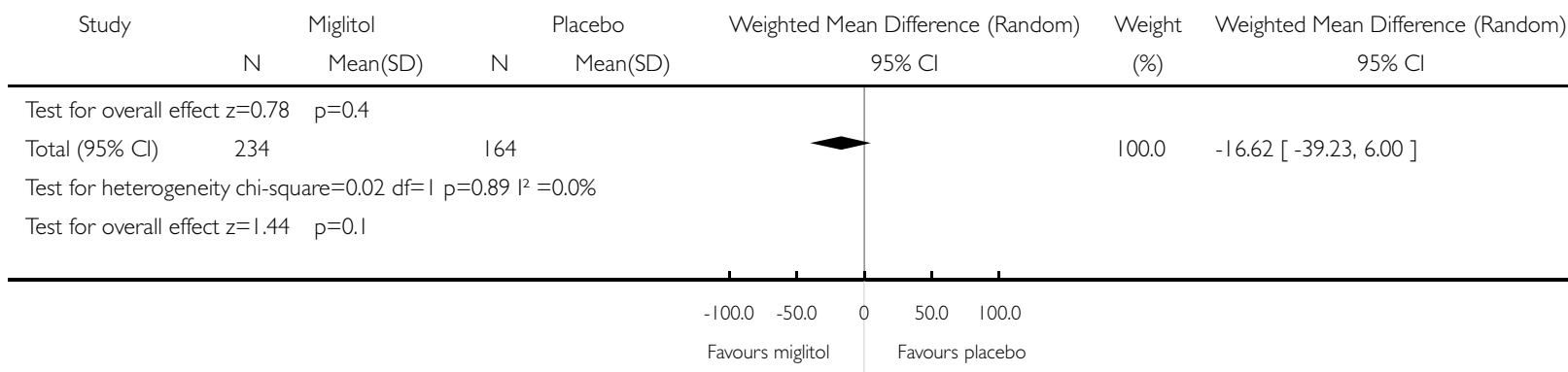

Fig. 65. Comparison 05. Miglitol versus placebo

\subsection{Change in body weight $(\mathrm{Kg})$}

Review: Alpha-glucosidase inhibitors for type 2 diabetes mellitus

Comparison: 05 Miglitol versus placebo

Outcome: 12 Change in body weight $(\mathrm{Kg})$

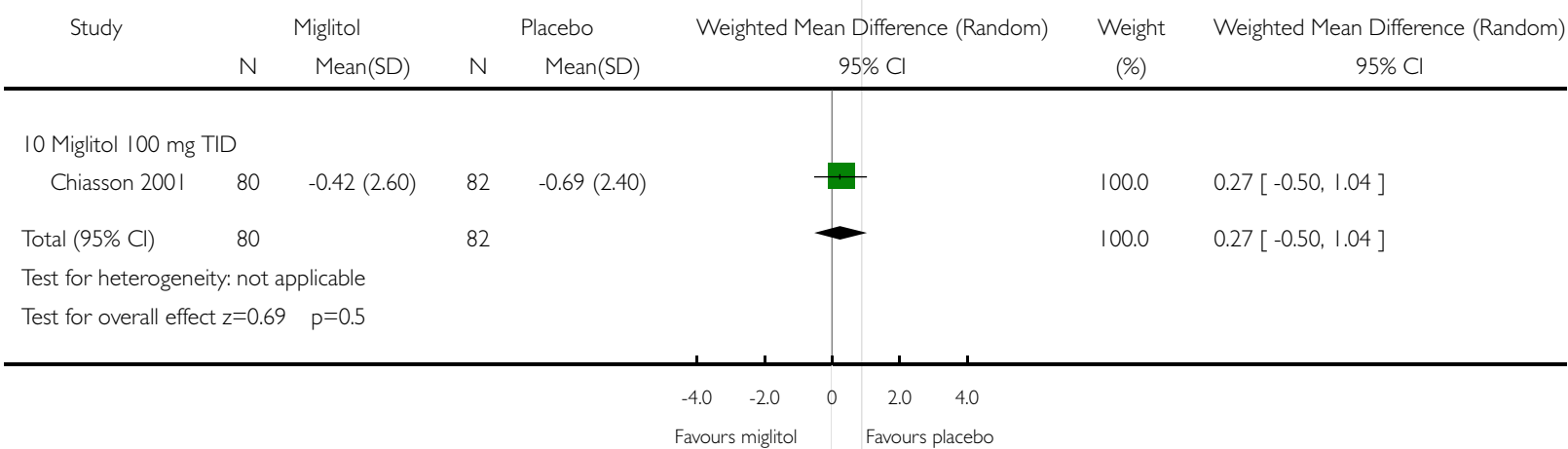


Fig. 66. Comparison 05. Miglitol versus placebo

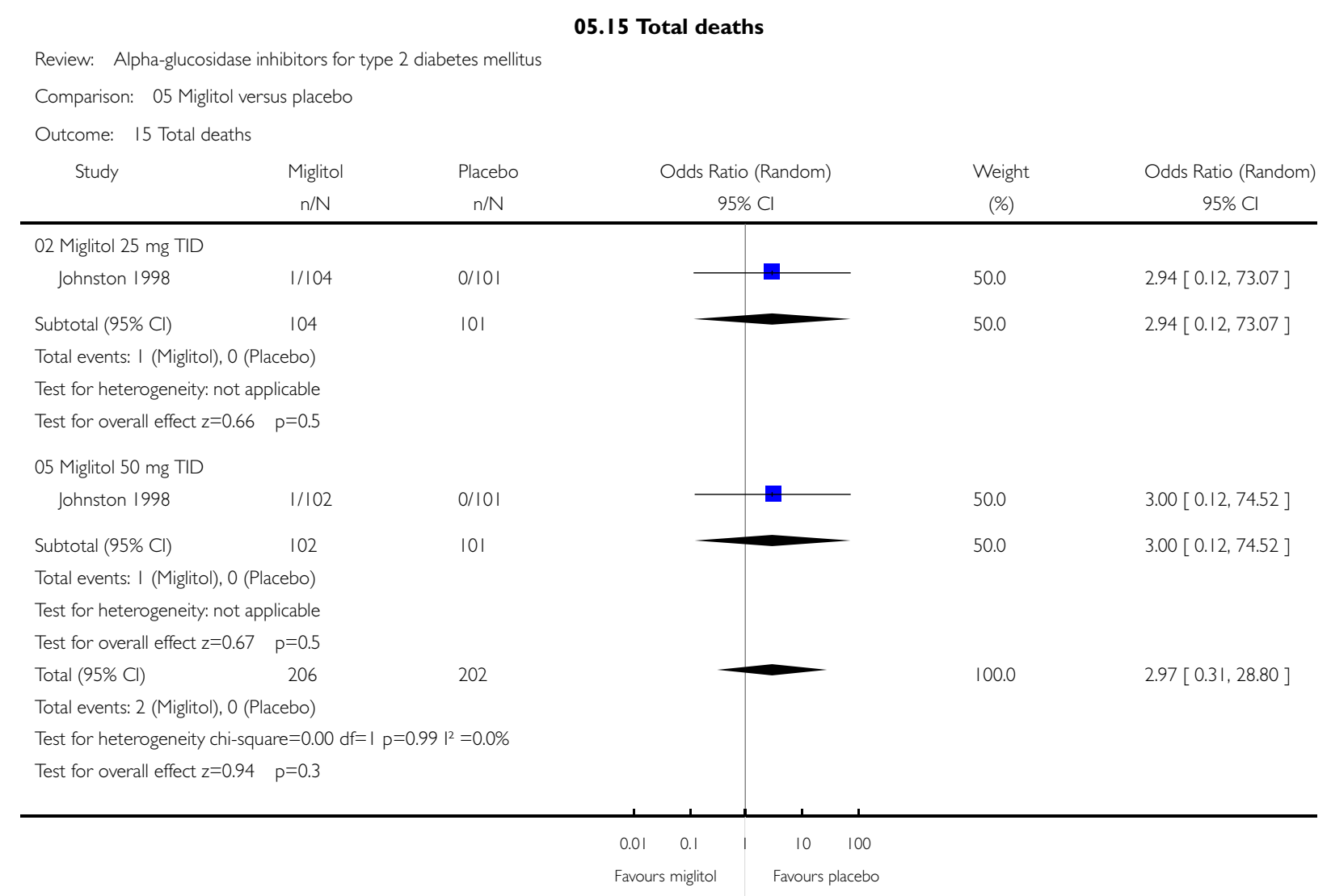

Alpha-glucosidase inhibitors for type 2 diabetes mellitus (Review) 
Fig. 67. Comparison 05. Miglitol versus placebo

05.16 Disease related deaths

Review: Alpha-glucosidase inhibitors for type 2 diabetes mellitus

Comparison: 05 Miglitol versus placebo

Outcome: 16 Disease related deaths

Study Miglito

Miglito

Placebo

Odds Ratio (Random)

Weight

Odds Ratio (Random)

$n / N$

$95 \% \mathrm{Cl}$

(\%)

$95 \% \mathrm{Cl}$

02 Miglitol $25 \mathrm{mg}$ TID

1/104

$0 / 101$

Johnston 1998

104

101

\begin{tabular}{r|r}
+1 \\
\hline
\end{tabular}

100.0

$2.94[0.12,73.07]$

Subtotal $(95 \% \mathrm{Cl})$

$\longrightarrow$

100.0

$2.94[0.12,73.07]$

Total events: I (Miglitol), 0 (Placebo)

Test for heterogeneity: not applicable

Test for overall effect $z=0.66 \quad p=0.5$

05 Miglitol $50 \mathrm{mg}$ TID

$\times$ Johnston $1998 \quad$ 0/102

0/102 0/101

Subtotal $(95 \% \mathrm{Cl})$

102

Total events: 0 (Miglitol), 0 (Placebo)

Test for heterogeneity: not applicable

Test for overall effect: not applicable

Total $(95 \% \mathrm{Cl}) \quad 206$

Total events: I (Miglitol), 0 (Placebo)

Test for heterogeneity: not applicable

Test for overall effect $z=0.66 \quad p=0.5$

I01

202

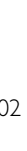

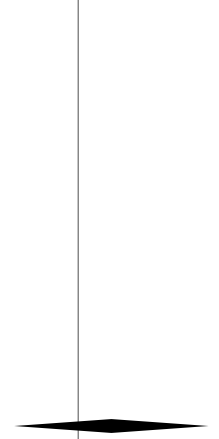

0.0

Not estimable

0.0

Not estimable

100.0

$2.94[0.12,73.07]$ 


\section{Fig. 68. Comparison 05. Miglitol versus placebo}

\subsection{Occurence of adverse effects}

Review: Alpha-glucosidase inhibitors for type 2 diabetes mellitus

Comparison: 05 Miglitol versus placebo

Outcome: 30 Occurence of adverse effects

Placebo

Odds Ratio (Random)

Weight

Odds Ratio (Random)

$n / N$

$n / N$

$95 \% \mathrm{Cl}$

$95 \% \mathrm{Cl}$

02 Miglitol 25 mg TID
Drent 2002

$6 / 92$

2/93

Subtotal $(95 \% \mathrm{Cl})$

92

93

Total events: 6 (Miglitol), 2 (Placebo)

Test for heterogeneity: not applicable

Test for overall effect $z=1.39 \quad p=0.2$

05 Miglitol $50 \mathrm{mg}$ TID

Drent 2002

$4 / 93$

2/93

Kawamori 2003

$132 / 174$

$57 / 89$

Subtotal $(95 \% \mathrm{Cl})$

267

182

Total events: 136 (Miglitol), 59 (Placebo)

Test for heterogeneity chi-square $=0.03 \mathrm{df}=\mid \mathrm{p}=0.87 \mathrm{l}^{2}=0.0 \%$

Test for overall effect $z=2.16 \quad p=0.03$

10 Miglitol $100 \mathrm{mg}$ TID

$\begin{array}{lll}\text { Chiasson } 2001 & 79 / 82 & 71 / 83\end{array}$

Drent 2002

$22 / 94$

$2 / 93$

Segal 1997

$18 / 67$

$14 / 65$

Subtotal $(95 \% \mathrm{Cl})$

243

241

Total events: I 19 (Miglitol), 87 (Placebo)

Test for heterogeneity chi-square $=8.61 \mathrm{df}=2 \mathrm{p}=0.01 \mathrm{I}^{2}=76.8 \%$

Test for overall effect $z=1.90 \quad p=0.06$

20 Miglitol $200 \mathrm{mg}$ TID

Drent $2002 \quad 40 / 93 \quad 2 / 93$

Subtotal $(95 \% \mathrm{Cl})$

93

93

Total events: 40 (Miglitol), 2 (Placebo)

Test for heterogeneity: not applicable

Test for overall effect $z=4.75 \quad p<0.0000$ I

Total $(95 \% \mathrm{Cl}) \quad 695$

(Placebo)

609

Total events: 30 I (Miglitol), 150 (Placebo)

Test for heterogeneity chi-square $=24.19 \mathrm{df}=6 \mathrm{p}=0.0005 \mathrm{I}^{2}=75.2 \%$

Test for overall effect $z=3.15 \quad p=0.002$

:

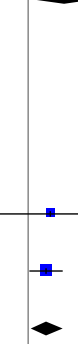

$<$

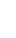

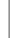

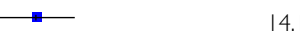

14.

12.9

17.6

44.6

19.1

30.5

12.0

12.0

$3.17[0.62,16.16]$

$3.17[0.62,16.16]$

$\begin{array}{ll}11.4 & 2.04[0.37,11.45] \\ 19.1 & 1.76[1.01,3.07] \\ 30.5 & 1.79[1.05,3.03]\end{array}$

$4.45[1.21,16.41]$

$13.90[3.16,61.08]$

$1.34[0.60,2.98]$

$3.93[0.96,16.12]$

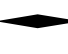

44.6

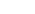

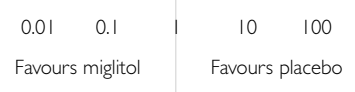




\section{Fig. 69. Comparison 05. Miglitol versus placebo}

05.3 I Occurence of gastro-intestinal adverse effects

Review: Alpha-glucosidase inhibitors for type 2 diabetes mellitus

Comparison: 05 Miglitol versus placebo

Outcome: 31 Occurence of gastro-intestinal adverse effects

Study

Miglitol Placebo

Odds Ratio (Random)

Weight

Odds Ratio (Random)

05 Miglitol 50 mg TID

$\mathrm{n} / \mathrm{N}$

$95 \% \mathrm{Cl}$

(\%)

$95 \% \mathrm{Cl}$

$$
\text { Kawamori } 2003
$$

$98 / 174$

$32 / 89$

Subtotal $(95 \% \mathrm{Cl})$

174

Total events: 98 (Miglitol), 32 (Placebo)

Test for heterogeneity: not applicable

Test for overall effect $z=3.10 \quad p=0.002$

10 Miglitol 100 mg TID

Chiasson 2001

$58 / 82$

$29 / 83$

89

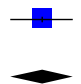

54.4

$2.30[1.36,3.89]$

Subtotal $(95 \% \mathrm{Cl})$

82

83

45.6

45.6

$4.50[2.34,8.67]$

Total events: 58 (Miglitol), 29 (Placebo)

Test for heterogeneity: not applicable

Test for overall effect $z=4.50 \quad p<0.0000$ I

Total $(95 \% \mathrm{Cl})$

256

172

45.6

$4.50[2.34,8.67]$

Total events: I 56 (Miglitol), 6 I (Placebo)

Test for heterogeneity chi-square $=2.46 \mathrm{df}=\mid \mathrm{p}=0.12 \mathrm{I}^{2}=59.3 \%$

Test for overall effect $z=3.40 \quad p=0.0007$

$\begin{array}{lllllll}0.1 & 0.2 & 0.5 & 1 & 2 & 5 & 10\end{array}$

Favours migitol Favours placebo 
Fig. 70. Comparison 05. Miglitol versus placebo

05.90 Change in post-load blood glucose $(\mathrm{mmol} / \mathrm{l})$ (2-hours)

Review: Alpha-glucosidase inhibitors for type 2 diabetes mellitus

Comparison: 05 Miglitol versus placebo

Outcome: 90 Change in post-load blood glucose ( $\mathrm{mmol} / \mathrm{l}$ ) (2-hours)

Study Treatment Control Weighted Mean Difference (Random) Weight Weighted Mean Difference (Random)

$\mathrm{N} \quad \mathrm{Mean}(\mathrm{SD}) \quad \mathrm{N} \quad \mathrm{Mean}(\mathrm{SD}) \quad 95 \% \mathrm{Cl}$

\%) $95 \% \mathrm{Cl}$

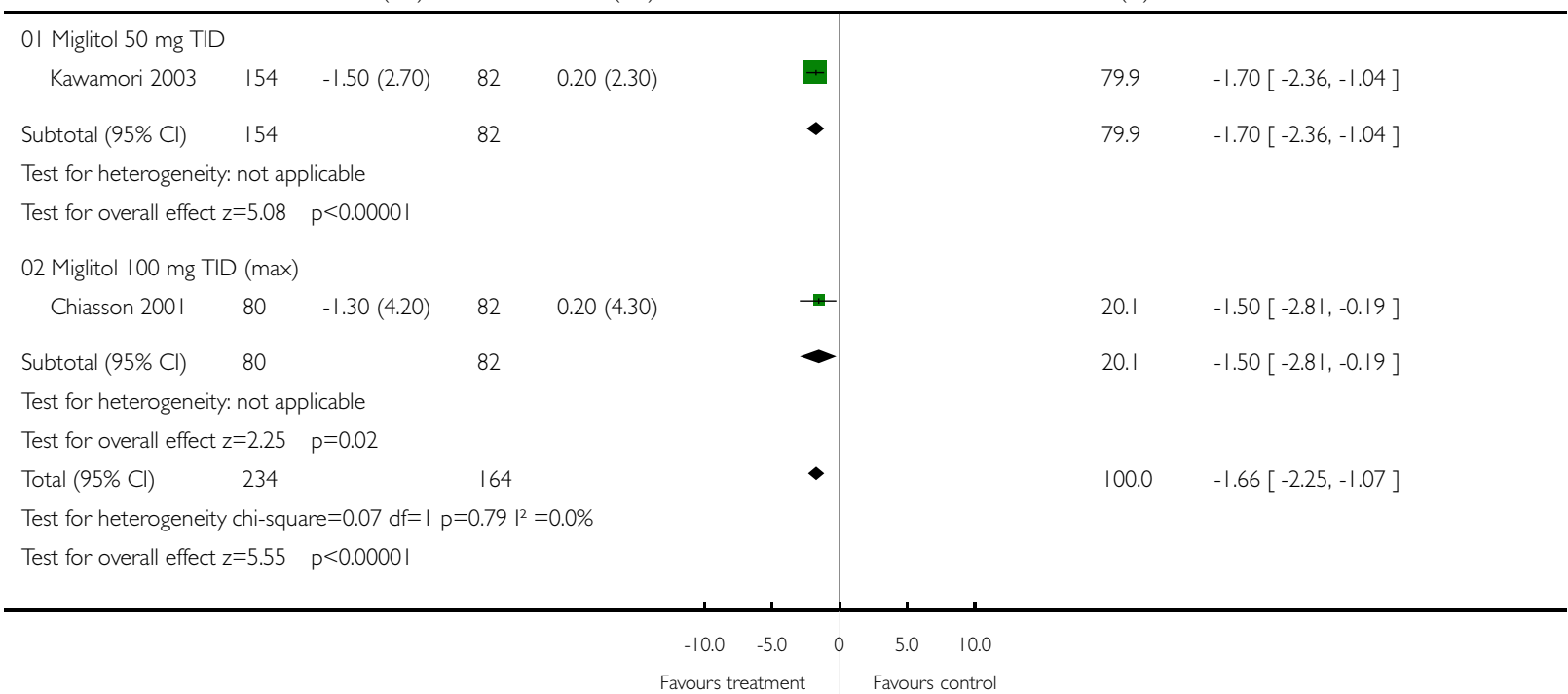




\section{Fig. 7I. Comparison 05. Miglitol versus placebo}

\subsection{Change in post-load insulin levels (pmol/l) (2-hours)}

Review: Alpha-glucosidase inhibitors for type 2 diabetes mellitus

Comparison: 05 Miglitol versus placebo

Outcome: 91 Change in post-load insulin levels (pmol/) (2-hours)

\begin{tabular}{|c|c|c|c|c|c|c|c|}
\hline \multirow[t]{2}{*}{ Study } & \multicolumn{2}{|r|}{ Treatment } & \multicolumn{2}{|r|}{ Control } & \multirow{2}{*}{$\begin{array}{l}\text { Weighted Mean Difference (Random) } \\
\qquad 95 \% \text { C }\end{array}$} & \multirow{2}{*}{$\begin{array}{c}\text { Weight } \\
(\%)\end{array}$} & \multirow{2}{*}{$\begin{array}{l}\text { Weighted Mean Difference (Random) } \\
\qquad 95 \% \mathrm{Cl}\end{array}$} \\
\hline & $\mathrm{N}$ & Mean(SD) & $N$ & Mean(SD) & & & \\
\hline \multicolumn{8}{|l|}{ 0I Miglitol 50 mg TID } \\
\hline Kawamori 2003 & 154 & $-20.10(126.30)$ & 82 & $-4.30(72.30)$ & & 81.8 & $-15.80[-41.15,9.55]$ \\
\hline Subtotal $(95 \% \mathrm{Cl})$ & 154 & & 82 & & & 81.8 & $-15.80[-41.15,9.55]$ \\
\hline \multicolumn{8}{|c|}{ Test for heterogeneity: not applicable } \\
\hline \multicolumn{8}{|c|}{ Test for overall effect $z=1.22 \quad p=0.2$} \\
\hline \multicolumn{8}{|c|}{02 Miglitol 100 mg TID } \\
\hline Chiasson 2001 & 80 & $-63.60(177.10)$ & 82 & $-48.40(172.10)$ & & 18.2 & $-15.20[-68.99,38.59]$ \\
\hline Subtotal $(95 \% \mathrm{Cl})$ & 80 & & 82 & & & 18.2 & $-15.20[-68.99,38.59]$ \\
\hline \multicolumn{8}{|c|}{ Test for heterogeneity: not applicable } \\
\hline \multicolumn{8}{|c|}{ Test for overall effect $z=0.55 \quad p=0.6$} \\
\hline Total $(95 \% \mathrm{Cl})$ & 234 & & 164 & & & 100.0 & $-15.69[-38.62,7.24]$ \\
\hline \multicolumn{8}{|c|}{ Test for heterogeneity chi-square $=0.00 \mathrm{df}=\mid \mathrm{p}=0.98 \mathrm{I}^{2}=0.0 \%$} \\
\hline Test for overall effec & $z=1.34$ & $p=0.2$ & & & & & \\
\hline
\end{tabular}

Fig. 72. Comparison 06. Miglitol versus sulphonylurea (SU)

06.01 Change in glycated haemoglobin (\%)

Review: Alpha-glucosidase inhibitors for type 2 diabetes mellitus

Comparison: 06 Miglitol versus sulphonylurea (SU)

Outcome: 0 I Change in glycated haemoglobin (\%)

Study Miglitol Sulphonylurea $\quad$ Weighted Mean Difference (Random) Weight Weighted Mean Difference (Random)
N Mean(SD) $95 \% \mathrm{Cl}$ $95 \% \mathrm{Cl}$

N Mean(SD)

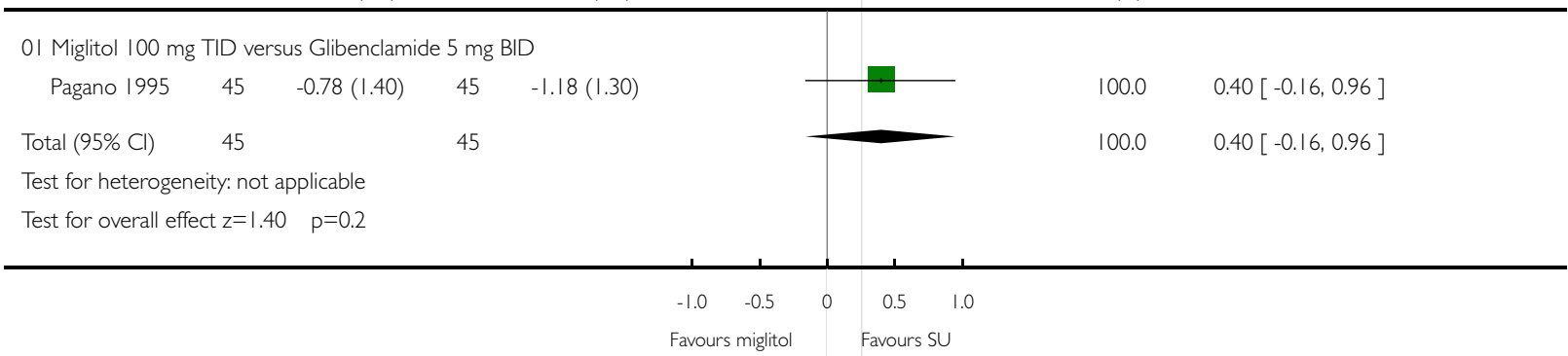




\section{Fig. 73. Comparison 06. Miglitol versus sulphonylurea (SU)}

\subsection{Change in fasting blood glucose $(\mathrm{mmol} / \mathrm{l})$}

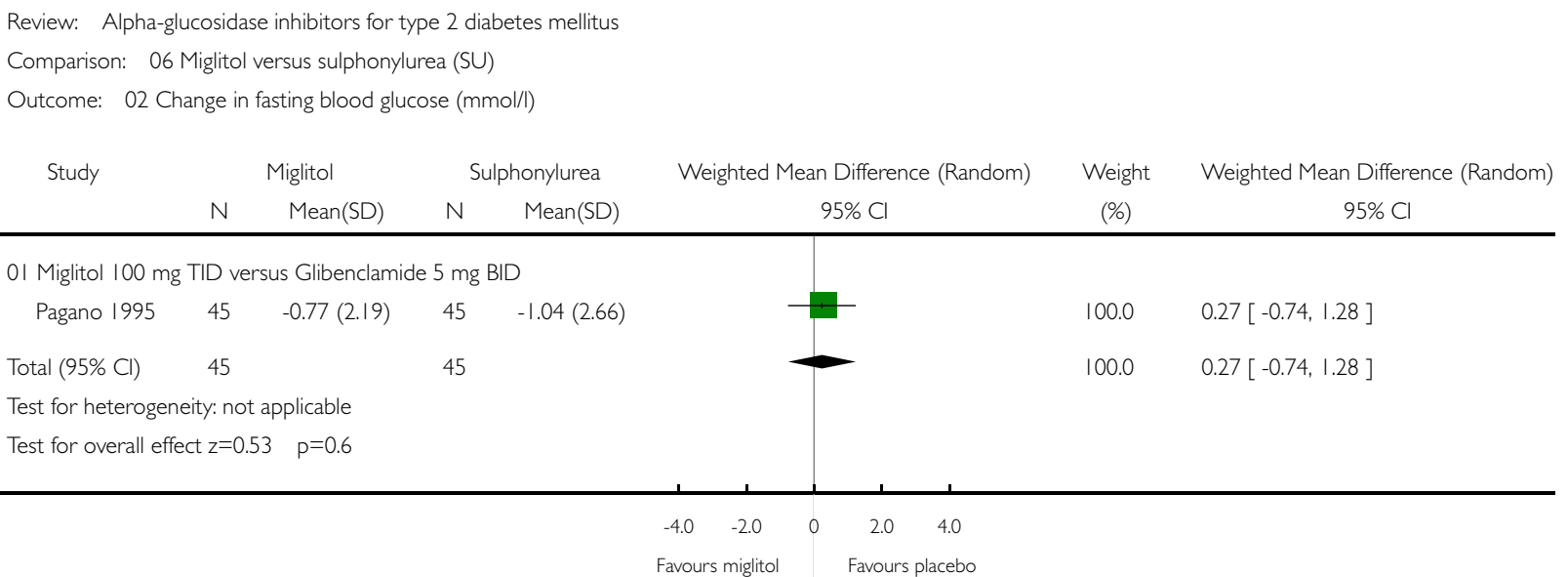

Fig. 74. Comparison 06. Miglitol versus sulphonylurea (SU)

06.03 Change in post-load blood glucose ( $\mathrm{mmol} / \mathrm{l})$

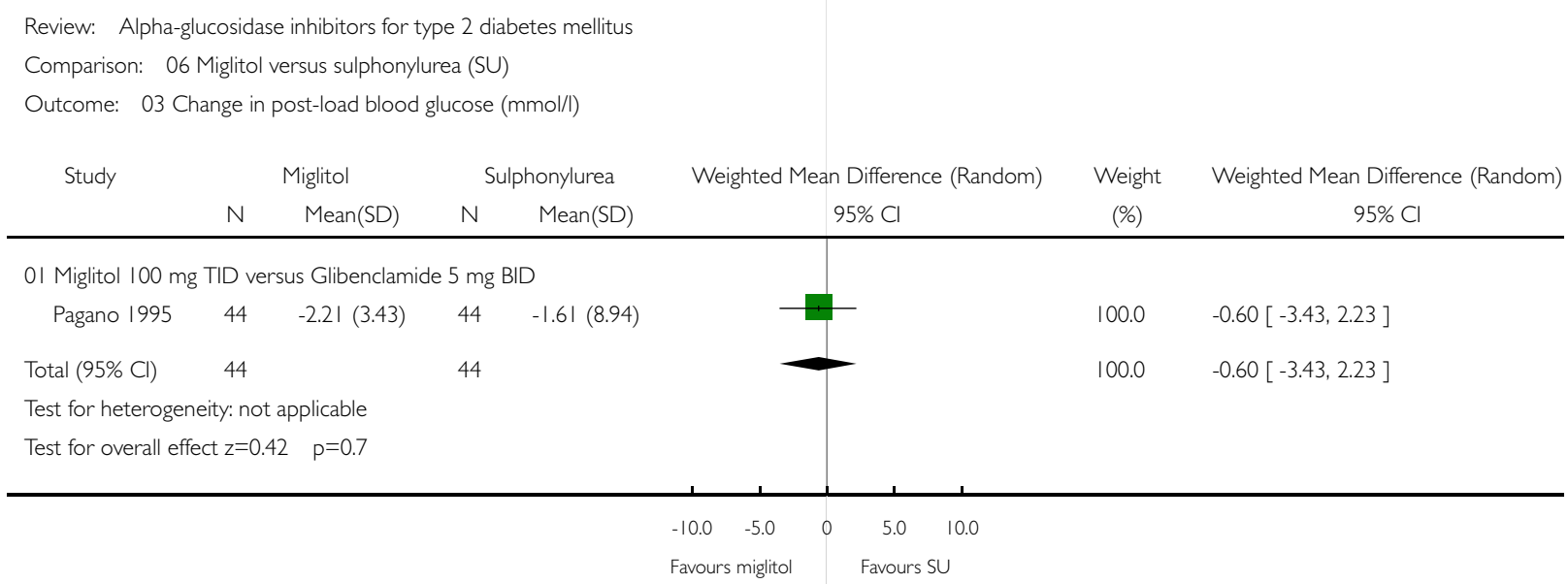


Fig. 75. Comparison 06. Miglitol versus sulphonylurea (SU)

06.04 Change in total cholesterol ( $\mathrm{mmol} / \mathrm{l})$

Review: Alpha-glucosidase inhibitors for type 2 diabetes mellitus

Comparison: 06 Miglitol versus sulphonylurea (SU)

Outcome: 04 Change in total cholesterol $(\mathrm{mmol} / \mathrm{l})$

Study Miglitol Sulphonylurea Weighted Mean Difference (Random) Weight Weighted Mean Difference (Random)

N Mean(SD) N Mean(SD) $95 \% \mathrm{Cl}$

$95 \% \mathrm{Cl}$

OI Miglitol 100 mg TID versus Glibenclamide 5 mg BID

Pagano $1995 \quad 45 \quad 0.03(0.85) \quad 43 \quad-0.05(0.92)$

Total $(95 \% \mathrm{Cl}) \quad 45 \quad 43$

Test for heterogeneity: not applicable

Test for overall effect $z=0.42 \quad p=0.7$

43

$100.0 \quad 0.08[-0.29,0.45]$

$100.0 \quad 0.08[-0.29,0.45]$

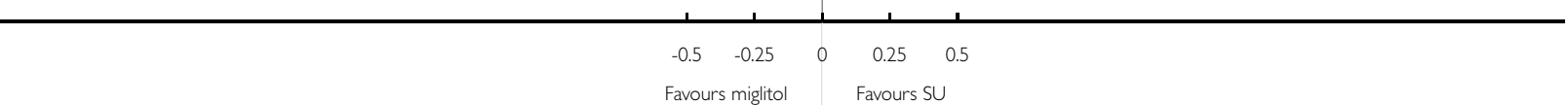

Fig. 76. Comparison 06. Miglitol versus sulphonylurea (SU)

06.05 Change in HDL-cholesterol ( $\mathrm{mmol} / \mathrm{I})$

Review: Alpha-glucosidase inhibitors for type 2 diabetes mellitus

Comparison: 06 Miglitol versus sulphonylurea (SU)

Outcome: 05 Change in HDL-cholesterol ( $\mathrm{mmol} / \mathrm{l})$

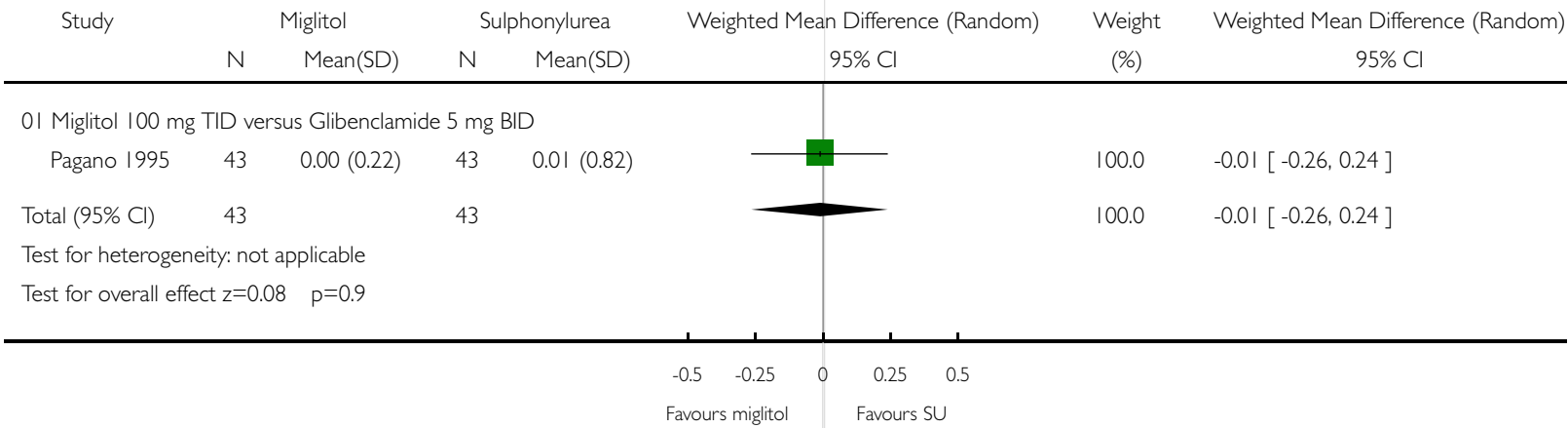




\section{Fig. 77. Comparison 06. Miglitol versus sulphonylurea (SU)}

\subsection{Change in triglycerides $(\mathrm{mmol} / \mathrm{l})$}

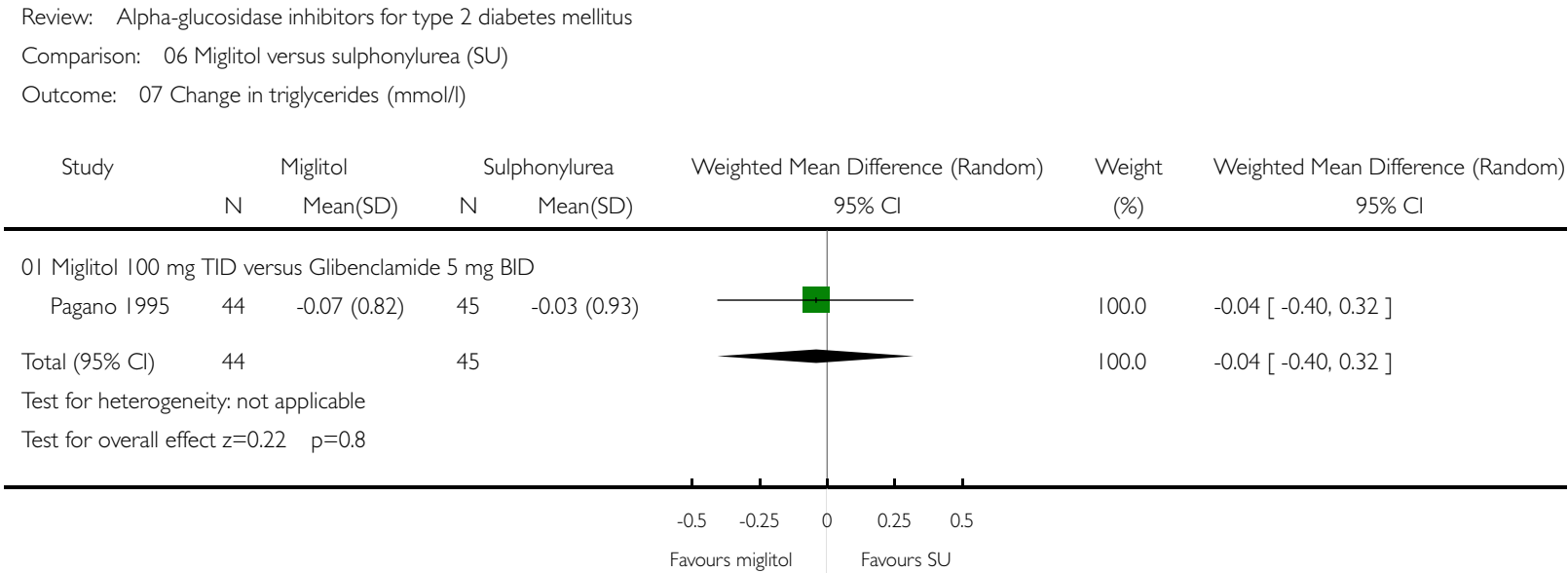

\section{Fig. 78. Comparison 06. Miglitol versus sulphonylurea (SU)}

06.08 Change in fasting insulin levels (pmol/l)

Review: Alpha-glucosidase inhibitors for type 2 diabetes mellitus

Comparison: 06 Miglitol versus sulphonylurea (SU)

Outcome: 08 Change in fasting insulin levels (pmol/l)

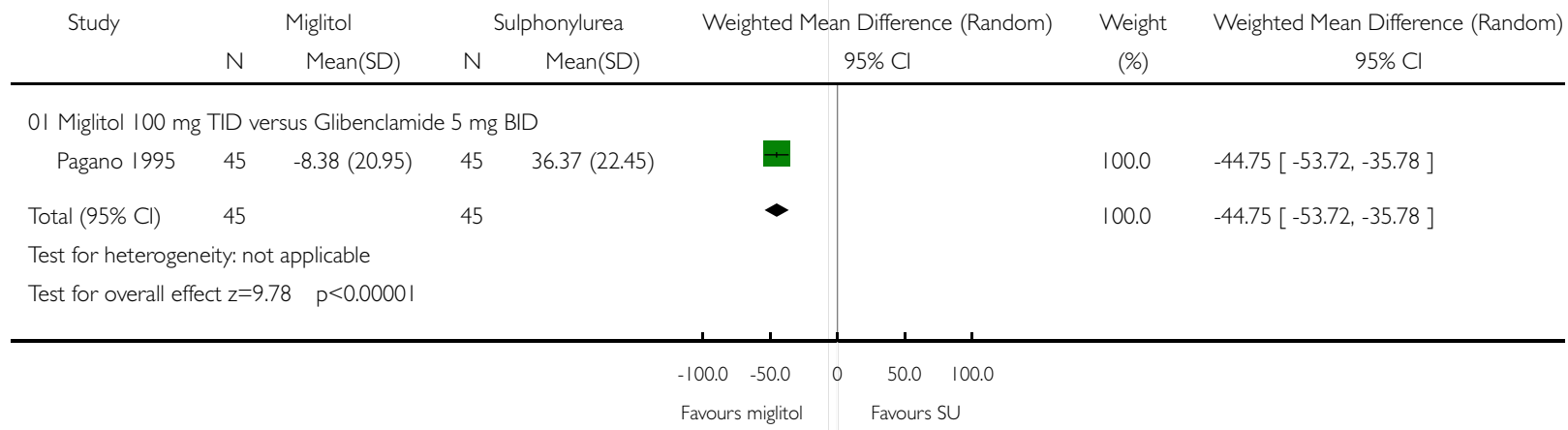




\section{Fig. 79. Comparison 06. Miglitol versus sulphonylurea (SU)}

\subsection{Change in body weight $(\mathrm{Kg})$}

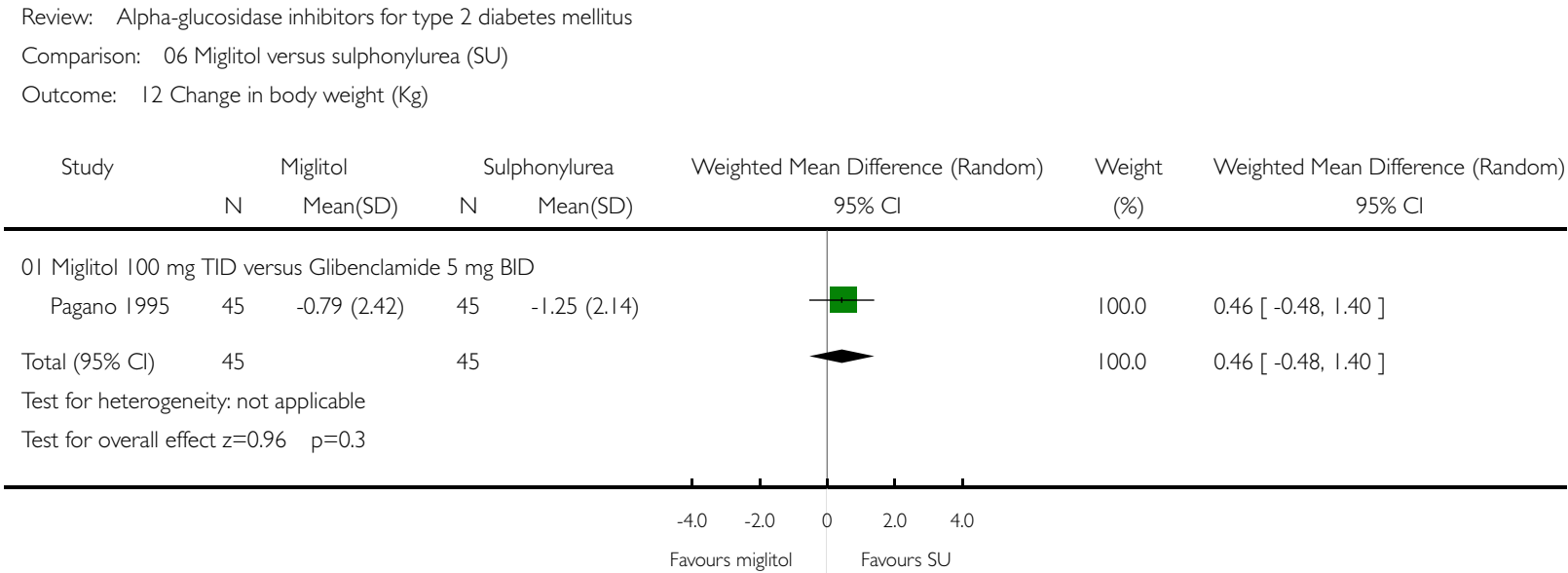

Fig. 80. Comparison 06. Miglitol versus sulphonylurea (SU)

\subsection{Total deaths}

Review: Alpha-glucosidase inhibitors for type 2 diabetes mellitus

Comparison: 06 Miglitol versus sulphonylurea (SU)

Outcome: 15 Total deaths

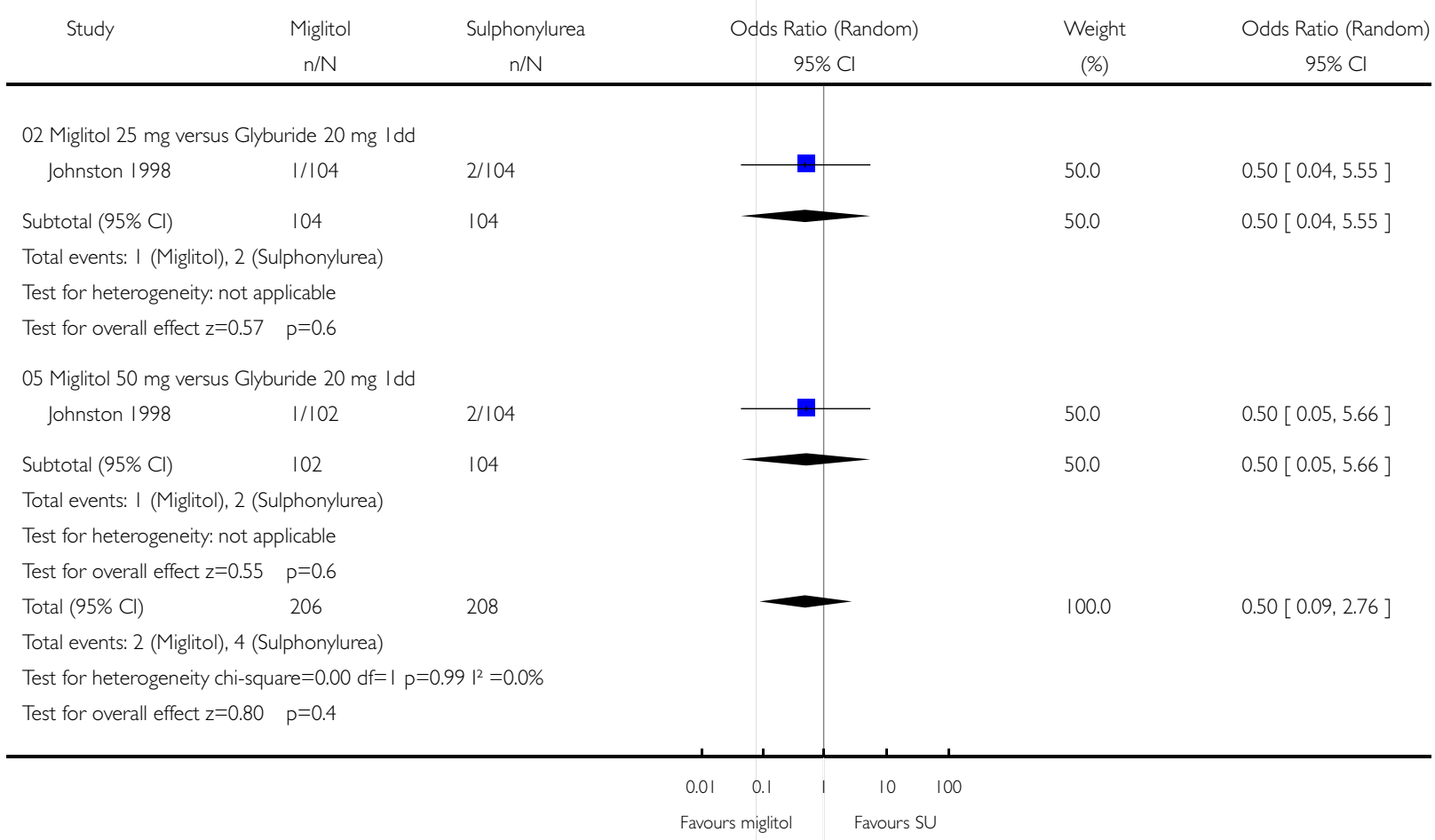


Fig. 8I. Comparison 06. Miglitol versus sulphonylurea (SU)

\subsection{Disease related deaths}

Review: Alpha-glucosidase inhibitors for type 2 diabetes mellitus

Comparison: 06 Miglitol versus sulphonylurea (SU)

Outcome: 16 Disease related deaths

Study

$\begin{array}{cc}\text { Miglitol } & \text { Sulphonylurea } \\ \mathrm{n} / \mathrm{N} & \mathrm{n} / \mathrm{N}\end{array}$

Odds Ratio (Random)

Weight

Odds Ratio (Random)

$\mathrm{n} / \mathrm{N}$

$\mathrm{n} / \mathrm{N}$

$95 \% \mathrm{Cl}$

(\%)

$95 \% \mathrm{Cl}$

02 Miglitol $25 \mathrm{mg}$ versus Glyburide $20 \mathrm{mg}$ Idd

Johnston 1998

$1 / 104$

104

Subtotal $(95 \% \mathrm{Cl})$

104

104

Total events: I (Miglitol), I (Sulphonylurea)

Test for heterogeneity: not applicable

Test for overall effect $z=0.00 \quad p=1$

05 Miglitol $50 \mathrm{mg}$ versus Glyburide $20 \mathrm{mg}$ I dd

$\begin{array}{lll}\text { Johnston } 1998 & 0 / 102 & 1 / 104 \\ \text { Subtotal }(95 \% \mathrm{Cl}) & 102 & 104\end{array}$

Total events: 0 (Miglitol), I (Sulphonylurea)

Test for heterogeneity: not applicable

Test for overall effect $z=0.66 \quad p=0.5$

Total $(95 \% \mathrm{Cl})$

206

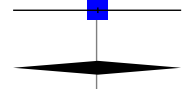

57.1

$1.00[0.06,16.20]$

Total events: I (Miglitol), 2 (Sulphonylurea)

Test for heterogeneity chi-square $=0.25 \mathrm{df}=|\mathrm{p}=0.6 \mathrm{|}|^{2}=0.0 \%$

Test for overall effect $z=0.44 \quad p=0.7$

$1 / 104$
04
208
$1^{2}=0.0 \%$

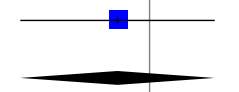

42.9

$0.34[0.01,8.36]$

42.9

$0.34[0.01,8.36]$

Test for overal effect $z=0.44$ p $p=0.7$ 
Fig. 82. Comparison 06. Miglitol versus sulphonylurea (SU)

06.30 Occurence of adverse effects

Review: Alpha-glucosidase inhibitors for type 2 diabetes mellitus

Comparison: 06 Miglitol versus sulphonylurea (SU)

Outcome: 30 Occurence of adverse effects

$\begin{array}{lllll}\text { Study } & \text { Miglitol } & \text { Sulphonylurea } & \text { Odds Ratio (Random) } & \text { Weight }\end{array}$

$\mathrm{n} / \mathrm{N} \quad \mathrm{n} / \mathrm{N}$

(\%)

$95 \% \mathrm{Cl}$

20 Miglitol $100 \mathrm{mg}$ TID versus Glibenclamide $5 \mathrm{mg}$ BID

Pagano 1995

10/49

10/47

Subtotal $(95 \% \mathrm{Cl})$

49

47

Total events: 10 (Miglitol), 10 (Sulphonylurea)

Test for heterogeneity: not applicable

Test for overall effect $z=0.10 \quad p=0.9$

25 Miglitol 100 mg TID versus Glibenclamide 3,5 mg BID

$\begin{array}{lll}\text { Segal } 1997 & 18 / 67 & 13 / 69\end{array}$

Subtotal $(95 \% \mathrm{Cl}) \quad 67 \quad 69$

Total events: 18 (Miglitol), 13 (Sulphonylurea)

Test for heterogeneity: not applicable

Test for overall effect $z=1.11 \quad p=0.3$

Total $(95 \% \mathrm{Cl}) \quad 116 \quad 116$

Total events: 28 (Miglitol), 23 (Sulphonylurea)

Test for heterogeneity chi-square $=0.62 \mathrm{df}=\mid \mathrm{p}=0.43 \mathrm{|}^{2}=0.0 \%$

Test for overall effect $z=0.79 \quad p=0.4$

$=0.0 \%$

\begin{tabular}{l|l} 
& \\
\hline & \\
\hline
\end{tabular}

40.3

$0.95[0.35,2.54]$

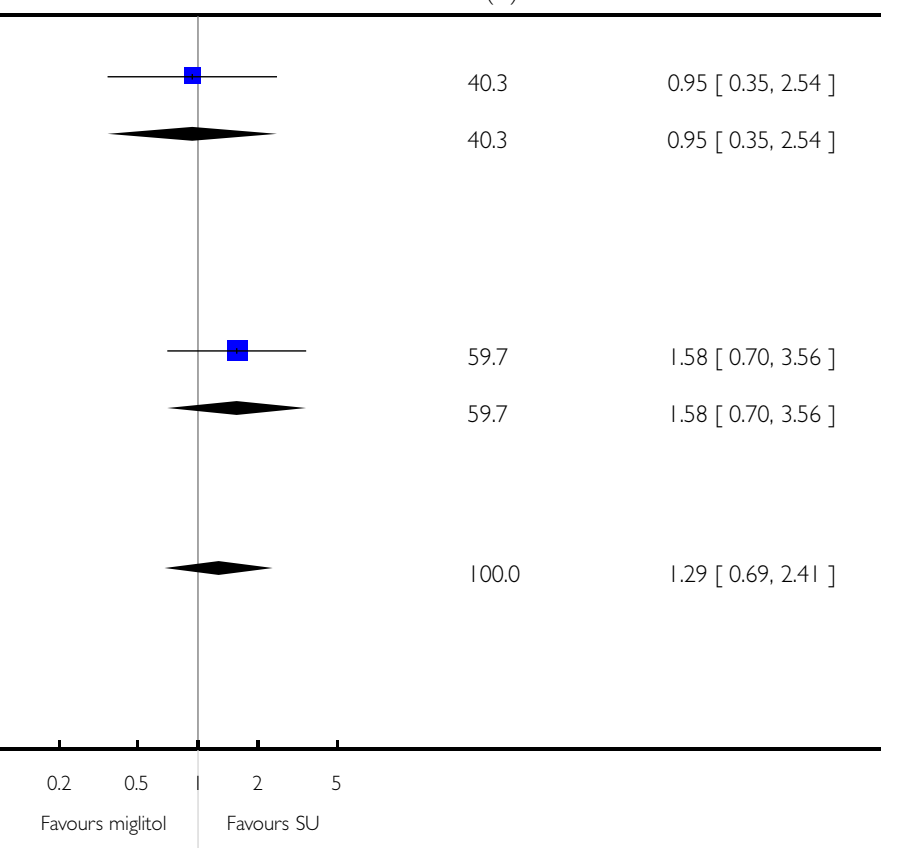

Fig. 83. Comparison 07. Miglitol versus metformin

07.01 Change in glycated haemoglobin (\%)

Review: Alpha-glucosidase inhibitors for type 2 diabetes mellitus

Comparison: 07 Miglitol versus metformin

Outcome: 0 I Change in glycated haemoglobin (\%)

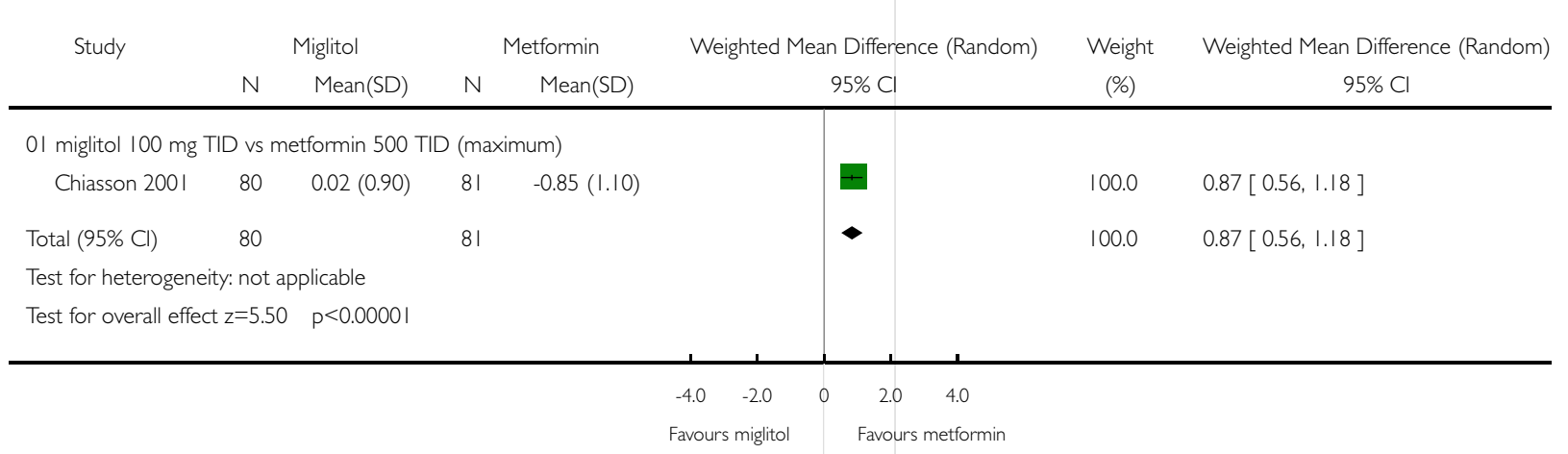

Alpha-glucosidase inhibitors for type 2 diabetes mellitus (Review) 


\section{Fig. 84. Comparison 07. Miglitol versus metformin}

\subsection{Change in fasting blood glucose ( $\mathrm{mmol} / \mathrm{l})$}

Review: Alpha-glucosidase inhibitors for type 2 diabetes mellitus

Comparison: 07 Miglitol versus metformin

Outcome: 02 Change in fasting blood glucose $(\mathrm{mmol} / \mathrm{l})$

Study Miglitol Metformin Weighted Mean Difference (Random) Weight Weighted Mean Difference (Random)

N Mean(SD) N Mean(SD) $\quad 95 \% \mathrm{Cl}$

(\%) $\quad 95 \% \mathrm{Cl}$

0I Miglitol 100 mg TID vs Metformin 500 mg TID

Chiasson 2001 $80 \quad-0.10(2.80) \quad 8$

$-1.10(2.50)$

$95 \% \mathrm{Cl}$

Total $(95 \% \mathrm{Cl}) \quad 80$

Test for heterogeneity: not applicable

Test for overall effect $z=2.39 p=0.02$

81

$\begin{array}{lll}\square & 100.0 & 1.00[0.18,1.82] \\ 100.0 & 1.00[0.18,1.82]\end{array}$

Fig. 85. Comparison 07. Miglitol versus metformin

07.03 Change in post-load blood glucose $(\mathrm{mmol} / \mathrm{l})$

Review: Alpha-glucosidase inhibitors for type 2 diabetes mellitus

Comparison: 07 Miglitol versus metformin

Outcome: 03 Change in post-load blood glucose ( $\mathrm{mmol} / \mathrm{l})$

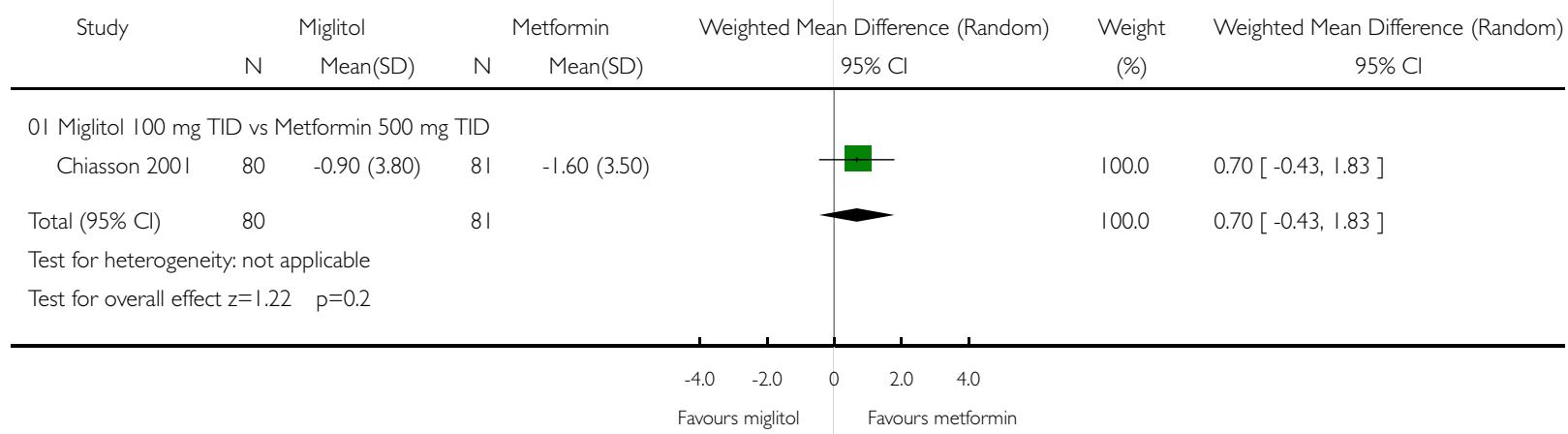


Fig. 86. Comparison 07. Miglitol versus metformin

07.08 Change in fasting insulin levels (pmol/l)

Review: Alpha-glucosidase inhibitors for type 2 diabetes mellitus

Comparison: 07 Miglitol versus metformin

Outcome: 08 Change in fasting insulin levels (pmol/l)

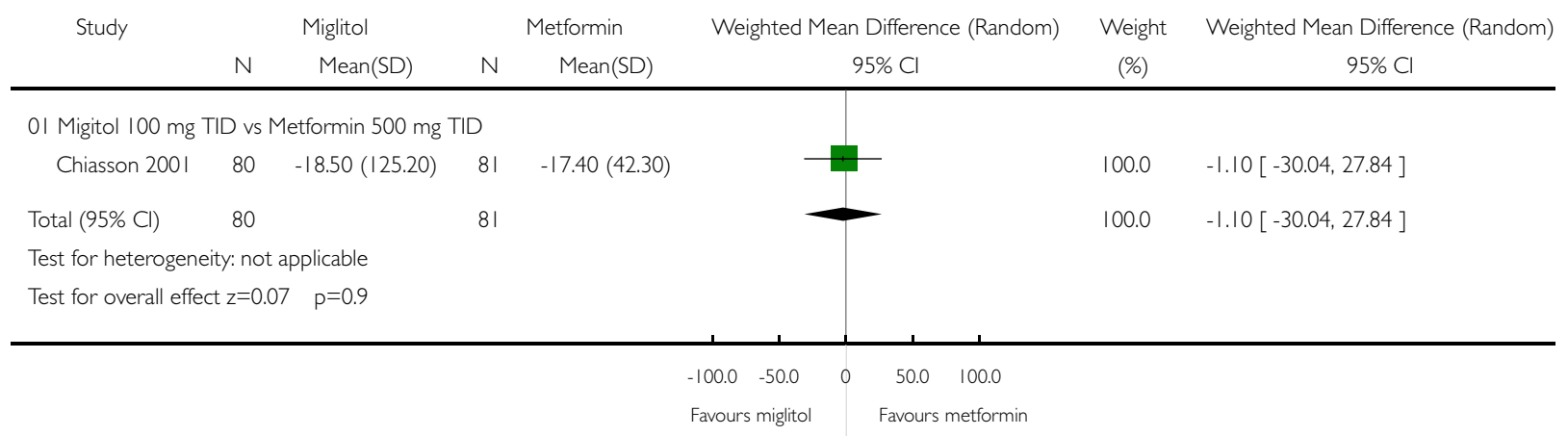

Fig. 87. Comparison 07. Miglitol versus metformin

07.09 Change in post-load insulin levels (pmol/l)

Review: Alpha-glucosidase inhibitors for type 2 diabetes mellitus

Comparison: 07 Miglitol versus metformin

Outcome: 09 Change in post-load insulin levels (pmol/l)

\begin{tabular}{|c|c|c|c|c|c|c|c|c|c|}
\hline \multirow[t]{2}{*}{ Study } & \multicolumn{2}{|r|}{ Miglitol } & \multicolumn{2}{|r|}{ Metformin } & \multicolumn{3}{|c|}{ Weighted Mean Difference (Random) } & \multirow{2}{*}{$\begin{array}{c}\text { Weight } \\
(\%)\end{array}$} & \multirow{2}{*}{$\begin{array}{l}\text { Weighted Mean Difference (Random) } \\
\qquad 95 \% \mathrm{Cl}\end{array}$} \\
\hline & $N$ & Mean(SD) & $N$ & Mean(SD) & & & $95 \% \mathrm{Cl}$ & & \\
\hline \multicolumn{10}{|c|}{ 0I Miglitol 100 mg (max) TID vs Metformin 500 mg TID } \\
\hline Chiasson 2001 & 80 & $-68.20(161.90)$ & 81 & $-19.90(135.00)$ & & & & 100.0 & $-48.30[-94.38,-2.22]$ \\
\hline Total $(95 \% \mathrm{Cl})$ & 80 & & 81 & & & & & 100.0 & $-48.30[-94.38,-2.22]$ \\
\hline \multicolumn{10}{|c|}{ Test for heterogeneity: not applicable } \\
\hline \multicolumn{10}{|c|}{ Test for overall effect $z=2.05 \quad p=0.04$} \\
\hline & & & & & -100.0 & -50.0 & $50.0 \quad 100.0$ & & \\
\hline & & & & & Favours & miglitol & Favours metformin & & \\
\hline
\end{tabular}




\section{Fig. 88. Comparison 07. Miglitol versus metformin}

\subsection{Change in body weight $(\mathrm{Kg})$}

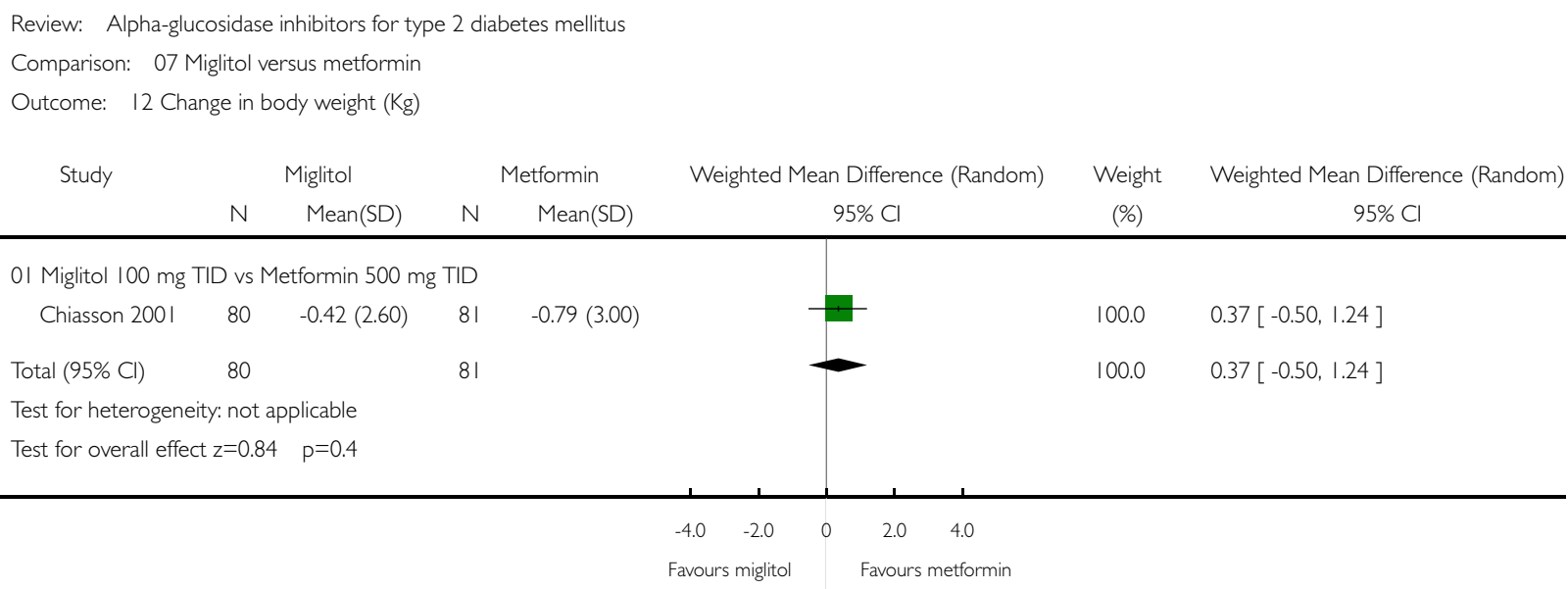

\section{Fig. 89. Comparison 07. Miglitol versus metformin}

07.17 Occurence of gastro-intestinal side-effects

Review: Alpha-glucosidase inhibitors for type 2 diabetes mellitus

Comparison: 07 Miglitol versus metformin

Outcome: 17 Occurence of gastro-intestinal side-effects

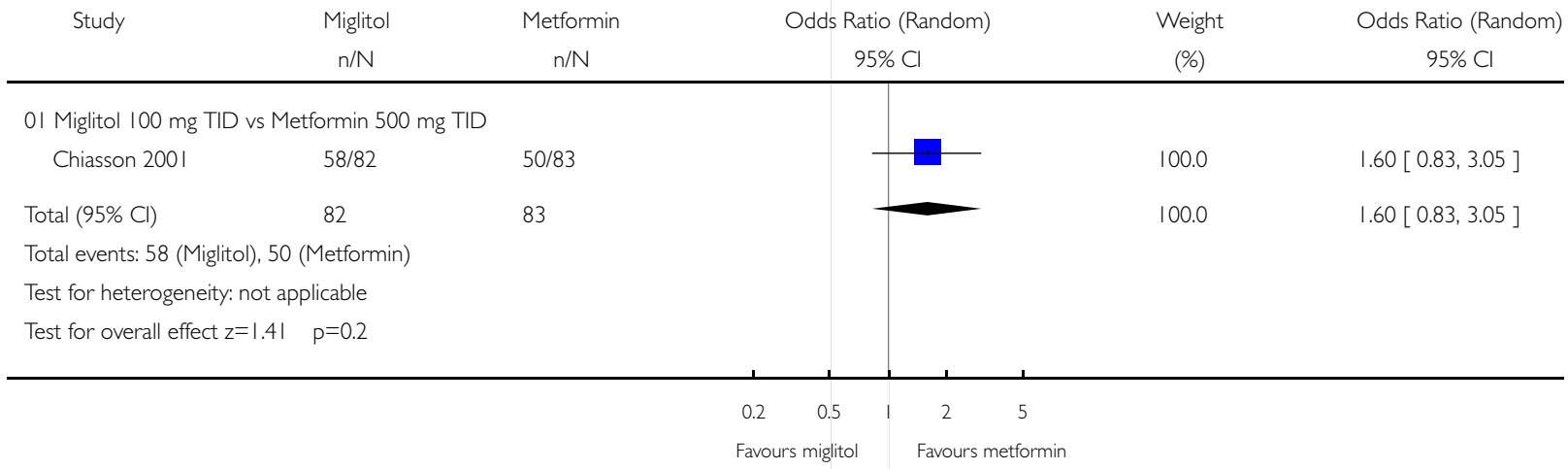




\section{Fig. 90. Comparison 07. Miglitol versus metformin}

\subsection{Occurence of adverse effects}

Review: Alpha-glucosidase inhibitors for type 2 diabetes mellitus

Comparison: 07 Miglitol versus metformin

Outcome: 30 Occurence of adverse effects

Study

$\begin{array}{cc}\text { Miglitol } & \text { Metformin } \\ \mathrm{n} / \mathrm{N} & \mathrm{n} / \mathrm{N}\end{array}$

Odds Ratio (Random)

Weight

Odds Ratio (Random)

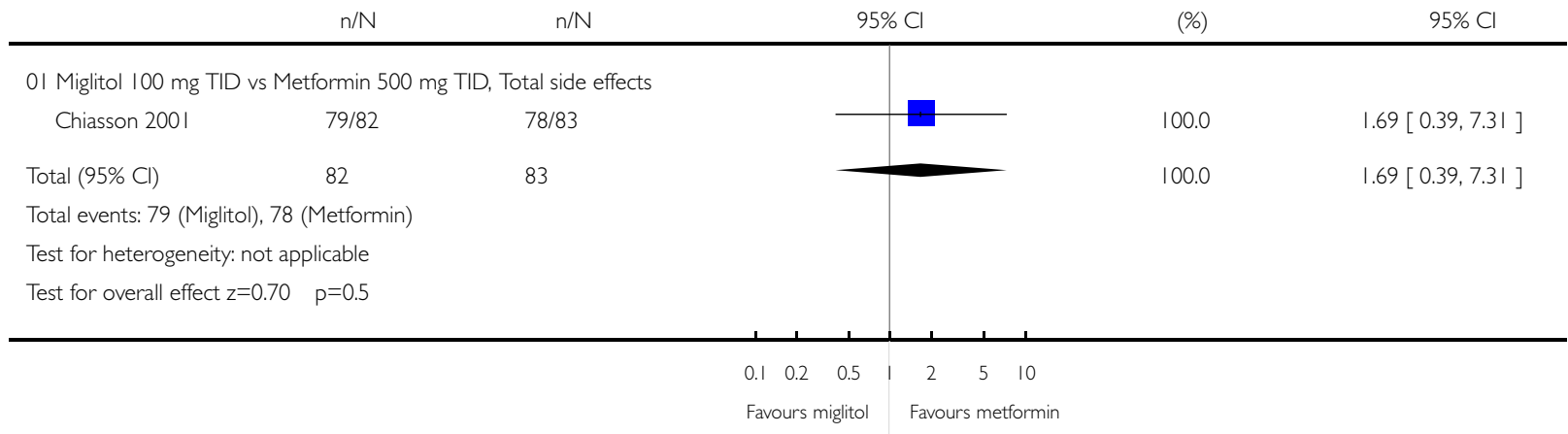

Fig. 91. Comparison 07. Miglitol versus metformin

07.90 Change in post-load blood glucose ( $\mathrm{mmol} / \mathrm{l})$ ( 2 hours)

Review: Alpha-glucosidase inhibitors for type 2 diabetes mellitus

Comparison: 07 Miglitol versus metformin

Outcome: 90 Change in post-load blood glucose ( $\mathrm{mmol} / \mathrm{l})$ ( 2 hours)

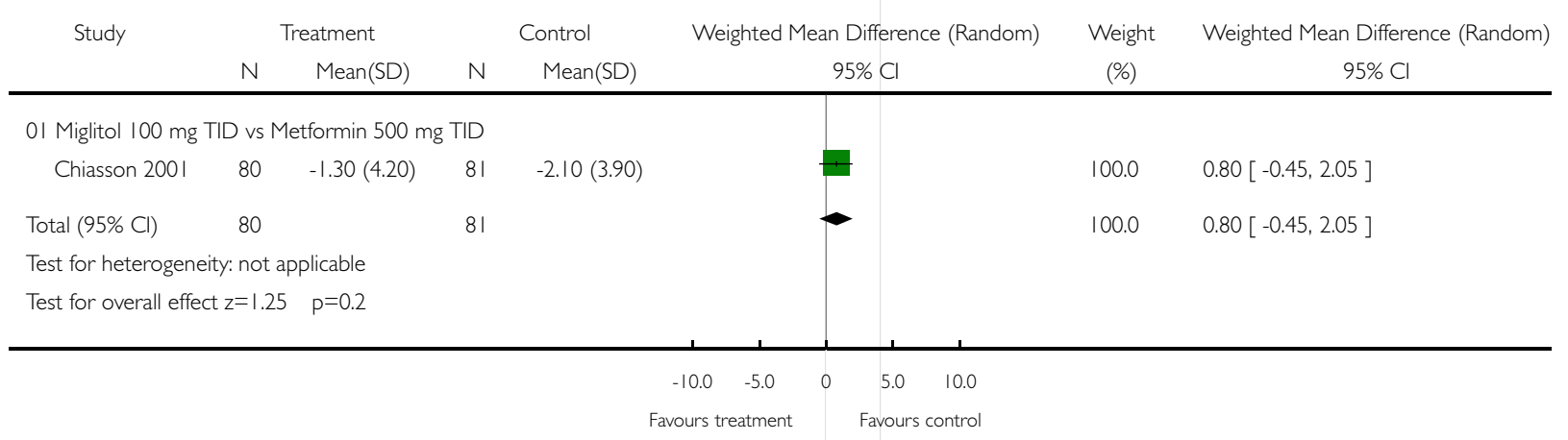




\section{Fig. 92. Comparison 07. Miglitol versus metformin}

\subsection{Change in post-load insulin levels (pmol/l) (2-hours)}

Review: Alpha-glucosidase inhibitors for type 2 diabetes mellitus

Comparison: 07 Miglitol versus metformin

Outcome: 91 Change in post-load insulin levels (pmol/l) (2-hours)

Study

$$
\text { Treatment }
$$

Control

Weighted Mean Difference (Random)

Weight Weighted Mean Difference (Random)

N

Mean(SD)

N Mean(SD)

$95 \% \mathrm{Cl}$

(\%)

$95 \% \mathrm{Cl}$

OI Miglitol 100 mg (max) TID vs Metformin 500 mg TID

$\begin{array}{lllllll}\text { Chiasson } 2001 & 80 & -63.30(177.10) & 81 & 3.90(133.20) & + & 100.0 \quad-67.20[-115.65,-18.75]\end{array}$

Total $(95 \% \mathrm{Cl}) \quad 80 \quad 81$

Test for heterogeneity: not applicable

Test for overall effect $z=2.72 \quad p=0.007$

81

$100.0-67.20[-115.65,-18.75]$

Fig. 93. Comparison 08. Voglibose versus placebo

08.0 I Change in glycated haemoglobin (\%)

Review: Alpha-glucosidase inhibitors for type 2 diabetes mellitus

Comparison: 08 Voglibose versus placebo

Outcome: 01 Change in glycated haemoglobin (\%)

Study Voglibose Placebo Weighted Mean Difference (Random) Weight Weighted Mean Difference (Random)

N Mean(SD) N Mean(SD)
$95 \% \mathrm{Cl}$

0I Voglibose 0.2 mg TID

Kawamori $2003-154$

$-0.22(0.50)$

$84 \quad 0.25(0.64)$

Subtotal $(95 \% \mathrm{Cl}) \quad 154$

84

100.0

$-0.47[-0.63,-0.31]$

Test for heterogeneity: not applicable

Test for overall effect $z=5.83 \quad p<0.0000$ ।

I 0 Voglibose 0,3 mg TID

Subtotal $(95 \% \mathrm{Cl}) \quad 0$

Test for heterogeneity: not applicable

Test for overall effect: not applicable

Total $(95 \% \mathrm{Cl})$

154

Test for heterogeneity: not applicable

Test for overall effect $z=5.83 \quad p<0.0000$ I

0

84
$100.0 \quad-0.47[-0.63,-0.31]$

$0.0 \quad$ Not estimable

$100.0 \quad-0.47[-0.63,-0.31]$ 


\section{Fig. 94. Comparison 08. Voglibose versus placebo}

\subsection{Change in fasting blood glucose ( $\mathrm{mmol} / \mathrm{l})$}

Review: Alpha-glucosidase inhibitors for type 2 diabetes mellitus

Comparison: 08 Voglibose versus placebo

Outcome: 02 Change in fasting blood glucose $(\mathrm{mmol} / \mathrm{l})$

Study Voglibose Placebo Weighted Mean Difference (Random) Weight Weighted Mean Difference (Random)

$N \quad M e a n(S D) \quad N \quad M e a n(S D)$

$95 \% \mathrm{Cl}$

$95 \% \mathrm{Cl}$

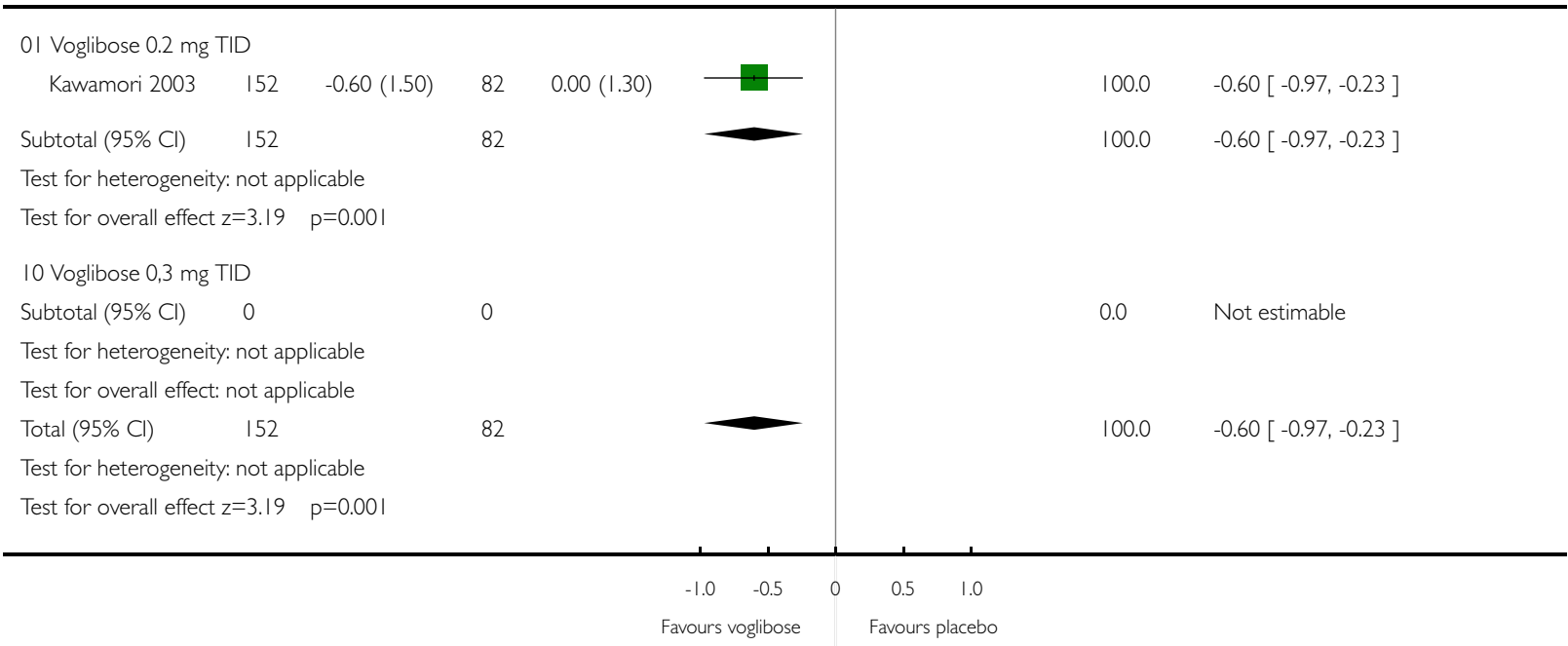

Fig. 95. Comparison 08. Voglibose versus placebo

08.03 Change in post-load blood glucose $(\mathrm{mmol} / \mathrm{l})$

Review: Alpha-glucosidase inhibitors for type 2 diabetes mellitus

Comparison: 08 Voglibose versus placebo

Outcome: 03 Change in post-load blood glucose $(\mathrm{mmol} / \mathrm{l})$

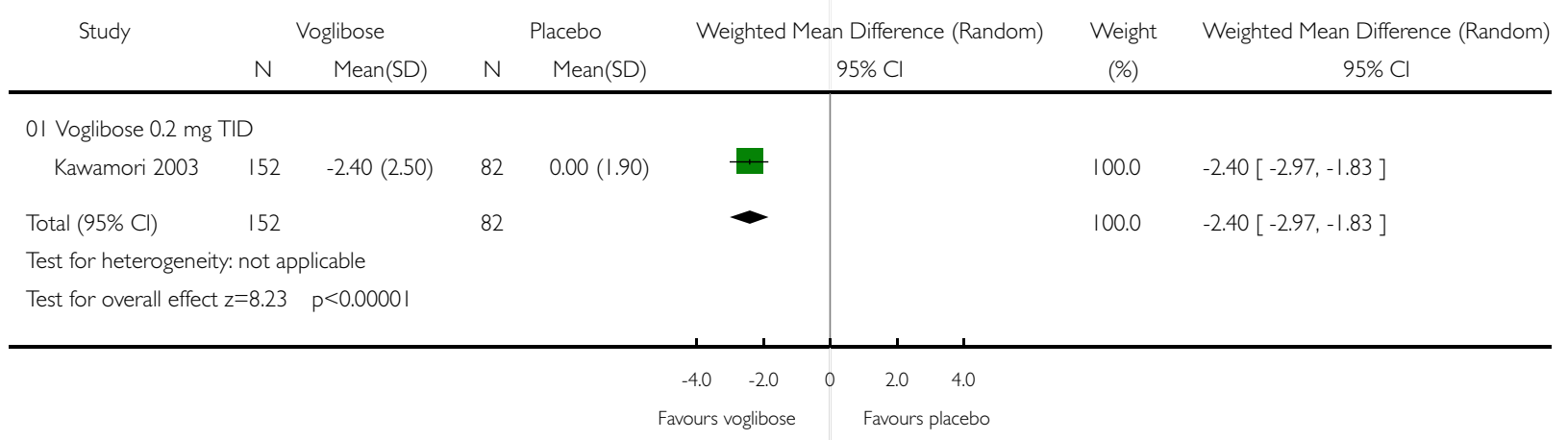




\section{Fig. 96. Comparison 08. Voglibose versus placebo}

\subsection{Change in post-load insulin levels (pmol/l)}

Review: Alpha-glucosidase inhibitors for type 2 diabetes mellitus

Comparison: 08 Voglibose versus placebo

Outcome: 08 Change in post-load insulin levels (pmol/l)

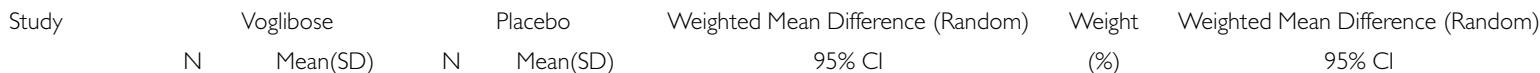

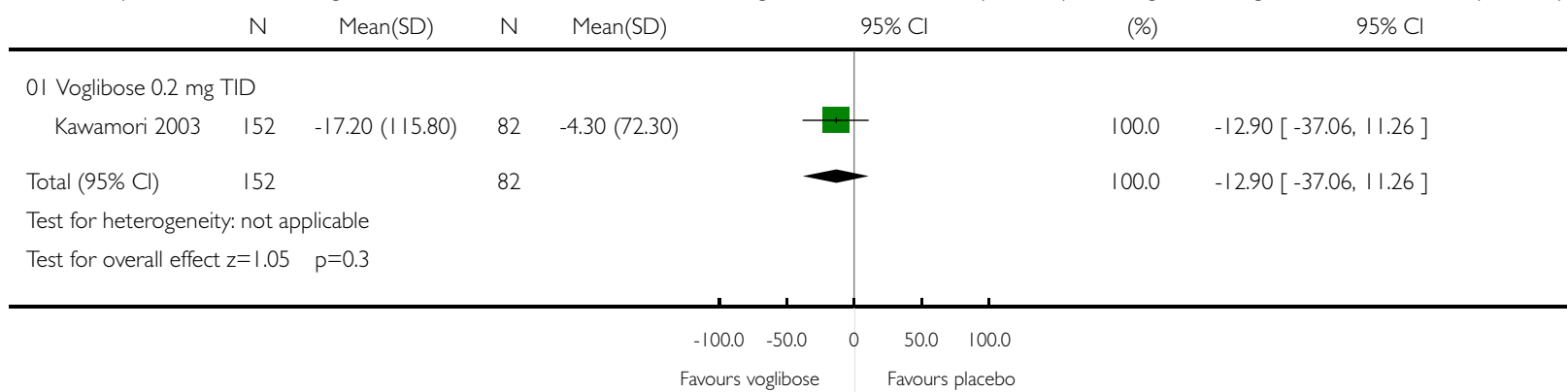

Fig. 97. Comparison 08. Voglibose versus placebo

08.30 Occurence of adverse effects

Review: Alpha-glucosidase inhibitors for type 2 diabetes mellitus

Comparison: 08 Voglibose versus placebo

Outcome: 30 Occurence of adverse effects

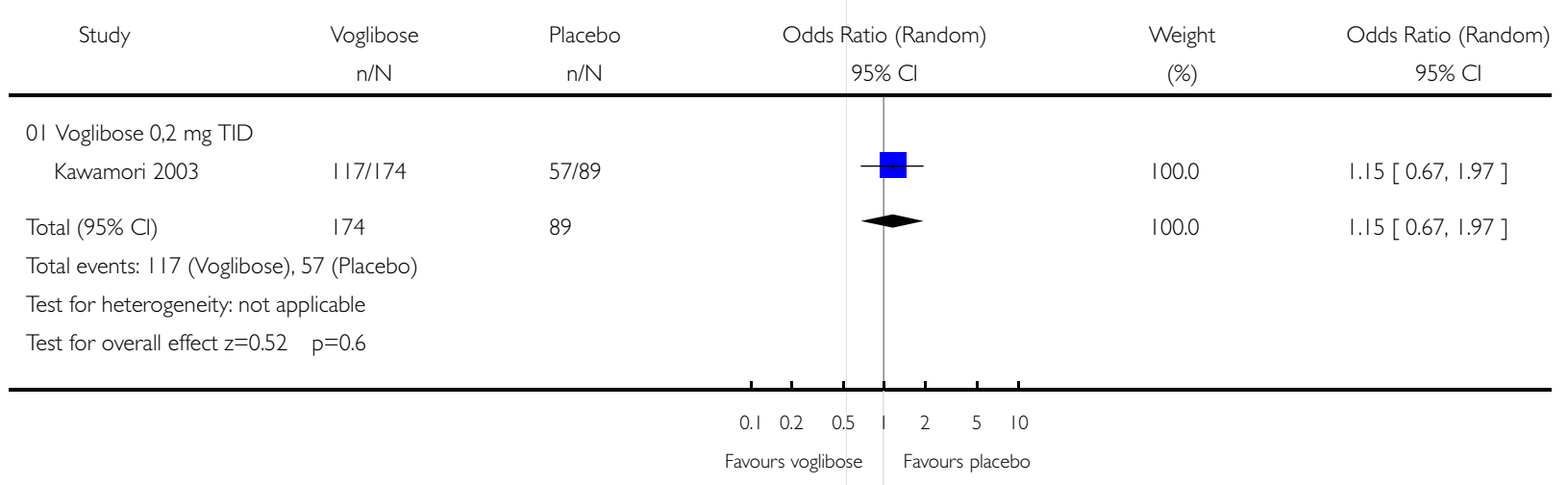




\section{Fig. 98. Comparison 08. Voglibose versus placebo}

\subsection{Occurence of gastro-intestinal adverse effects}

Review: Alpha-glucosidase inhibitors for type 2 diabetes mellitus

Comparison: 08 Voglibose versus placebo

Outcome: 31 Occurence of gastro-intestinal adverse effects

Voglibose

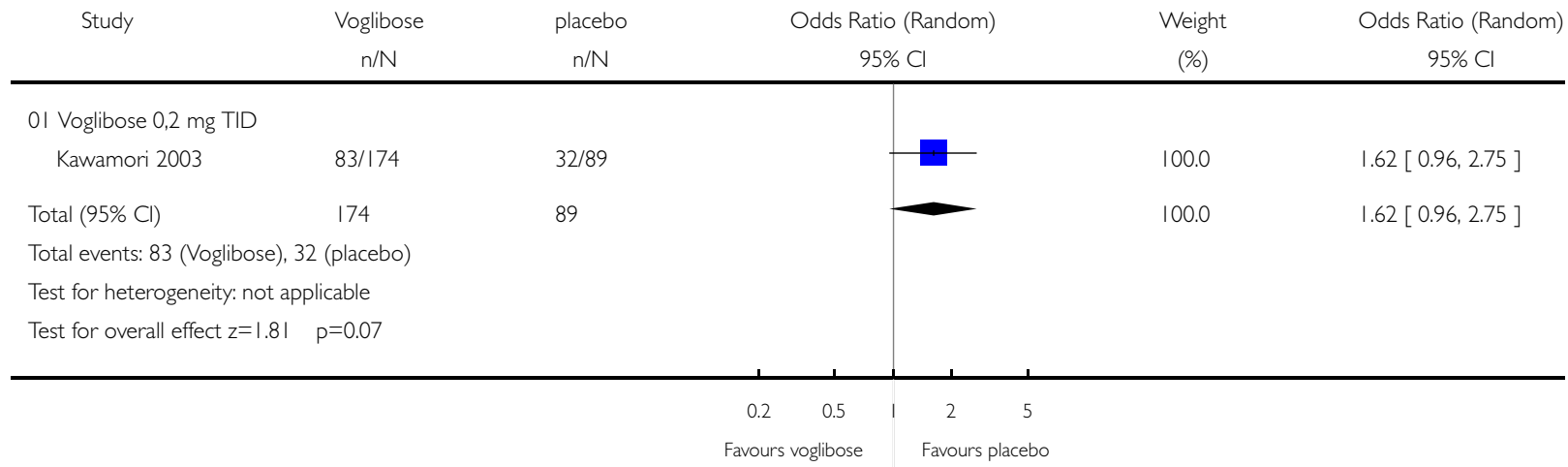

Fig. 99. Comparison 08. Voglibose versus placebo

08.90 Change in post-load blood glucose ( $\mathrm{mmol} / \mathrm{l})$ ( 2 hours)

Review: Alpha-glucosidase inhibitors for type 2 diabetes mellitus

Comparison: 08 Voglibose versus placebo

Outcome: 90 Change in post-load blood glucose ( $\mathrm{mmol} / \mathrm{l})$ (2 hours)

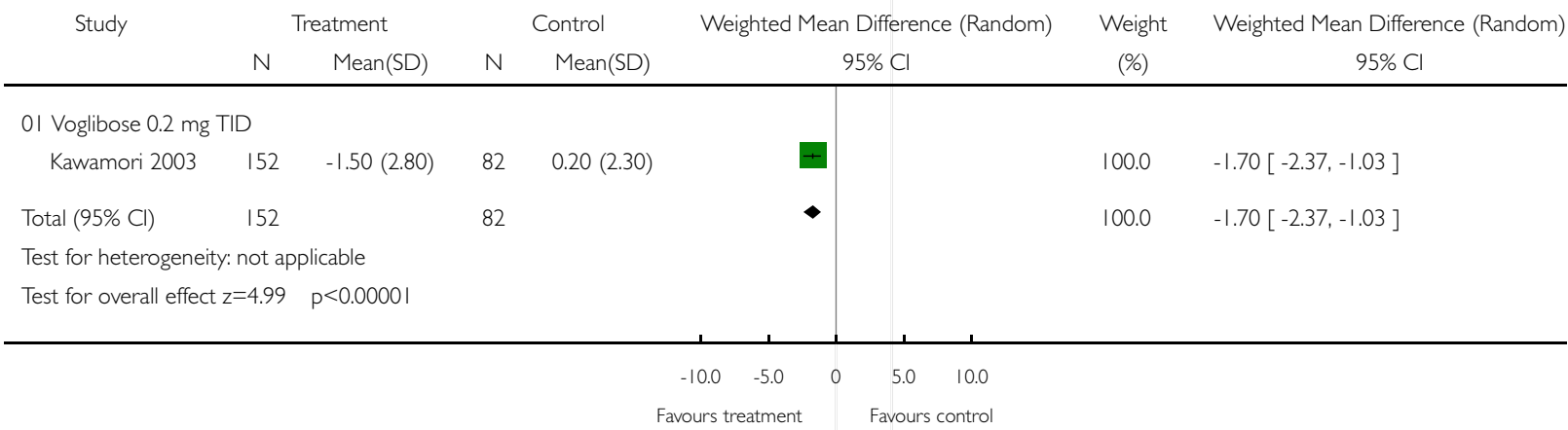


Fig. 100. Comparison 09. Voglibose versus diet therapy

09.01 Change in glycated haemoglobin (\%)

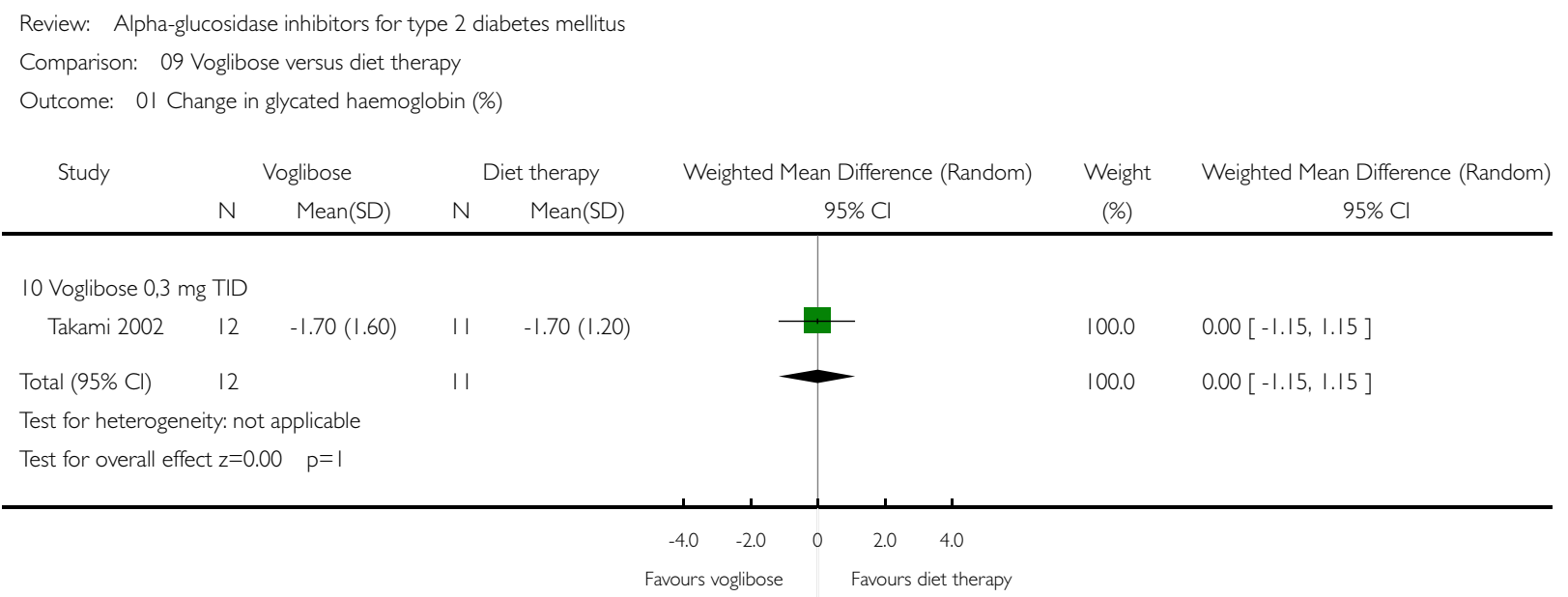

Fig. 101. Comparison 09. Voglibose versus diet therapy

09.02 Change in fasting blood glucose $(\mathrm{mmol} / \mathrm{l})$

Review: Alpha-glucosidase inhibitors for type 2 diabetes mellitus

Comparison: 09 Voglibose versus diet therapy

Outcome: 02 Change in fasting blood glucose ( $\mathrm{mmol} / \mathrm{l})$

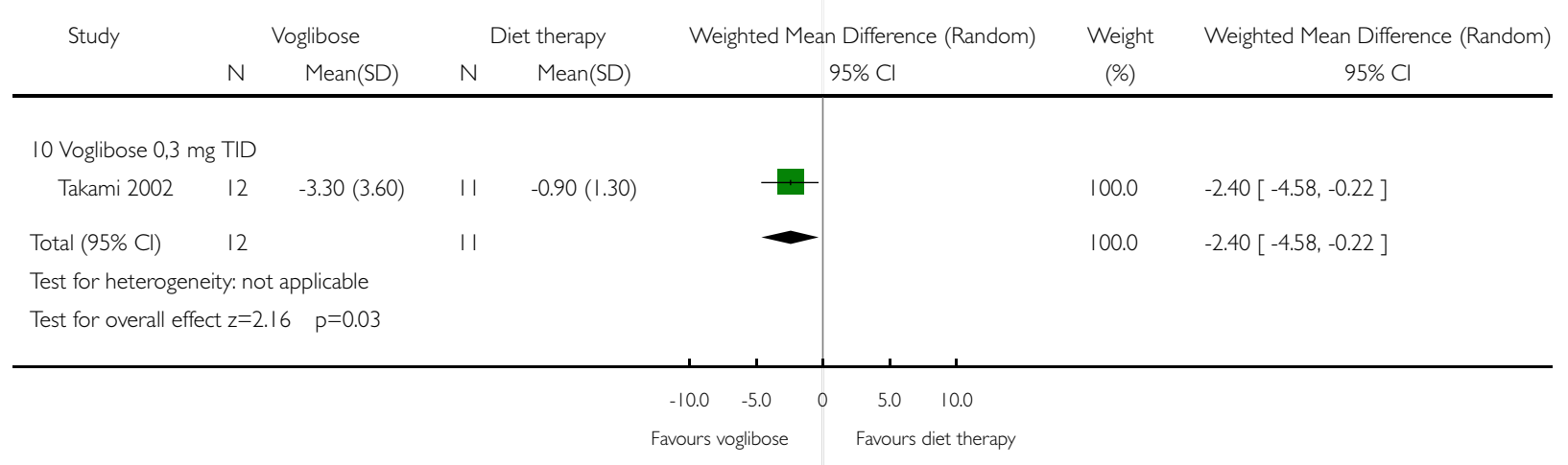


Fig. 102. Comparison 09. Voglibose versus diet therapy

09.04 Change in total cholesterol ( $\mathrm{mmol} / \mathrm{l})$

Review: Alpha-glucosidase inhibitors for type 2 diabetes mellitus

Comparison: 09 Voglibose versus diet therapy

Outcome: 04 Change in total cholesterol $(\mathrm{mmol} / \mathrm{l})$

Study Voglibose Diet therapy Weighted Mean Difference (Random) Weight Weighted Mean Difference (Random)

N $\quad$ Mean(SD) N Mean(SD) $95 \% \mathrm{Cl}$

(\%)

$95 \% \mathrm{Cl}$

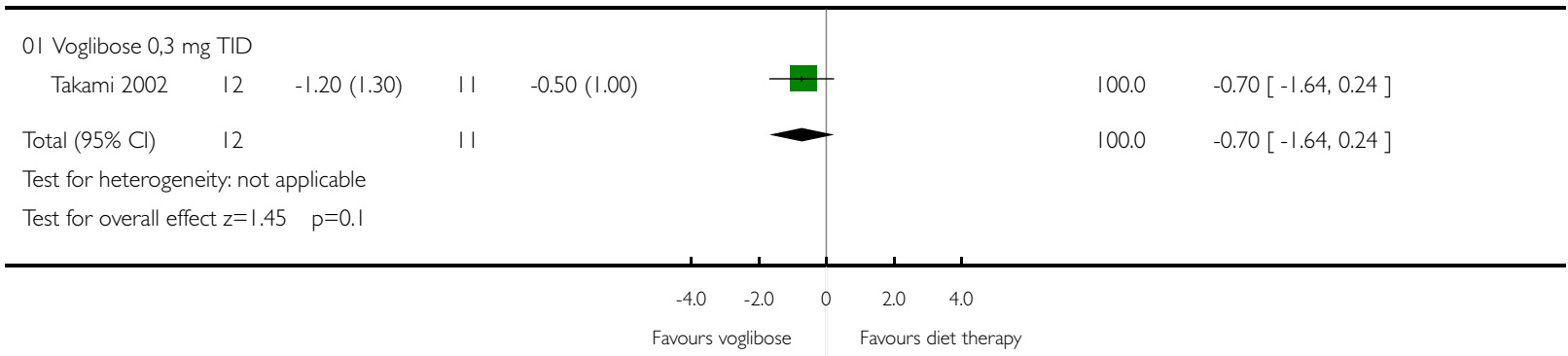

Fig. 103. Comparison 09. Voglibose versus diet therapy

09.05 Change in HDL-cholesterol ( $\mathrm{mmol} / \mathrm{l})$

Review: Alpha-glucosidase inhibitors for type 2 diabetes mellitus

Comparison: 09 Voglibose versus diet therapy

Outcome: 05 Change in HDL-cholesterol (mmol/l)

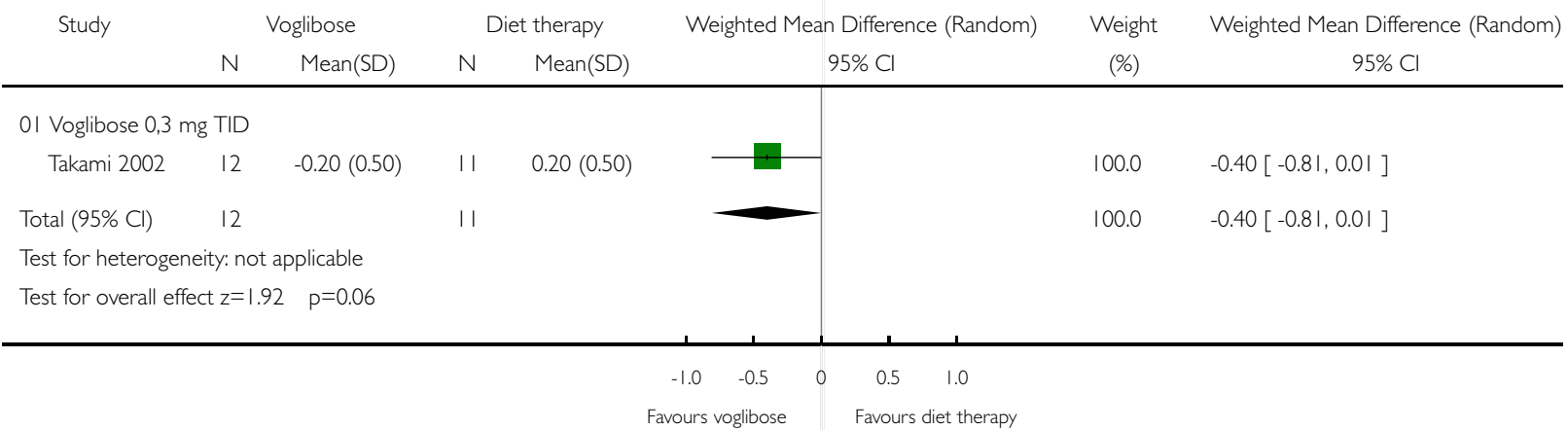


Fig. 104. Comparison 09. Voglibose versus diet therapy

09.08 Change in fasting insulin levels (pmol/l)

Review: Alpha-glucosidase inhibitors for type 2 diabetes mellitus

Comparison: 09 Voglibose versus diet therapy

Outcome: 08 Change in fasting insulin levels (pmol/l)

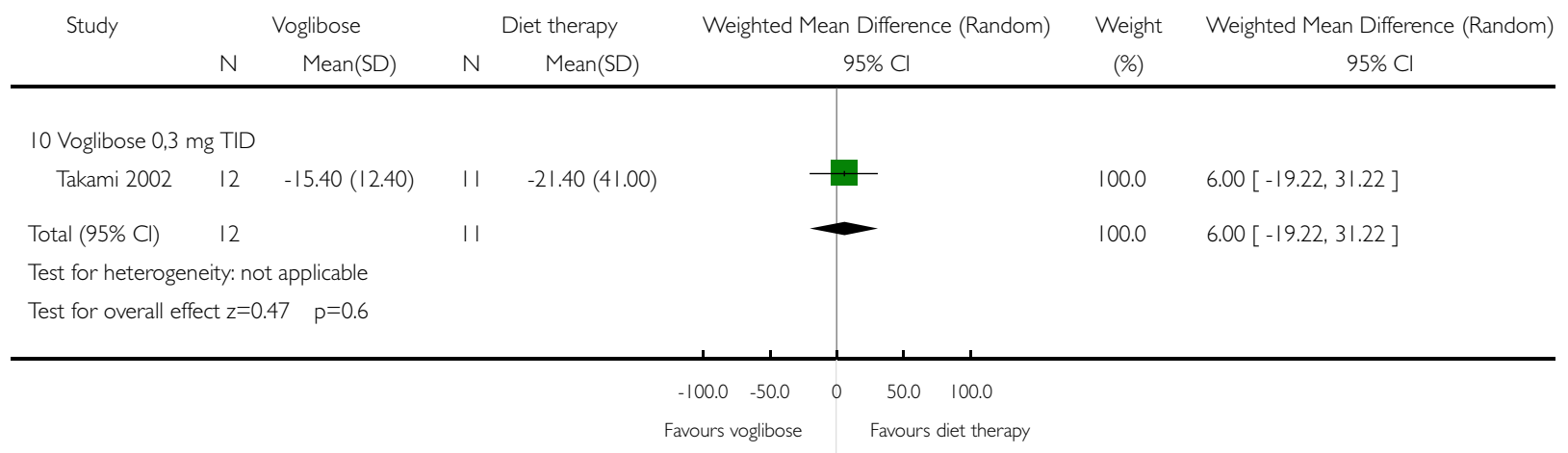

Fig. 105. Comparison 09. Voglibose versus diet therapy

09.12 Change in body weight $(\mathrm{Kg})$

Review: Alpha-glucosidase inhibitors for type 2 diabetes mellitus

Comparison: 09 Voglibose versus diet therapy

Outcome: 12 Change in body weight $(\mathrm{Kg})$

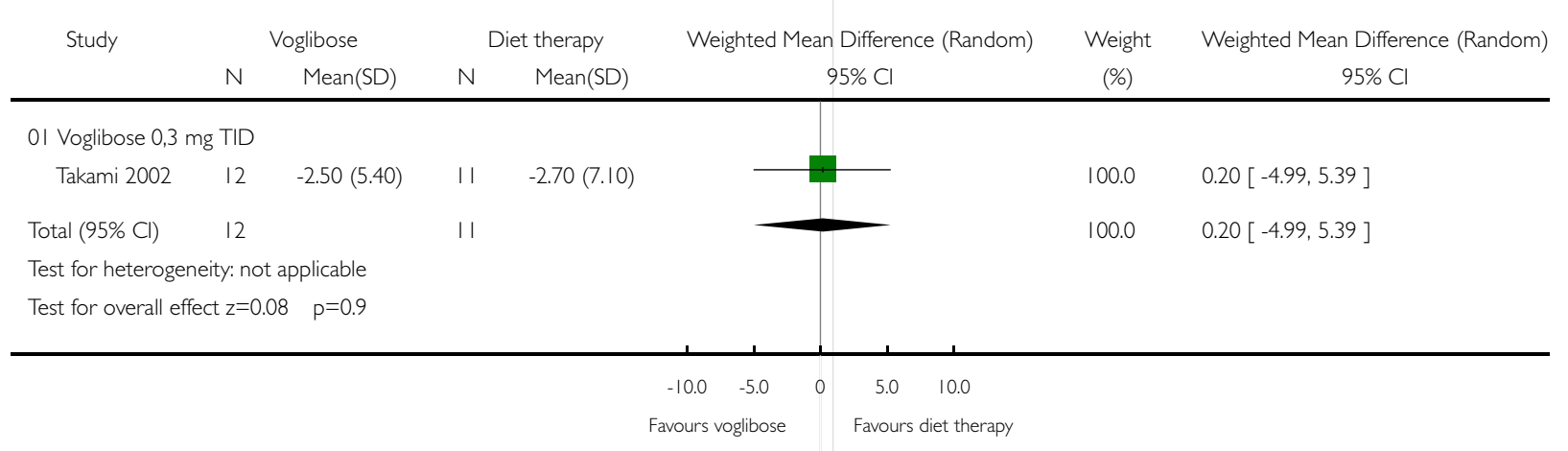


Fig. 106. Comparison 09. Voglibose versus diet therapy

09.13 Change in body mass index $(\mathrm{Kg} / \mathrm{m} 2)$

Review: Alpha-glucosidase inhibitors for type 2 diabetes mellitus

Comparison: 09 Voglibose versus diet therapy

Outcome: 13 Change in body mass index $(\mathrm{Kg} / \mathrm{m} 2)$

Study Voglibose Diet therapy Weighted Mean Difference (Random) Weight Weighted Mean Difference (Random)

N Mean(SD) N Mean(SD)

$95 \% \mathrm{Cl}$

(\%)

$95 \% \mathrm{Cl}$

\begin{tabular}{|c|c|c|c|c|c|c|c|c|c|c|}
\hline \multicolumn{11}{|c|}{ 0I Voglibose 0,3 mg TID } \\
\hline Takami 2002 & 12 & $-1.10(3.20)$ & 11 & $-1.10(2.30)$ & & & & & 100.0 & $0.00[-2.26,2.26]$ \\
\hline Total $(95 \% \mathrm{Cl})$ & 12 & & 11 & & & & & & 100.0 & $0.00[-2.26,2.26]$ \\
\hline \multicolumn{11}{|c|}{ Test for heterogeneity: not applicable } \\
\hline \multicolumn{11}{|c|}{ Test for overall effect $z=0.00 \quad p=1$} \\
\hline & & & & -4.0 & -2.0 & 0 & 2.0 & 4.0 & & \\
\hline \multicolumn{11}{|c|}{ Favours voglibose } \\
\hline
\end{tabular}

Fig. 107. Comparison 10. .Voglibose versus sulphonylurea (SU)

I 0.0 I Change in glycated haemoglobin (\%)

Review: Alpha-glucosidase inhibitors for type 2 diabetes mellitus

Comparison: 10.Voglibose versus sulphonylurea (SU)

Outcome: 0 I Change in glycated haemoglobin (\%)






\section{Fig. 108. Comparison I0. .Voglibose versus sulphonylurea (SU)}

\subsection{Change in fasting blood glucose ( $\mathrm{mmol} / \mathrm{l})$}

Review: Alpha-glucosidase inhibitors for type 2 diabetes mellitus

Comparison: 10 .Voglibose versus sulphonylurea (SU)

Outcome: 02 Change in fasting blood glucose $(\mathrm{mmol} / \mathrm{l})$

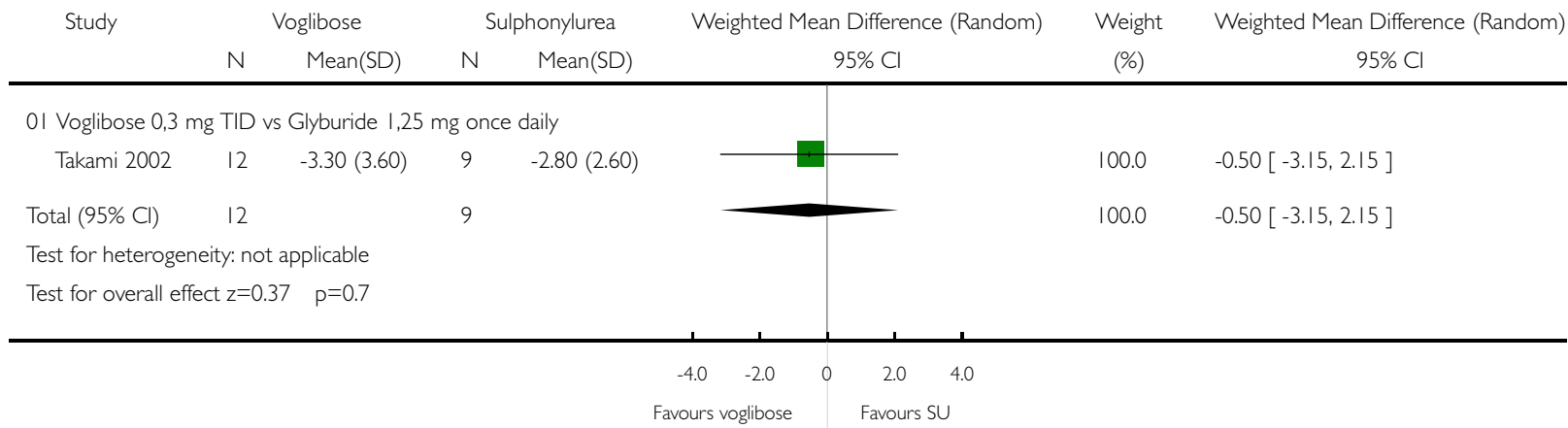

Fig. 109. Comparison 10. .Voglibose versus sulphonylurea (SU)

I 0.04 Change in total cholesterol $(\mathrm{mmol} / \mathrm{l})$

Review: Alpha-glucosidase inhibitors for type 2 diabetes mellitus

Comparison: 10 .Voglibose versus sulphonylurea (SU)

Outcome: 04 Change in total cholesterol $(\mathrm{mmol} / \mathrm{l})$

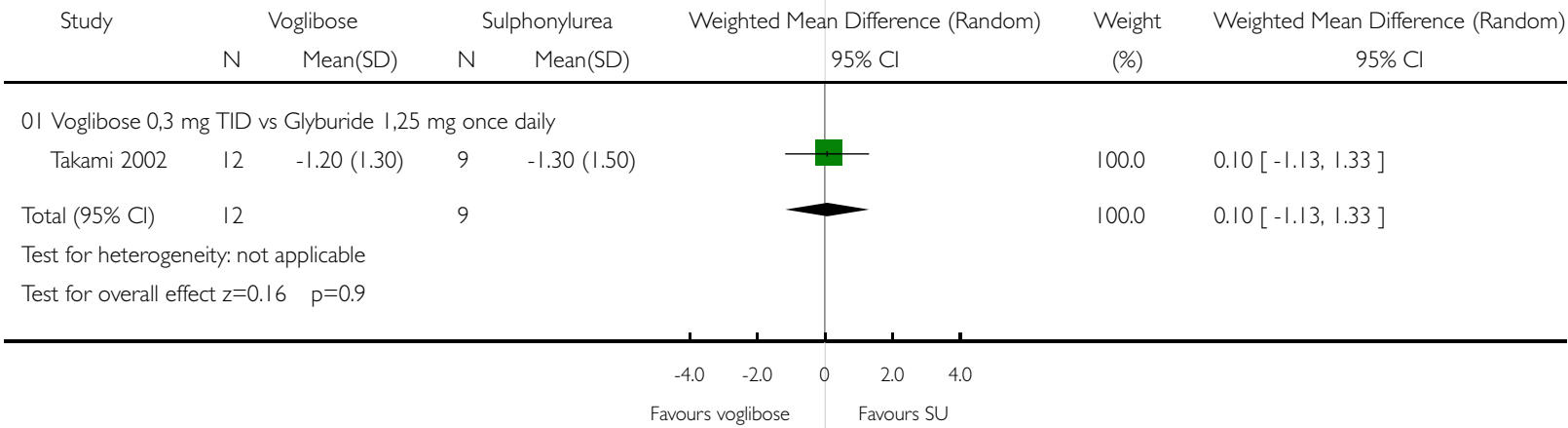


Fig. I I0. Comparison IO. .Voglibose versus sulphonylurea (SU)

10.05 Change in HDL-cholesterol ( $\mathrm{mmol} / \mathrm{l})$

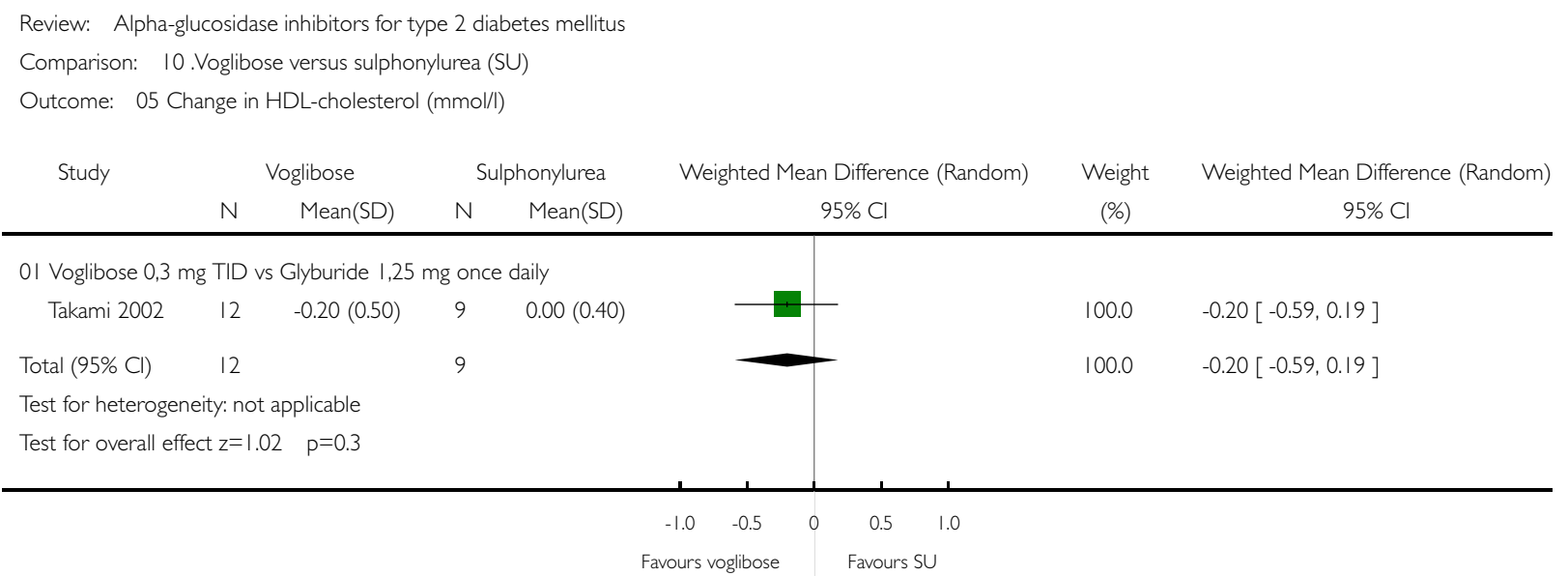

Fig. III. Comparison 10. .Voglibose versus sulphonylurea (SU)

10.08 Change in fasting insulin levels (pmol/l)

Review: Alpha-glucosidase inhibitors for type 2 diabetes mellitus

Comparison: 10. Voglibose versus sulphonylurea (SU)

Outcome: 08 Change in fasting insulin levels (pmol/l)

\begin{tabular}{|c|c|c|c|c|c|c|c|c|}
\hline \multirow[t]{2}{*}{ Study } & \multicolumn{2}{|r|}{ Voglibose } & \multicolumn{2}{|c|}{ Sulphonylurea } & \multicolumn{2}{|c|}{ Weighted Mean Difference (Random) } & \multirow{2}{*}{$\begin{array}{c}\text { Weight } \\
(\%)\end{array}$} & \multirow{2}{*}{$\begin{array}{l}\text { Weighted Mean Difference (Random) } \\
\qquad 95 \% \mathrm{Cl}\end{array}$} \\
\hline & N & Mean(SD) & N & Mean(SD) & & $95 \% \mathrm{Cl}$ & & \\
\hline \multicolumn{9}{|c|}{ 0I Voglibose 0,3 mg TID vs Glyburide 1,25 mg once daily } \\
\hline Takami 2002 & 12 & $-15.40(12.40)$ & 9 & $-3.60(18.00)$ & & & 100.0 & $-11.80[-25.49,1.89]$ \\
\hline Total $(95 \% \mathrm{Cl})$ & 12 & & 9 & & & & 100.0 & $-11.80[-25.49,1.89]$ \\
\hline \multicolumn{9}{|c|}{ Test for heterogeneity: not applicable } \\
\hline \multicolumn{9}{|c|}{ Test for overall effect $z=1.69 \quad p=0.09$} \\
\hline & & & & & $-100.0-50.0$ & $50.0 \quad 100.0$ & & \\
\hline & & & & & Favours voglibos & Favours SU & & \\
\hline
\end{tabular}




\section{Fig. I I2. Comparison I0. .Voglibose versus sulphonylurea (SU)}

\subsection{Change in body weight $(\mathrm{Kg})$}

\begin{tabular}{|c|c|c|c|c|c|c|c|}
\hline \multicolumn{8}{|c|}{ Comparison: 10. Voglibose versus sulphonylurea (SU) } \\
\hline \multirow[t]{2}{*}{ Study } & \multicolumn{2}{|c|}{ Voglibose } & \multicolumn{2}{|c|}{ Sulphonylurea } & Weighted Mean Difference (Random) & \multirow{2}{*}{$\begin{array}{l}\text { Weight } \\
(\%)\end{array}$} & \multirow{2}{*}{$\begin{array}{l}\text { Weighted Mean Difference (Random) } \\
\qquad 95 \% \mathrm{Cl}\end{array}$} \\
\hline & $\mathrm{N}$ & Mean(SD) & $\mathrm{N}$ & Mean(SD) & $95 \% \mathrm{Cl}$ & & \\
\hline \multicolumn{8}{|c|}{ 0I Voglibose 0,3 mg TID vs Glyburide I,25 mg once daily } \\
\hline Takami 2002 & 12 & $-2.50(5.40)$ & 9 & $-3.10(15.10)$ & \pm & 100.0 & $0.60[-9.73,10.93]$ \\
\hline Total $(95 \% \mathrm{Cl})$ & 12 & & 9 & & & 100.0 & $0.60[-9.73,10.93]$ \\
\hline \multicolumn{8}{|c|}{ Test for heterogeneity: not applicable } \\
\hline \multicolumn{8}{|c|}{ Test for overall effect $z=0.11 \quad p=0.9$} \\
\hline
\end{tabular}

\section{Fig. I I3. Comparison I0. .Voglibose versus sulphonylurea (SU)}

\subsection{Change in body mass index $(\mathrm{Kg} / \mathrm{m} 2)$}

Review: Alpha-glucosidase inhibitors for type 2 diabetes mellitus

Comparison: 10. Voglibose versus sulphonylurea (SU)

Outcome: 13 Change in body mass index $(\mathrm{Kg} / \mathrm{m} 2)$

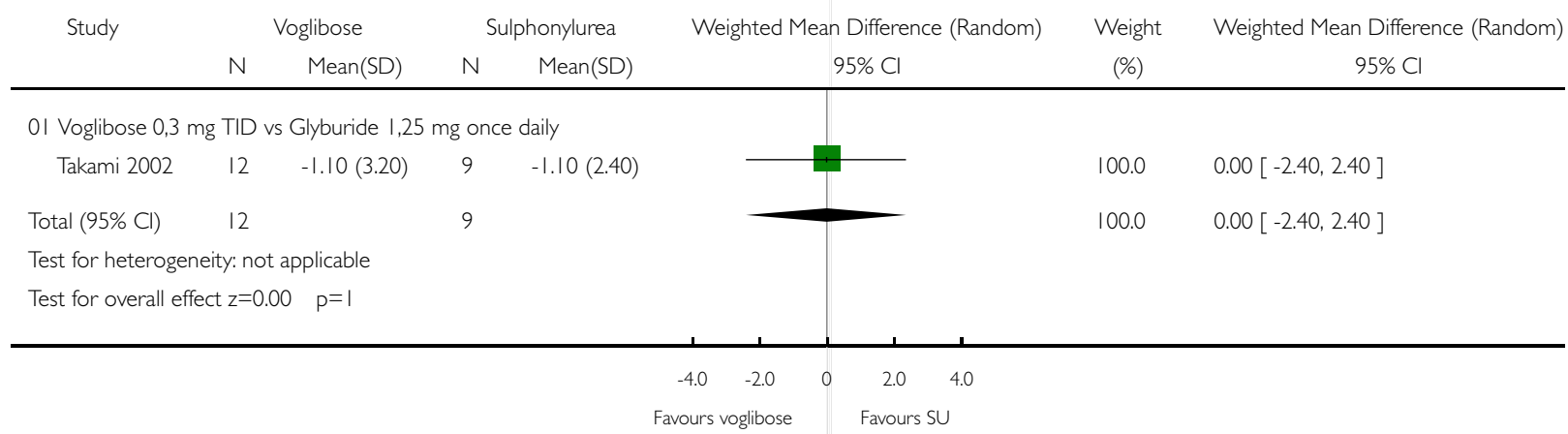


Fig. I I4. Comparison II. Miglitol versus voglibose

I I.0 Change in glycated haemoglobin (\%)

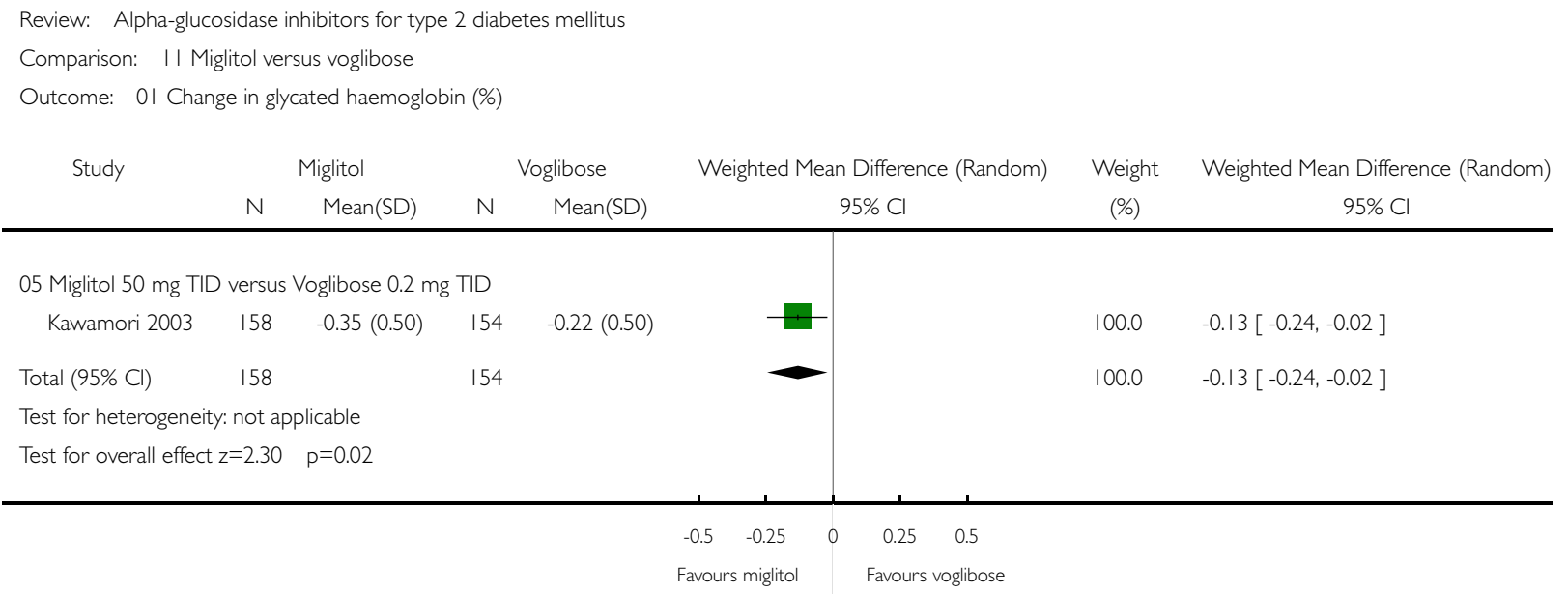

\section{Fig. II5. Comparison II. Miglitol versus voglibose}

\section{I.02 Change in fasting blood glucose ( $\mathrm{mmol} / \mathrm{l})$}

Review: Alpha-glucosidase inhibitors for type 2 diabetes mellitus

Comparison: I Miglitol versus voglibose

Outcome: 02 Change in fasting blood glucose $(\mathrm{mmol} / \mathrm{l})$

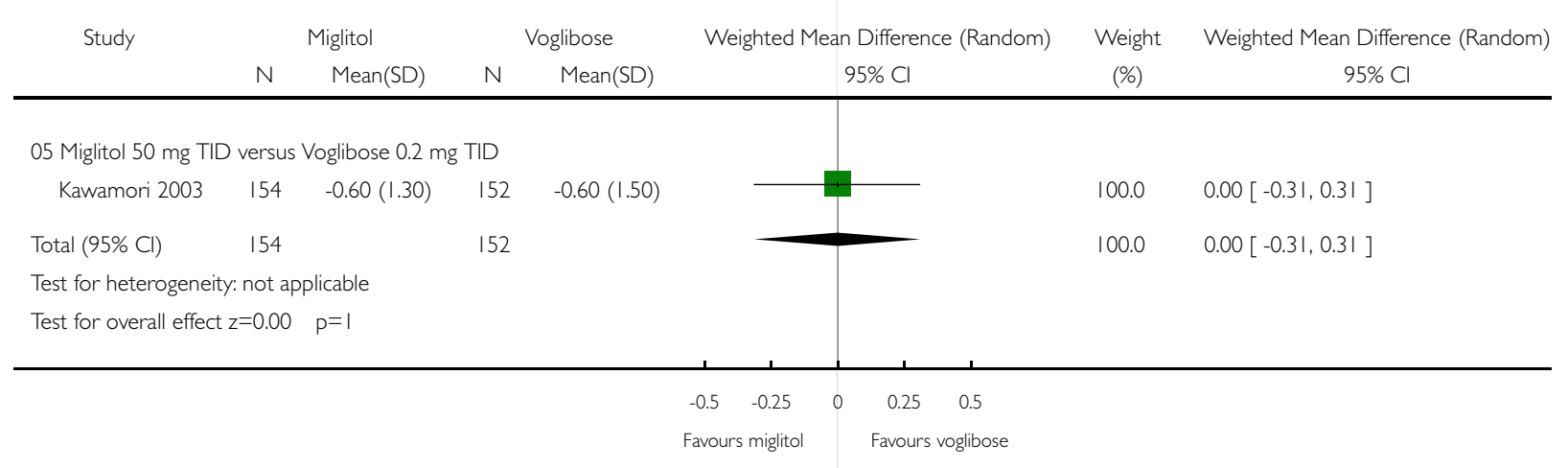




\section{Fig. I I6. Comparison I I. Miglitol versus voglibose}

\section{I.03 Change in post-load blood glucose $(\mathrm{mmol} / \mathrm{l})$}

Review: Alpha-glucosidase inhibitors for type 2 diabetes mellitus

Comparison: II Miglitol versus voglibose

Outcome: 03 Change in post-load blood glucose $(\mathrm{mmol} / \mathrm{l})$

$\begin{array}{cccccc} & \text { Miglitol } & \text { Voglibose } & \text { Weighted Mean Difference (Random) } & \text { Weight } & \text { Weighted Mean Difference (Random) } \\ \text { N } & \text { Mean(SD) } & \text { N } & \text { Mean(SD) } & 95 \% \mathrm{Cl} & (\%)\end{array}$

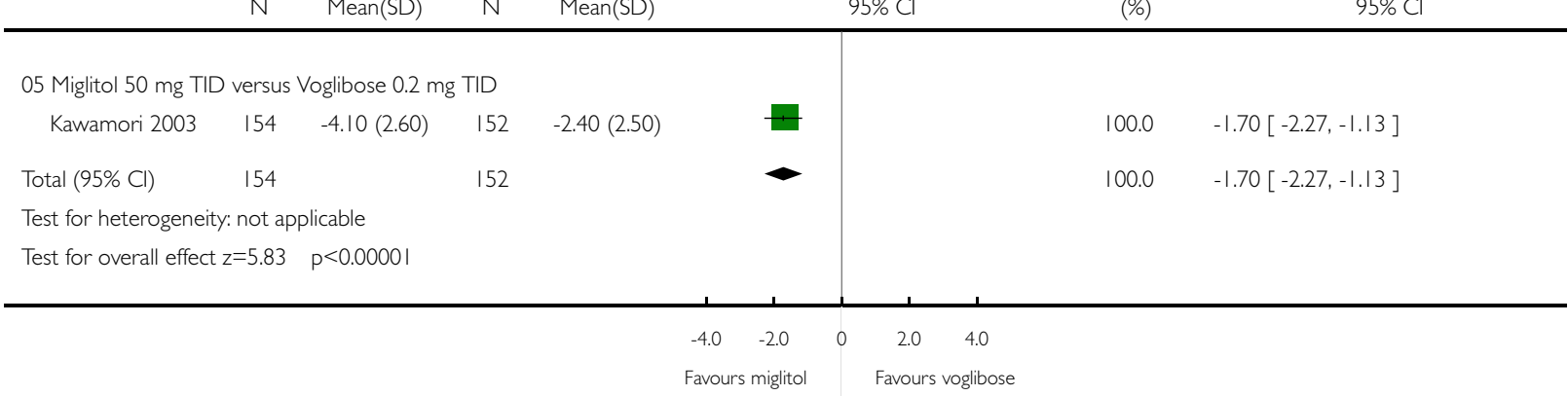

Fig. I 17. Comparison II. Miglitol versus voglibose

I I.09 Change in post-load insulin levels (pmol/l)

Review: Alpha-glucosidase inhibitors for type 2 diabetes mellitus

Comparison: II Miglitol versus voglibose

Outcome: 09 Change in post-load insulin levels (pmol/l)

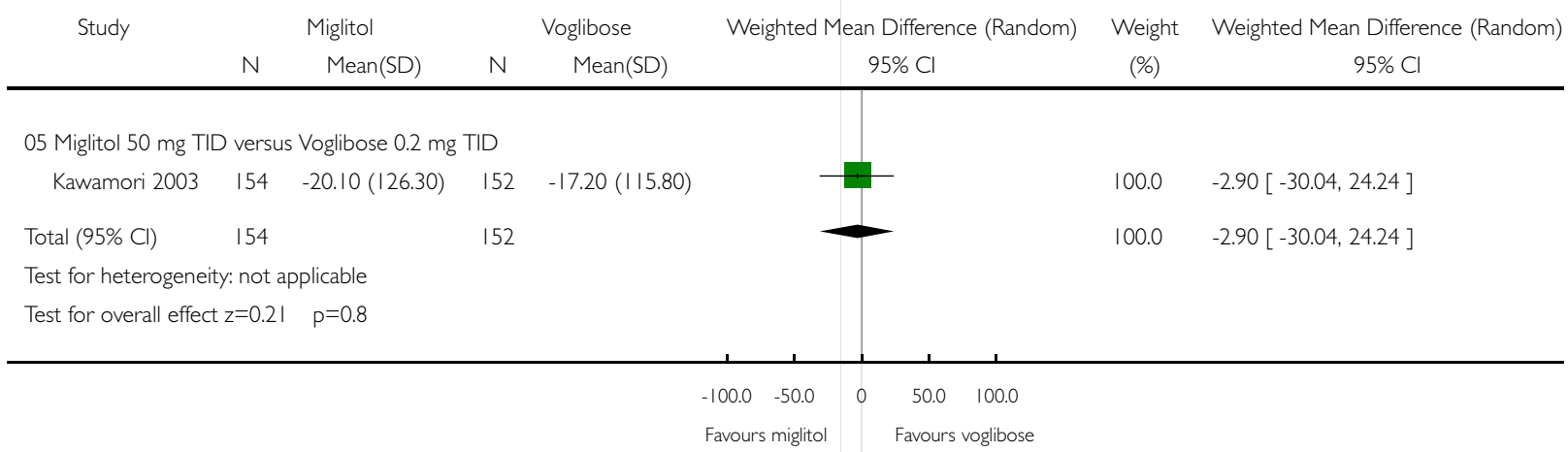




\section{Fig. I I 8. Comparison I I. Miglitol versus voglibose}

\section{I.30 Occurence of adverse effects}

Review: Alpha-glucosidase inhibitors for type 2 diabetes mellitus

Comparison: II Miglitol versus voglibose

Outcome: 30 Occurence of adverse effects

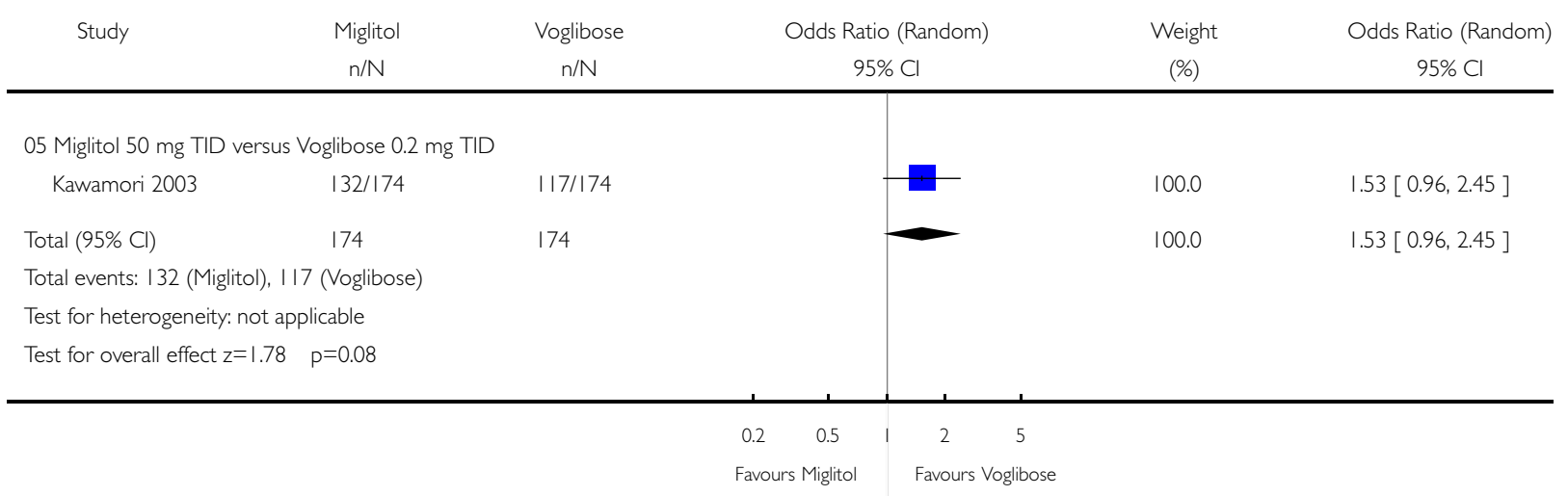

Fig. I I9. Comparison I I. Miglitol versus voglibose

I I.3 I Occurence of gastro-intestinal adverse effects

Review: Alpha-glucosidase inhibitors for type 2 diabetes mellitus

Comparison: II Miglitol versus voglibose

Outcome: 31 Occurence of gastro-intestinal adverse effects

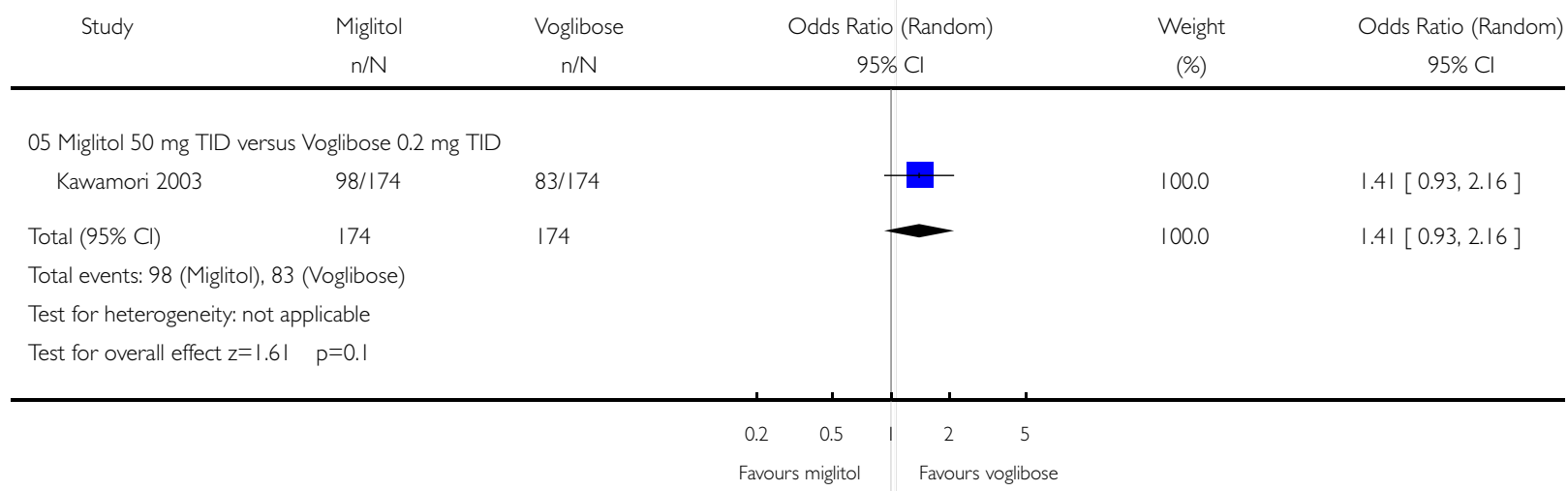


Fig. 120. Comparison II. Miglitol versus voglibose

I 1.90 Change in post-load blood glucose $(\mathrm{mmol} / \mathrm{l})$ ( 2 hours)

Review: Alpha-glucosidase inhibitors for type 2 diabetes mellitus

Comparison: I I Miglitol versus voglibose

Outcome: 90 Change in post-load blood glucose ( $\mathrm{mmol} / \mathrm{l})(2$ hours $)$

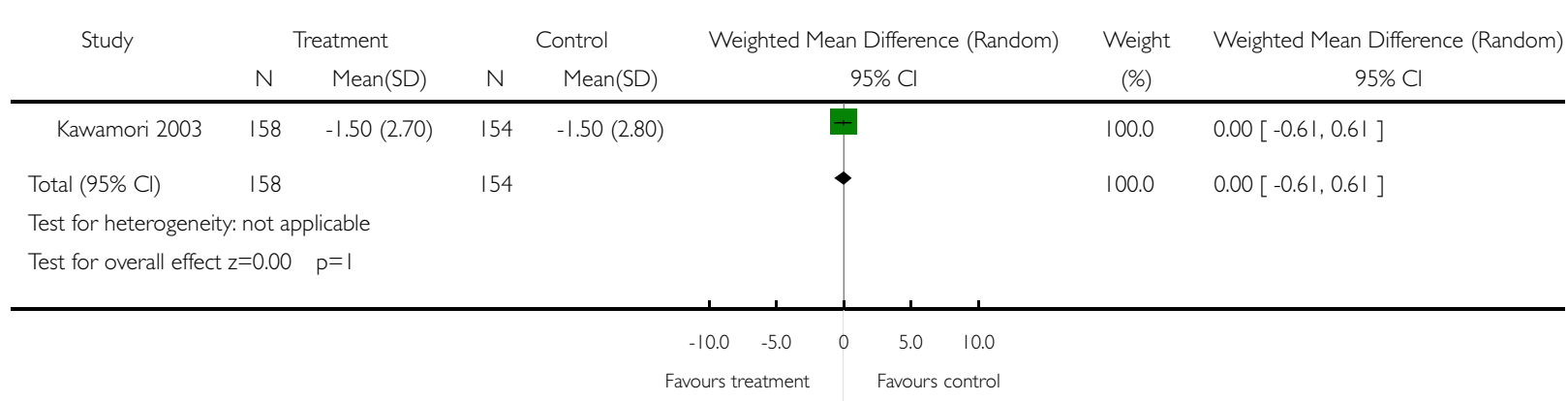

